\title{
Um Estudo Comparativo de Benchmarks Paralelos
}

\author{
Claudia Leiko Satake Couto
}

Orientadora: Profa. Dra. Regina Helena Carlucci Santana

Dissertação apresentada ao Instituto de Ciências Matemáticas e de Computação - ICMC-USP, como parte dos requisitos para obtenção do título de Mestre em Ciências - Área: Ciências de Computação e Matemática Computacional. 
À minha pequena Lia, meu marido Marcelo, e meus pais e irmãos que sempre me incentivaram a seguir em frente. 


\section{Agradecimentos}

Agradeço a todos os amigos que propiciaram momentos de descontração e alegria durante esses anos de mestrado, e que também me ajudaram nos momentos de dificuldades (especialmente à Nilda, Maristela e Omar).

Também à minha família pelo grande incentivo, com atenção especial à minha irmã Fabiana que me deu uma grande ajuda nas últimas semanas.

Ao meu marido Marcelo, por toda a ajuda que ele sempre me deu, pelo constante incentivo e pelo companherismo. À minha filha Lia, por toda a alegria que ela me proporcionou com seu nascimento.

Agradeço à minha orientadora Regina e aos colegas do laboratório LaSDPC, por toda a ajuda, e aos órgãos que financiaram o meu projeto - CAPES e FAPESP, cujo suporte financeiro foi imprescindível. 


\section{CONTEÚDO}

1. INTRODUÇÄO...............................................................................................................................................................1

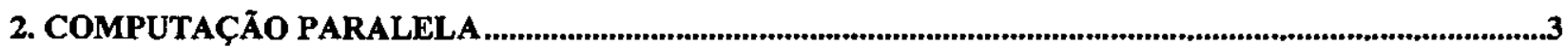

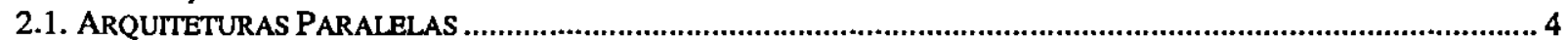

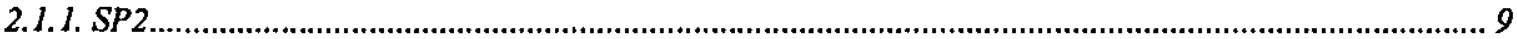

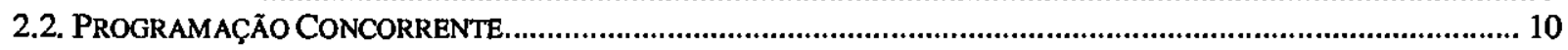

2.2.1. Concorrência em sistemas uniprocessadores e multiprocessadores .............................................. 10

2.2.2. Formas de se obter processamento paralelo .............................................................................. 11

2.2.3. Desenvolvimento de um programa paralelo ................................................................................... II

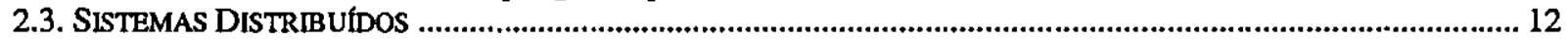

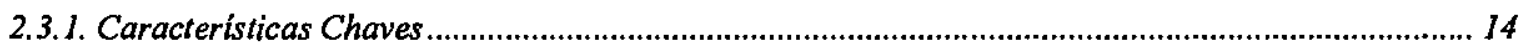

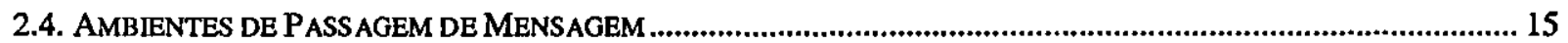

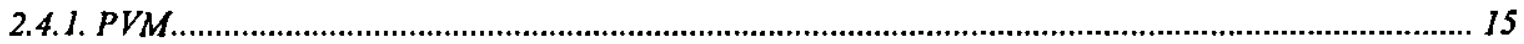

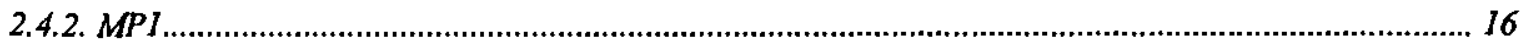

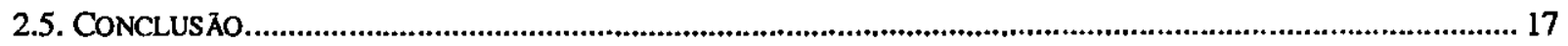

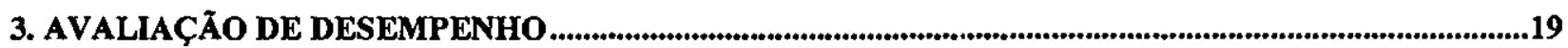

3.1. INFLUÊNCIA DA ESTAÇÃO DE TRABALHO, DO SISTEMA DE COMUNICAÇÃO E DO SERVIDOR DE ARQUIVOS NO

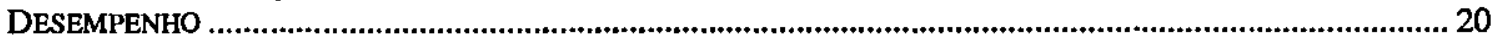

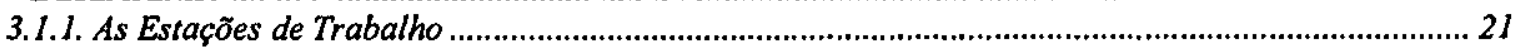

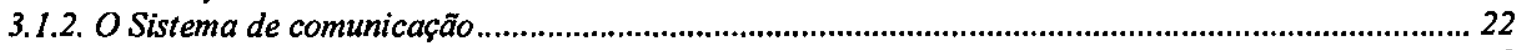

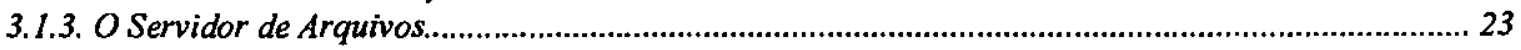

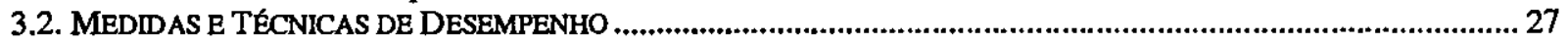

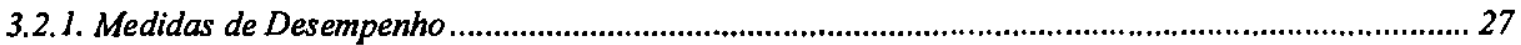

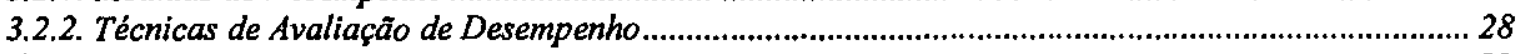

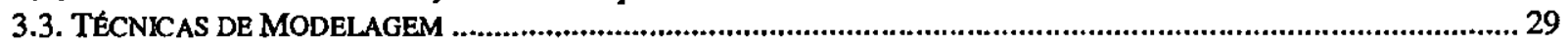

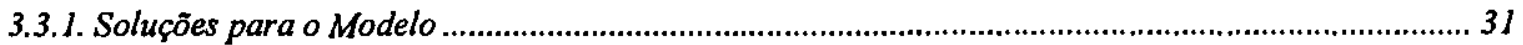

3.3.2. Considerações Finais sobre as Técnicas de Modelagem .............................................................32

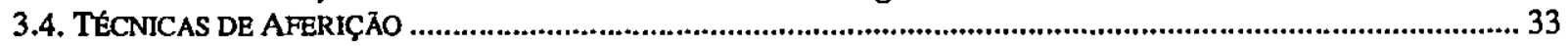

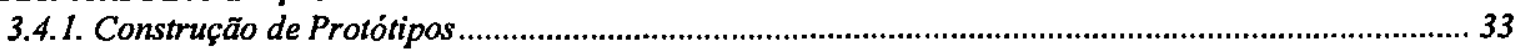

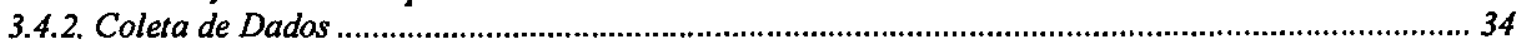

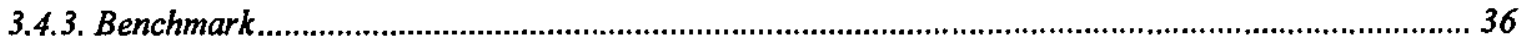

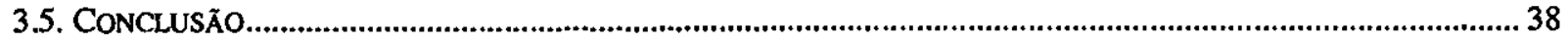

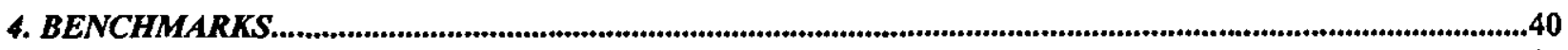

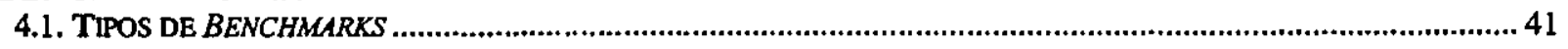

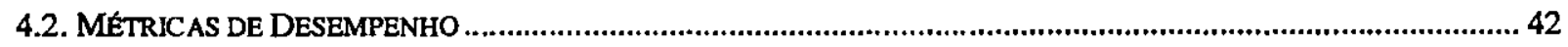

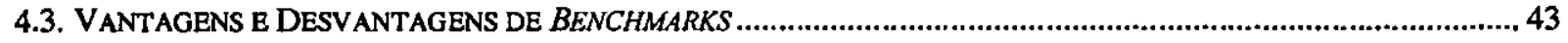

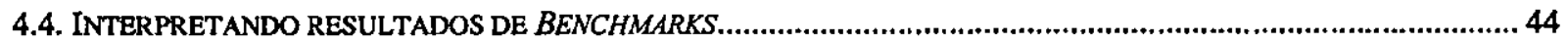

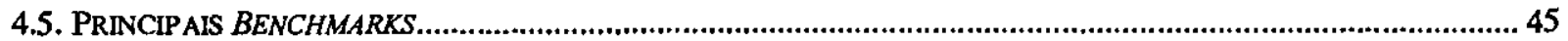

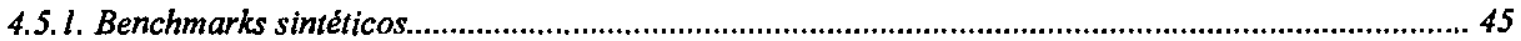

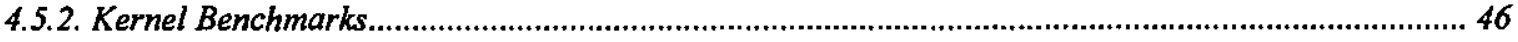

4.5.3. Benchmark Suites................................................................................................................4 47

4.5.4. Benchmarks Suites em múltiplas camadas............................................................................. 48

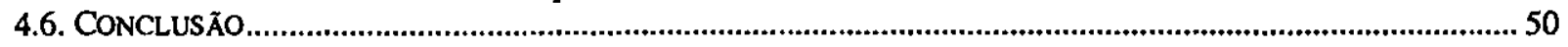

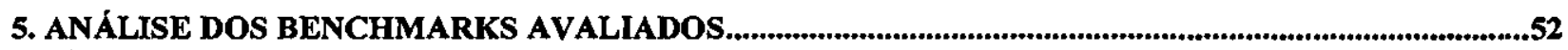

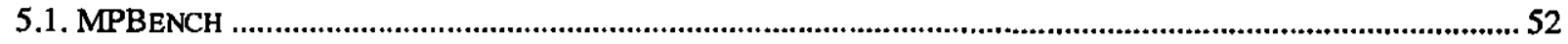

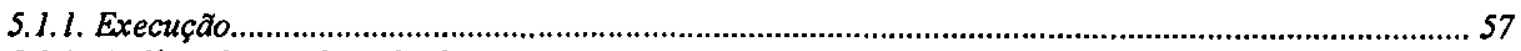

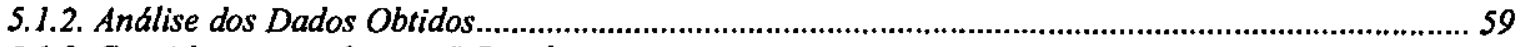

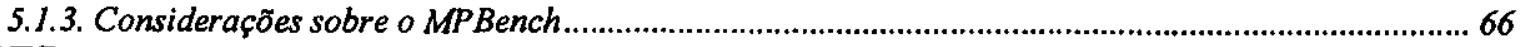

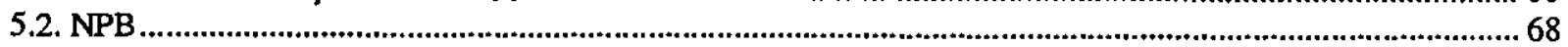

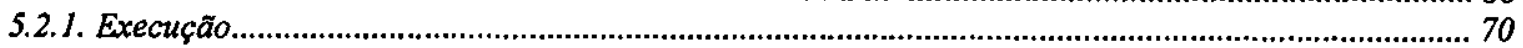




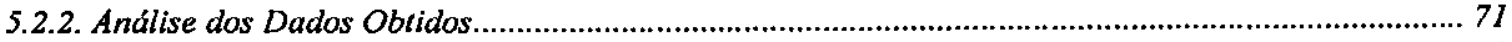

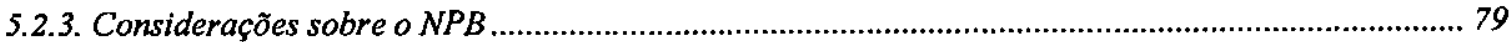

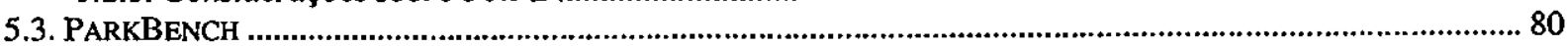

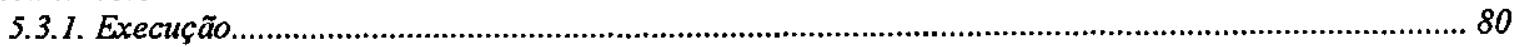

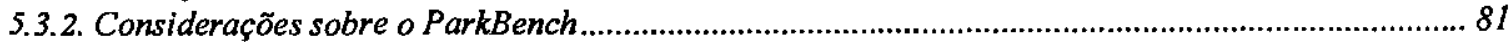

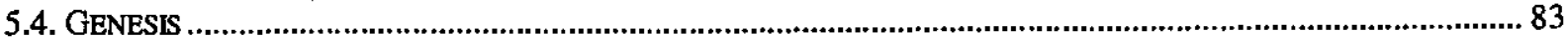

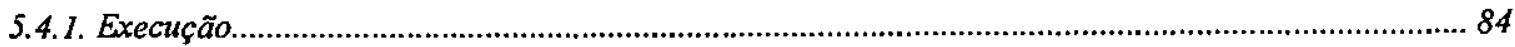

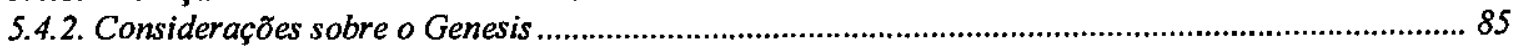

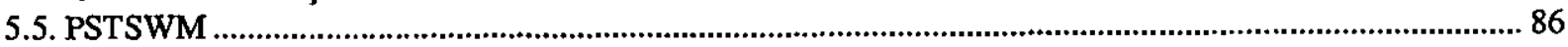

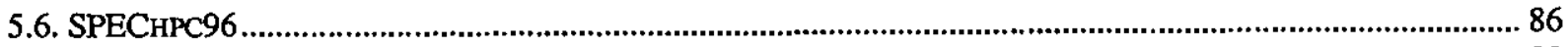

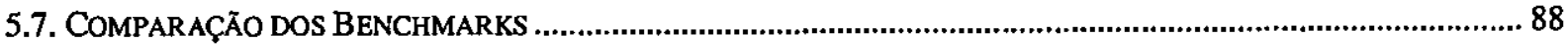

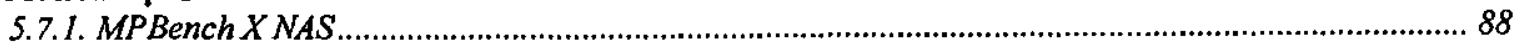

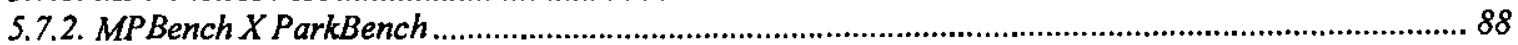

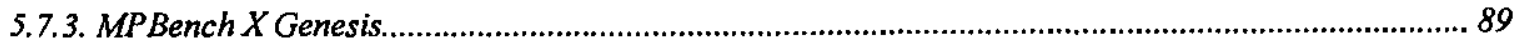

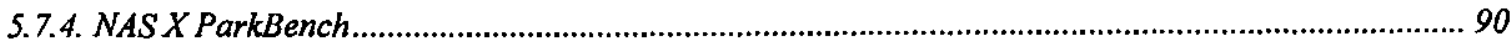

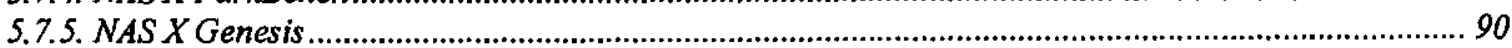

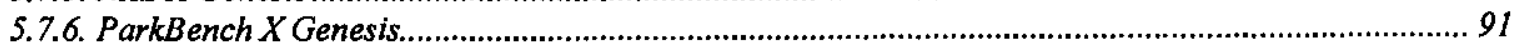

5.8. BENCHMARKS DE BAIXO NIVEL X BENCHMARKS DE ALTO NIVEL............................................................92

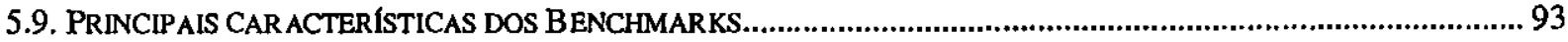

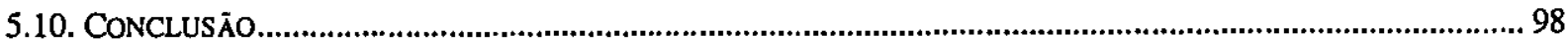

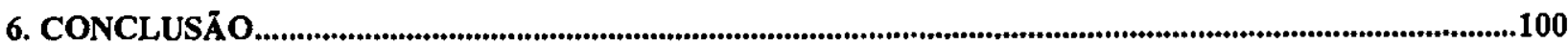

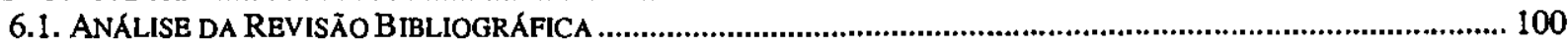

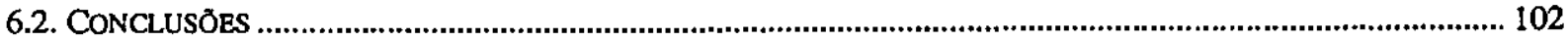

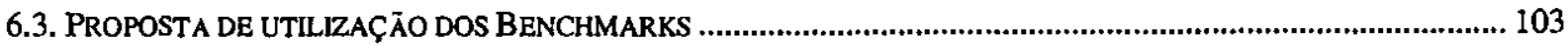

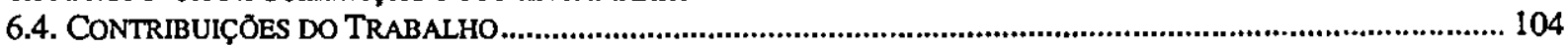

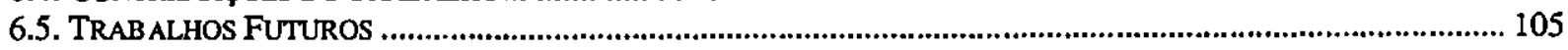

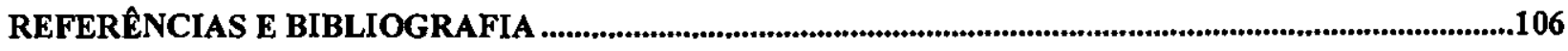

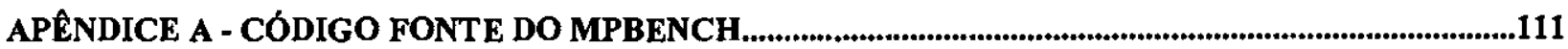

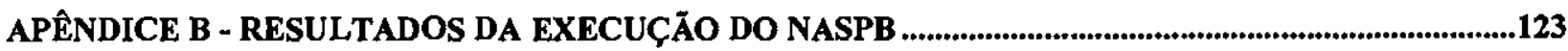

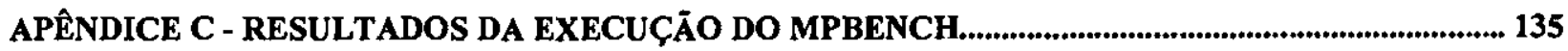

APENDICE D - EXEMPLOS DE RESULTADOS DO PARKBENCH ......................................................163 


\section{Índice de Figuras}

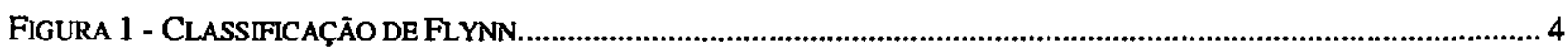

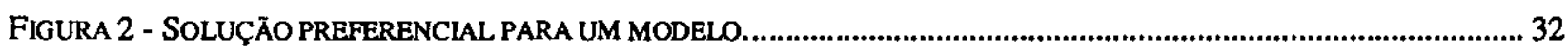

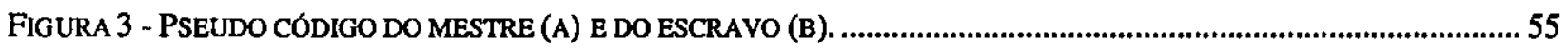

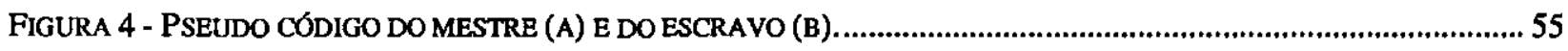

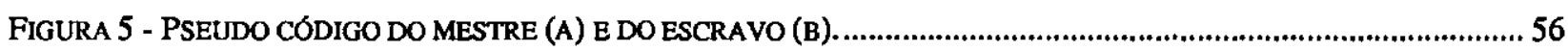

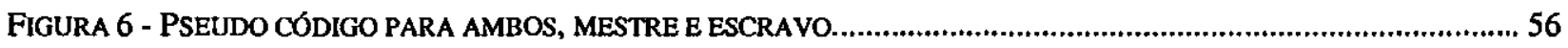

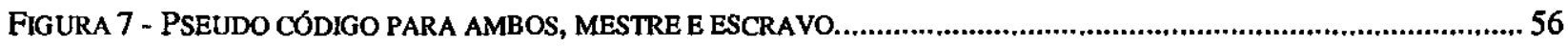

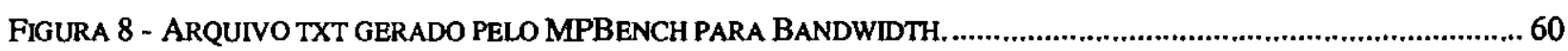

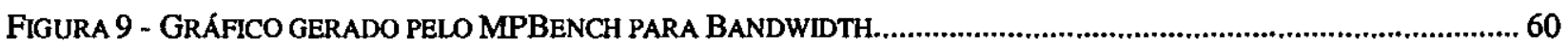

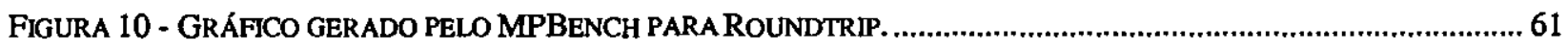

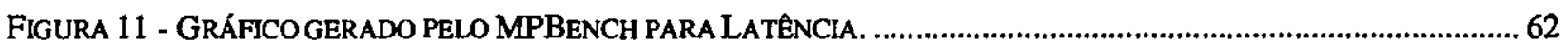

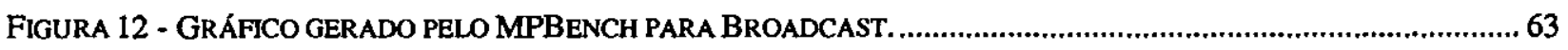

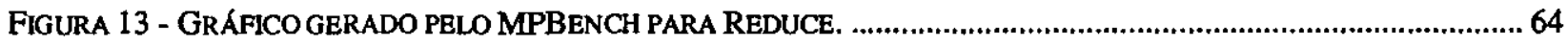

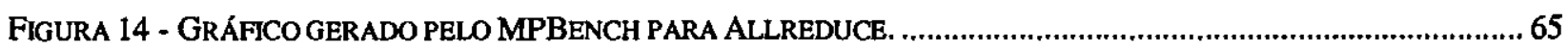

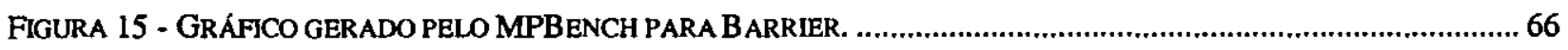

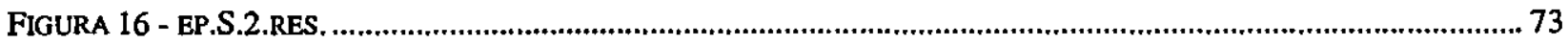

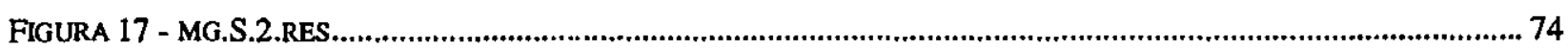

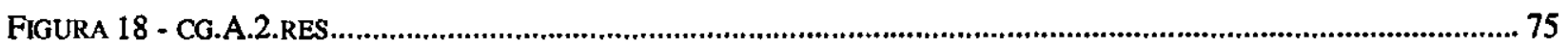

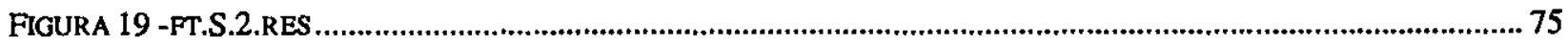

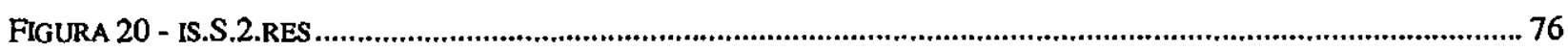

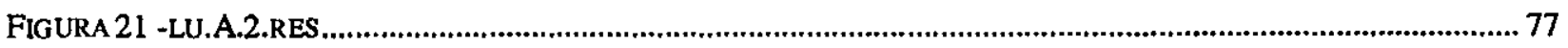

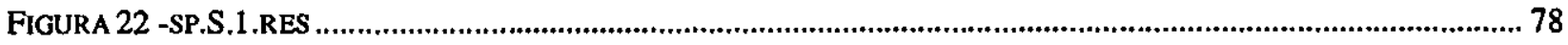

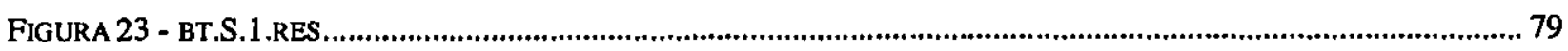

\section{Índice de Tabelas}

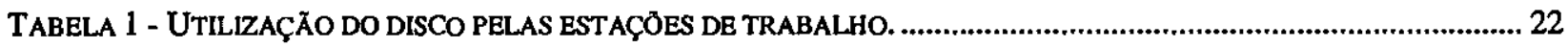

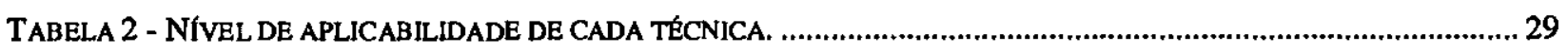

TABELA 3 - VANTAGENS E DESVANTAGENS DAS TÉCNICAS DE MODELAGEM. ....................................................... 33

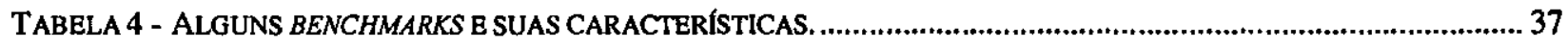

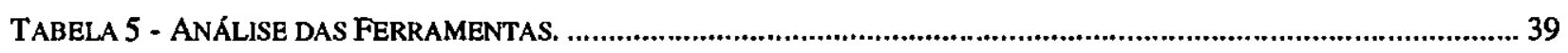

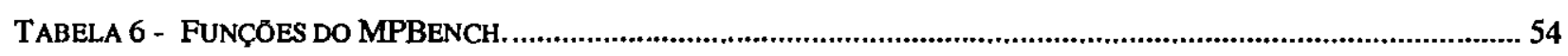

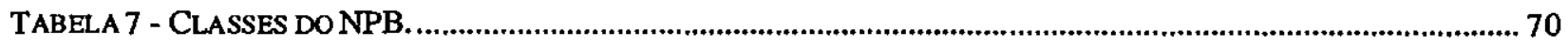

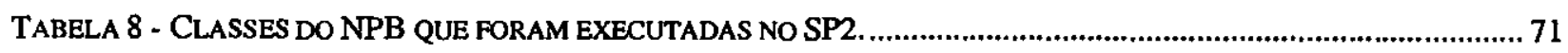

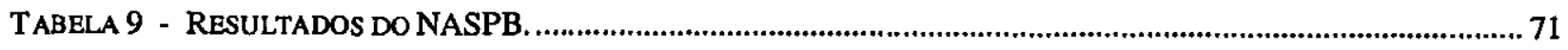

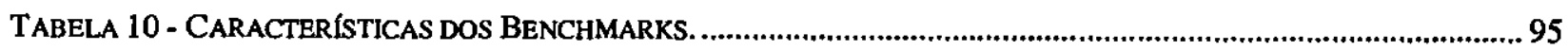




\section{RESUMO}

Existem vários tipos de benchmarks, cada tipo está relacionado ao tipo de informação que se deseja obter. Os benchmarks de baixo nível, assim como os sintéticos, medem o desempenho de componentes do sistema, tais como memória, E/S, comunicação, etc. Já os de alto nível medem o desempenho do sistema como um todo, e são mais complexos. $O$ que dificulta a escolha do benchmark mais adequado para o tipo de objeto que se deseja avaliar é a grande quantidade de benchmarks existentes, sendo que muitos nem ao menos possuem uma documentação adequada para que se possa compreendê-los. Para superar essa dificuldade esta dissertação apresenta uma avaliação dos benchmarks quanto a sua área de utilização, quanto aos componentes do sistema que ele pode avaliar com eficácia, facilidade de utilização, etc. A avaliação dos benchmarks se baseia não apenas no estudo teórico, mas também em sua execução em diferentes plataformas de hardware e software. Os resultados obtidos são analisados e classificados de acordo com a área em que ele melhor atua, ou seja, a área em que ele poderá ser aplicado com eficácia. 


\begin{abstract}
There are several types of benchmarks and their aplications are normally related to the kind of the desired information. Low level benchmarks, as well as the synthetic ones, measure the performance of system components such as memory, I/O devices, communication subsystems, etc. The high level benchmarks measure the performance of the whole system and therefore they are more complex. The difficulty in selecting the best benchmark for a specific problem is the large number of benchmarks available, many of them without an appropriate documentation. In order to overcome this difficulty, this thesis presents an evaluation of the existing benchmarks with relation to their use, to the components of the system that they can evaluate with effectiveness, to the use easiness, etc. The evaluation is based not only on the theoretical study but also in their execution on different hardware and software platforms. The results are analyzed and classified in accordance to the area they can be applied with effectiveness.
\end{abstract}




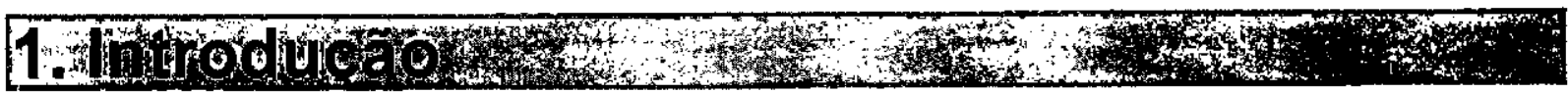

Devido a seu poder computacional e à redução do tempo de execução de programas, a computação paralela vem sendo cada dia mais utilizada. Sem ela, problemas como simulação de sistemas biológicos, que são utilizados na solução de problemas da engenharia genética e que necessitam de um grande poder computacional, não poderiam ser solucionados facilmente.

Computação paralela deve apresentar alto desempenho. Desempenho não é um atributo isolado de sistemas de computadores ou algoritmos, mas depende da interação entre ambos. Assim, torna-se necessária uma avaliação de desempenho para identificar a eficácia e os pontos fracos de sistemas de computadores e aplicações em particular. Desempenho é uma questão fundamental nos dias atuais principalmente quando se refere a computadores paralelos, visto que o objeti vo destes é facilitar a solução de problemas complexos.

Existem várias técnicas de avaliação de desempenho sendo a escolha de uma delas dependendo do objeto que se deseja avaliar. As técnicas de análise de desempenho obtêm informações que podem ser obtidas a partir do próprio sistema, através das técnicas de aferição ou através de um modelo representativo do sistema, que corresponde ao emprego de técnicas de modelagem.

Os benchmarks são uma das técnicas de aferição que se adequa à análise de hardware, software e de sistema computacionais como um todo. Essa última característica é sua principal vantagem sobre as outras técnicas de avaliação de desempenho existentes.

A literatura apresenta diversas propostas de benchmarks. Para cada tipo de sistema i: (paralelo, distribuído ou sequiencial) e para cada componente do sistema (rede de comunicação, processador, unidade de ponto flutuante, dispositivos de E/S, memória, etc.) que se deseja analisar, pode-se utilizar um tipo de benchmark diferente. A grande quantidade e grande variedade de benchmarks existentes dificulta a escolha do mais adequado quando se deseja avaliar o desempenho de um determinado objeto.

Esse projeto apresenta alguns benchmarks e os avalia com o objetivo de obter dados sobre sua aplicabilidade e representatividade. Determinando assim, a área de utilização em que eles são melhor empregados e os componentes do sistema que eles podem avaliar com eficácia. A classificação dos benchmarks considerados é baseada não apenas no estudo teórico, mas também em sua execução em diferentes plataformas, tanto de hardware como de 
software. Para o desenvolvimento desse estudo utiliza-se arquiteturas paralelas e máquinas paralelas virtuais baseadas em sistemas distribuídos.

Os benchmarks escolhidos para essa avaliação foram: The NAS Parallel Benchmarks, Genesis Distributed Memory Benchmarks, Parkbench e MPBench. Estes benchmarks foram escolhidos por serem bem conhecidos e por abrangerem diferentes tipos de benchmarks. A máquina paralela utilizada para a execução dos benchmarks é um IBM RISC System/6000 Scalable Power parallel System (SP2) e as plataformas de comunicação utilizadas foram PVMe, PVM3 e MPI. Alguns benchmarks também foram executados em uma rede LINUX constituída por três máquinas Pentium.

Os capítulos 2, 3 e 4 desta dissertação apresentam a revisão bibliográfica necessária para o desenvolvimento do trabalho. No Capítulo 2 é discutida a importância da computação paralela, relacionando tópicos de arquiteturas paralelas (incluindo o SP2), programação concorrente, sistemas distribuídos e ambientes de passagem de mensagem (incluindo PVM e MPI).

O Capítulo 3 apresenta as medidas e técnicas de avaliação de desempenho, analisando seus pontos fracos e fortes, indicando a área de aplicação (projeto, seleção ou avaliação) na qual as técnicas são melhor aplicadas.

O Capítulo 4 apresenta uma visão geral dos benchmarks, categorizando-os e relacionando suas vantagens e desvantagens, além de citar os principais benchmarks existentes.

No Capítulo 5 é feita uma análise dos benchmarks avaliados, apresentando as características principais de cada benchmark estudado, os resultados obtidos de sua execução, algumas considerações e uma comparação entre os benchmarks citando suas semelhanças e diferenças.

O Capítulo 6 apresenta uma revisão da bibliografia, as conclusões desse trabalho com relação aos benchmarks analisados, uma proposta da área de melhor utilização dos benchmarks, as contribuições e os trabalhos futuros. 
Computadores de alto desempenho estão se tornando cada dia mais importantes. Sem eles, muitas áreas como exploração de petróleo, diagnósticos médicos, simulação aerodinâmica, inteligência artificial, automação industrial, engenharia genética, entre outras, não teriam em tão pouco tempo alcançado o avanço que se observa atualmente. Para explorar de forma adequada estas máquinas de alto desempenho, e em particular as arquiteturas paralelas, são necessários novos algoritmos, sistemas operacionais, linguagens, e paradigmas de programação, bem como ferramentas de software.

Muitos fatores influenciam no desempenho de um computador, sendo que o uso de dispositivos de hardware mais rápidos e confiáveis não basta para se obter alto desempenho: a arquitetura do computador e os algoritmos utilizados também têm influencia direta.

O processamento paralelo dispõe de uma alta potência computacional, que se torna necessário quando algoritmos complexos e/ou um grande conjunto de dados devem ser processados. Outros fatores que motivam o desenvolvimento da computação paralela são o desenvolvimento tecnológico, as restrições físicas (velocidade da luz), a tolerância a falhas, entre outras [SAN97].

Como já salientado nesta introdução, o objetivo principal da computação paralela é o aumento de desempenho na solução de problemas. Dessa forma, o desempenho é um fator fundamental no projeto de computadores paralelos. Desempenho não é um atributo isolado de sistemas de computadores ou algoritmos, mas depende da interação entre ambos. Áreas como análise de algoritmos, projeto de sistemas operacionais e projeto de compiladores, consideram aspectos parciais de desempenho, e freqüentemente lidam com um modelo simplificado de todo o sistema. Resultados obtidos nessas áreas ajudam a garantir desempenho de programa, mas não fornece visão do desempenho de aplicações em computadores reais. Consequientemente, avaliação de desempenho é necessária para identificar a eficácia e os pontos fracos de sistemas de computadores e aplicações em particular.

Nas próximas seções será apresentada uma breve revisão dos tópicos necessários para o desenvolvimento do plano de pesquisa a ser realizado. Como o objetivo do plano considerado é avaliar a utilização da computação paralela através de benchmarks, os seguintes tópicos serão abordados: arquiteturas paralelas, definição e detalhamento da plataforma SP2; programação concorrente: definição e principais características; sistemas distribuídos: 
definição e características chave; e ambientes de passagem de mensagem, descrição dos ambientes PVM e MPI.

\subsection{Arquiteturas Paralelas}

Muito já foi desenvolvido em termos de hardware paralelo, e várias classificações foram propostas [ALM94; DUN90; FLY72; HWA84]. Uma das classificações mais utilizadas pela comunidade computacional é a classificação de Flynn (Figura 1) [FLY72], que é baseada no fluxo de instruções e dados e dividida em quatro classes:

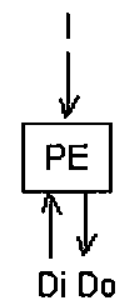

(a) SISD

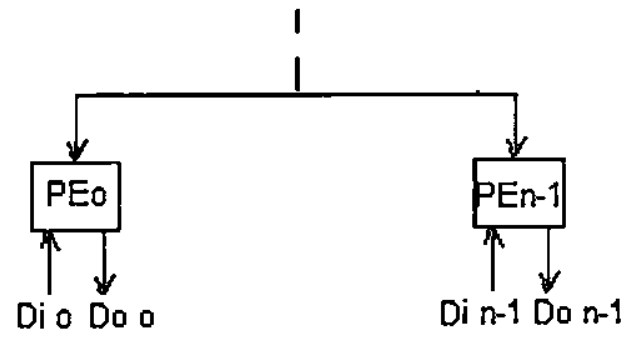

(b) SIMD

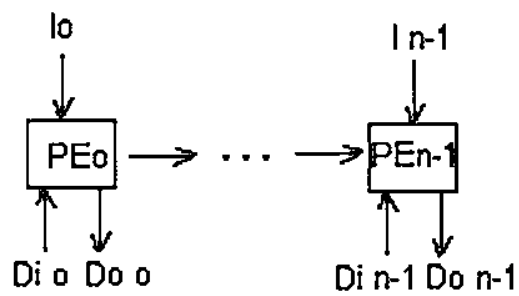

(c) MISD

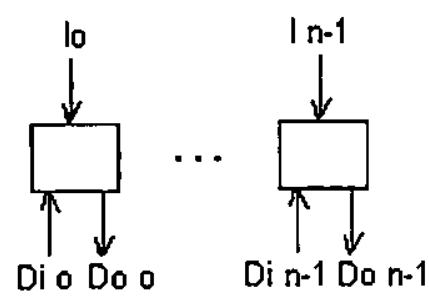

(d) MIMD

Figura 1 - Classificação de Flynn.

SISD (Single Instruction, Single Data) $\quad \Rightarrow \quad$ arquitetura com único fluxo de instruções e único fluxo de dados (Figura 1(a)), que são as arquiteturas com apenas um processador.

SIMD (Single Instruction, Multiple Data) $\quad \Rightarrow \quad$ arquitetura com único fluxo de instruções e múltiplos fluxos de dados (Figura 1(b)). Nessa classe incluem-se os processadores matriciais e os processadores massivamente paralelos (MPP - Massive Parallel Processors).

MISD (Multiple Instruction, Single Data) $\quad \Rightarrow \quad$ arquitetura com múltiplos fluxos de instruções e único fluxo de dados (Figura 1(c)), tais como "systolic arrays". 
MIMD (Multiple Instruction, Multiple Data) $\Rightarrow \quad$ arquitetura com múltiplos fluxos de instruções e de dados (Figura 1(d)). Incluem multiprocessadores e as redes de estações de trabalho (multicomputadores).

A classe SISD é a mais familiar e a que oferece o menor grau de concorrência, sendo que esta concorrência é feita através da técnica de pipelining. Essa técnica realiza concorrência de processamento e não de execução, sendo que esta última pode ser realizada através das técnicas ILP (Instruction Level Parallelism), onde operações diferentes são organizadas para que possam ser executadas paralelamente, baseando-se na análise de dependência entre as operações no fluxo de instrução.

Processadores matriciais e processadores vetoriais entram na classe SIMD. Um processador matricial tem muitos elementos de processamento operando em paralelo em muitos elementos de dados. Um vector processor tem um único elemento de processamento que opera seqüencialmente em muitos elementos de dados.

De uma forma abstrata a classe MISD é representada por pipeline de múltiplas unidades funcionais independentes, cada uma, executando operações em cima de um único fluxo de dados. Os resultados são transmitidos de uma unidade funcional para a próxima. Não há muito interesse nesse tipo de arquitetura, pois atualmente não existe uma forma simples de se construir programas nesse tipo de organização.

A classe MIMD lida com múltiplos elementos de processamento interligados. Quando se lida com comunicação entre elementos de processamento, através de um espaço de endereçamento de memória compartilhado, dois problemas ocorrem: consistência de memória e coerência de cache. Consistência de memória geralmente é resolvida através de uma combinação de técnicas de hardware e de software. Já o problema de coerência de cache geralmente é resolvido por técnicas de hardware.

Uma outra classificação bastante aceita é a de Duncan [DUN90], onde as arquiteturas são divididas em: síncronas, que incluem processadores vetoriais, SIMD e arquiteturas sistólicas; e assíncronas, que incluem MIMD e paradigma MIMD.

Segundo Duncan,

"Uma arquitetura paralela fornece uma estrutura explícita e de alto nivel para o desenvolvimento de soluções utilizando o processamento paralelo, através da existência de múltiplos processadores, simples ou complexos, que cooperam para resolver problemas através de execução concorrente". 
Essa metodologia permite classificar computadores que o esquema de Flynn não comporta, e exclui arquiteturas que só incorporam paralelismo de baixo nível. A metodologia de Duncan é composta por três categorias principais que são divididas em subcategorias, as quais estão especificadas abaixo.

Arquiteturas síncronas $\Rightarrow$ permitem concorrência através de relógios globais, unidades de controle central, ou controladores de unidade vetoriais [DUN90]. Essa categoria é dividida em:

- Processadores vetoriais: possuem múltiplas unidades funcionais com pipeline, que implementam operaçóes aritméticas e booleanas. $\mathrm{O}$ processamento paralelo vetorial é obtido pelo seqüenciamento de elementos vetoriais através de um pipeline e pela introdução dos resultados de uma unidade no pipeline de outra como entrada [DUN90].

- SIMD: consiste basicamente de uma unidade de controle central, múltiplos processadores, e uma rede de conexão para comunicação entre processadores e entre o processador e a memória. Essa classe é ainda subdividida em:

Processadores matriciais: empregados para cálculos científicos de grande escala como processamento de imagens. Fornecem acesso à memória via endereço, o que os diferencia do modelo associativo.

Processadores de memória associativa: esse tipo de arquitetura usa uma lógica de comparação especial para ter acesso aos dados em paralelo de acordo com seu conteúdo.

- Arquiteturas Sistólicas: são indicadas para a solução de problemas que necessitam - de computação intensiva junto a grande quantidade de operações de E/S. Possuem vários processadores em pipeline formando uma cadeia na qual apenas os processadores localizados nos limites dessa estrutura possuem comụnicação com a memória. Dessa maneira, o conjunto de dados percorre toda a cadeia de processadores, de maneira rítmica e sincronizada por um relógio global, não havendo armazenamento temporário na memória na comunicação entre os processadores [SAN97].

Arquiteturas assíncronas $\Rightarrow \quad$ caracteriza-se pelo controle descentralizado de hardware, de maneira que os processadores são independentes entre si [DUN90]. 
- MIMD: dão suporte a soluções paralelas que requerem processadores operando de maneira autônoma. Embora haja sincronização de processos por passagem de mensagens, ou pelo compartilhamento de dados, as arquiteturas MIMD são computadores assíncronos pelo fato do controle de hardware ser descentralizado [DUN90]. Arquiteturas MIMD podem ser de memória distribuída ou centralizada.

Memória Distribuída: cada processador tem sua própria memória local e se comunica com os outros processadores através de uma rede de comunicação por troca de mensagem. Diferentes topologias de rede de conexão podem ser usadas.

Memória Compartilhada: tem-se uma memória global que é compartilhada por todos os processadores. Esse tipo de arquitetura não apresenta problemas tais como latência para enviar mensagens. Entretanto ocorrem outros problemas como a sincronização do acesso aos dados e a coerência de cache.

- Paradigma MIMD: as arquiteturas que fazem parte dessa classe se baseiam nos princípios MIMD de operações assíncronas e manipulação concorrente de várias instruções e fluxo de dados. Entretanto, cada arquitetura é baseada em um princípio de organização diferente [DUN90].

MIMD/SIMD: é uma arquitetura híbrida, onde porções selecionadas de uma arquitetura MIMD são controladas de forma SIMD. Esse tipo de arquitetura se torna atrativo para pesquisas futuras pela sua flexibilidade.

Dataflow: são usados para conseguir paralelismo máximo em um programa. Ao contrário dos computadores de fluxo de controle (máquinas von Neumann) os computadores de fluxo de dados não executam as instruções em ordem e não necessitam de um contador de programa. Isso faz com que um grau máximo de concorrência seja alcançado, sendo que essa concorrência fica restrita apenas pela dependência dos dados e pela disponibilidade de recursos de hardware.

Redução: também conhecidas como arquiteturas dirigidas a demanda, baseiamse no conceito de redução, que implica que partes do código fonte original sejam reduzidas aos seus resultados em tempo de execução [KIR91]. As instruções são ativadas para serem executadas quando os seus resultados são necessários como operandos por uma instrução, previamente ativada [SAN97]. 
Frente de Onda: apresentam uma arquitetura sistólica de processadores, combinada ao paradigma assíncrono de execução baseada no fluxo de dados [SAN97].

Dentre todas essas classificações de arquiteturas apresentadas acima, existem três grandes classes de máquinas que são interessantes:

- SIMD ou máquinas síncronas: tem-se uma matriz de computadores acoplados com memória distribuída e unidades de processamento, exemplos de computadores que pertencem a essa classe são MP-2, CM-1 e CM-2 da Connection Machine, e CM200 da Thinking Machine.

- MIMD: se encaixam os MPP's (Massive Parallel Processors), como o CM-5 da Thinking Machine entre outros.

- Projeto de máquinas MIMD com memória compartilhada: estão incluídos Silicon Graphics (SGI) Power Challenge Systems.

Arquiteturas de memória distribuída vêm recebendo mais atenção com o aumento da potência computacional de cada no, o baixo custo dos nós e pela facilidade de implementação de ambientes de software atrativos.

Outro tipo de sistema que surge são os clusters de workstations, que são estaçōes de trabalho ligadas a redes convencionais como Ethernet, FDDI, ou ATM. Cada componente do cluster troca mensagens, efetivamente colaborando na resolução de um programa em paralelo. Estes sistemas são classificados como máquinas paralelas de memória distribuída MIMD.

Um motivo que retarda a adoção de máquinas paralelas como uma ferramenta de computação é a falta de códigos de aplicações gerais que possam extrair o paralelismo dessas máquinas com eficiência. As arquiteturas mudam muito rápido, $\mathrm{e} o$ tempo de desenvolvimento do software é muito longo. Assim, atualmente a computação paralela está sendo mais utilizada nas áreas científicas. Entretanto, um progresso significante tem sido feito com relação a isso. HPF (High Performance Fortran) tem sido adotado como um padrão industrial, e os primeiros compiladores comerciais estão se tornando disponíveis. HPF oferece um ambiente de software uniforme, que irá permitir ao usuário implementar aplicações independentemente das diferentes arquiteturas de hardware.

Extensōes do Fortran mais gerais, e com menos demanda no compilador, permitem ao usuário gerar explicitamente as mensagens necessárias em máquinas MIMD. Fortran + MP 
(Message Passing) ocupa mais tempo de desenvolvimento do usuário do que Fortran de dados paralelos (HPF) e é somente para máquinas MIMD. Por outro lado é portátil e escalável, usando sistemas de troca de mensagens como PVM e MPI.

\subsubsection{SP2}

O IBM RISC System/6000 Scalable Power parallel System (SP2) é uma máquina paralela com memória distribuída, composta de nós (processadores com memória e disco próprio) interligados por interfaces de rede e por uma rede de chaveamento (switch) de alto desempenho. Os processadores utilizados são os RISC/6000 POWER [CIS96].

A rede de chaveamento de alto desempenho conecta todos os nós (processadores), permitindo que todos eles possam enviar mensagens simultaneamente [IBM95].

O SP2 instalado no CISC (Centro de Informática de são Carlos) possui três nós, sendo dois nós do tipo thin e um do tipo wide [CIS96]. Os nós do tipo thin são mais adequados para executar os programas do usuário, fornecendo alta potência de processamento. Nós thin oferecem a flexibilidade de executar alguma combinação de processos interativos, em lote, seriais e paralelos simultaneamente, podendo ser compartilhados por qualquer um desses processos ou ser dedicados a executar uma única aplicação. Nós do tipo wide são geralmente configurados para agirem como servidores do sistema; eles podem oferecer vários serviços que são requeridos para executar processos submetidos pelos usuários. Os nós wide também oferecem, opcionalmente, a integração de memória expandida e dispositivos de armazenamento conectados diretamente aos nós. Eles dão suporte a uma variedade de adaptadores de microcanais, permitindo ao SP2 manipular um grande número de aplicações complexas.

Os nós podem ser interligados através da ETHERNET e FDDI além da rede de chaveamento de alto desempenho que chega a ter um bandwidth de 35 MBytes/segundo e latência de 50 micro-segundos [CISC96].

Uma estação de trabalho IBM RISC/6000 3CT é utilizada como nó interativo do SP2. Possui processador POWER2 de $66.7 \mathrm{MHz}, 128$ KBytes de cache de dados, 32 KBytes de cache de instrução, barramento de 64 bits e 2 GBytes de disco de trabalho.

O sistema operacional utilizado nos nós do SP2 e o nó interativo é o $\underline{U N I X} \underline{A L X}$, versão 4.1.4. Versões da IBM para compiladores C, $C++$, Fortran 77 e Fortran 90 também estão disponíveis. Os programas paralelos utilizam a versão IBM das bibliotecas MPI 
(Message Passing Interface), PVM (Parallel Virtual Machine) e ESSL (Engineering and Scientific Subroutine Library), juntamente com o ambiente POE (Parallel Operating Environment) e ferramentas como Visualization Tool e Parallel Debugger [CISC96].

\subsection{Programação Concorrente}

A programação concorrente tem se tornado importante nos últimos anos principalmente devido aos multiprocessadores e multicomputadores. Em particular, redes de microcomputadores, que estão rapidamente se tornando alternativas a supercomputadores tradicionais. Várias razões podem ser dadas à importância da programação concorrente [GEH88]:

- conveniência de notação e elegância conceitual na escrita de sistemas em que muitos eventos ocorrem concorrentemente, por exemplo, em sistemas operacionais, sistemas de tempo real e sistemas de banco de dados.

- preservar a estrutura de algoritmos concorrentes.

- aumento na velocidade de execução de programas em hardware de multiprocessamento genérico tal como em redes de microcomputadores.

- aumento na velocidade de execução de programas até mesmo em uniprocessadores; programação concorrente permite que operações de E/S longas e operações de processamento sejam executadas em paralelo.

Um argumento contra a programação concorrente é que ela introduz outra dimensão de complexidade à já difícil tarefa de escrita correta de programas seqüenciais pois ela é suscetível a uma grande quantidade de novos erros potenciais, não encontrados em programas seqüenciais. Por exemplo, deadlock. Há também a possibilidade de erros de temporização, que são muito difíceis de localizar, pois em geral não são repetíveis.

\subsubsection{Concorrência em sistemas uniprocessadores e multiprocessadores}

Concorrência existe quando, em um determinado instante, dois ou processos começam a sua execução, mas não terminam. Por essa definição, concorrência pode ocorrer tanto em sistemas com um único processador, quanto em sistemas com múltiplos processadores. Em sistemas uniprocessadores, pode ser alcançado das seguintes maneiras [HWA84]:

- Múltiplas unidades funcionais. 
- Paralelismo e pipelining dentro do processador.

- Sobrepondo operações de processamento e E/S.

- Uso de um sistema de memória hierárquico.

- Multiprogramação e compartilhamento de tempo.

Já em sistemas com múltiplos processadores, pode ocorrer através de multiprocessamento se os processadores compartilham uma memória em comum, ou através de processamento distribuído se os processadores estão conectados por uma rede de comunicação. Também podem existir metodologias híbridas como, por exemplo, processadores em um sistema distribuído serem multiprogramados.

\subsubsection{Formas de se obter processamento paralelo}

Pode-se obter processamento paralelo de várias formas, o nível mais alto é entre múltiplos programas ou jobs através da multiprogramação, time-sharing, e multiprocessamento. O próximo nível de paralelismo se dá entre procedimentos ou tarefas dentro do mesmo programa, envolvendo a decomposição do programa em múltiplas tarefas. $\mathrm{O}$ terceiro nível trata de concorrência entre múltiplas instruções, sendo necessária uma análise de dependência dos dados para revelar o grau de paralelismo. O último nível de processamento paralelo considerado é dentro de cada instrução (intra-instrução). O nível mais alto é realizado através de algoritmos (software) e o mais baixo é implementado diretamente por hardware.

Processamento paralelo e distribuído estão fortemente inter-relacionados. Técnicas de processamento distribuído são usadas, algumas vezes, para garantir paralelismo. Com o avanço das técnicas de comunicação a distância entre processamento paralelo e distribuído diminui cada vez mais. Assim, pode-se ver o processamento distribuído como uma forma de processamento paralelo em um ambiente especial.

\subsubsection{Desenvolvimento de um programa paralelo}

No desenvolvimento de um programa paralelo, várias etapas, além daquelas consideradas na programação sequencial, devem ser consideradas:

- definição e organização das tarefas paralelas $\rightarrow$ implementação de um algoritmo paralelo. 
- implementação do programa paralelo, através de ferramentas apropriadas para ativação e comunicação entre processos.

A fase de definição da organização das tarefas paralelas é de extrema importância, pois o ganho de desempenho adquirido na paralelização depende fortemente da melhor configuração das tarefas a serem executadas concorrentemente.

Definido o algoritmo, é necessário um conjunto de ferramentas para que o programador possa representar a concorrência, estabelecendo quais partes do código serão executadas seqüencialmente e quais serão paralelas. Além disso, processos cooperando para a resolução de determinado problema devem comunicar-se e sincronizar-se, a fim de que haja interação entre eles. A maneira como se implementa a comunicação entre processos depende da arquitetura onde se executa a aplicação: em caso de memória centralizada, utilizam-se variáveis compartilhadas; no caso de memória distribuída, utiliza-se troca de mensagens [SAN97].

No projeto de programas concorrentes um bom método para solucionar os problemas é tentar relacioná-los a problemas familiares, que possuam soluções bem conhecidas. Esse método é importante para programas concorrentes, pois as dificuldades encontradas na depuração de programas concorrentes, tornam os novos projetos muito suspeitos, sendo que eles só serão aceitos depois de terem sido minuciosamente analisados e usados. Quando confiança é importante, uma boa idéia é aderir a técnicas conhecidas usando algoritmos consagrados e que tenham sido minuciosamente usados e testados [AXF89].

\subsection{Sistemas Distribuídos}

$\mathrm{Na}$ última década, as redes de computadores se tornaram mais rápidas e mais confiáveis, o que possibilitou a interligação dos computadores pessoais e estações de trabalho de maneira eficiente, formando os sistemas distribuídos. Sistemas distribuídos são construídos com o intuito de oferecer uma imagem de sistema único (apesar da distribuição de seus componentes), de maneira que o usuário não perceba que está trabalhando em vários computadores ao mesmo tempo.

Vantagens e desvantagens podem ser atribuídas aos sistemas distribuídos. Entre as vantagens se incluem:

- extensibilidade: flexibilidade, modularidade e expansibilidade;

- economia: de especificação, de custos de comunicação de dados; 
- desempenho e disponibilidade: menor tempo de resposta e maior throughput;

- aproveitamento dos recursos computacionais: redução da sobrecarga do software dos sistemas; compartilhamento remoto; degradação lenta; boa resposta para sobrecargas temporárias; redução dos efeitos locais de congestionamento;

- integridade: identificação, deteç̧ão e diagnóstico de erros; recuperação, reparação e reinicio após falhas; confiabilidade;

- utilização dos recursos da organização: conveniências; menor burocracia; aproveitamento de potencialidades locais; maior envolvimento humano.

entre as desvantagens estão:

- aplicações: complexidade das aplicações;

- esforços replicados: pessoal; equipamentos;

- administração: recursos remotos; grupos e gerentes locais;

- padronizações mais rígidas: protocolos; compatibilizações de sistemas não homogêneos;

- sistemas de controle e gerência de recursos: controle sobre recursos dispersos; complexos algoritmos de alocação de recursos; sincronização de eventos remotos;

- sistema de gerência de banco de dados: múltiplos acessos; integridade; segurança; sincronização.

Ultimamente, as vantagens estão se sobrepondo às desvantagens na utilização de sistemas distribuídos. A maior flexibilidade e o menor custo de sistemas distribuídos, em relação às arquiteturas paralelas, têm levado à utilização de sistemas distribuídos para a execução de programas paralelos. Nesse sentido, apesar de terem surgido por motivações diferentes, a computação paralela e a computação distribuída têm demonstrado uma certa convergência, visto que ambas possuem características e problemas semelhantes. Balanceamento de carga e perda de desempenho devido ao congestionamento no meio de comunicação são exemplos de problemas comuns às duas áreas e que são, ainda, amplamente pesquisados.

Devido às características em comum, vários trabalhos foram desenvolvidos com 0 objetivo de utilizar os sistemas distribuídos para computação paralela. A idéia básica é ter um grupo de computadores interligados, funcionando como os elementos de processamento de 
uma máquina paralela. Apesar de possuir um meio de comunicação mais lento, tornando-se um fator que degrada rapidamente o desempenho, tais sistemas têm sido utilizados com sucesso para paralelizar aplicações que possuem granulação grossa e pouca necessidade de comunicação entre os processos.

Para a realização da computação paralela sobre sistemas distribuídos são utilizados ambientes de passagem de mensagem. Esses ambientes têm sido aperfeiçoados nos últimos anos para serem utilizados por uma grande quantidade de equipamentos diferentes, ganhando com isso popularidade e aceitação, visto que proporcionam o desenvolvimento de aplicações paralelas a um custo relativamente baixo em relação às máquinas paralelas. Os ambientes mais conhecidos e utilizados são PVM e MPI. Na seção 2.4 estes ambientes de passagem de mensagem são apresentados em mais detalhes.

Quanto ao projeto de sistemas distribuídos, cuidados adicionais devem ser tomados, pois existem outras questões, além daquelas normais a qualquer sistema, que devem ser tratadas, tais como esquema de nomeação, comunicação, estrutura do software, alocação da carga de trabalho e manutenção da consistência.

\subsubsection{Características Chaves}

Seis características chaves são primariamente responsáveis pela utilidade de sistemas distribuídos: compartilhamento de recursos, abertura, concorrência, escalabilidade, tolerância a falhas e transparência [COU95].

- Compartilhamento de Recursos: é a característica fundamental de sistemas distribuídos. Recursos podem ser dados, programas ou componentes de hardware.

- Abertura: deve ser disponível interfaces bem definidas para os gerenciadores de recursos. Em sistemas distribuídos, as interfaces são acessadas por comunicação interprocesso.

- Concorrência: permite que vários processos possam ser executados simultaneamente, obtendo assim um alto desempenho do sistema como um todo.

- Escalabilidade: é uma preocupação dominante no projeto de um sistema distribuído. A replicação de dados e distribuição de carga entre os servidores são importantes pontos a serem considerados. 
- Tolerância a falhas: pode ser tratado mais eficientemente em sistemas distribuídos do que em sistemas centralizados. Redundância de hardware pode ser explorada para garantir a migração de tarefas essenciais para outro computador em caso de falha.

- Transparência: trata da necessidade de usuários e programadores de compreender o conjunto de computadores conectados em rede como um sistema integrado, escondendo a natureza distribuída dos recursos usados para realizar as tarefas dos usuários.

\subsection{Ambientes de Passagem de Mensagem}

Em qualquer computação paralela, dados devem ser trocados entre processos cooperantes. Muitos paradigmas têm sido experimentados, incluindo memória compartilhada, compiladores paralelos, e troca de mensagem. O modelo de passagem de mensagem tem sido o escolhido pela perspectiva do número e variedade de multiprocessadores que lhe dão suporte, assim como em termos de aplicações, linguagens, e sistemas de software que ele usa [GEI94]. Os ambientes de passagem de mensagem PVM e MPI serão discutidos a seguir, por serem os mais utilizados atualmente.

\subsubsection{PVM}

PVM (Parallel Virtual Machine) é um conjunto integrado de ferramentas de software e bibliotecas que emulam um sistema computacional concorrente de arquitetura heterogênea, flexível e de propósito geral, em computadores interconectados. PVM vê uma coleção de computadores heterogêneos como uma única máquina paralela virtual. Sua interface de comunicação é clara, o usuário escreve sua aplicação como uma coleção de tarefas cooperantes. Essas tarefas têm acesso aos recursos do PVM através de uma biblioteca de rotinas de interface padrão e essas rotinas permitem o inicio e término de tarefas através de uma rede, assim como a comunicação e sincronização entre as tarefas [GEI94].

Em qualquer etapa da execução de uma aplicação concorrente, uma tarefa pode iniciar ou suspender outra tarefa ou adicionar ou retirar computadores da máquina virtual. Qualquer processo pode se comunicar com qualquer outro.

PVM é composto de duas partes: um daemon que esta presente em todos os computadores participantes da máquina virtual, e um conjunto de primitivas de interface do usuário. Daemons PVM se comunicam através de sockets UDP enquanto que a comunicação 
entre uma tarefa PVM e o daemon é feita através de uma conexão TCP. Uma tarefa PVM pode se comunicar com todas as outras tarefas pelo estabelecimento de uma ligação direta TCP entre as tarefas.

PVM suporta comunicação síncrona e assíncrona, tanto ponto a ponto como em grupo. Exemplos dessa última são multicast e broadcast. Outras vantagens que PVM possui é quanto a tolerância a falhas, portabilidade e interoperabilidade.

Devido à sua natureza onipresente (especialmente o conceito de máquina virtual) e também por causa da sua interface de programação simples, mas completa, o PVM tem ganhado grande aceitação na comunidade de computação científica de alto desempenho.

\subsubsection{MPI}

MPI (Message Passing Interface) é o resultado de um esforço em tentar definir a sintaxe e a semântica das rotinas da biblioteca de passagem de mensagens, que pode ser útil a um grande número de usuários e eficientemente implementado em um grande número de MPPs. A principal vantagem de se estabelecer um padrão de passagem de mensagem é a portabilidade. Um dos objetivos do desenvolvimento do MPI é prover os vendedores de MPPs com um grupo base bem definido de rotinas que eles possam implementar eficientemente ou, em alguns casos, fornecer suporte ao hardware para, desse modo, acentuar escalabilidade [GE194].

Como características principais de MPI, pode-se citar:

- Um grande conjunto de rotinas de comunicação ponto a ponto.

- Um grande conjunto de rotinas de comunicação coletivas para comunicação entre grupos de processos.

- Um contexto de comunicação que provê suporte ao projeto de bibliotecas de software paralelo seguras.

- A habilidade para especificar topologias de comunicação.

- A habilidade para criar tipos de dados derivados que descrevern mensagens de dados não contíguos.

Não se espera que MPI forneça uma infra-estrutura de software completa que possa ser usada para computação distribuída. MPI não inclui ferramentas para gerenciamento de processo, configuração de máquina, e suporte para entrada e saída. Por isso, espera-se que 
MPI seja usado como uma camada de interface de comunicação construída acima dos nativos da plataforma de hardware, com exceção de certas operações de transferência de dados que podem ser implementadas em um nível mais próximo do hardware. Isso permite que o PVM seja portado para MPI para explorar qualquer desempenho de comunicação que um vendedor forneça.

\subsection{Conclusão}

A_compútação paralela tem propiciado um grande avanço a muitas áreas, pois além dè of erecer uma alta potência computacional tem-se um aumento de desempenho na soluctão de problèmas;

Relacionado a este avanço tem-se o avanço das arquiteturas paralelas, dos sistemas distribuídos e da programação concorrente, que são meios onde executam e meios de se aplicar a computação paralela. A cada dia surgem novas arquiteturas paralelas, cada uma delas com grande número de processadores. Sabe-se, entretanto, que uma pequena quantidade de processadores rápidos é sempre melhor que muitos processadores lentos, pois existe uma sobrecarga relacionada ao acréscimo de cada processador.

Com o advento das redes de computadores, os sistemas distribuídos têm se tornado uma ferramenta poderosa no desenvolvimento da computação paralela. Entraves como lentidão e segurança tem sido melhorados para permitir uma computação rápida e eficiente aos seus usuários.

Programação concorrente vem mudando substancialmente nos últimos anos. Avanços teóricos têm causado definições de novas notações de programação que expressam computações concorrentes simples e fazem pedidos de sincronização explícitos. A disponibilidade de processadores de baixo custo tem tornado possível a construção de sistemas distribuídos e multiprocessadores que eram economicamente inviáveis algum tempo atrás. A programação concorrente logo será a melhor opção para aqueles que projetam e implementam sistemas operacionais; ela tem se tornado importante para programadores de todos os tipos de aplicações, incluindo sistemas de gerenciamento de banco de dados, computações paralelas científicas de grande escala, sistemas de tempo real, e sistemas de controle embutidos [GEH88].

Atualmente, quando se fala de paralelismo, este se aplica mais a vendedores de supercomputadores e a seus usuários, mas segundo [FOX95], no ano 2000 a maioria dos 
computadores terão que tratar de questões de hardware, de algoritmos, e de software para lidar com paralelismo, pois paralelismo permite a construção de computadores mais rápidos e com melhor custo/benefício. 


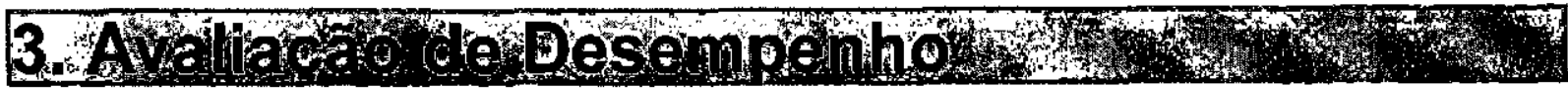

O estudo de desempenho de um sistema computacional é uma tarefa importante, pois possibilita alcançar vários objetivos: maximização da eficiência do sistema, maximização da utilização de um dado recurso, processamento de uma dada carga de trabalho a um custo mínimo, minimização do tempo de resposta, previsões do comportamento de um novo sistema, seleção de um novo sistema, entre outros. Apesar de sua importância, muitas vezes esta tarefa é ignorada, trazendo sérias conseqüências para as atividades do sistema em questão.

Apesar da contínua melhora da relação custo/desempenho dos sistemas modernos, a necessidade de otimização desses sistemas não desaparecerá. Pelo contrário, quanto mais poderoso for o hardware e mais sofisticado o software, tanto maior será a distância entre bom e mau desempenho, e mais amplos os objetivos de um estudo de desempenho [MAC79].

A chave para uma avaliação de desempenho e otimização do uso de recursos, principalmente os de maior custo, é a identificação e compreensão dos pontos críticos do sistema. Isto é obtido pela realização de uma medida grosseira de todo o sistema para localizar os problemas, seguida de análises mais detalhadas, isolando causas específicas.

Entretanto, segundo [KIM72], antes de avaliar é necessário estabelecer:

- a viabilidade do uso da avaliação de desempenho;

- o propósito do trabalho, determinando o campo de ação e a amplitude com as quais as características de carga de trabalho e do sistema devem ser analisadas;

- a função objetivo, para permitir a medida e comparação do sistema. Esta é dependente das variáveis escolhidas e do meio de obter informações sobre as mesmas;

- os aspectos organizacionais e tecnológicos que constituem os componentes dominantes. Além de considerarem os aspectos físicos (hardware) e lógicos (software), abordam também o atendimento das necessidades dos usuários e da organização como um todo.

Esses princípios, mesmo descritos antes do advento dos sistemas distribuídos, podem perfeitamente ser estendidos a estes para responder à questão do "como" distribuir. 
Na computação paralela, o hardware, software, tão bem como arquiteturas altamente paralelas, são intensivamente pesquisados. No que se refere a arquiteturas altamente paralelas, as pesquisas estão concentradas na organização dos processadores e na rede de conexão. Quanto a hardware, o estudo se concentra no projeto dos elementos do computador paralelo e na tecnologia de implementação. $\mathrm{Na}$ área de software, os temas mais importantes para pesquisa são compilador de alto desempenho, compilador paralelizador, sistema de E/S paralelo, avaliação de desempenho do sistema como um todo, e benchmarking. Um estudo interessante é sobre como essas três partes são otimamente integradas para uma computação paralela eficiente.

Para avaliar o desempenho de um sistema várias técnicas são utilizadas. A utilização de uma ou outra técnica depende do tipo de avaliação desejada e do tipo de sistema em questão. As técnicas de análise de desempenho obtêm informações associadas aos parâmetros significativos à análise de desempenho. Essas informações podem ser obtidas a partir do próprio sistema, através das técnicas de aferição (construção de protótipos, coleta de dados e benchmark) ou através de um modelo representativo do sistema, que são as técnicas de modelagem (modelo analítico ou modelo de simulação).

Através da utilização de alguma dessas técnicas (ou mais de uma), em cima do objeto a ser analisado (rede de comunicação, servidores ou estações de trabalho), obtêm-se os dados necessários para efetuar a análise de desempenho, identificando assim, onde o objeto é eficaz e quais seus pontos fracos.

\subsection{Influência da Estação de Trabalho, do Sistema de Comunicação e do Servidor de Arquivos no Desempenho}

Existem em um sistema distribuído três entidades principais que influenciam no desempenho do sistema como um todo: as estações de trabalho, o sistema de comunicação e os servidores. $O$ desempenho da estação de trabalho não depende apenas dela mesma, mas também da rede e dos servidores que ela tem acesso. Nas próximas seções será discutida a análise de desempenho em sistemas computacionais distribuídos, organizados segundo o modelo de estações de trabalho-servidores. 


\subsubsection{As Estações de Trabalho}

O desempenho da estação de trabalho é afetado pela rede de comunicação e pelos servidores, pois quando a estação executa uma operação de acesso a um arquivo, por exemplo, ela tem que utilizar o servidor de arquivos, ou seja, só poderá continuar seu processamento quando receber a resposta fornecida pelo servidor de arquivos. Esse acesso ao servidor de arquivos é feito através da rede de comunicação, sendo que ela fica dependendo também do desempenho desta.

Se o servidor de arquivos sair do ar e a estação fizer um acesso a ele, esta não conseguirá localizar o servidor (no caso de só haver um servidor de arquivos e nenhum tipo de tolerância a falhas que consiga tratar esse tipo de problema), causando a perda de desempenho da estação, que gastará um certo tempo tentando localizar o servidor.

Outro fator de influência é a estação de trabalho possuir disco local ou não. Se a estação de trabalho não possuir disco, ou seja, ser diskless, o sistema de arquivos terá de ser implementado em um ou mais servidores em qualquer ponto da rede. Já se a estação de trabalho possuir disco local, esse poderá ser usado para: paginação, arquivos temporários, arquivos binários do sistema, cache de arquivos, ou como sistema de arquivos local completo.

Na Tabela 1 [TAN95], são apresentadas as principais vantagens e desvantagens de se ter disco ou não nas estações de trabalho. Nos esquemas apresentados na Tabela 1 têm-se vários aspectos que podem melhorar e piorar o desempenho do sistema, dependendo do caso em questão.

Outra metodologia que pode ser citada para melhorar o desempenho é o uso das estações de trabalho ociosas. Visto que segundo estudos realizados [OVE95] as estações de trabalho permanecem cerca de $80 \%$ do tempo ociosas, vários métodos têm sido estudados nessa área, tais como DynamicPVM, que utiliza a capacidade de processamento das estações de trabalho ociosas fazendo balanceamento de carga entre as estações, e o NOW Network Of Workstations) de Berkeley que utiliza a memória das máquinas ociosas como se fosse sua; ela usa a RAM de todas as máquinas como um cache gigante e a melhora do desempenho é garantida, pois a rede de comunicação é rápida (ATM/FDDI). 
Tabela 1 - Utilização do dlsco pelas estaçōes de trabalho.

\begin{tabular}{|c|c|c|}
\hline Uso do disco & Vantagens & Desivantagens \\
\hline Diskless & $\begin{array}{l}\text { Baixo custo, facilidade de } \\
\text { manutenção do software e do } \\
\text { hardware, simetria e } \\
\text { flexibilidade }\end{array}$ & $\begin{array}{l}\text { Alta utilização da rede; os } \\
\text { servidores de arquivos podem se } \\
\text { transformar em gargalos }\end{array}$ \\
\hline $\begin{array}{c}\text { Paginação, arquivos } \\
\text { temporários }\end{array}$ & $\begin{array}{c}\text { Reduz a carga na rede em } \\
\text { relação ao diskless }\end{array}$ & $\begin{array}{l}\text { Custo mais alto devido ao grande } \\
\text { número de discos necessários }\end{array}$ \\
\hline $\begin{array}{c}\text { Paginação, arquivos } \\
\text { temporários, arquivos binários }\end{array}$ & $\begin{array}{c}\text { Reduz ainda mais a carga na } \\
\text { rede }\end{array}$ & $\begin{array}{l}\text { Alto custo; complexidade adicional } \\
\text { na atualizaçāo de arquivos binários }\end{array}$ \\
\hline $\begin{array}{c}\text { Paginação, arquivos } \\
\text { temporários, arquivos } \\
\text { binários, cache de arquivos }\end{array}$ & $\begin{array}{l}\text { Carga ainda menor na rede; } \\
\text { reduz a carga nos servidores de } \\
\text { arquivos }\end{array}$ & $\begin{array}{l}\text { Alto custo; problemas de } \\
\text { consistência de cache }\end{array}$ \\
\hline Sistema de arquivos local & $\begin{array}{l}\text { Elimina qualquer carga na rede; } \\
\text { elimina a necessidade dos } \\
\text { servidores de arquivos }\end{array}$ & Perda da transparência \\
\hline
\end{tabular}

\subsubsection{O Sistema de comunicação}

O problema de desempenho é também muito influenciado pela rede de comunicação, essencial para um sistema distribuído. Em uma rede local, o tempo gasto entre o envio de uma mensagem e a obtenção da resposta é gasto quase que totalmente no tratamento do protocolo de ambos os lados. Para otimizar o desempenho deve-se diminuir o número de mensagens enviadas. A dificuldade em adotar essa estratégia é que a forma mais adequada de melhorar o desempenho é ter várias atividades executando em paralelo, em diferentes processadores e para isso muitas trocas de mensagens são necessárias.

Outra questão que diz respeito ao desempenho é quanto a granulosidade do processamento. Execuções que exibem um paralelismo de granulosidade fina (pequenos processamentos) não são adequadas para serem executadas em um sistema distribuído devido à sobrecarga causada pela lentidão da comunicação. Já se tratando de execuções que exibem um paralelismo de granulosidade grossa (grandes processamentos com baixa interação com outras execuções e com poucos dados) produzem um resultado melhor quando processadas em um sistema distribuído.

A rede de comunicação é essencial para a obtenção de bom desempenho em um sistema distribuído. Ela tem que ter um mínimo de confiabilidade, ou seja, não pode perder mensagens, pois isso exige o reenvio e reduz o desempenho do sistema como um todo. Se a rede estiver sobrecarregada, o desempenho também decairá substancialmente. Um outro problema que pode ocorrer é a saturação da rede; como o sistema depende da rede, sua perda ou saturação influencia negativamente, acabando com as vantagens de se ter um sistema distribuído. 


\subsubsection{O Servidor de Arquivos}

Os servidores de arquivos serão o foco do estudo aqui apresentado, pois eles constituem um ponto de estrangulamento potencial do sistema, tanto em termos de desempenho, como de confiabilidade. Assim, o desempenho e a confiabilidade global do sistema estão diretamente relacionados ao desempenho e confiabilidade do(s) servidor(es) de arquivos. Outro fator que motiva essa escolha é a existência de um amplo campo de pesquisa envolvendo os servidores de arquivos. Como exemplo destacam-se: a determinação de qual componente do servidor de arquivos é o responsável pelo estrangulamento do sistema e a busca de uma solução viável para esse problema (utilizar memória cache, DMA, trocar o disco, trocar o processador, utilizar um processador front-end, etc).

Servidores de arquivos são sistemas especiais que oferecem armazenamento remoto de dados para os usuários de um SCD (Sistema Computacional Distribuído). O sistema de arquivos é responsável pelo reconhecimento textual de nomes de arquivos, gerenciamento de diretórios de arquivos e também pelo desempenho e confiabilidade do sistema. $\mathrm{O}$ sistema de arquivos pode ser implementado no servidor, no cliente ou pode ser parcialmente implementado em cada um [SAN90].

Existem algumas características que são desejáveis em um servidor de arquivos [ORL95]:

- Rapidez: o desempenho tem que ser pelo menos compatível com o desempenho observado no dispositivo de disco local.

- Segurança: deve oferecer proteção contra usuários não autorizados.

- Confiabilidade: deve ser tolerante a falhas no cliente e também no servidor.

- Flexibilidade: arquivos podem ser compartilhados entre diferentes máquinas simultaneamente.

Essas características são difíceis de serem obtidas na prática. Analisando o desempenho apresentado pelo servidor de arquivos, nota-se que certos aspectos 0 afetam significativamente, podendo comprometer e até mesmo degradá-Io [ORL95]. Esses aspectos são:

- Comunicação: Apesar das redes locais apresentarem alta velocidade de comunicação entre cliente e servidor, os protocolos podem determinar uma overhead, reduzindo consideravelmente a capacidade (bandwidth) de comunicação. 
- Dispositivos de armazenamento e política de alocação: A velocidade de acesso a um arquivo depende do dispositivo de armazenamento (determinando o tempo de acesso e taxa de transferência), dos algoritmos usados para alocação de espaço em disco e outras características adotadas, como por exemplo, tamanho do bloco de dados que pode ser escrito ou lido.

- Processador do servidor de arquivos: A alta velocidade oferecida pelas redes locais determina uma sobrecarga de computação para o processador do servidor, que deve ser capaz de processar eficientemente as solicitações recebidas pela rede.

- Número de clientes - Um aumento considerável no número de clientes pode provocar a degradação do desempenho do servidor, já que aumenta significativamente o nível de concorrência no servidor.

Existem propostas para minimizar os efeitos dos problemas apresentados acima, destacando-se:

- O overhead de comunicação pode ser reduzida utilizando-se protocolos especiais, ou ainda empregando-se técnicas de cache ou dispositivos de armazenamento secundário (replicação dos dados), de tal forma que 0 acesso a um arquivo resulte em uma transferência pela rede somente se o dado desejado não estiver presente em cache ou em armazenamento secundário.

- Quanto ao dispositivo de armazenamento e política de alocação: a utilização de algoritmos apropriados de alocação de espaço resulta em uma organização do arquivo que minimiza o tempo de busca em operações de escrita e algumas vezes de leitura. A presença de um cache no cliente ou um dispositivo de armazenamento secundário minimiza os acessos ao disco e também pode melhorar o desempenho. Em particular o tamanho do bloco de transferência do arquivo é determinante no desempenho; a adoção de blocos grandes melhora consideravelmente 0 desempenho (mais informações podem ser transferidas através de uma única busca).

- Quanto ao número de clientes, propõe-se a replicação do servidor de arquivos, que pode trazer dois benefícios: aumentar a disponibilidade do arquivo e aumentar $o$ desempenho. Problemas que devem ser considerados quando se adota essa técnica são relativos à consistência dos dados e à transparência do sistema. Para o 
problema do processador do servidor uma alternativa é a utilização de um processador de alto desempenho, ou uma arquitetura com mais de um processador.

Outros fatores que também afetam o desempenho de servidores de arquivo são:

- cobertura a tolerância a falhas, visto que ela é obtida muitas vezes com o uso de vários servidores que cooperam entre si em uma única requisição. Quando um servidor recebe uma solicitação, ele pode enviar imediatamente uma cópia da mensagem a um dos seus colegas, de modo que se ele tiver algum problema e não conseguir terminar o processamento da mensagem, um de seus colegas assume a função. Se ele conseguir terminar com sucesso é necessário enviar uma mensagem comunicando o fato. Portanto, tem-se no mínimo duas mensagens extras, que normalmente custam tempo e capacidade de rede.

- Concorrência: dependendo do mecanismo que é usado para controlar a concorrência, pode-se ter uma melhora no desempenho. Três métodos são utilizados para controle de concorrência:

bloqueio de acesso, o processo gerente possui uma lista dos arquivos bloqueados, se um arquivo esta sendo utilizado ele é bloqueado e colocado na lista, sendo que nenhuma outra transação pode ter acesso a esse arquivo. Esse método é altamente restritivo, podendo ser melhorado fazendo a distinção entre bloqueio de leitura e bloqueio de escrita, permitindo a leitura concorrente com o conseguinte aumento de desempenho. A granulosidade do bloqueio (arquivo, registro, página, etc.) também é relevante. Quanto mais fina a granulosidade mais preciso será o bloqueio e mais paralelismo pode ser obtido, porém mais bloqueios levam a um custo maior e a possibilidade de haver deadlocks aumenta.

controle otimista da concorrência: consiste em fazer tudo o que precisar ser feito sem prestar atenção no que os outros estão fazendo, preocupandose com os problemas somente quando ocorrerem. Esse método leva em consideração que na prática os problemas são raros. Sua vantagem é ser imune a deadlocks e permitir um grau de paralelismo máximo, pois nenhum processo tem que esperar por um bloqueio. A desvantagem é que às vezes pọde falhar e se isso acontecer a transação tem que ser executada 
novamente. Em condições de forte carga do sistema esse método não é recomendado.

método do carimbo: consiste em carimbar a transação no momento em que ela começa. Através do algoritmo de Lamport pode-se assegurar que os carimbos são únicos. $\mathrm{O}$ arquivo tem um carimbo de leitura e um de escrita, quando ocorre um acesso ao arquivo, compara-se o carimbo atual com o carimbo anterior; se a ordem for respeitada, ou seja, o carimbo atual é maior que o carimbo anterior, a transação é feita. A transação é abortada se a ordem não for respeitada.

- deadlocks: são situações indesejáveis que em sistemas distribuídos são ainda mais difíceis de serem solucionadas, evitados e até mesmo detectados. Deadlocks em sistemas distribuídos podem ocorrer na comunicação entre processos e na alocação de recursos. Há 4 métodos para se tratar deadlocks, dois que são bastante usados (algoritmo da avestruz e deteç̧ão), um que é difícil de ser aplicado em sistemas distribuídos, mas é possível através de exclusão mútua (prevenção) e outro que não se aplica a sistemas distribuídos (evitar a ocorrência de deadlock com uma política de alocação de recursos bastante cuidadosa) pelo fato dos algoritmos precisarem saber com antecedência os recursos que cada um dos processos vai precisar.

- diretórios em servidores diferentes. Esse caso ocorre quando há separação do servidor de arquivos do servidor de diretório. Se os diretórios que dão acesso a um determinado arquivo estão em servidores diferentes (e.x. /home/grupo/sd/teste.txt, onde o diretório home se encontra em um determinado servidor, o diretório grupo se encontra em outro servidor e o diretório sd se encontra em um terceiro servidor), duas estratégias podem ser utilizadas:

- a informação obtida no primeiro servidor de diretório é enviada de volta ao cliente que se encarrega de contactar os outros servidores. Nessa estratégia o cliente precisa estar ciente da alocação de diretórios e servidores; a desvantagem é que consome a banda passante da rede;

- na segunda estratégia o servidor passa as informações obtidas para o segundo servidor, que passa as informações para o terceiro servidor que finalmente obtém os dados do arquivo e os envia ao cliente. Essa estratégia é mais eficiente, mas não pode ser tratada através das 
chamadas remotas convencionais, pois o processo para o qual o cliente enviou a mensagem não é aquele que responde ao cliente.

Para melhorar o desempenho caches podem ser mantidos com os nomes que foram procurados recentemente e com os resultados das buscas. Quando o diretório é aberto, o cache é verificado para ver se o caminho está armazenado, se estiver, o endereço binário do arquivo é obtido diretamente do cache.

\subsection{Medidas e Técnicas de Desempenho}

\subsubsection{Medidas de Desempenho}

Classificar o desempenho de um sistema como ótimo, significa dizer que a qualidade do serviço oferecido pelo sistema excede alguma expectativa. Mas os termos "medida da qualidade do serviço" e "exceder a expectativa" variam dependendo dos indivíduos envolvidos, projetistas do sistema, gerentes de instalação ou usuários e de como foi obtida a medida [ORL95].

Visando agrupar os indivíduos com diferentes interesses, pode-se classificar as medidas de desempenho em duas categorias: medidas orientadas ao usuário e medidas orientadas ao sistema.

As medidas orientadas ao usuário incluem quantidades como tempo de ciclo (turnaround time) em um ambiente baseado em processamento de lotes e o tempo de resposta em um sistema de tempo real e/ou interativo. O tempo de ciclo corresponde ao intervalo de tempo decorrido desde a requisição da tarefa até a disponibilidade do resultado processado. Analogamente, em um ambiente interativo, o tempo de resposta a um pedido representa o intervalo decorrido desde a chegada do pedido até que ele seja completado. Geralmente os pedidos são colocados em classes de prioridades diferentes. Dessa forma associa-se a um pedido individual o valor de prioridade de sua classe. Isso permite saber sua urgência, sua importância e as características de demanda do recurso. Em geral o tempo de ciclo e o tempo de resposta são definidos e calculados separadamente para cada classe de prioridade.

As medidas orientadas ao sistema são tipicamente a capacidade de trabalho (throughput) e a utilização. A capacidade de trabalho corresponde ao número médio de pedidos processados por unidade de tempo, o que avalia o grau de produtividade médio que o sistema apresenta. Geralmente a carga do sistema é expressa em função da proporção de 
carga máxima que o sistema pode comportar. Essa proporção é a utilização do sistema, que pode ser definida pela razão entre a carga real do sistema pela carga máxima.

\subsubsection{Técnicas de Avaliação de Desempenho}

Técnicas de avaliação são métodos pelos quais informações associadas aos parâmetros significativos à análise de desempenho são obtidas. Essas informações podem ser obtidas a partir do próprio sistema (técnicas de aferição) ou através de um modelo representativo do sistema (modelo analítico ou modelo de simulação).

Análise de desempenho pode ser aplicada a três grandes áreas:

- Projeto de componentes de hardware e/ou software de novos sistemas, como ferramenta de avaliação progressiva durante o decorrer do projeto;

- Seleção de sistemas, como instrumento de decisão na aquisição ou substituição de componentes de hardware e/ou software;

- Avaliação de sistemas já implantados, para otimização, previsão e planejamento de futuras alterações.

As técnicas de avaliação de desempenho existentes podem mostrar diferentes graus de adequação a cada uma das 3 áreas definidas. As técnicas mais importantes (descritas nas seções 3.3 e 3.4) são mostradas na Tabela 2, obtida em [MAC79], juntamente com o nível de aplicabilidade a cada um dos casos. 
Tabela 2 - Nivel de apllcabilidade de cada técnica.

\begin{tabular}{|c|c|c|c|c|c|c|}
\hline & \multicolumn{3}{|c|}{ Área de Aplicaçăo } & \multicolumn{2}{c|}{ Avaliação } \\
\hline Técnicas & \multicolumn{2}{|c|}{ Projeto } & \multicolumn{2}{c|}{ Seleção } & \multicolumn{2}{c|}{ Software } \\
\hline & Hardware & Software & Hardware & Software & Hardware & 0 \\
\hline Prototipo & 3 & 3 & 2 & 2 & 0 & 2 \\
\hline Benchmark & 0 & 1 & 3 & 3 & 2 & 1 \\
\hline Modelos Analíticos & 2 & 1 & 2 & 1 & 2 & 2 \\
\hline Simulação & 3 & 3 & 2 & 2 & 2 & 3 \\
\hline Monitoramento & 2 & 2 & 2 & 2 & 3 & 3 \\
\hline
\end{tabular}

0 - Técnica não aplicável na área.

1 - Técnica aplicável, porém inadequada.

2 - Técnica aplicável, porém insuficiente (utilizada em conj. com outra técnica).

3 - Técnica satisfatória.

Conforme já mencionado, para a realização da análise de desempenho de um sistema, existem as técnicas de aferição e as técnicas de modelagem. As técnicas de modelagem são adotadas quando os sistemas computacionais são complexos e as técnicas de aferição são difíceis de serem aplicadas. Já as técnicas de aferição são utilizadas quando se tem o sistema pronto e em uso ou existe um protótipo disponível.

Os dois tipos de técnicas possuem vantagens e desvantagens. Uma das desvantagens das técnicas de aferição é quando o sistema a ser testado ainda não existe e é necessária a realização de testes prognósticos sobre o sistema em desenvolvimento. As técnicas de modelagem oferecem grande flexibilidade e baixo custo, podendo ser aplicadas tanto quando o sistema ainda não está concluído, como quando está, e também quando o uso das técnicas de aferição apresenta um custo elevado.

\subsection{Técnicas de Modelagem}

As técnicas de modelagem consistem na construção e análise de modelos representativos do sistema em estudo. Um modelo é uma abstração do sistema em questão, onde somente as características essenciais são refletidas. Essa técnica é utilizada quando se deseja avaliar um sistema ainda inexistente, ou que não seja conveniente sua experimentação prática.

Os dados fornecidos pelos modelos sofrem alterações no decorrer do tempo, pois as variáveis de estado de um sistema, via de regra, são dependentes do tempo. Assim, pode-se classificar os modelos quanto ao comportamento de suas variáveis de estado em relação ao tempo. Essas variáveis podem comportar-se de duas maneiras: discreta ou continuamente. $\mathrm{Na}$ modelagem de sistemas computacionais utilizam-se modelos discretos, uma vez que a alteração de estado em computadores ocorre a intervalos discretos de tempo [FRA97]. 
A representação de um determinado sistema em forma de um modelo é a realização da modelagem desse sistema. Existem várias técnicas para modelar um sistema computacional, e três delas (redes de fila, redes de Petri e statecharts) têm sido amplamente utilizadas. Essas três técnicas são apresentadas abaixo [FRA97].

\section{Redes de Filas}

Em computação, há várias situações em que usuários concorrem pela utilização de um determinado recurso do sistema computacional. Essa situação ocasionará o surgimento de filas de clientes que requisitam um determinado serviço. Para modelar sistemas nos quais a ocorrência de filas é um fenômeno inevitável, foi criada uma técnica baseada na teoria de filas (um ramo das probabilidades) denominada rede de filas.

Uma rede de filas é uma coleção de centros de serviço, os quais representam recursos do sistema, e clientes que representam usuários ou transações dispostos em áreas de espera (filas), os quais, de alguma forma, solicitam a prestação de um serviço a um determinado servidor, dentro dos centros. Esses centros podem possuir servidores únicos ou múltiplos, dependendo do número de recursos disponíveis no modelo.

Alguns parâmetros são identificados para a adoção de redes de filas, tais como tempo de serviço, algoritmos de escalonamento para a disciplina das filas de espera, tempo entre as chegadas, algoritmos para escolha de servidores e algoritmos para escolha de qual fila retirar o próximo cliente e algoritmos para o cliente escolher em qual fila irá entrar.

\section{Redes de Petri}

Rede de Petri, numa definição informal, é uma técnica de especificação de sistemas que possibilita uma representação matemática e possui mecanismos de análise poderosos, que permitem a verificação de propriedades e a verificação da correção do sistema especificado. Essa técnica de modelagem possui a particularidade de permitir modelar sistemas paralelos, concorrentes, assíncronos e não determinísticos, o que é absolutamente conveniente e desejável na modelagem dos sistemas computacionais atuais [FRA97].

\section{Statecharts}

A técnica statecharts é uma extensão das máquinas de estado finito, que possibilita a representação de hierarquia, concorrência e comunicação entre os diversos estados de um determinado sistema. Os statecharts têm, preferencialmente, a finalidade de especificar 
sistemas reativos, ou seja, sistemas que devem reagir a estímulos externos e internos, normalmente sob condições críticas em relação ao tempo.

A definição básica de statecharts é fundamentada em conjuntos de estados, transições, eventos primitivos, condições primitivas e variáveis, a partir dos quais o modelador poderá especificar os valores das variáveis do sistema em um certo instante. A idéia central é suprir a deficiência dos diagramas de estado em representar sistemas complexos. Sistemas complexos requerem uma estrutura de representação hierárquica (com agrupamento e refinamento de estados) e de concorrência, de maneira que seja facilmente visível o movimento através dos estados do sistema no decorrer do tempo.

\subsubsection{Soluções para o Modelo}

Após a escolha da técnica que será aplicada para a construção do modelo do sistema, deve-se decidir qual a resolução dada. Existem duas técnicas de resolução: analítica e simulação.

\section{Solução Analítica}

O método analítico é geralmente mais rápido e, por isso, o preferido. Porém, nem sempre ele é aplicável pois geralmente, é necessário um certo número de simplificações para que seja possível obter uma solução com o modelo. Deve-se entender por simplificações algumas restrições impostas pela solução analítica, que geralmente não correspondem às situações verificadas nos sistemas reais. Apesar de ser um método que propicie resultados expressivamente exatos, as simplificações introduzidas podem fazer com que os mesmos não sejam representativos. Isto pode simplesmente tornar sem sentido a utilização do modelo [FRA97].

Para exemplificar a dificuldade imposta por certas restrições, na solução analítica de modelos baseados em redes de filas, não se podem estabelecer prioridades para as disciplinas de filas, ou seja, todos os usuários de um determinado recurso possuem a mesma prioridade, $o$ que inviabilizaria, por exemplo, a representação do esquema de prioridades do sistema Unix. Ainda há várias outras restrições impostas à solução analítica do modelo de filas. A posse simultânea de recursos, não permitida, e a capacidade infinita das filas são alguns exemplos das várias restrições, que em sua maioria são violadas em sistemas reais.

Nas situações em que várias simplificações (restrições) comprometem a exatidão dos resultados do modelo, pode ser mais conveniente adotar-se a solução por simulação. 


\section{Simulação}

Em computação, a simulação refere-se ao emprego de um programa computacional para implementar um modelo de algum fenômeno ou sistema dinâmico (sistemas cujos estados se alteram com o tempo) [ORL95].

Flexibilidade, facilidade de utilização e custo relativamente baixo são alguns dos fatores que facilitaram a aceitação e utilização da simulação.

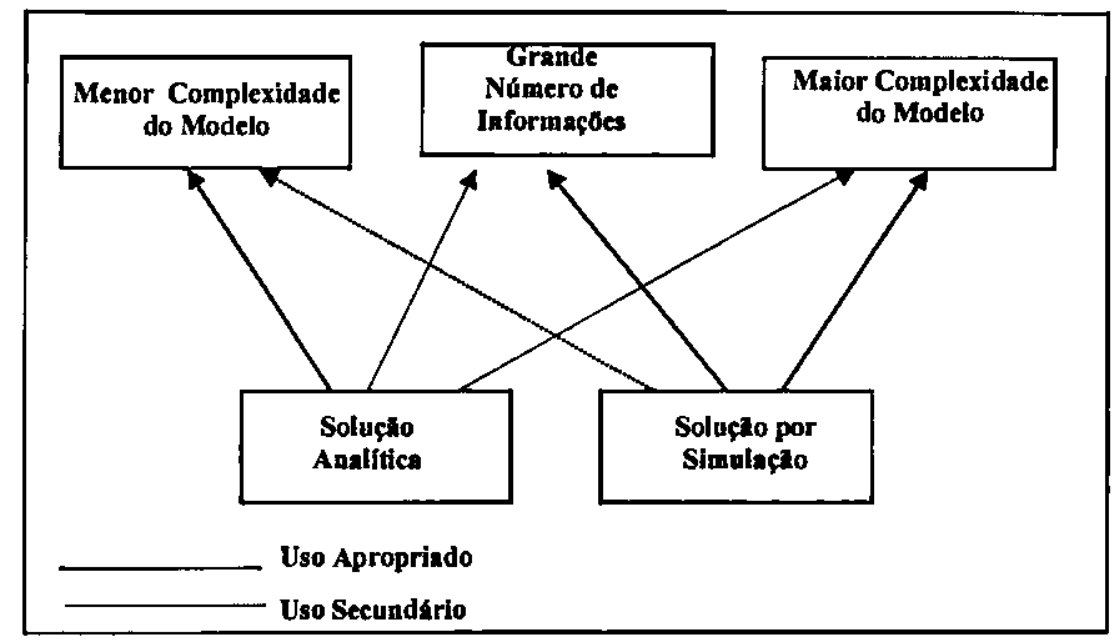

Figura 2 - Soluçăo preferencial para um modelo.

A Figura 2 apresenta o inter-relacionamento entre as duas soluções de um modelo, assim como as variantes que determinam quando, preferencialmente, utilizar uma solução em detrimento da outra.

\subsubsection{Considerações Finais sobre as Técnicas de Modelagem}

De uma forma geral, os modelos analíticos são mais adequados quando se tem uma menor complexidade, e modelos de simulação são mais adequados quando se tem um grande número de informações e uma maior complexidade do modelo.

A vantagem geral da técnica de modelagem é poder ser usada tanto em sistemas existentes quanto inexistentes, e também as relações de custo versus grau de precisão dos resultados obtidos. 
Quanto à decisão entre a escolha de um deles é tomada de acordo com o contexto onde serão utilizados. A Tabela 3 resume as vantagens e desvantagens existentes nos modelos analíticos e de simulação [ORL95]:

Tabela 3 - Vantagens e Desvantagens das Técnicas de Modelagem.

\begin{tabular}{|c|l|l|}
\hline & \multicolumn{1}{|c|}{ Vantagens } & \multicolumn{1}{|c|}{ Desvantagens } \\
\hline Modelos Analíticos & $\begin{array}{l}\text { Mais rápido e mais preciso; oferece, em } \\
\text { alguns casos, soluções simplificadas, mas } \\
\text { na maioria das vezes tem-se sistemas } \\
\text { complexos determinando simplificações e } \\
\text { suposições exaustivas para que as equações } \\
\text { possam ser resolvidas. }\end{array}$ & $\begin{array}{l}\text { As ferramentas analíticas não são } \\
\text { capazes de resolver uma grande } \\
\text { quantidade de problemas práticos em } \\
\text { diversas áreas; para fazer modificações } \\
\text { no sistema tem-se que refazer todo o } \\
\text { modelo e solucioná-lo. }\end{array}$ \\
\hline Simulação & $\begin{array}{l}\text { Possui características de flexibilidade, } \\
\text { facilidade de utilização e custo } \\
\text { relativamente baixo; permite refletir as } \\
\text { modificações no sistema de uma forma } \\
\text { mais simplificada. }\end{array}$ & $\begin{array}{l}\text { Pode requerer um tempo extensivo de } \\
\text { processamento para algumas aplicações. }\end{array}$ \\
\hline
\end{tabular}

\subsection{Técnicas de Aferição}

Em situações nas quais já existe um sistema computacional, ou este está na fase final de desenvolvimento, pode-se analisar o seu desempenho através de experimentação realizada sobre o sistema. Essa experimentação pode ser feita através de hardware ou de software. Para medir o desempenho de um sistema que já está em uso ou na sua fase final de implementação, existem técnicas denominadas de Técnicas de Aferição. Essas técnicas são: Construção de Protótipos, Coleta de Dados e Benchmarks.

\subsubsection{Construção de Protótipos}

Essa técnica consiste na construção simplificada do sistema que se quer medir o desempenho. A versão simplificada do sistema, ou seja, o protótipo do sistema, suprime suas características irrelevantes, dando ênfase às suas características essenciais. Apesar do custo do desenvolvimento do protótipo não ser alto, há a dificuldade em se determinar as características mais relevantes do sistema. Essa técnica é aplicada quando o sistema ainda não está pronto. Sua principal vantagem é ter disponíveis informações sobre o comportamento futuro do sistema a um custo menor em relação à construção do sistema [STU87].

Segundo [BOA84], há seis passos que devem ser analisados quando se deseja realizar a prototipação:

- Passo 1. Deve-se analisar se o sistema é um bom candidato à prototipação. 
- Passo 2. O desenvolvedor do protótipo deve delimitar e conhecer perfeitamente os domínios funcionais e comportamentais do sistema.

- Passo 3. O protótipo é desenvolvido.

- Passo 4. O protótipo é testado e aprimorado.

- Passo 5. Aqui o protótipo já fornece uma idéia do sistema real. Neste instante, o desenvolvedor pode analisar as características fundamentais do sistema e, se for o caso, fazer modificações no protótipo.

Passo 6. Os passos 4 e 5 são repetidos iterativamente até que se tenha toda a funcionalidade do sistema representada no protótipo.

\subsubsection{Coleta de Dados}

A técnica de Coleta de Dados consiste na coleta de informações sobre o desempenho de um sistema existente e sua posterior análise. Portanto, essa técnica só é viável em sistemas que já estejam operando.

Esta é a mais precisa de todas as técnicas de aferição, quando o objetivo for avaliar o desempenho através da obtenção direta dos dados no sistema computacional [ORL95]. Sua utilização pode ser tanto para localização de pontos de saturação (que reduzem a eficiência de uma instalação), quanto para a obtenção de um perfil operacional de um sistema [MAC79]. Outra utilização dessa técnica é comparar os valores dos dados obtidos de um sistema existente, com os valores fornecidos por um modelo do mesmo sistema. Com isso, pode-se validar o modelo, através de uma comparação da realidade com o sistema que foi modelado.

Macedo, em [MAC79] define três fases no processo de coleta de dados:

1. Coleta de dados: executada durante a operação normal do sistema, gerando uma grande quantidade de dados.

2. Redução de dados: tratamento dos dados coletados de modo a apresentá-los sob a forma de médias, desvios-padrão, máximos, mínimos, histogramas de distribuição, etc.

3. Análise de dados: nesta fase os dados serão analisados, sendo de fundamental importância a criatividade, experiência e bom senso do analista responsável pelo monitoramento. 
A técnica de Coleta de Dados pode ser realizada através de dois recursos: monitores de hardware e monitores de software.

\section{Monitores de Hardware}

Monitores de Hardware consistem de hardwares específicos que são utilizados para detectar e gravar sinais dos níveis de atividades dos diversos recursos do sistema. Os sinais captados pelos sensores são transmitidos ao monitor, que através de contadores pode contabilizar eventos ou tempos. Os Monitores de hardware devem se limitar a obter os sinais sem alterá-los, mantendo fidelidade aos valores originais.

\section{Monitores de Software}

Monitores de Software consistem de softwares para observar características específicas do sistema. Por exemplo, a verificação da existência ou inexistência de uma fila de espera associada a um recurso do sistema. As informações obtidas pelos monitores de software podem ser utilizadas, por exemplo, para estudos de como algumas características dos sistemas operacionais podem influenciar o desempenho de um sistema (políticas de escalonamento do processador, de alocação de memória, etc.).

O monitoramento por software pode ser feito por contabilizadores ou por monitores de software.

Contabilizadores - refere-se aos contabilizadores internos do proprio sistema. Estes geram dados que podem ser utilizados para um estudo inicial do desempenho do sistema. Algumas informações que poderiam ser provenientes dos contabilizadores internos são:

- Identificação dos programas que consomem a maior quantidade de recursos.

- Identificação das características globais da carga do sistema.

- Identificação dos pontos críticos do sistema.

- Obtenção de dados que possibilitem a revisão das verbas alocadas a cada projeto.

- Coleta de informações que permitem efetuar uma análise segura das tendências observadas na carga da instalação.

Monitores de Software - são programas executados sob o controle do sistema operacional junto com a carga normal do sistema. As informações a respeito do sistema são coletadas por esses programas em intervalos de tempo regulares ou quando ocorre algum 
evento importante. Esses programas examinam blocos de controle e/ou registradores especiais.

As informaçōes podem ser coletadas de duas maneiras nos monitores de software:

1. Orientada a eventos - os monitores são ativados quando ocorrem determinados eventos específicos, como por exemplo, interrupções. Antes do sistema operacional executar a função correspondente ao evento, o controle é transferido a uma rotina do monitor, que registra a ocorrência do evento. Assim, um monitor de software pode medir o comprimento da fila de um dispositivo, a freqüência de acesso a estes dispositivos, etc. Contudo, esse modo pode acrescentar uma sobrecarga ao sistema, pois a toda interrupção ou ocorrência de algum evento a rotina para coletar os dados do monitor é executada, consumindo tempo de processamento, memória principal, entre outros.

2. Orientada a amostragem - para solucionar o problema da sobrecarga causado pela técnica de monitoramento de software orientada a evento pode-se utilizar a técnica orientada a amostragem, que testa as condições do sistema em intervalos regulares de tempo. Essa técnica é recomendada quando a grandeza a ser medida admite resultados de menor precisão.

Essas duas maneiras (orientada a eventos e a amostragem) de coletar informações nos monitores de software podem ser combinadas em um único monitor. Assim, as grandezas mais específicas são medidas com a técnica orientada a eventos e a grande maioria dos dados é coletada por amostragem.

Há ainda monitores que combinam características comuns dos monitores de hardware e software. Esses monitores são denominados monitores híbridos e necessitam de uma interface para que as informações obtidas por software e hardware possam ser compartilhadas.

\subsubsection{Benchmark}

Benchmark consiste de um conjunto de programas utilizados para testar o desempenho de um determinado software, hardware ou sistema computacional. O mesmo programa é submetido a diferentes sistemas, e seus resultados são comparados entre si. São exemplos típicos de benchmarks os programas de ordenação e atualização de arquivos [TAN95]. 
Os benchmarks são uma boa opção para comparação de sistemas diferentes quando se deseja adquirir um novo sistema e ainda pode ser utilizado em uma série de avaliações mais específicas como testar a eficiência de um compilador.

Segundo Weicker [WEI90], um bom benchmark deve satisfazer algumas condições:

1. O programa deve ser escrito em linguagem de alto nível, sendo possível executá-lo em qualquer máquina.

2. O programa deve ser representativo de algum estilo de programação (numérico, comercial).

3. O programa pode ser avaliado facilmente.

4. O programa possui larga distribuição.

A Tabela 4 [PRI89] apresenta um quadro com três benchmarks e suas principais características.

Tabela 4 - Alguns benchmarks e suas características.

\begin{tabular}{|c|c|l|}
\hline Benchmarks & Finalidade & \multicolumn{1}{c|}{ Peculiaridades } \\
\hline Bonnie & $\begin{array}{c}\text { Aplicações de I/O } \\
\text { intensivas }\end{array}$ & $\begin{array}{l}\text { Desenvolve uma série de testes em um arquivo de tamanho } \\
\text { conhecido; } \\
\text { Utilizado no projeto do novo dicionário de inglês Oxford, na } \\
\text { Universidade de Waterloo. }\end{array}$ \\
\hline Stanford & $\begin{array}{c}\text { Comparação entre } \\
\text { arquiteturas RISC } \\
\text { CISC }\end{array}$ & $\begin{array}{l}\text { Desenvolvido pela Universidade de Stanford, em 1988; } \\
\text { Dois módulos: um de aplicações de inteiros e outro de aplicações } \\
\text { de ponto flutuante; } \\
\text { Linguagem de implementação: C. }\end{array}$ \\
\hline TTCP & $\begin{array}{c}\text { Desempenho de TCP } \\
\text { e UDP entre dois } \\
\text { sistemas }\end{array}$ & $\begin{array}{l}\text { Criado no US Army Ballistics Research Lab (BRL); } \\
\text { Desenvolvido em Cray; } \\
\text { Mede tempos de transmissão e recepção de dados entre dois } \\
\text { sistemas usando protocolos UDP ou TCP; } \\
\text { Domínio Público. }\end{array}$ \\
\hline
\end{tabular}

Quando se utiliza um benchmark para avaliar o desempenho de um sistema deve-se observar se a própria execução do benchmark não influenciará nos resultados obtidos. Porém, o maior problema dos benchmarks é que ele pode não ser representativo do programa do usuário.

Como o uso de benchmarks na avaliação de desempenho será a base deste projeto de mestrado, no capítulo seguinte será dada uma visão mais detalhada desta metodologia. 


\subsection{Conclusão}

No trabalho descrito em [ORL95], é feito um estudo no qual são analisadas as ferramentas descritas anteriormente sobre alguns parâmetros. Esse estudo teve por finalidade orientar o responsável pela análise de desempenho, na escolha de uma ferramenta apropriada aos seus propósitos. A Tabela 5 estabelece os parâmetros analisados nas ferramentas descritas. Para cada um dos parâmetros considerados, atribui-se um índice variando de 1 a 3. Os parâmetros são:

1. Adeqüabilidade - o índice 3 é atribuído quando a ferramenta constitui uma opção apropriada, o índice 2 é atribuído quando existe alguma limitação no uso da ferramenta e o índice 1 quando a utilização da ferramenta não é indicada.

2. Facilidade - o índice 3 indica que a ferramenta não requer conhecimento específico por parte do usuário para utilizá-la, o índice 2 indica que a ferramenta requer algum conhecimento e o índice 1 indica que a ferramenta necessita de conhecimento específico.

3. Precisão - o índice 3 indica que a ferramenta apresenta resultados com alta precisão, índice 2 indica que a ferramenta apresenta nível satisfatório de precisão e $o$ índice 1 indica que os resultados fornecidos pela ferramenta apresentam baixa precisão.

4. Tempo - o índice 3 indica que a ferramenta não requer muito tempo para apresentar os resultados, o índice 2 indica que a ferramenta consome tempo considerável para apresentar os resultados e o índice 1 indica que o tempo para se obter resultados é inadequado.

5. Custo - o índice 1 indica que a ferramenta pode apresentar alto custo de desenvolvimento e/ou utilização, o índice 2 indica que a ferramenta apresenta custo considerável de desenvolvimento e/ou utilização e o índice 3 indica que a ferramenta é de baixo custo.

6. Alteraçōes - $o$ índice 3 indica que a ferramenta permite avaliação adequada sobre $o$ comportamento do sistema a partir de alterações propostas para o sistema real, o índice 2 indica que a ferramenta permite uma avaliação razoável nesse caso e índice 1 indica que as alterações propostas são difíceis de serem refletidas pela ferramenta. 
Tabela 5 - Análise das Ferramentas.

\begin{tabular}{|c|c|c|c|c|c|c|c|c|}
\hline & \multicolumn{3}{|c|}{ Adequabilidade } & Facilidade & Precisão & Tempo & Custo & Alteraçбes \\
\hline & Avaliação & Seleçăo & Projeto & & & & & \\
\hline Benchmarks & 3 & 3 & 1 & 3 & 2 & 3 & 3 & 1 \\
\hline $\begin{array}{c}\text { Construçăo de } \\
\text { Protótipos }\end{array}$ & 1 & 1 & 3 & 1 & 2 & 1 & 1 & 1 \\
\hline $\begin{array}{c}\text { Monitores de } \\
\text { Software }\end{array}$ & 3 & 2 & 1 & 2 & 3 & 1 & 3 & 2 \\
\hline $\begin{array}{c}\text { Monitores de } \\
\text { Hardware }\end{array}$ & 3 & 2 & 1 & 1 & 3 & 1 & 1 & 1 \\
\hline $\begin{array}{c}\text { Modelos } \\
\text { Analíticos }\end{array}$ & 3 & 2 & 2 & 2 & 3 & 2 & 3 & 2 \\
\hline Simulaçẵo & 3 & 2 & 2 & 2 & 3 & 2 & 3 & 3 \\
\hline
\end{tabular}




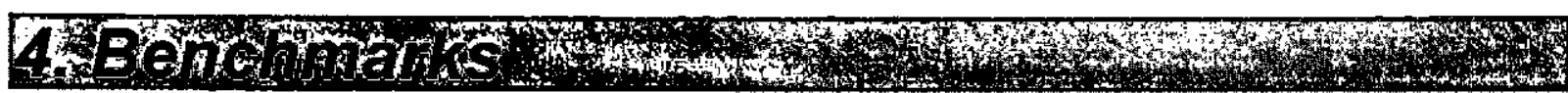

Benchmarks têm sido utilizados intensamente, tanto como apoio na tomada de decisões para compra de equipamentos, como no planejamento da capacidade computacional necessária para um dado conjunto de aplicações.

Os benchmarks são utilizados para comparar o desempenho de máquinas diferentes, reprojetar hardware e software, decidir sobre a aquisição de um certo sistema, fazer a previsão de desempenho de aplicações em computadores específicos e ajudar os programadores na otimização de seus programas.

Assim, benchmarks constituem uma ferramenta importante para a comparação de desempenho de sistemas de computação. O objetivo do uso de benchmarks é predizer o desempenho da carga de trabalho em uma plataforma em particular, através da execução de um programa que represente a carga de trabalho em estudo [SUN95].

Os benchmarks são programas que possuem modelos representativos de carga de trabalho, podendo ser construídos de duas maneiras:

- Carga de trabalho real: parte do código da aplicação, ou a aplicação inteira, é executada e medida. Essa carga de trabalho inclui o código que o usuário executa, possuindo um alto grau de representatividade e, portanto, os benchmarks que o usam fornecem um bom prognóstico de desempenho.

- Carga de trabalho sintética: um software, que exibe características de consumo de recursos similar a uma carga de trabalho real, é construído. Um exemplo desse tipo de carga de trabalho é o benchmark LADDIS, que faz requisições NFS (Network File System) seguindo os mesmos padrões de cargas de trabalho reais. Benchmarks sintéticos são úteis para determinar picos de desempenho do sistema e de seus componentes, pois a intensidade da carga de trabalho pode ser variada enquanto se mantêm as mesmas operações.

Avaliação de desempenho não é uma tarefa fácil, e dependendo do objeto que está sendo avaliado, é irreal esperar que algum grupo de benchmarks forneça todas as informações necessárias de forma representativa. Sabe-se que benchmarks fornecem muitas informações úteis sobre as características de cada computador e que, tomando certos cuidados, sua utilização fornece resultados representativos do comportamento do sistema. 


\subsection{Tipos de Benchmarks}

Os benchmarks podem ser classificados de diferentes formas, dependendo da característica a ser considerada e do tipo de avaliação a ser efetuada. Quanto ao tipo de informação a ser obtida, os benchmarks podem ser subdivididos em:

- Benchmarks de baixo nível: medem o desempenho de componentes individuais do sistema, tais como processador, memória, dispositivos de $\mathrm{E} / \mathrm{S}$, e recursos de rede em geral. Esses tipos de benchmarks são populares porque seus resultados são fáceis de se entender.

- Benchmarks de alto nível: medem o desempenho de aplicações. Eles avaliam o desempenho de muitos componentes do sistema que estão trabalhando juntos para produzir o resultado observado pelo usuário. Esse tipo de Benchmark é construído para ser representativo do mundo real, e por isso fornecem um bom prognóstico de desempenho.

Os benchmarks de baixo nível são mais fáceis e rápidos de serem executados, e em muitos aspectos são considerados mais úteis, pois seus resultados medem as características básicas de hardware. Além disso, o desempenho dos benchmarks de alto nível é apresentado em termos dos benchmarks de baixo nível. Benchmarks de alto nível são considerados menos úteis, pois é muito difícil fazer generalizações de seus resultados se o benchmark não é exatamente o que o usuário irá utilizar [HOC96]. Exemplos de benchmarks de baixo nível são os benchmarks sintéticos e kernel benchmarks.

Benchmarks sintéticos são derivados de estatísticas obtidas enquanto o software do usuário está executando em um sistema. Estes benchmarks são criados usando um perfil do sistema do usuário e compilando estatísticas do modo como o sistema se comporta.

Kernel benchmarks são benchmarks compostos por kernels. Um Kernel é um grupo de instruções normalmente usadas em grandes aplicações, como por exemplo, produto interno e multiplicação de matrizes. Há muitas vantagens no uso de kernels em vez de aplicações reais, uma delas é que os resultados podem ser relacionados à análise do código fonte mais facilmente que os resultados de benchmarks de aplicações. Isto é importante pelo fato de que o desempenho do kernel pode ser usado como base para a análise de desempenho de aplicações mais complexas. 
Deve ser mencionado, entretanto, que apenas o desempenho em kernels é insuficiente para avaliar o desempenho potencial de uma máquina paralela em aplicaçōes científicas. A grande dificuldade é que uma certa estrutura de dados pode ser muito eficiente em um sistema para um dos kernels em isolado, e esta mesma estrutura de dados pode ser inapropriada se incorporada a uma grande aplicação.

\subsection{Métricas de Desempenho}

As conclusões tiradas do estudo de desempenho de um computador através de um benchmark não dependem somente dos resultados de tempo obtidos, mas também do modo como eles são interpretados e convertidos em figuras de desempenho. A escolha da métrica de desempenho pode influenciar nas conclusões. Cada métrica tem seu uso próprio, e oferece diferentes informações sobre o computador e o algoritmo usado no benchmark.

Em geral, é aceito que não é possível caracterizar computadores de alto desempenho com métricas de benchmarks específicos. Muitos autores têm sugerido explorar a variação de desempenho de uma forma modular e em camadas, dando um perfil do desempenho.

As principais métricas de desempenho, segundo Hockney [HOC96] são: temporal, de simulação, de benchmark, e de hardware.

\section{Desempenho Temporal}

Usado para comparar o desempenho de algoritmos diferentes para a solução do mesmo problema. O desempenho temporal $\left(\mathrm{R}_{\mathrm{T}}\right)$ é definido pela equação 1 , onde $N$ representa o tamanho do problema, $p$ o número de processadores e $\mathrm{T}(N, p)$ o tempo de execução.

$$
\mathrm{R}_{\mathrm{T}}(N ; p)=\mathrm{T}^{-1}(N ; p)
$$

Como pode ser observado na equação 1 , o desempenho temporal corresponde ao inverso do tempo de execução. Com essa métrica pode-se ter certeza de que o algoritmo com o mais alto desempenho executa em menor tempo, e, portanto é o melhor algoritmo.

\section{Desempenho de Simulação}

É um caso especial de desempenho temporal que ocorre para programas de simulação em que o problema de benchmark é definido como a simulação de um certo período de tempo físico. Nesse caso, utilizam-se unidades como dias simulados por dia (sim'd/d) na previsão de tempo, ou pico- segundos por segundo na simulação de dispositivos eletrônicos. 


\section{Desempenho de Benchmark}

Usado para comparar o desempenho de um computador em um benchmark com seu desempenho em outro benchmark. Pode-se definir desempenho de benchmark $\left(\mathrm{R}_{\mathrm{B}}\right)$ pela equação 2 , onde $\mathrm{F}_{\mathrm{B}}(N)$ é o contador de operações de ponto flutuante (flop).

$$
\mathrm{R}_{\mathrm{B}}(N ; p)=\mathrm{F}_{\mathrm{B}}(N) / \mathrm{T}(N ; p)
$$

A unidade usada aqui é Mflop/s (<nome do benchmark>). O propósito da métrica de desempenho de benchmark é comparar diferentes implementações e algoritmos em diferentes computadores para a solução de um mesmo problema, usando como base que o melhor desempenho significa o menor tempo de execução.

\section{Desempenho de Hardware}

Para comparar o desempenho observado nos dispositivos de hardware $\left(\mathrm{R}_{\mathrm{H}}\right)$, deve-se computar o número real de operações de ponto flutuante executadas, $\mathrm{F}_{\mathrm{H}}(N ; p)$, e através dele calcular o desempenho de hardware real, como podemos ver na equação 3 .

$$
\mathrm{R}_{\mathrm{H}}(N ; p)=\mathrm{F}_{\mathrm{H}}(N ; p) / \mathrm{T}(N ; p)
$$

Também tem como unidade Mflop/s.

\subsection{Vantagens e Desvantagens de Benchmarks}

A principal vantagem de se utilizar benchmarks sobre outros métodos de avaliação de desempenho é que eles permitem avaliar o sistema de computador como um todo. A execução de um programa real avalia todos os aspectos necessários, incluindo aqueles relacionados com a arquitetura do sistema, eficiência do compilador, sobrecarga do sistema operacional, etc [GON96]. Entretanto, fazer uma comparação razoável de computadores usando benchmarks não é uma tarefa fácil. Para que os resultados obtidos sejam confiáveis, muitos aspectos têm que ser cobertos, e se houver algum esquecimento, por mais descartável que pareça, os resultados podem ser inválidos.

Os benchmarks também são úteis para identificar os pontos fracos e fortes de um sistema de computador em particular ou de aplicações. Conseqüentemente, os resultados de benchmarks podem ser úteis para orientar a otimização de programas. 
Com o avanço permanente dos sistemas computacionais e dos estilos de programação, alguns benchmarks reconhecidos tornam-se obsoletos. Uma revisão constante dos fatores mais importantes em computadores paralelos é necessária para a atualização dos benchmarks.

Outras vantagens apresentadas pela utilização de benchmarks são: fornecer uma visão do sistema; os resultados podem ser generalizados (com cuidado); os sistemas podem ser comparados; etc. Como pontos negativos pode-se citar: benchmarks não podem responder a questões que não foram perguntadas; benchmarks de aplicações específicas não poderão fornecer informações sobre outra aplicação sem uma análise dessa aplicação; benchmarks gerais não poderão informar todos os detalhes de desempenho de uma aplicação específica; para estar preparado para entender corretamente a história que um benchmark irá contar, temse que conhecer sua base.

\subsection{Interpretando resultados de Benchmarks}

Existem muitos perigos envolvidos na interpretação e entendimento correto dos resultados de um benchmark. Três aspectos importantes devem ser considerados [SUN95]:

- Conhecer o que está sendo medido. É tentador tomar importantes decisões de negócio baseando-se em um grupo de benchmarks padrões, sem conhecer o que realmente está sendo medido. Sem essa informação, é impossível saber se as medidas são relevantes à aplicação para qual o sistema está sendo adquirido.

- Representatividade. Quanto mais próximo o benchmark for da aplicação que vai ser executada, melhor será a predição de desempenho. Benchmarks de componentes, onde aplicações fazem uso do sistema inteiro, não fornecem um bom prognóstico de desempenho. Benchmarks de aplicação fornecem um melhor prognóstico de desempenho para aplicações individuais.

- Evitar uma única métrica de medida. Desempenho de aplicações é uma questão complexa, e dificilmente poderá ser descrito como um único número. Deve-se evitar benchmarks que fazem a média de muitos resultados em uma única métrica, pois informações são perdidas em médias, e a informação que se perdeu pode ser crítica. Os resultados de todos os benchmarks relevantes a uma aplicação em particular devem ser avaliados.

Um erro muito comum no uso de benchmarks é com relação à oomparação de sistemas que não podem na realidade ser comparados. Quando dois ou mais sistemas são 
comparados, todas as suas características têm que ser consideradas, e deve-se fazer um estudo para garantir que os sistemas em questão pertencem a uma mesma área e possuem características em comum. Quando se compara os resultados de testes de benchmarks em dois produtos concorrentes e os resultados são muitos diferentes, fica claro que esses sistemas não devem ser comparados e os resultados têm pequena validade, a não ser que os sistemas realmente sejam diferentes.

Outros cuidados que devem ser considerados na execução de um benchmark incluem:

- É necessário saber o nome, a versão, e detalhes de qualquer mudança feita, seja para portabilidade ou para melhorar o desempenho;

- A configuração em que o benchmark é executado também é importante e deve ser analisada. Informações sobre o modelo do processador, velocidade, cache, número de processadores, memória, versões do software (sistema operacional, compiladores, aplicações relevantes, etc.), estado do sistema (único ou vários usuário, etc.) e periféricos.

\subsection{Principais Benchmarks}

Nesta seção será apresentada uma introdução aos principais benchmarks, classificando-os em diferentes categorias.

\subsubsection{Benchmarks sintéticos}

Como já citado anteriormente neste trabalho, benchmarks sintéticos são benchmarks de baixo nível, que não necessariamente resolvem qualquer problema ou partes de um problema. Eles tentam representar uma carga de trabalho real pela execução de uma quantidade similar de instruções. Esse tipo de benchmark dá aos usuários o valor de um parâmetro particular relacionado à máquina. A seguir são discutidos alguns benchmarks que fazem parte dessa categoria.

\section{Whetstone}

Este benchmark foi projetado para comparar e observar a frequência das operações usadas em programas Algol. Ele é composto por 11 módulos, que foram construídos a partir de instruções whetstone, que são instruções de linguagens intermediária usada por um compilador Algol. Muitas características do processador, como aritmética de ponto flutuante, chamadas de sub-rotinas e passagem de parâmetros são analisados por este benchmark. As 
métricas obtidas são chamadas de KWIPS (Kilo Whetstone Instructions Per Second) e representam o número de tais estruturas executadas por segundo [GON96].

\section{Dhrystone}

É um programa que consiste de uma coleção de rotinas baseadas na distribuição de características da linguagem em aplicações não numéricas. Dhrystone mede o desempenho de operações de inteiro e E/S, e uma grande porcentagem do tempo é gasto fazendo comparações e cópias de cadeias de caracteres. Similar ao Whetstone, esse benchmark usa uma métrica chamada DIPS (Dhrystone Instructions Per Second) [WEI84].

\section{CoMet}

É um benchmark que mede o desempenho de comunicação em máquinas de memória distribuída. Esse benchmark é baseado em padrões de comunicação comuns encontrados em aplicações científicas. Ele contém dois níveis de kernels de comunicação. O primeiro nível mede parâmetros de desempenho básicos, como tempo de inicialização e largura de banda e tempo de sincronização. O segundo nível contém padrões de comunicação relacionados a matrizes, como troca de dados com o nó vizinho e movimento de dados. CoMet implementa comunicação usando macros e funções de alto nível, que por sua vez podem ser implementados no topo das bibliotecas de comunicação nativas [GAN94].

\subsubsection{Kernel Benchmarks}

Os códigos de benchmarks de baixo nível são projetados para medir as características arquiteturais básicas de máquinas paralelas. Códigos completos de aplicações obviamente medem o desempenho de um sistema paralelo como um todo e, é isso que o usuário deseja. Entretanto, em muitos casos, os códigos das aplicações são complexos, e não estão disponíveis em uma versão paralela adequada. Para obter um guia de desempenho de qualquer sistema paralelo em uma aplicação em particular, alguma coisa menos complexa do que a aplicação do usuário é útil. Para esses casos, aplicam-se os kernels benchmarks, que são benchmarks compostos por kernels e são mais simples que as aplicações completas.

\section{Livermore Loops}

É um grupo de 24 laços Fortran extraído do código operacional usado no Lawrence Livermore National Laboratory. Muitos laços contêm operações matemáticas comuns usadas na fŕsica computacional, mas tambêm há laços não numéricos. Esse benchmark tem sido 
utilizado para medir o desempenho de operações em ponto flutuante de computadores e compiladores. Os vários testes executam um grupo de 24 kernels três vezes. $O$ teste inteiro repetido 7 vezes para relatar erros de temporização experimentais. As medidas são feitas em Mflops (milhões de operações de ponto flutuante por segundo) [HOC96].

\section{LINPACK}

É um programa baseado em uma única decomposição LU de um sistema linear denso (eliminação de Gauss), que foi originalmente projetado para comparar o desempenho de uniprocessadores escalares, embora máquinas vetoriais e multiprocessadores também têm sido avaliados. Há duas versões do $L I N P A C K$, a primeira usa matrizes $100 \times 100$, e os usuários dos benchmarks podem mudar a biblioteca principal, chamada BLAS (Basic Linear Algebra Subrotines). Muito do tempo gasto com a execução desse benchmark é devido às chamadas às funções BLAS. A segunda versão usa matrizes $1000 \times 1000$ e os usuários dos benchmarks podem fazer qualquer mudança no código. As medidas são feitas em Mflops, que são calculados a partir do número de operações de ponto flutuante necessárias para resolver as equações lineares [HOC96].

\section{Parallel Loops}

São testes que consistem de dois componentes, um grupo de 36 sub-rotinas e 64 laços individuais. O principal objetivo desse benchmark é medir a capacidade do compilador para reconhecer e explorar paralelismo. Esse benchmark foi projetado para ser usado em sistemas com memória compartilhada, que são mais apropriados para paralelismo de granulosidade fina, explorando muitos laços numéricos. O speedup da versão paralelizada com respeito à versão sequiencial é usado para medir a efetividade da paralelização do compilador/hardware [DON91].

\subsubsection{Benchmark Suites}

Quando se utiliza um conjunto de kernels para fazer benchmarks leva-se adiante o problema de representatividade. Um modo de superar esse problema é fazer benchmarks com aplicações reais, pois aplicações diferentes utilizam os componentes do computador de um modo diferente. A proposta de uso de benchmarks baseada em aplicações é composta por um grupo de aplicações, esse tipo de benchmark é usualmente chamado de benchmark suite [GON96]. 


\section{The Perfect Club Benchmarks}

É uma coleção de 13 programas obtidos de quatro áreas de aplicação: dinâmica dos fluídos, modelagem química e física, projeto de engenharia e processamento de sinal. Os programas escolhidos são representativos de suas áreas específicas. Esses programas não foram desenvolvidos para máquinas paralelas $\mathrm{MIMD}$, mas para máquinas escalares e uniprocessadores vetoriais [MIC94].

\section{SPEC (Standard Performance Evaluation Corporation)}

O SPEC foi a primeira tentativa de selecionar aplicações completas largamente usadas para fazer um benchmark suite. Um grupo de 20 aplicações completas normalmente usadas em ambiente Unix foi escolhido para formar o SPEC, e por esta razão ele é dito ser representativo. $O$ principal argumento para a escolha de aplicações reais é que pequenos benchmarks não podem representar grandes aplicações, pois eles usam o sistema de memória de uma maneira muito diferente. Um dos principais problemas do SPEC é que seus benchmarks necessitam de um sistema Unix completo, tornando difícil a condução de testes de arquiteturas em estágios anteriores ao desenvolvimento ou testes através de diferentes sistemas operacionais [DIX91].

\section{SPLASH}

Mais tarde substituído por SPLASH-2, é um benchmark suite projetado para estudar multiprocessadores com espaço de endereçamento compartilhado. A versão atual consiste de 8 aplicações completas e 4 kernels, que representam uma variedade de aplicações de engenharia, científicas e gráficas.

\subsubsection{Benchmarks Suites em múltiplas camadas}

São benchmarks suites estruturados em camadas, que com um aumento na ordem de dificuldade podem ser úteis para explicar o comportamento de programas complexos usando resultados de programas mais simples.

\section{The NAS Parallel Benchmarks}

Baseado em vários princípios sobre a diversidade do projeto de sistemas paralelos e na rápida evolução das arquiteturas paralelas. O NAS Parallel Benchmarks foi originalmente proposto em 1991. A metodologia é chamada "paper and pencil", e consiste em especificar um conjunto de problemas somente a nível matemático. A escolha da estrutura de dados, 
algoritmos, alocação do processador e uso da memória é deixado a cargo do implementador. O tipo de especificação do benchmark tenta evitar a avaliação de computadores com programas que podem favorecer arquiteturas particulares, e também evita problemas de portabilidade que aplicações de larga escala podem ter. A principal desvantagem dessa metodologia é que vendedores criam suas próprias versões de programas e não as tomam públicas. O NAS Parallel Benchmarks está disponível em versões de Fortran 77, que podem ser usadas como ponto inicial para implementações otimizadas. Uma segunda versão do $N A S$ Parallel Benchmarks contém 5 dos 8 benchmarks originais, e fomece o código fonte desses programas em Fortran 77 usando MPI para passagem de mensagem. Esses benchmarks incluem dois kernels (FT e MG) mais três aplicações simuladas (LU, SP e BT) [BAI94].

\section{Euroben}

Este benchmark suite foi originalmente projetado para avaliar o desempenho de sistemas de computador com um único processador em programas orientados numericamente. O Euroben tenta explorar a variação de desempenho de sistemas de computador, dando um perfil do desempenho, em vez de uma única figura de desempenho. O benchmark é organizado em três módulos, o primeiro contém programas para avaliar operações básicas, o segundo contém programas para medir o desempenho de algoritmos básicos, e o terceiro mede o desempenho de vários kernels de aplicações. Recentemente estes programas foram completados com benchmarks paralelos do Genesis benchmark suite [STE95].

\section{Genesis Distributed-Memory Benchmarks}

É um conjunto de programas sequenciais e paralelos escritos em Fortran 77, com macros PARMACS para comunicação. Eles são escritos especialmente para testar computadores de memória distribuída que utilizam o paradigma de comunicação de passagem de mensagem. Esse é um benchmark suite em múltiplas camadas com 3 níveis: no primeiro nível têm-se os fragmentos de código sintéticos, que foram projetados para medir propriedades básicas da máquina relacionadas à vetorização, comunicação e sincronização; no segundo nível têm-se os kernels de aplicações, ou códigos de intensiva computação que freqüentemente são partes de uma aplicação mais complexa; no terceiro nível têm-se os códigos de aplicações completas, usados principalmente para verificar se os kernels de aplicações fornecem prognósticos de desempenho confiáveis [HEY91]. 


\section{Parkbench}

O Parkbench distributed memory benchmarks é um benchmark suite para máquinas MIMD feitos em Fortran 77 com funções de comunicação por passagem de mensagem. Parkbench possui três níveis de programas: benchmarks de baixo nível, que avaliam características arquiteturais básicas como resolução de tempo e parâmetros de comunicação; kernel benchmarks, que são seções de intensiva computação de aplicações comuns; e códigos de aplicações compactas, selecionados de muitas áreas científicas. Os benchmarks do Parkbench também são organizados em três níveis: benchmarks de baixo nível, estes benchmarks são os mesmos do Genesis, e recentemente versões em PVM e MPI de benchmarks de comunicação foram incluídas; kernel benchmarks; e benchmarks de aplicações compactas, que executam um número de algoritmos diferentes, e têm diferentes características de comunicação e E/S [HOC96].

\subsection{Conclusão}

Benchmarks fornecem um bom prognóstico de desempenho quando executados corretamente. Para que se possa confiar nos resultados apresentados pelos benchmarks, todos os aspectos relacionados à criação e a execução do benchmark, tais como representatividade e portabilidade têm que ser cobertos. Se algum ponto deixar de ser lembrado, os resultados podem ser considerados inválidos.

A decisão sobre qual tipo de benchmark aplicar na avaliação, depende do que se quer avaliar, um componente do sistema em particular ou o sistema como um todo. Quando se deseja analisar apenas um componente do sistema, os benchmarks de baixo nível, como os benchmarks sintéticos, devem ser utilizados. Utilizam-se os kernels benchmarks quando a avaliação de uma parte de intensiva computação (kernel) da aplicação é suficiente para fornecer os dados necessários. Se os kernels benchmarks não forem suficientes para fornecer todos os dados necessários para a avaliação, um benchmark de alto nível, ou seja, de aplicações reais, é aplicado.

Limitar a análise a um único benchmark é insuficiente em determinados casos. Benchmarks são programas individuais. Desempenho real é observado em um ambiente muito mais complexo onde muitos programas interagem entre si. Para solucionar esse problema surgiram os benchmarks suites e os benchmarks suites organizados em múltiplas camadas. 
Essa é uma proposta de uso de benchmarks baseada em várias aplicações, onde vários aspectos podem ser cobertos.

O uso de benchmarks tem algumas limitações como uma metodologia para avaliação de desempenho. Ele pode ser útil para predição de desempenho de aplicações complexas, e também pode guiar os esforços realizados na paralelização e na otimização de desempenho. As limitações estão relacionadas ao fato de que a interpretação dos resultados de um benchmark não é uma tarefa fácil, especialmente quando os benchmarks são aplicações complexas.

A evolução das arquiteturas de computadores força a evolução dos benchmarks, pois eles devem medir os novos gargalos potenciais. Desempenho de comunicação tem sido um parâmetro importante a ser medido, pois ele representa o maior componente da sobrecarga produzida pela paralelização [GON96]. 


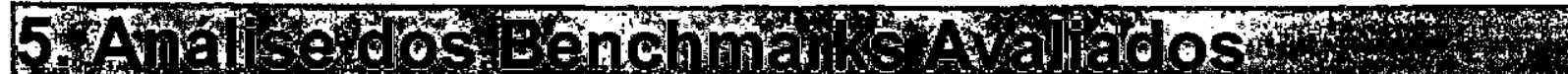

Este capítulo apresenta as características observadas em cada benchmark, suas vantagens e desvantagens, sua funcionalidade, o que medem, em que linguagem foram desenvolvidos, qual a plataforma de software paralela, pra qual plataforma de hardware já existe um script pronto e quais são os seus autores.

Uma análise dos dados coletados durante a execução dos benchmarks e as conclusões tiradas de cada benchmark também são apresentadas.

Os ambientes utilizados para a execução do MPBench foram:

- IBM RISC System/6000 Scalable Power parallel System (SP2) com 3 nós, 2 thin com $128 \mathrm{MB}$ e um wide com $256 \mathrm{MB}$. Os nós se comunicam por uma rede de chaveamento (switch) de alto desempenho. O sistema operacional utilizado nos nós do SP2 é o UNIX AIX versão 4.1.4. Maiores detalhes sobre o a máquina SP2 utilizada podem ser encontrados na seção 2.1.1;

- rede LINUX com 3 máquinas Pentium interligadas por uma rede ethernet de 10 Mbits. As máquinas possuem as seguintes configurações:

LASD06 - Pentium 100Mhz, 32Mb, $1 \mathrm{~Gb}$ de disco;

LASD07 - Pentium 166Mhz, 32Mb, 2.5Gb de disco;

LASD08 - Pentium II, 400Mhz, 128Mb, 6Gb de disco.

Os ambientes de passagem de mensagem utilizados foram MPI, PVM3 e PVMe.

\subsection{MPBench}

Inicialmente o primeiro benchmark escolhido para execução foi o ParkBench, mas este por ser um benchmark suite em múltiplas camadas gerou vários problemas de configuração e compilação relacionados ao ambiente de execução, os quais eram de difícil análise e compreensão. Dado que um benchmark de baixo nível é bem menos complexo do que um de alto nível, resolveu-se iniciar a execução com um de baixo nível. Depois de selecionar vários benchmarks existentes, o escolhido foi o MPBench, pois este analisa o ambiente de comunicação que é essencial para o bom desempenho de qualquer ambiente paralelo distribuído. 
A intensão dessa mudança foi justamente deixar o ambiente de execução totalmente configurado de acordo com os parâmetros que o benchmark exigia, visto que o trabalho se torna bem mais fácil e claro com um benchmark mais simples, como é o caso do MPBench, onde todo o código principal esta contido em apenas um arquivo.

O MPBench mede o desempenho de algumas operações essenciais de MPI e PVM. É um benchmark sintético de baixo nível e visa o desempenho ótimo da máquina. Para alcançar esse desempenho ótimo algumas opções do PVM e do MPI são utilizadas [MUC98]:

- PVM:

Roteamento Direto: conexão direta TCP/IP entre os processos, como uma opção a enviar mensagens via processos daemon.

Empacotamento In-place: todas as mensagens são empacotadas em buffers pvm antes da transmissão.

- MPI:

Utiliza-se o modo default para o envio de mensagens, ou seja, não é utilizada nenhuma chamada de comunicação não bloqueante ou imediata. Com isso evita-se cópias desnecessárias dos dados que freqüentemente dominam o custo da camada de comunicação.

O MPBench foi desenvolvido na linguagem $\mathrm{C}$, e é portável para as seguintes plataformas: IBM SP2, t3e, pca-r8k, o2k, sgi32-lam, sgi64-lam, linux-mpich, linux-lam, solaris-mpich, sun4-mpich e alpha. Como resultado, apresenta dois tipos de relatórios, um arquivo de dados e gráficos postscript. $\mathrm{O}$ arquivo de dados contém para cada tamanho de mensagem enviada, que varia de $4 \mathrm{~B} y$ tes a $16 \mathrm{Mbytes,} \mathrm{o} \mathrm{tempo} \mathrm{gasto} \mathrm{para} \mathrm{cada} \mathrm{operação}$ realizada. $\mathrm{O}$ gráfico postscript é gerado através desse arquivo de dados.

O tamanho das mensagens consideradas são: $4,8,16,32$, 64Bytes até chegar a 1 Mbyte. Depois disto, o tamanho da mensagem varia de um em um Mbyte, ou seja, 1, 2, 3, 4 Mbytes ate 16 Mbytes.

A Tabela 6 mostra as funções e as unidades de medida utilizadas pelo MPBench. 
Tabela 6 - Funçס̄es do MPBench.

\begin{tabular}{cl}
\hline Benchmark & Units \\
\hline Bandwidth & Megabytes/Seg. \\
\hline Roundtrip & Transações/Seg. \\
\hline Barrier synchronization & Barriers/Seg. \\
\hline Aplication Latency & Microsegundos \\
\hline Broadcast & Megabytes/Seg. \\
\hline Reduce & Megabytes/Seg. \\
\hline AllReduce & Megabytes/Seg. \\
\hline
\end{tabular}

Todos os testes são realizados seguindo os passos abaixo [MUC98]:
a) Configurar o teste.
b) Inicializar o timer.
c) Loop de operações sobre o tamanho da mensagem e sobre o contador de iterações.
d) Verificar se as operações acima estão completas.
e) Parar o timer.
f) Calcular a métrica apropriada.

No MPBench o timer não é chamado em cada operação, pois isso frequientemente resulta em uma análise dos dados não adequada, uma vez que as operações dentro do loop são tão rápidas, que a latência de acessar o sistema de clock a todo instante pode afetar os dados obtidos.

O MPBench inicializa dois tipos de tarefas, o mestre e o escravo. Os testes para comunicação ponto a ponto usam somente duas tarefas, um mestre e um escravo. Os outros testes rodam com qualquer número de escravos, sendo que o padrão é 16.

MPBench mede desempenho considerando o número de iterações. Esse número é especificado pelo usuário quando este executa o benchmark, sendo que o padrão é 500 . Nos casos em que o tamanho da mensagem é considerada muito grande para quantidade de 
iterações especificada pelo usuário, o MPBench utiliza um número menor de iterações. Isto não deve afetar a precisão dos resultados, pois o contador de iterações somente é mudado quando o tamanho da mensagem é tão grande que iria afetar a execução do benchmark.

As funções medidas no MPBench são computadas da seguinte maneira [MUC98]:

Bandwidth: Dois loops intercalados são responsáveis por essa medida. O loop mais externo varia o tamanho da mensagem e o mais interno varia o contador de iterações. Quando o processo escravo recebe todas as mensagens de um mesmo tamanho, ele envia para o processo mestre um sinal de 4 Bytes para indicar que recebeu todos os dados e esta pronto para prosseguir. A Figura 3 mostra os algoritmos que são executados para determinar bandwidth.

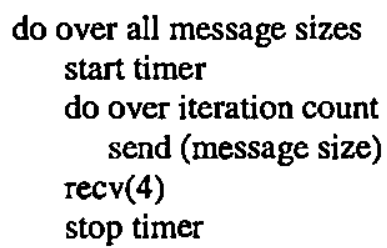

(a)

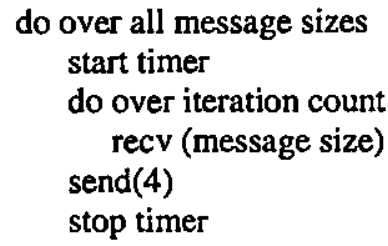

(b)

Figura 3 - Pseudo código do mestre (a) e do escravo (b).

Roundtrip: É medido da mesma forma que o Bandwidth, exceto pelo fato de que o processo escravo depois de receber a mensagem, a envia de volta para o mestre. A Figura 4 mostra os algoritmos que são executados para determinar roundtrip.

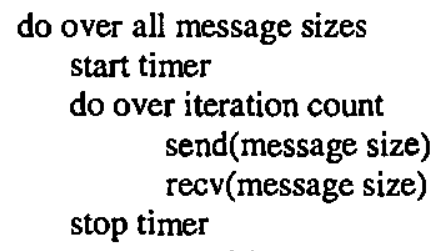

(a)

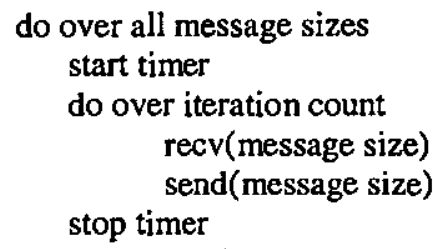

(b)

Figura 4 - Pseudo código do mestre (a) e do escravo (b).

Aplication Latency: Mede o tempo necessário para que uma aplicação envie um send e continue o processamento. Os resultados variam de acordo com a implementação da camada de passagem de mensagem. Por exemplo, o PVM irá armazenar todas as mensagens para transmiti-las independentemente do nó remoto estar pronto ou não para receber os dados. Já o MPI não armazena os dados, e ficara bloqueado até o processo remoto ter executado algum tipo de receive. É medido da mesma forma que o Bandwidth, a diferença é que nenhum sinal é 
enviado ao processo mestre e os resultados são reportados em unidades de tempo. A Aplication Latency representa o tempo que a aplicação irá esperar para realizar seu processamento enquanto está fazendo comunicação. A Figura 5 mostra os algoritmos que são executados para determinar latência.

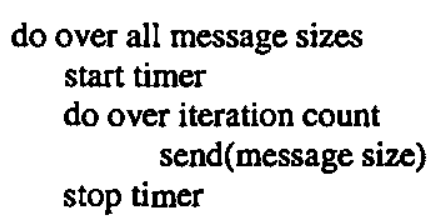

(a)

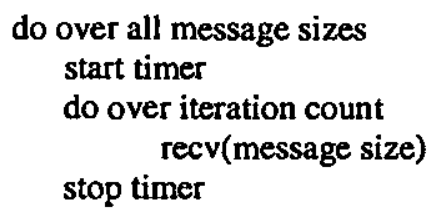

(b)

Figura 5 - Pseudo codigo do mestre (a) e do escravo (b).

Broadcast e Reduce: Essas funções são muito usadas em aplicações paralelas. Essencialmente estas operações são espelho uma da outra, a diferença é que a operação reduce reverte a direção da comunicação e faz algum processamento com os dados durante passos intermediários. No PVM, broadcast e reduce não irão executar a menos que a aplicação tenha feito um barrier imediatamente antes da operação. Por isso, no PVM ambos os testes incluem o custo de uma operação barrier em cada iteração. A Figura 6 mostra os algoritmos que são executados para determinar broadcast ou reduce.

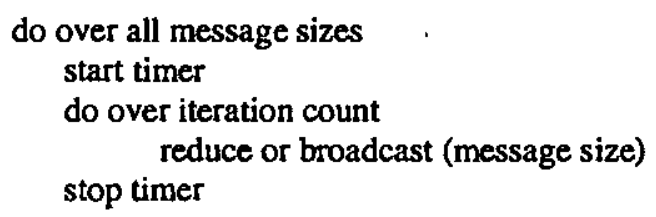

Figura 6 - Pseudo codigo para ambos, mestre e escravo.

Allreduce: Nesta operação cada processo envia dados para todos os outros processos. Esta operação pode ser implementada com um reduce seguido de um broadcast, como é feito na versão PVM, mas é altamente ineficiente para mensagens grandes. No PVM tem-se ainda uma chamada adicional ao barrier. O objetivo desta função é reconhecer implementações ineficientes para que o engenheiro da aplicação possa reestruturar sua comunicação. A Figura 7 mostra os algoritmos que são executados para determinar allreduce.

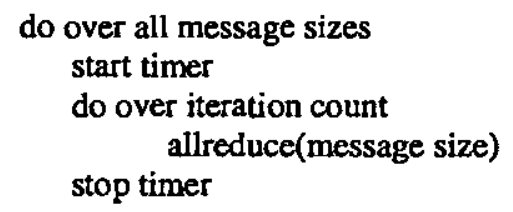

Figura 7 - Pseudo código para ambos, mestre e escravo. 
Barrier: Esta operação fornece a quantidade de barriers executada por segundo. Essa operação é medida para $2,4,8,16, \ldots$ processos e mede o tempo de sincronização entre os processos.

\subsubsection{Execução}

O código fonte do MPBench pode ser obtido na rede pelo seguinte endereço, ftp://cs.utk.edu/pub/mucci/mpbench.tar.gz, sendo que o relatório sobre o MPBench pode ser encontrado na página do autor (http://www.cs.utk.edu/ mucci). Depois de descompactar o arquivo os seguintes diretórios e arquivos são gerados:

\section{CVS/}

makefile

README

conf/

Index.html*

lib/

make.def

make_graphs.sh*

mpbench.c

samples/

O primeiro passo para se executar o MPBench é configura-lo para a execução na máquina específica, escolher o sistema operacional e a versão de MPI utilizada. Todas as configurações suportam PVM. Para realizar essa configuração, basta ler o arquivo README. Este arquivo contém todos os passos necessários para a instalação e execução do MPBench.

O número de iterações a serem executadas e o número de tarefas são dados que devem ser informados. O número de iterações se refere ao número de vezes que o pacote de tamanho $\mathrm{N}$ será enviado e/ou recebido, dependendo da função. Depois de executar o número de iterações o MPBench faz a média do tempo gasto.

A execução utilizando as bibliotecas MPI não gerou maiores problemas, o que já não aconteceu com o PVM3. Os passos seguidos para a execução do MPBench, assim como problemas e soluções tomadas são apresentados abaixo: 
- No SP2 a versão em MPI não gerou qualquer tipo de problema, sendo que o MPBench foi executado até com 1000 iterações;

- Na rede LINUX utilizando MPICH houve apenas um problema com o tamanho do vetor de entrada gerado, que era considerado muito grande para a quantidade de memória disponível nas máquinas em que estava sendo executado (32Mb). $\mathrm{O}$ tamanho máximo do vetor de entrada era de $16 \mathrm{MB}$, diminuindo esse tamanho para $4 \mathrm{MB}$, o MPBench executou sem problemas.

- A versão em PVM3 no SP2 apresentou várias dificuldades. Primeiro o PVM3 não estava configurado para execução através do console, a execução era controlada pelo LoadLeveler, onde o processo era colocado em uma fila de submissão e depois executado. Como a execução do MPBench se dá pelo console, esse ambiente teve que ser totalmente reconfigurado. Um bom tempo foi gasto com essa reconfiguração, visto que era necessário um bom conhecimento da máquina SP2 e do PVM3.

- Enquanto a reconfiguração do PVM3 no SP2 era efetuado, executou-se o MPBench através do PVMe, onde não foram constatados problemas na configuração.

- Como no PVMe não havia a função $P V M$ frezeegroup, que é uma função nova implementada no PVM 3.3.11, nem uma função correspondente a ela, esta função foi comentada. O MPBench foi executado até com 100 iterações, acima disto foi constatado um problema com a variável N64KBUFF, que indica o número de buffers de recepção alocados em cada nó. Por default é atribuído a essa variável o valor 16, que é o valor mínimo, aumentando seu valor para o máximo permitido, que foi 512 , conseguimos executar para 1000 iterações, mas para valores acima 0 problema persistiu.

- No LINUX executando em PVM3 também não se obteve problemas, foi necessário apenas uma alteração da variável MPIBUFSIZ que por default estava em 4MB, para 20MB. Após essa alteração o MPBench foi executado com o vetor de entrada original de $16 \mathrm{MB}$. 
- Após o término da reconfiguração do PVM3 no SP2, tentou-se executar o MPBench com 2 tarefas, o que não foi possível. A seguinte mensagem de erro foi apresentada: ERROR: mpp_new 0 not enought nodes in partition. Segundo o técnico consultado esse é um problema do PVM público no IBM SP, segundo o qual não se conseguiria a execução com um número de filhos maior ou igual a 2.

Realizados todos os passos descritos acima, obtive-se os resultados que serão apresentados na próxima seção.

\subsubsection{Análise dos Dados Obtidos}

Esta seção apresenta os dados obtidos com a execução do MPBench e uma análise sobre esses dados para checar a que tipo de conclusões o benchmarker pode chegar utilizando esse benchmark.

Nenhuma interpretação ou análise dos dados é feita pelo MPBench. $O$ usuário se encarrega de analisar os dados obtidos e através deles tirar suas próprias conclusões. Como já dito antes, os arquivos de saída gerados são um dat e um postscript para cada função medida.

Os resultados apresentados a seguir foram obtidos com a execução do MPBench no IBM SP2 com 3 nós e 1000 iterações utilizando MPI.

\section{Bandwidth}

$\mathrm{O}$ arquivo de dados gerado possui a seguinte nomenclatura:

"Nomedamáquina_ambientedepassagemdemensagemutilizado_funçãoqueestasendoavaliada"

Para a execução realizada no SP2 tem-se:

AIX-hades03_mpi_bandwidth.dat e AIX-hades03_mpi_bandwidth.ps.

A Figura 8 apresenta os resultados obtidos na execução do MPBench. Os dados disponíveis no arquivo (.dat) são o tamanho da mensagem em bytes e a quantidade de megabytes por segundo correspondente a execução da função.

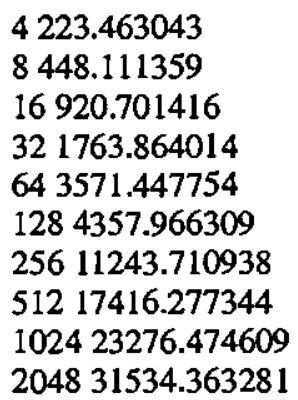




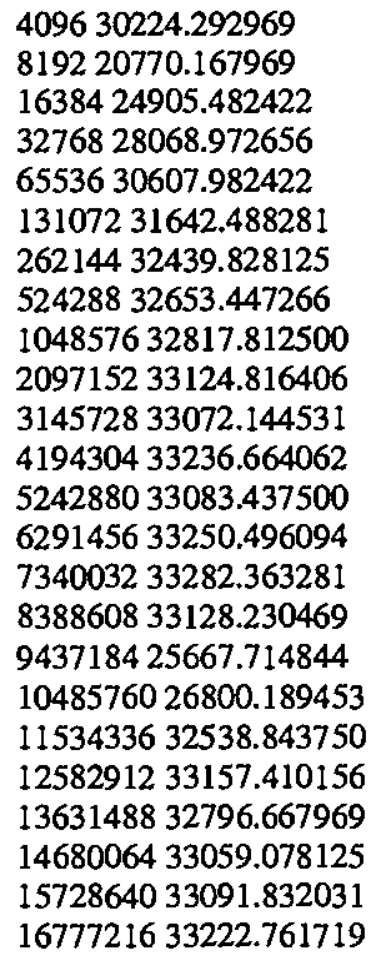

Figura 8 - Arquivo txt gerado pelo MPBench para Bandwidth.

A partir desses dados o MPBench gera o gráfico postscript representado na Figura 9.

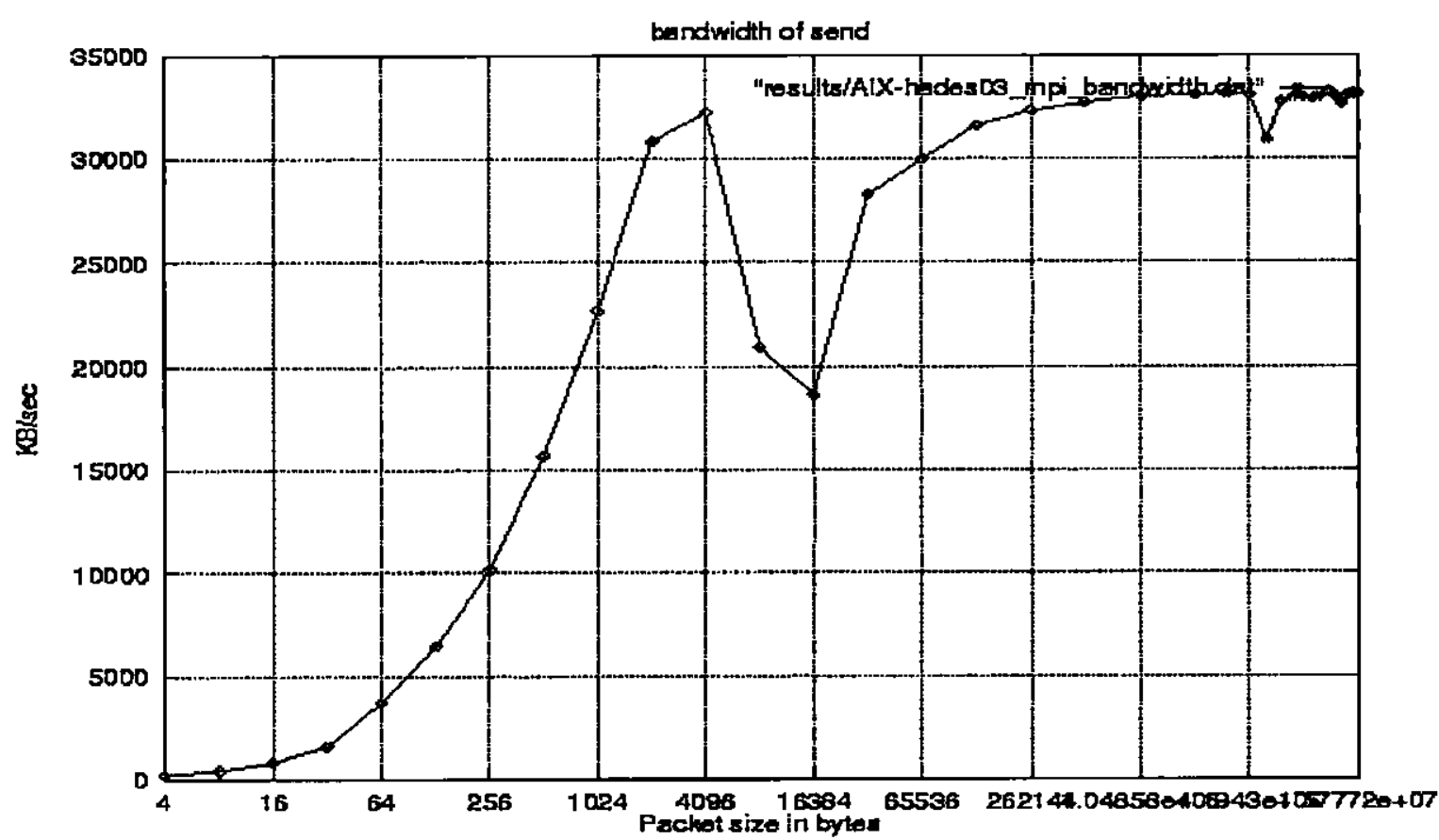

Figura 9 - Gráfico gerado pelo MPBench para Bandwidth.

O gráfico da Figura 9 pode ser utilizado para definir: 
- Comportamento do sistema para cada tamanho do pacote, podendo detectar e sanar possíveis pontos de queda de desempenho (como no exemplo, no gráfico da Figura 9, para pacotes de 16kbytes);

- Tamanho ideal do pacote para se obter um desempenho 6timo na rede analisada; No exemplo pode-se notar que um pacote de $4 \mathrm{Kbytes}$ obteria uma maior quantidade de Kbytes por segundo trafegando na rede;

- Escolha do melhor ambiente de troca de mensagens; Analisando o gráfico para todos os ambientes, pode-se escolher o que melhor se comporta;

- Comparação entre máquinas diferentes quanto ao comportamento do sistema relacionado ao desempenho quanto ao tamanho dos pacotes;

\section{Roundtrip}

O arquivo de resultados é semelhante para todas as funções, o que muda é a unidade em que a função é medida (conforme mostrado na tabela 1). A Figura 10 apresenta os resultados obtidos para roundtrip.

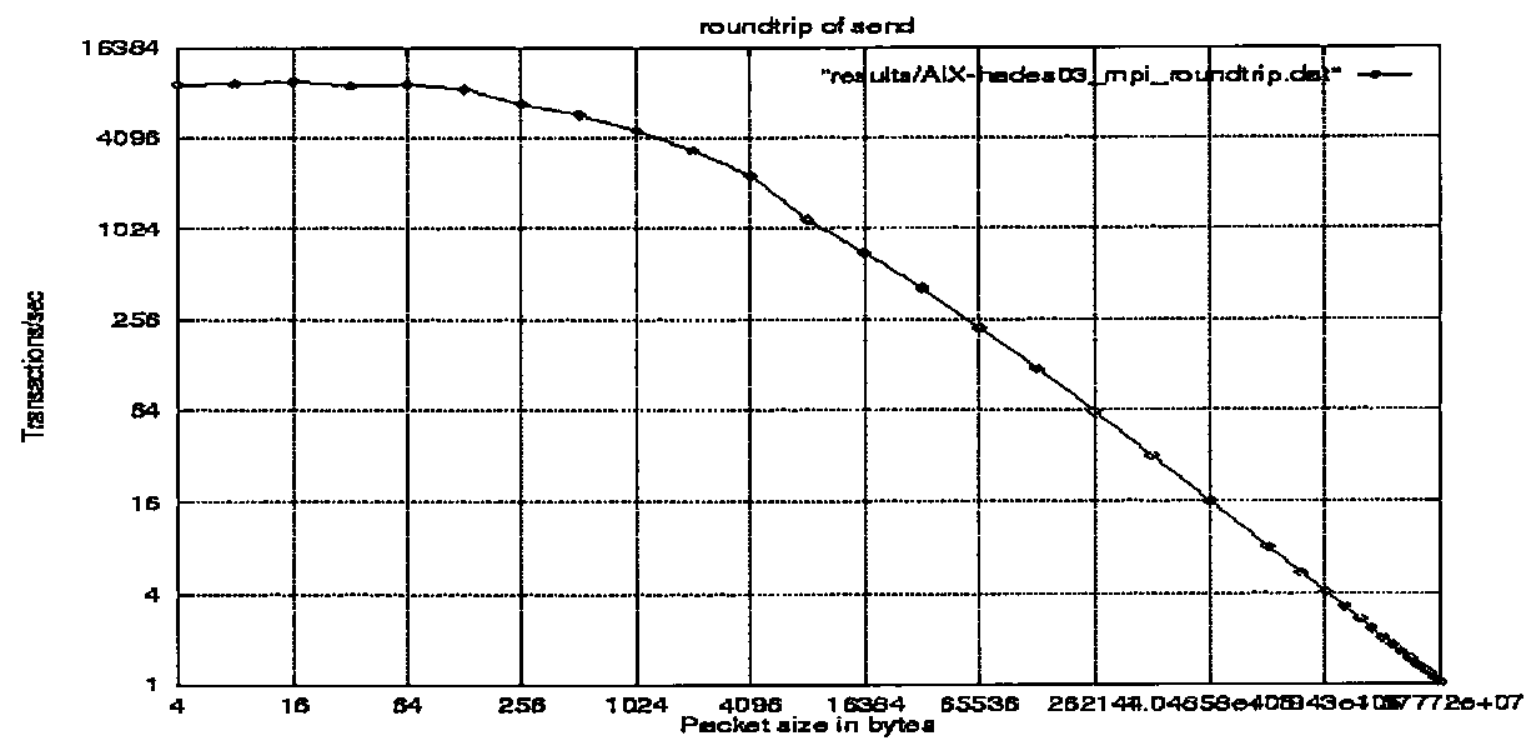

Figura 10 - Gráfico gerado pelo MPBench para Roundtrip.

É medido da mesma forma que o Bandwidth, exceto pelo fato de que o processo escravo depois de receber a mensagem, a envia de volta para o mestre.

Uma transação se refere ao envio e recebimento da mensagem. 
O gráfico de roundtrip pode ser utilizado para se definir os mesmos pontos citados para bandwidth (menos as questões relacionadas a bandwidth), mais o comportamento do sistema para roundtrip. Nota-se que o comportamento da curva muda a partir de pacotes de 4Kbytes, onde passa de exponencial para uma reta, isso indica que a partir de $4 \mathrm{Kbytes} \mathrm{tem-se}$ uma queda de desempenho menor em comparação com os pacotes menores que 4Kbytes. Essa mudança na curva mostra em que ponto o comportamento do sistema analisado muda.

\section{Aplication Latency}

É o tempo necessário para que a aplicação execute um send e continue seu processamento. Quanto menor o tempo de latência melhor. Essa função é medida em microsegundos por tamanho da mensagem.

O gráfico pode ser utilizado para se definir os mesmos pontos citados para bandwidth (menos as questões relacionadas a bandwidth), mais o comportamento da latência do sistema. Nota-se que a curva do gráfico da Figura 11, para pacotes pequenos, toma a forma de uma curva exponencial, mas quando chega a pacotes de 4 Kbytes tem-se uma pequena queda na curva e depois essa se comporta como uma reta. Essa mudança indica que a partir de $4 \mathrm{Kbytes}$ tem-se uma latência menor que quando comparado com pacotes menores.

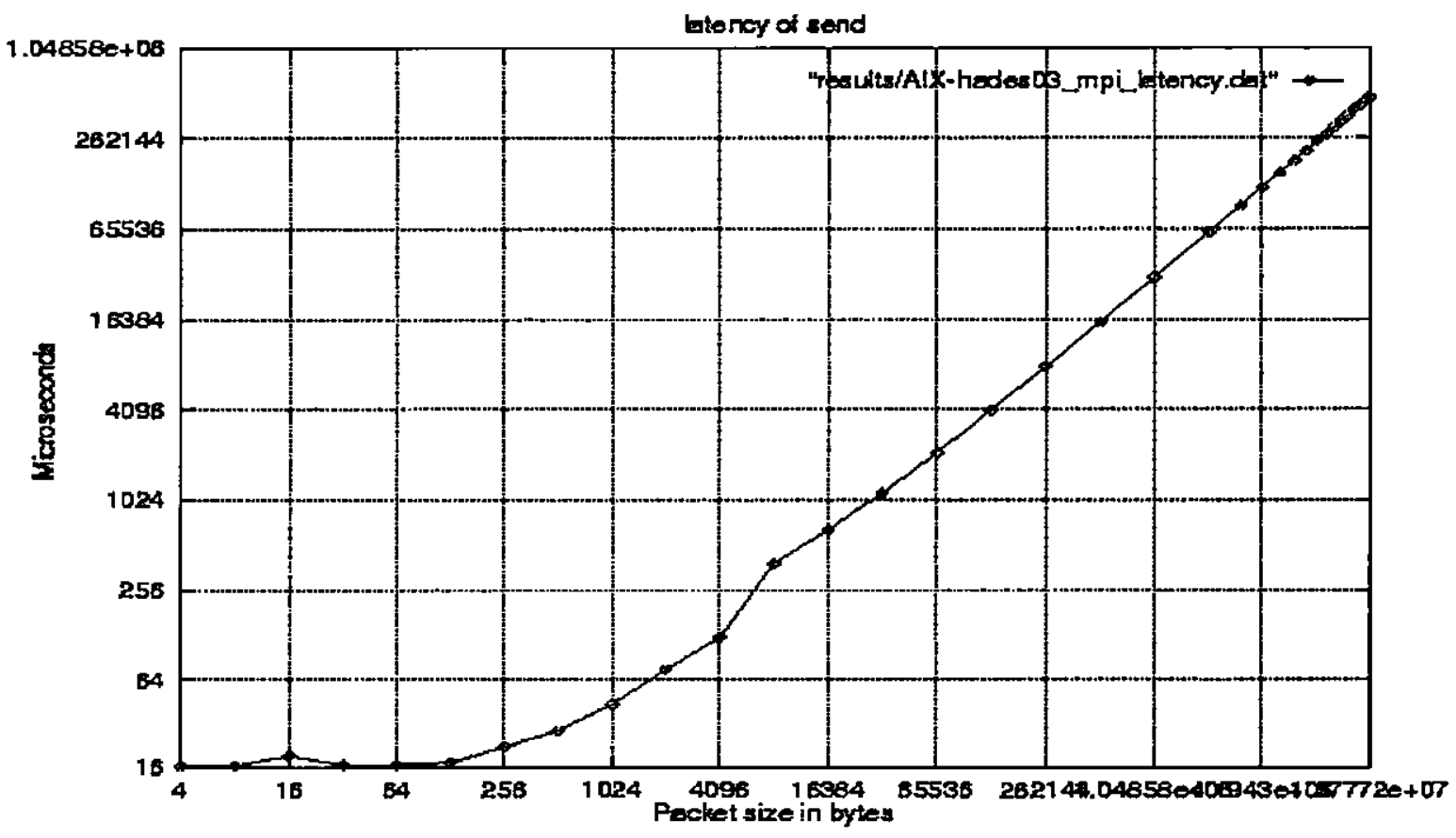

Figura 11 - Gráfico gerado pelo MPBench para Latência. 


\section{Broadcast}

É o tempo necessário para que a aplicação faça um broadcast pela rede. Quando se utiliza PVM torna-se necessário a realização de um Barrier antes da execução da função. Os resultados da execução dessa função são dados em megabytes por segundo.

O gráfico da Figura 12 pode ser utilizado para se definir os mesmos pontos citados para bandwidth (menos as questões relacionadas a bandwidth), mais o comportamento do sistema para broadcast. Nota-se que a curva cresce exponencialmente até pacotes de $4 \mathrm{Kbytes,}$ sendo que para pacotes maiores tem-se uma queda súbita de desempenho e posteriormente a curva se comporta como uma reta.

O tamanho da mensagem em que se consegue o maior e mais eficiente tráfego na rede para o sistema em questão é com pacotes de $4 \mathrm{Kbytes}$. Sendo que o desempenho do sistema cai bastante para pacotes de 8 e 32 Kbytes. Seria interessante a utilização desse gráfico para analisar as possíveis causas dessa queda de desempenho.

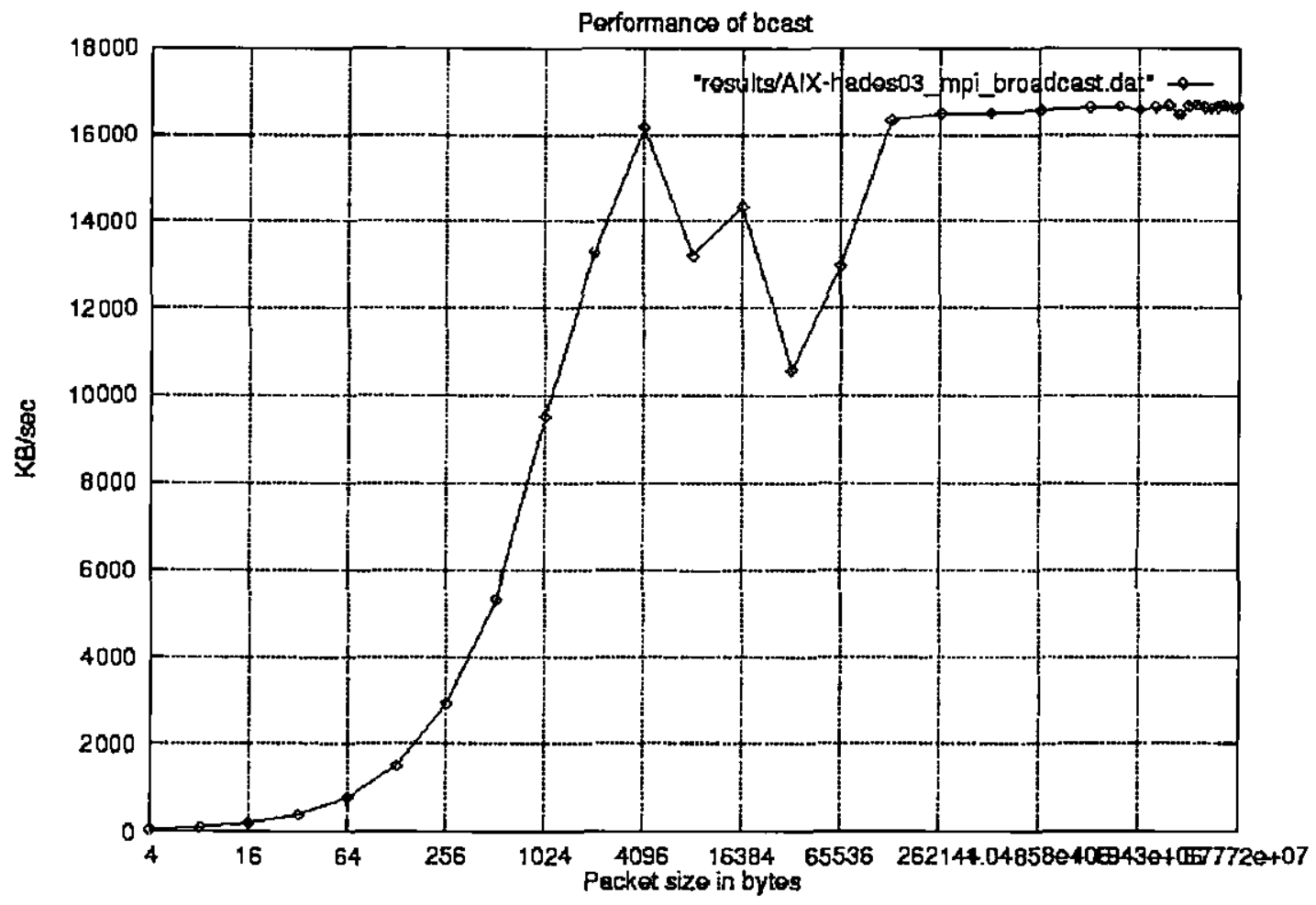

Figura 12 - Gráfico gerado pelo MPBench para Broadcast. 


\section{Reduce}

É o tempo necessário para que a aplicação faça um reduce pela rede. Quando se utiliza PVM torna-se necessário a realização de um Barrier antes da execução da função. Os resultados da execução dessa função estão representados na Figura 13 e são dados em megabytes por segundo. A diferença entre o reduce e o broadcast é a direção da comunicação realizada, que no broadcast é do mestre para os escravos e no reduce é dos escravos pro mestre. No reduce há a possibilidade de haver algum processamento com os dados durante passos intermediários, o que não acontece no broadcast.

O gráfico pode ser utilizado para se definir os mesmos pontos citados para bandwidth (menos as questões relacionadas a bandwidth), mais o comportamento do sistema para reduce.

Nota-se que a curva cresce exponencialmente até pacotes de $4 \mathrm{Kbytes}$, para pacotes de $8 \mathrm{~K}$ bytes tem-se uma queda súbita de desempenho o logo em seguida, para pacotes de 16 Kbytes tem-se a retomada sa curva mas sem o crescimento exponencial, ou seja, o desempenho passa a aumentar mas não da forma como aumentava até pacotes de $4 \mathrm{Kbytes}$.

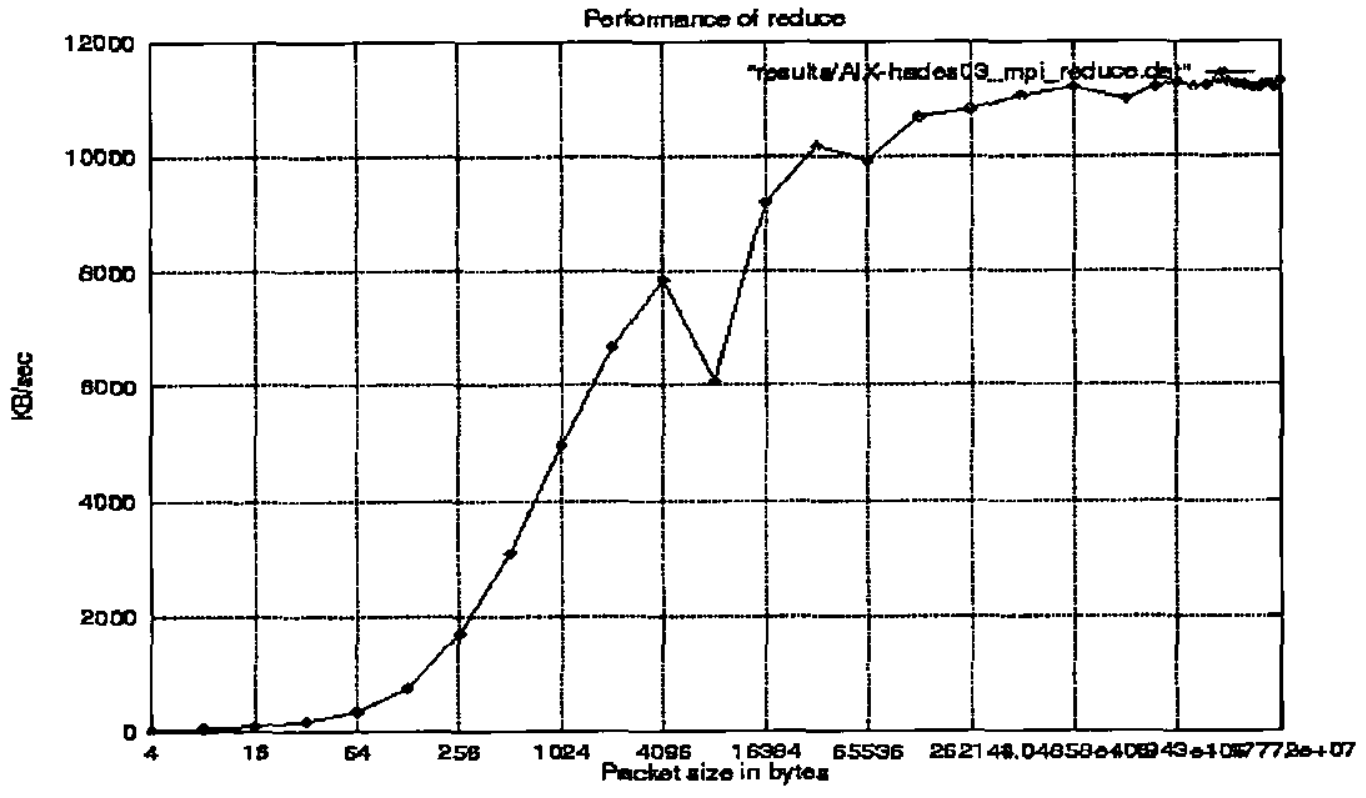

Figura 13 - Gráfico gerado pelo MPBench para Reduce. 


\section{Allreduce}

É o tempo necessário para que a aplicação faça um reduce seguido de um broadcast. Quando se utiliza PVM torna-se necessário a realização de um Barrier antes da execução da função.

O gráfico da Figura 14 pode ser utilizado para definir os mesmos pontos citados para bandwidth (menos as questões relacionadas a bandwidth), mais o comportamento do sistema para allreduce.

Nota-se o comportamento exponencial da curva até pacotes de $2 \mathrm{Kbytes}$. Para pacotes de $4 \mathrm{Kbytes}$ tem-se uma pequena queda na curva. Nota-se um bom comportamento para pacotes de $8 \mathrm{k}$ e 32k, já para outros tamanhos de pacotes tem-se um aumento de desempenho menor.

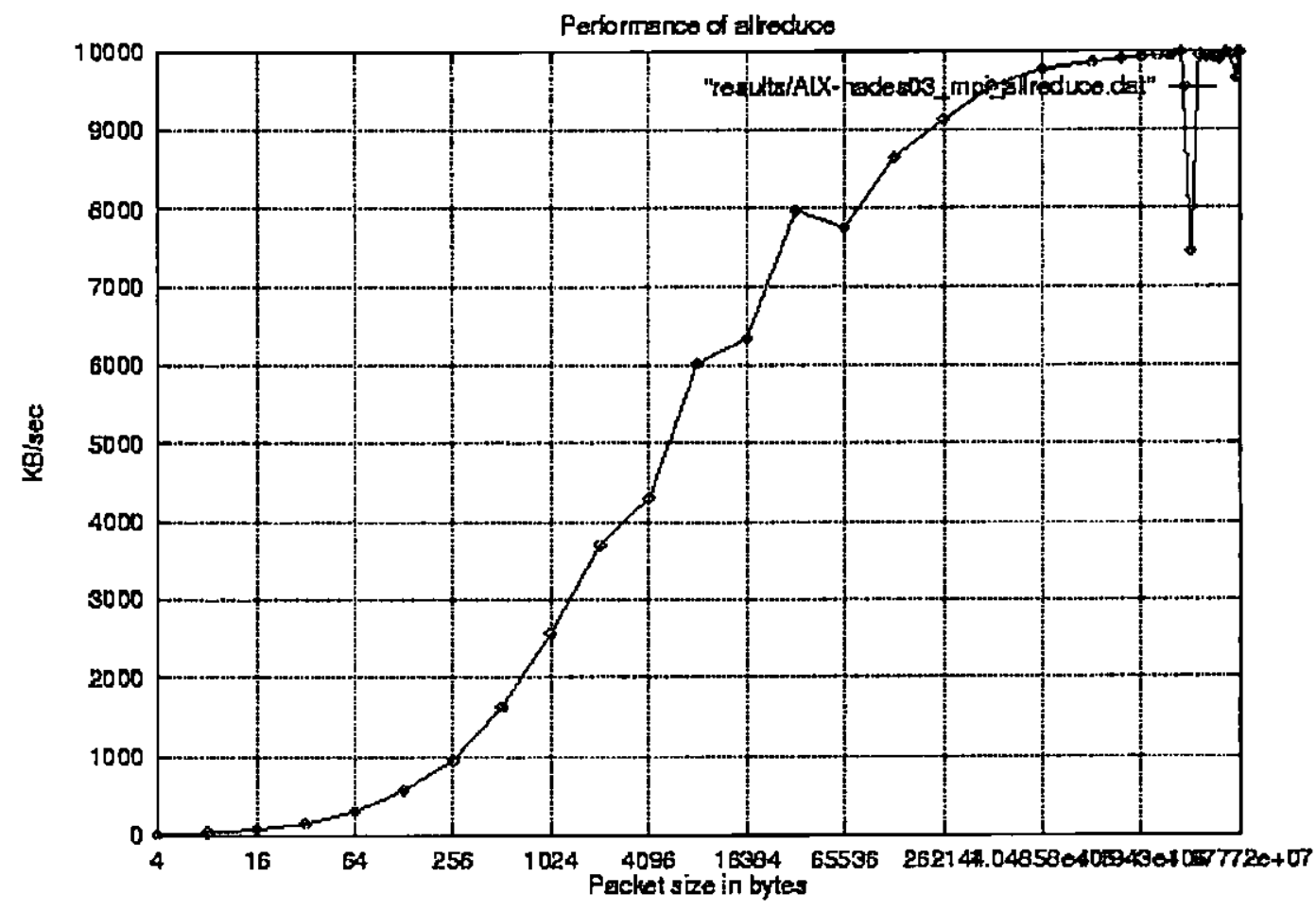

Figura 14 - Gráfico gerado pelo MPBench para Allreduce. 


\section{Barrier}

É a quantidade de barriers que a aplicação executa por segundo.

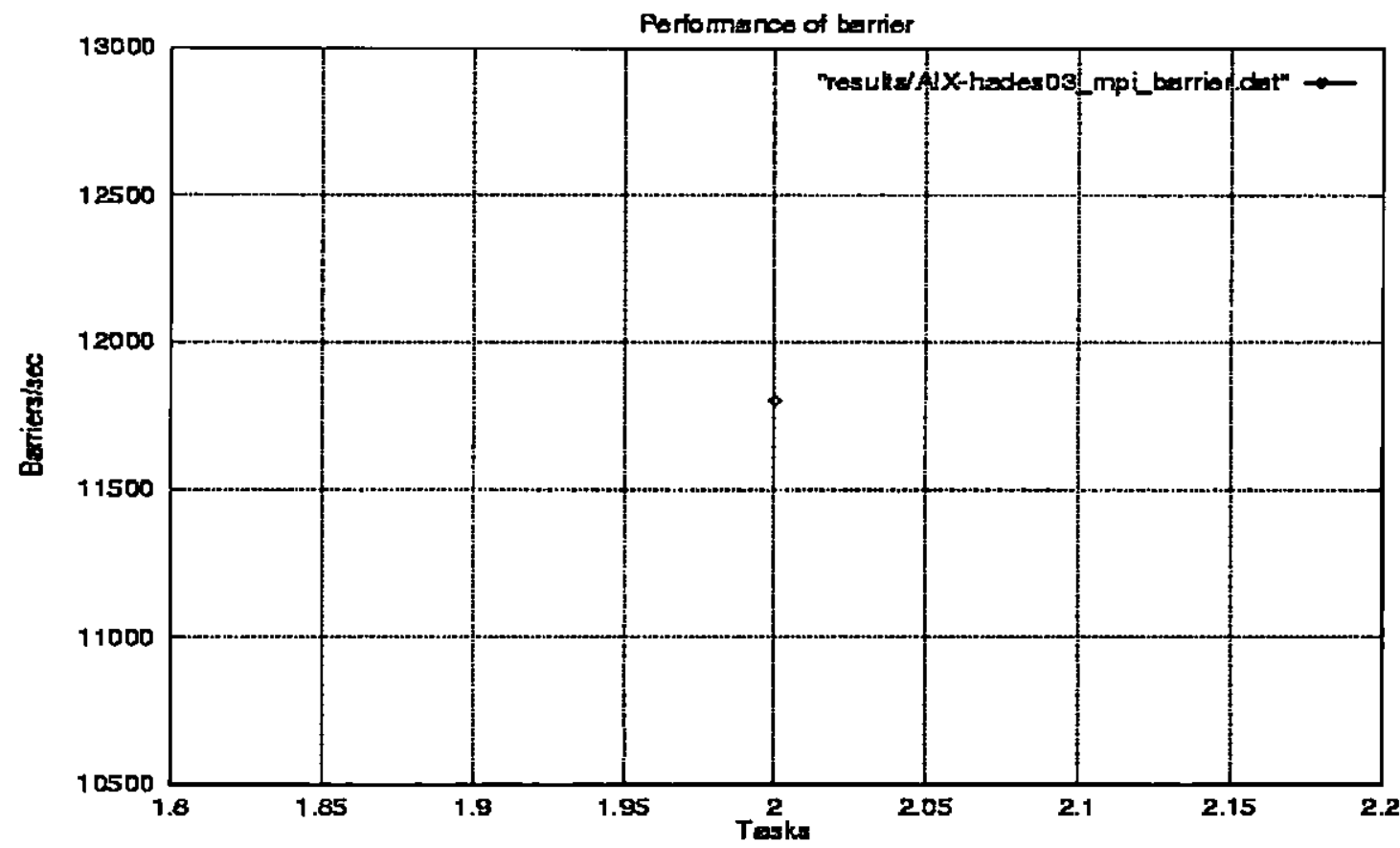

Figura 15 - Gráfico gerado peio MPBench para Barrier.

Como a máquina SP2 utilizada só possuía 3 nós só foi possível a execução do MPBench com 2 tasks (pois a função é executada para $2,4,8, \ldots$ nós), o que não possibilitou a avaliação do comportamento do sistema com relação a função barrier, visto que só possui-se os dados para 2 tasks, ou seja, um ponto do gráfico da Figura 15 só apresenta o número de barriers executados por segundo quando são consideradas 2 tarefas.

\subsubsection{Considerações sobre o MPBench}

A versão do MPBench utilizada neste trabalho é a 3.1 de 1998, que é a última versão disponível. A análise dos resultados gerados é feita totalmente pelo usuário, sendo que este faz sua interpretação de acordo com o que deseja analisar, que nesse caso, é o ambiente de comunicação.

Este benchmark é de fácil configuração e execução, sendo que apenas alguns pequenos problemas foram constatados quanto ao seu código fonte, tais como:

- Ao executar o MPBench este reclamava que não encontrava o arquivo pvmbench.sh - isto também aconteceu devido a um descuido do programador, 
pois o benchmark gerava o arquivo corretamente, mas o chamava de pvm_bench.sh. Solucionou-se o problema criando um link para o arquivo correto.

Os problemas relacionados ao MPBench foram poucos e de fácil solução, o que já não aconteceu com a configuração do ambiente de execução no IBM SP2 do CISC (Centro de Informática de São Carlos).

O MPBench gera gráficos pelos quais o benchmarker pode checar as qualidades e pontos fracos da máquina e do ambiente de comunicação, podendo fazer a escolha que é mais apropriada para o caso em questão. Os gráficos podem ser analisados individualmente, para resolver um problema específico do ambiente, ou em conjunto, para uma análise geral do ambiente de comunicação.

O MPBench é um benchmark de baixo nível sintético, onde apenas o ambiente de comunicação é analisado, nenhuma computação é realizada. 


\subsection{NPB}

O Numerical Aerodynamic Simulation (NAS) Parallel Benchmarks (NPB) é um conjunto de 8 benchmarks que simulam características de computação e comunicação de aplicações CFD (Computational Fluid Dynamics). Foi desenvolvido em 1991 na NASA Ames Research Center, e teve como objetivo medir o desempenho de computadores altamente paralelos e comparar seu desempenho com o desempenho dos supercomputadores convencionais.

O NPB é chamado de "pencil and paper" benchmark, ou seja, ele é especificado apenas algoriticamente. Dependendo da máquina que se deseja avaliar defini-se o algoritmo e o modelo de programação mais apropriado. Os implementadores são livres para usar construtores de linguagens, estruturas de dados, particionamento de dados e detalhes algoritmicos que maximizam o desempenho de um sistema em particular. Esse tipo de benchmark gera alguns problemas, pois a maioria das implementações são proprietárias, ou seja, seus implementadores não disponibilizam o código fonte do benchmark, apenas mostram os resultados obtidos. As técnicas utilizadas para se alcançar o desempenho apresentado são mantidas em segredo. Se o código fonte não é disponibilizado não há como saber se as especificações originais do benchmark foram mantidas, e, por conseguinte seus resultados são considerados duvidosos. Por essa razão, atualmente muitas das implementações dos benchmarks estão documentadas e disponíveis publicamente [BAI95].

A biblioteca de passagem de mensagem utilizada é o MPI, a linguagem de programação utilizada é Fortran, sendo que alguns códigos são em C. A versão executada é a 2.3 de 1997 e é portável para as seguintes plataformas IBM SP2, T3d_cosmos, Sun_ultra_sparc, Dec_alpha, Irix 6.2, Sgi_powerchalle e nge.

O padrão de passagem de mensagem MPI foi escolhido por estar disponível, estar em uso em todas as máquinas da NASA, por ser um padrão industrial, e por ser projetado para alcançar alto desempenho. Já o PVM não foi projetado para obter alto desempenho, e é mais apropriado para aplicações fracamente acopladas, dinâmicas e tolerantes a falha, o que não representa as aplicações do NPB [BAI95].

Dentre os 8 benchmarks 5 são kernels, que estão relacionados a métodos numéricos usados por aplicações CFD (Computational Fluid Dynamics), e 3 são aplicações compactas, que reproduzem muitos dos movimentos de dados e computação encontrados em códigos CFD. Um resumo de cada um dos benchmarks é apresentado a seguir. 
Kernel FT: é uma solução de equação diferencial 3-D usando FFTs. Representa a essência de muitos códigos que utilizam o método "spectral". É um teste rigoroso de desempenho de comunicação de longa distância.

Kernel MG: é um kernel multigrid simplificado. Requer comunicação de longa distância altamente estruturada. Testa comunicação de curta e longa distância.

Kernel EP: é um embarrassingly parallel kernel. Fornece uma estimativa dos mais altos limites de desempenho de ponto flutuante obtidos, ou seja, o desempenho sem comunicação significante entre processadores.

Kernel CG: é um método de gradiente conjugado. É usado para computar uma aproximação para os oito menores valores de uma matriz larga, esparsa, simétrica, positiva e definida.

Kernel IS: Integer Sort. Executa uma operação de ordenação que é importante em códigos particle method. Testa a velocidade de computação de inteiros e desempenho de comunicação.

Application LU: LU solver é uma aplicação CFD simulada que usa SSOR (symmetric successive over-relaxation) para resolver um sistema de equações de Navier-Stokes em 3 dimensões.

Application SP and BT: são aplicações CFD simuladas que resolvem sistemas de equações resultantes de uma discretização aproximada de equações Navier-Stokes. BT resolve sistemas block-tridiagonal 5x5, e SP resolve sistemas scalar pentadiagonal.

Os benchmarks do NPB podem ser executados para vários "tamanhos do problema". Esses tamanhos são definidos como classes e para cada benchmark essas classes possuem um tamanho do problema diferente. O tamanho do problema para cada classe e para cada benchmark são apresentados na Tabela 7. 
Tabela 7 - Classes do NPB.

\begin{tabular}{|c|c|c|c|c|c|}
\hline Benchmark code & S & W & A & B & C \\
\hline EP & $2^{25}$ & $2^{26}$ & $2^{29}$ & $2^{31}$ & $2^{33}$ \\
\hline MG & $32^{3}$ & $64^{3}$ & $128^{3}$ & $256^{3}$ & $512^{3}$ \\
\hline CG & 1400 & 7000 & 14000 & 75000 & 150000 \\
\hline FT & $64^{3}$ & $128^{2} \times 32$ & $256^{2} \times 128$ & $256^{2} \times 512$ & $512^{3}$ \\
\hline IS & $2^{16}$ & $2^{20}$ & $2^{23}$ & $2^{25}$ & $2^{27}$ \\
\hline LU & $12^{3}$ & $33^{3}$ & $64^{3}$ & $102^{3}$ & $162^{3}$ \\
\hline SP & $12^{3}$ & $36^{3}$ & $64^{3}$ & $102^{3}$ & $162^{3}$ \\
\hline BT & $12^{3}$ & $24^{3}$ & $64^{3}$ & $102^{3}$ & $162^{3}$ \\
\hline
\end{tabular}

As classes vão de $\mathrm{S}$ a $\mathrm{C}$ em ordem crescente do tamanho do problema, e dependendo da máquina que se pretende avaliar uma determinada classe é adotada. As classes são aplicadas a: S - Sample, W - Workstations, A - Workstations moderadamente poderosas (MG16, FT128), B - Workstations altamente poderosas ou pequenos sistemas paralelos e C Supercomputadores.

\subsubsection{Execução}

O código fonte do NASPB pode ser obtido na rede pelo seguinte endereço, http://science.nas.nasa.gov/Software/NPB/. Neste endereço também se encontra informações sobre as últimas versões existentes do código fonte desenvolvido pela NASA.

O primeiro passo para se executar o NASPB é configura-lo para a execução na máquina específica. Para realizar essa configuração, basta ler os arquivos existentes no diretório Doc. Estes arquivos contêm todos os passos necessários para a instalação e execução do NASPB.

A execução do NASPB no SP2 não gerou maiores dificuldades, tendo sido necessárias alterações no script para configurar o ambiente de execução. Como a máquina SP2 utilizada tem apenas 3 nós e o número de processadores tem que ser potência de 2, os benchmarks do NASPB foram executados com 2 processadores, sendo que para as aplicações SP e BT o número de processadores utilizado foi 1 , visto que este tem que ser quadrado $\left(x^{2}-1,4,9, \ldots\right)$.

Tentou-se executar o NASPB para todas as classes existentes S, W, A, B, C, apenas para ver até que classe o SP2 conseguia executar os benchmarks. Os resultados obtidos são apresentados na próxima seção.

Um script para o LINUX foi feito, visto que na versão original do NASPB não existia. Os problemas encontrados foram quanto aos softwares instalados nas máquinas em que foi 
executado o NASPB. O compilador Fortran utilizado não compreendia os códigos, visto que sua versão era muito antiga. Os códigos que eram em $\mathrm{C}$ foram compilados sem problema.

\subsubsection{Análise dos Dados Obtidos}

No SP2 conseguiu-se a execução dos benchmarks do NASPB para as classes apresentadas na tabela 3 , sendo que as classes que estão marcadas com um $\mathbf{x}$ foram executadas e as que não estão não terminaram sua execução, pois não eram adequadas à máquina utilizada que possui apenas 3 nós.

Tabela 8 - Classes do NPB que foram executadas no SP2.

\begin{tabular}{|c|c|c|c|c|c|}
\hline Benchmark code & S & W & A & B & C \\
\hline EP & X & X & X & X & X \\
\hline MG & X & X & - & - & - \\
\hline CG & X & X & X & - & - \\
\hline FT & X & X & - & - & - \\
\hline IS & X & X & X & - & - \\
\hline LU & X & X & X & X & - \\
\hline SP & X & X & X & - & - \\
\hline BT & X & X & - & - & - \\
\hline
\end{tabular}

O NASPB gera arquivos de resultados com extensão .res como saída. Esses arquivos possuem a seguinte nomenclatura: Nomedobenchmark_classe_númerodeprocessos. Para a execução do benchmark CG na classe A com 2 processos ter-se-ia: cg.A.2.res.

Um exemplo dos resultados obtidos dos benchmarks do NPB é apresentado na Figura 16 a Figura 23. Todos os resultados gerados são textos, possuem tamanho semelhante e sua análise deve ser efetuada pelo benchmarker. A Tabela 9 descreve quais exemplos são apresentados nas figuras a seguir.

\begin{tabular}{|c|c|c|}
\hline Benchmark Code & Classe & Figura \\
\hline EP & S & Figura 16 \\
\hline MG & S & Figura 17 \\
\hline CG & A & Figura 18 \\
\hline FT & S & Figura 19 \\
\hline IS & S & Figura 20 \\
\hline LU & A & Figura 21 \\
\hline SP & S & Figura 22 \\
\hline BT & S & Figura 23 \\
\hline
\end{tabular}

Tabela 9 - Resultados do NASPB.

Todos os benchmarks do NPB apresentam um conjunto comum de resultados e alguns resultados específicos de cada benchmark.

Os resultados da execução dos benchmarks do NPB para as outras classes (fora a da tabela) são encontrados no Apêndice B. 
O conjunto comum a todos os benchmarks engloba:

1. Identificação do Benchmark;

2. Resultados e condições da execução, incluindo:

I. Número de processos ativos;

II. Tamanho do problema (que corresponde a classe);

III. Número de iterações realizado;

IV. Tempo de execução em segundos;

V. Número de processos compilados;

VI. $M o p / s$ (milhões de operações por segundo) total;

VII. Mop/s realizado por cada processo. Sendo que para cada benchmark tem-se o tipo de operação em questão. Para o benchmark CG o tipo de operação considerado é ponto flutuante, já para o EP o tipo de operação considerado são os números randômicos gerados;

VIII. Tipo de operação;

IX. Versão do benchmark que esta sendo executada;

X. Data de compilação.

3. Opções utilizadas na compilação, incluindo:

I. Compilador utilizado;

II. Bibliotecas;

III. Flags;

IV. Função de geração de números utilizada pelo Benchmark.

Além desse conjunto de resultados cada benchmark fornece informações específicas da aplicação implementada .

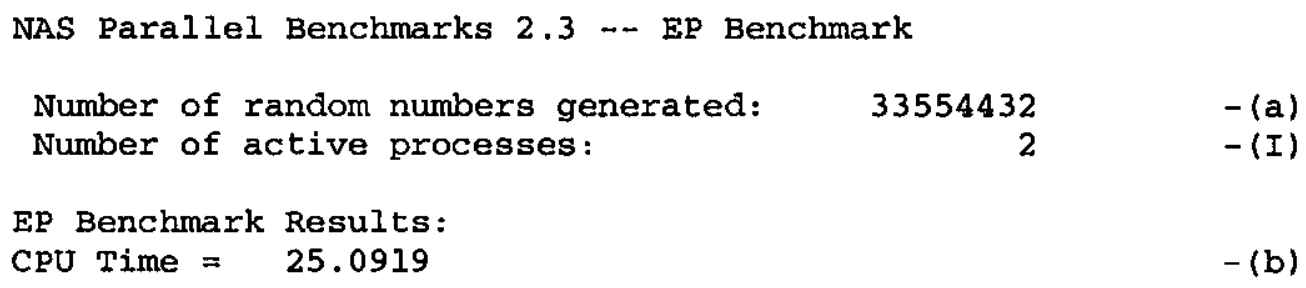




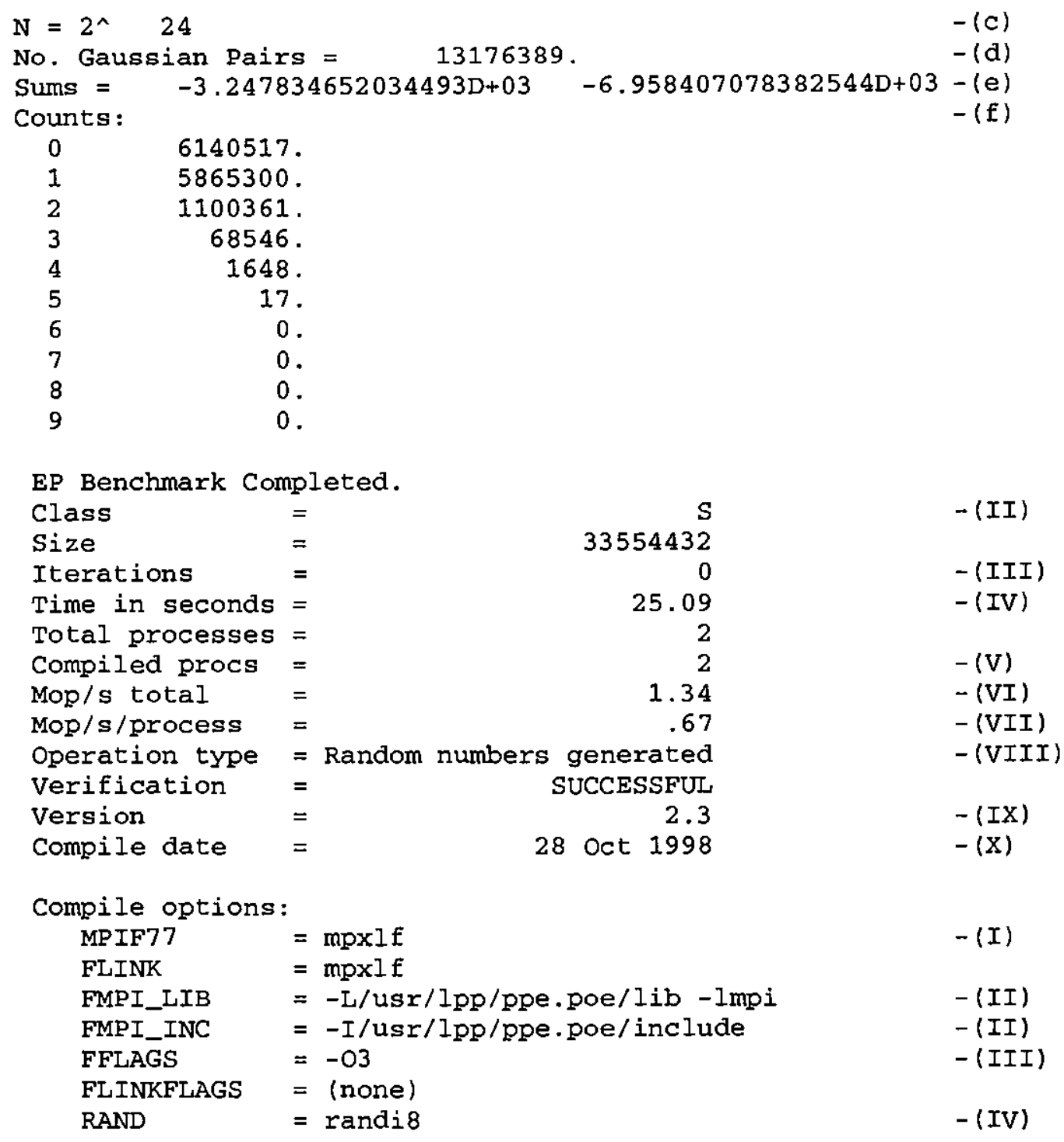

Figura 16 - ep.S.2.res.

NAS Parallel Benchmarks 2.3 -- MG Benchmark

No input file. Using compiled defaults

Size: $32 \times 32 \times 32$ (class $s$ )

- (II)

Iterations: 4

Number of processes:

2

- (III)

- (I)

Initialization time:
Benchmark completed

.166 seconds

$-(\mathrm{a})$

VERIFICATION SUCCESSFUL,

L2 Norm is $.530770700573 \mathrm{E}-04$

$-(b)$

Error is

$.489381755606 \mathrm{E}-16$

$-(c)$

MG Benchmark Completed.

$\begin{array}{llrr}\text { Class } & = & \mathrm{S} & - \text { (II) } \\ \text { Size } & = & 32 \times 32 \times 32 & - \text { (III) } \\ \text { Iterations } & = & 4 & - \text { (IV) } \\ \text { Time in seconds } & & .15 & \\ \text { Total processes } & = & 2 & - \text { (V) } \\ \text { Compiled procs } & = & 2 & - \text { (VI) } \\ \text { Mop/s total } & = & 49.69 & - \text { (VII) } \\ \text { Mop/s/process } & = & 24.84 & \end{array}$




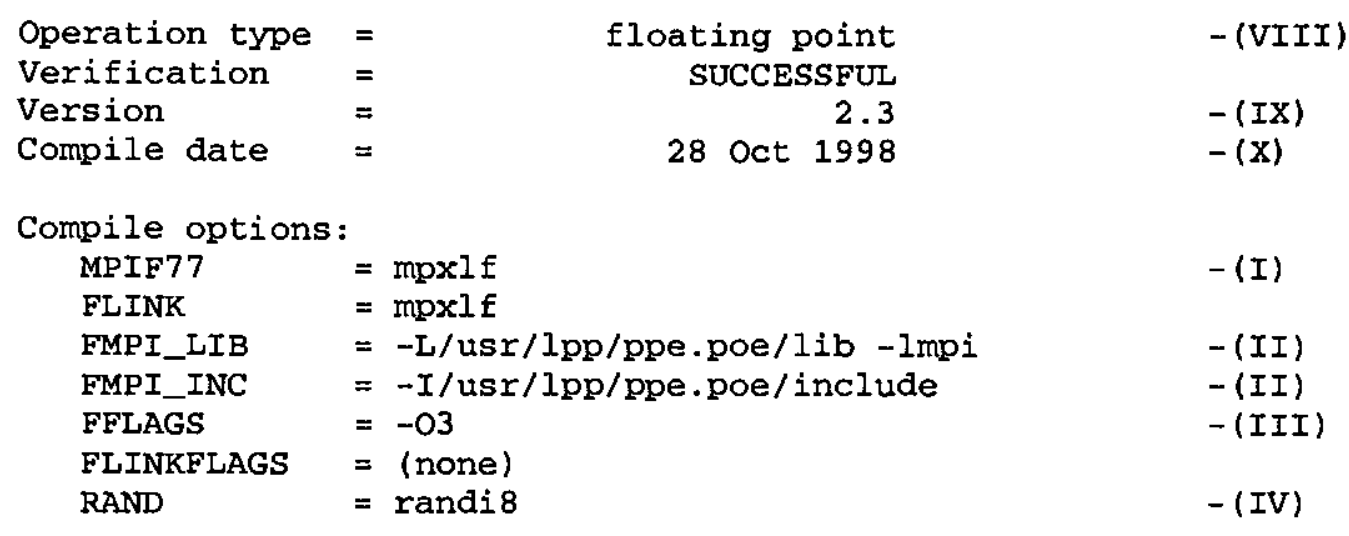

Figura 17 - mg.S.2.res

NAS Parallel Benchmarks 2.3 -- CG Benchmark

\begin{tabular}{cc} 
Size: & \multicolumn{2}{c}{14000} \\
Iterations: & 15 \\
Number of active processes : & 2 \\
& ||$r||$ \\
iteration & $\mid 30580929470584 \mathrm{E}-12$ \\
1 & $.30877083039958 \mathrm{E}-14$ \\
2 & $.30854963094619 \mathrm{E}-14$ \\
3 & $.30802922107143 \mathrm{E}-14$ \\
4 & $.30394655104773 \mathrm{E}-14$ \\
5 & $.30160341222727 \mathrm{E}-14$ \\
6 & $.29942580326409 \mathrm{E}-14$ \\
7 & $.30041230298434 \mathrm{E}-14$ \\
8 & $.30526833667290 \mathrm{E}-14$ \\
9 & $.30030339579950 \mathrm{E}-14$ \\
10 & $.30315310881012 \mathrm{E}-14$ \\
11 & $.29990103167339 \mathrm{E}-14$ \\
12 & $.29569288852551 \mathrm{E}-14$ \\
13 & $.30074069685492 \mathrm{E}-14$ \\
14 & $.29738909189574 \mathrm{E}-14$ \\
15 &
\end{tabular}

$-(I I)$

$-($ III)

$-(I)$

Benchmark completed

VERIFICATION SUCCESSFUL

$\begin{array}{ll}\text { Zeta is } & .171302350540 \mathrm{E}+02 \\ \text { Error is } & .895283847058 \mathrm{E}-12\end{array}$

zeta
19.9997581277040
17.1140495745506
17.1296668946143
17.1302113581193
17.1302338856353
17.1302349879482
17.1302350498916
17.1302350537510
17.1302350540101
17.1302350540284
17.1302350540298
17.1302350540299
17.1302350540299
17.1302350540299
17.1302350540299

CG Benchmark Completed.

$\begin{array}{llrl}\text { Class } & & \text { A } & - \text { (II) } \\ \text { Size } & = & 14000 & \\ \text { Iterations } & = & 15 & - \text { (III) } \\ \text { Time in seconds } & = & 23.73 & - \text { (IV) } \\ \text { Total processes } & = & 2 & \\ \text { Compiled procs } & = & 2 & - \text { (V) } \\ \text { Mop/s total } & = & 63.06 & - \text { (VI) } \\ \text { Mop/s/process } & = & 31.53 & - \text { (VII) } \\ \text { Operation type } & = & \text { (VIII) } \\ \text { Verification } & = & \text { SUCCESSFUL } & \\ \text { Version } & = & 2.3 & - \text { (IX) } \\ \text { Compile date } & = & 28 \text { Oct 1998 } & -(\mathrm{X})\end{array}$

Compile options :

$$
\text { MPIF77 }=\operatorname{mpxlf}
$$

$-(a)$

- (b)

$-(I I)$

(III)

$-(\mathrm{V})$

(VI)

(VII)

$-(I X)$

(3) 


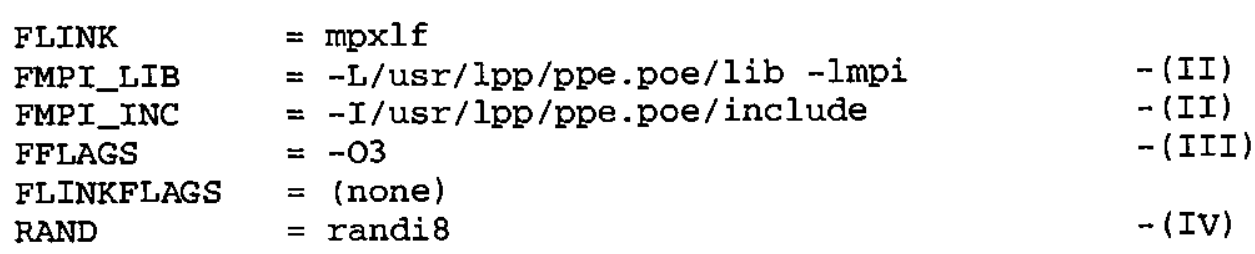

Figura 18 - cg.A.2.res

NAS Parallel Benchmarks 2.3 -- FT Benchmark

No input file inputft.data. Using compiled defaults

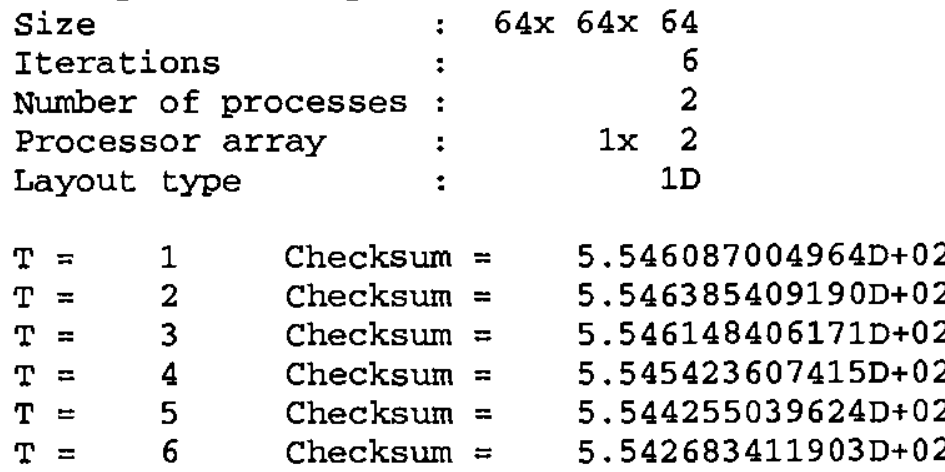

Result verification successful

class $=\mathrm{s}$

FT Benchmark Completed.

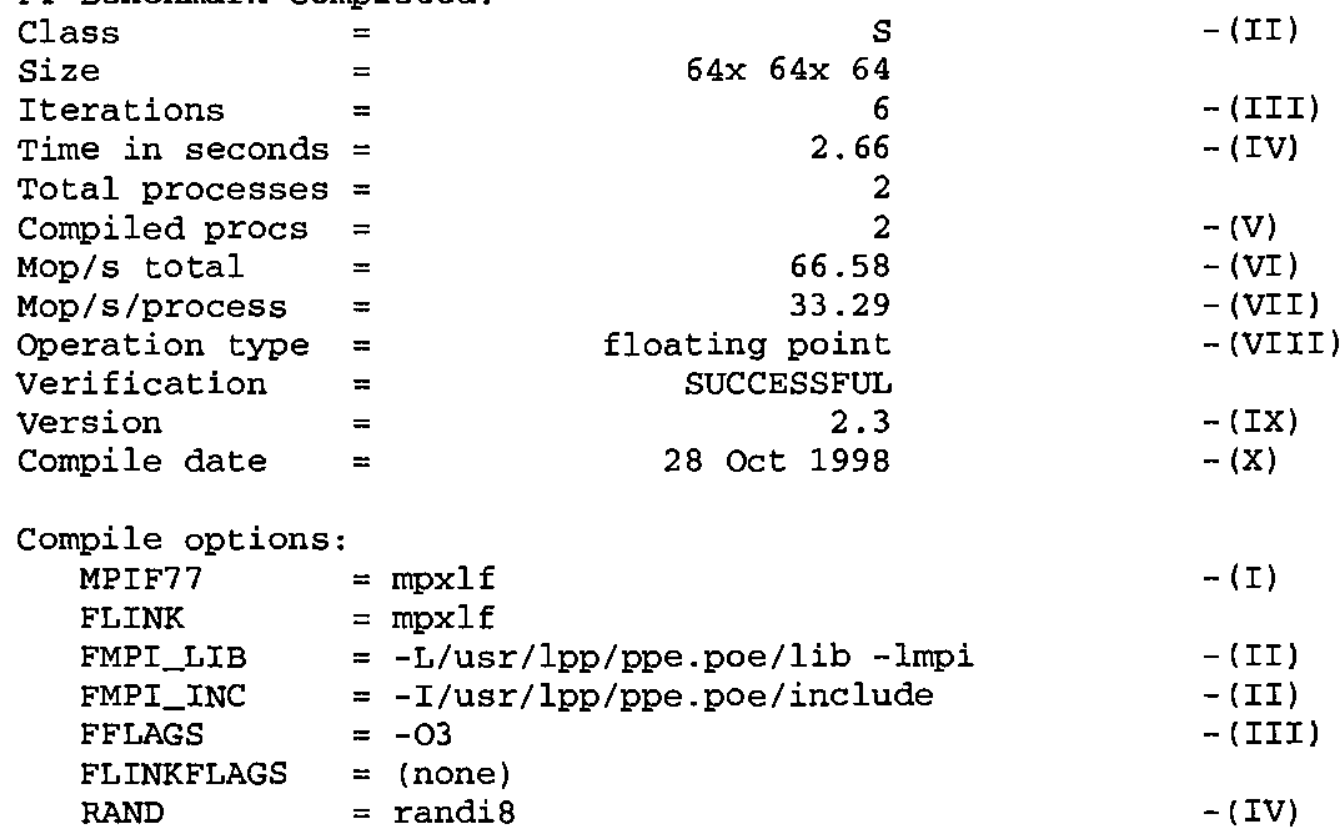

$-($ III)

$-(I)$

$-(a)$

- (b)

$4.845363331978 \mathrm{D}+02$

$4.865304269511 \mathrm{D}+02$

$4.883910722337 \mathrm{D}+02$

$4.901273169046 \mathrm{D}+02$

$4.917475857993 \mathrm{D}+02$

$4.932597244941 D+02$

Figura 19 -ft.S.2.res

NAS Parallel Benchmarks 2.3 -- IS Benchmark

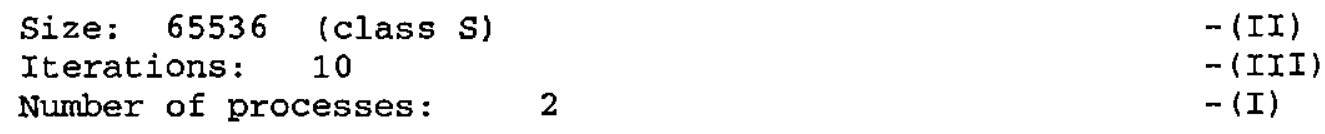


Is Benchmark Completed

\begin{tabular}{|c|c|c|}
\hline \multirow{2}{*}{\multicolumn{3}{|c|}{ Class }} \\
\hline & $S$ & $-(I I)$ \\
\hline Size & 65536 & \\
\hline Iterations & 10 & $-(I I I)$ \\
\hline Time in seconds & 0.11 & $-(I V)$ \\
\hline Total processes & 2 & \\
\hline Compiled procs & $=$ & $-(\mathrm{V})$ \\
\hline Mop/s total & 5.81 & $-(V I)$ \\
\hline Mop/s/process & 2.90 & $-(V I I)$ \\
\hline Operation type & keys ranked & $-(V I I I)$ \\
\hline Verification & SUCCESSFUL & \\
\hline Version & 2.3 & $-(I X)$ \\
\hline Compile date & 28 Oct 1998 & $-(X)$ \\
\hline Compile options: & & \\
\hline MPICC & $=\operatorname{mpcc}$ & $-(I)$ \\
\hline CLINK & $=\operatorname{mpcc}$ & \\
\hline CMPI_LIB & $=-\mathrm{L} / \mathrm{usr} / 1 \mathrm{pp} / \mathrm{ppe} \cdot \mathrm{poe} / 1 \mathrm{ib}-1 \mathrm{mpj}$ & $-(I I)$ \\
\hline CMPI_INC & $=-I /$ usr/lpp/ppe.poe/include & $-(I I)$ \\
\hline $\begin{array}{l}\text { CFLAGS } \\
\text { CLINKFLAGS }\end{array}$ & $\begin{array}{l}=-03 \\
=\text { (none) }\end{array}$ & $-($ III $)$ \\
\hline
\end{tabular}

Figura 20 - is.S.2.res

NAS Parallel Benchmarks 2.2 -- LU Benchmark

$\begin{array}{lr}\text { Size: } 64 \mathrm{x} & 64 \mathrm{x} \\ \text { Iterations: } & 250 \\ \text { Number of } & \text { proces } \\ & \\ \text { Time step } & 1 \\ \text { Time step } & 20 \\ \text { Time step } & 40 \\ \text { Time step } & 60 \\ \text { Time step } & 80 \\ \text { Time step } & 100 \\ \text { Time step } & 120 \\ \text { Time step } & 140 \\ \text { Time step } & 160 \\ \text { Time step } & 180 \\ \text { Time step } & 200 \\ \text { Time step } & 220 \\ \text { Time step } & 240 \\ \text { Time step } & 250\end{array}$

Verification being performed for class A Accuracy setting for epsilon $=.1000000000000 \mathrm{E}-07 \quad-(\mathrm{b})$ Comparison of RMS-norms of residual

$$
\begin{array}{ccccc}
1 & .7790210760669 \mathrm{E}+03 & .7790210760669 \mathrm{E}+03 & .1692851911310 \mathrm{E}-13 \\
2 & .6340276525969 \mathrm{E}+02 & .6340276525969 \mathrm{E}+02 & .7172358319450 \mathrm{E}-14 \\
3 & .1949924972729 \mathrm{E}+03 & .1949924972729 \mathrm{E}+03 & .6121834495028 \mathrm{E}-14 \\
4 & .1784530116042 \mathrm{E}+03 & .1784530116042 \mathrm{E}+03 & .1911206261519 \mathrm{E}-14 \\
5 & .1838476034946 \mathrm{E}+04 & .1838476034946 \mathrm{E}+04 & .1793288697409 \mathrm{E}-13 \\
\text { Comparison } & \text { of RMS-norms of solution error } & \\
1 & .2996408568547 \mathrm{E}+02 & .2996408568547 \mathrm{E}+02 & .1897051672375 \mathrm{E}-14 \\
2 & .2819457636500 \mathrm{E}+01 & .2819457636500 \mathrm{E}+01 & .2205122310551 \mathrm{E}-14 \\
3 & .7347341269878 \mathrm{E}+01 & .7347341269877 \mathrm{E}+01 & .6890406755769 \mathrm{E}-14 \\
4 & .6713922568778 \mathrm{E}+01 & .6713922568778 \mathrm{E}+01 & .6217585219114 \mathrm{E}-14 \\
5 & .7071531568839 \mathrm{E}+02 & .7071531568839 \mathrm{E}+02 & .9445056776069 \mathrm{E}-14 \\
\text { Comparison } & \text { of surface integral } & & \\
5 & .2603092560489 \mathrm{E}+02 & .2603092560489 \mathrm{E}+02 & .4094414927144 \mathrm{E}-15
\end{array}
$$


Verification Successful

LU Benchmark Completed.

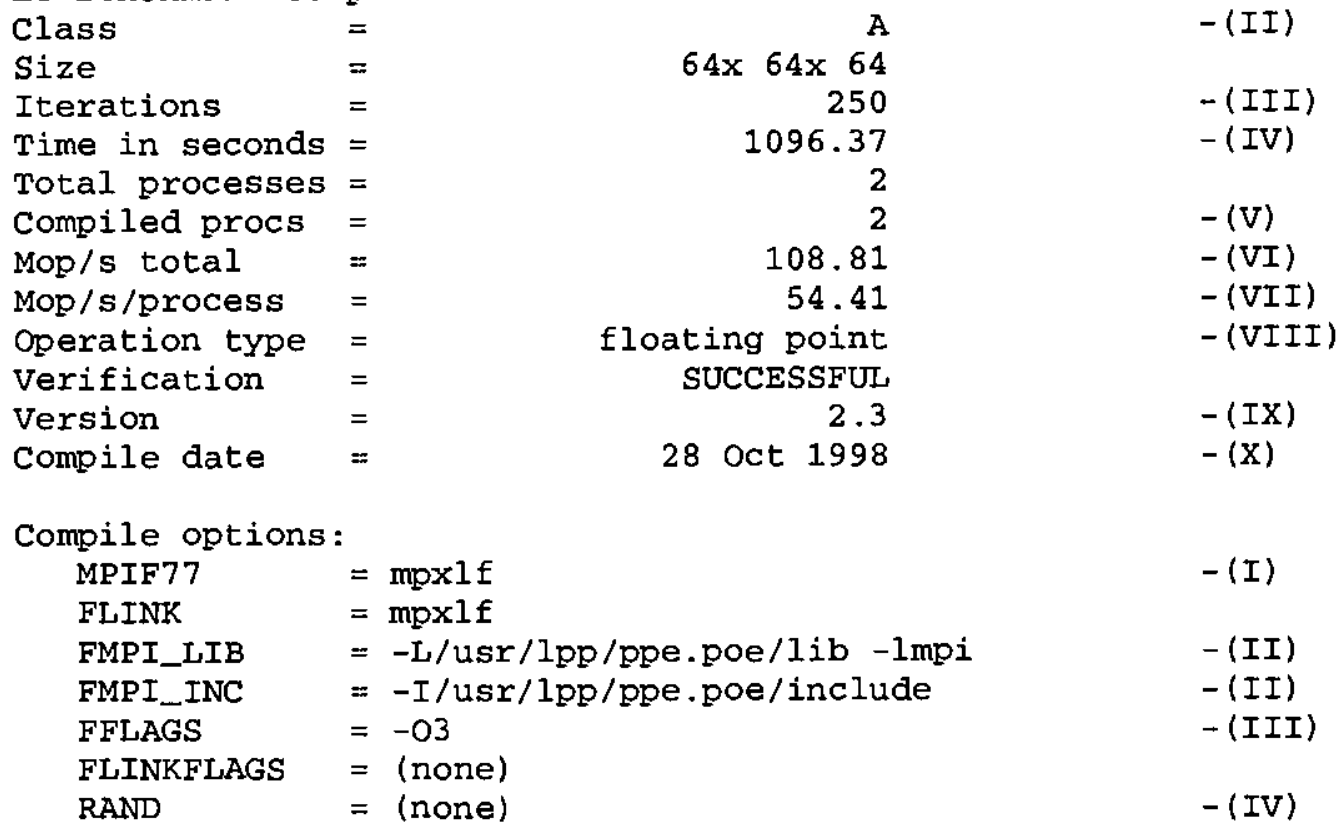

Figura 21 -lu.A.2.res

NAS Parallel Benchmarks 2.3 -- SP Benchmark

No input file inputsp.data. Using compiled defaults Size: $12 \times 12 \times 12$

Iterations: 100

dt: $\quad .015000$

Number of active processes:

1

Time step 1

Time step 20

Time step 40

Time step 60

Time step 80

Time step 100

Verification being performed for class $S$

accuracy setting for epsilon $=.1000000000000 \mathrm{E}-07 \quad$ - (c)

Comparison of RMS-norms of residual

$\begin{array}{lllll}1 & .2747031545136 \mathrm{E}-01 & .2747031545134 \mathrm{E}-01 & .9084617892215 \mathrm{E}-12 \\ 2 & .1036074670527 \mathrm{E}-01 & .1036074670529 \mathrm{E}-01 & .1547576593130 \mathrm{E}-11 \\ 3 & .1623574506505 \mathrm{E}-01 & .1623574506510 \mathrm{E}-01 & .2877361218765 \mathrm{E}-11 \\ 4 & .1584055722446 \mathrm{E}-01 & .1584055722446 \mathrm{E}-01 & .4630147003356 \mathrm{E}-12 \\ 5 & .3484904060941 \mathrm{E}-01 & .3484904060936 \mathrm{E}-01 & .1226734641598 \mathrm{E}-11\end{array}$

Comparison of RMS-norms of solution error

$1.2728925855740 \mathrm{E}-04 \quad .2728925855738 \mathrm{E}-04 \quad .6940333926913 \mathrm{E}-12$

$2.1036444664082 \mathrm{E}-04 \quad .1036444664084 \mathrm{E}-04 \quad .1293867978257 \mathrm{E}-11$

$3.1615479828712 \mathrm{E}-04 \quad .1615479828717 \mathrm{E}-04 \quad .3096650603467 \mathrm{E}-11$

$4.1575070499448 \mathrm{E}-04 \quad .1575070499448 \mathrm{E}-04 \quad .2385568236683 \mathrm{E}-12$

$5.3417766618343 \mathrm{E}-04 \quad .3417766618339 \mathrm{E}-04 \quad .1065282339918 \mathrm{E}-11$

Verification Successful

SP Benchmark Completed.

Class 


\begin{tabular}{|c|c|c|}
\hline Size & $12 \times \quad 12 \times \quad 12$ & \\
\hline Iterations & 100 & $-($ III $)$ \\
\hline Time in seconds & 2.40 & $-(I V)$ \\
\hline Total processes & 1 & \\
\hline Compiled procs & $=$ & $-(V)$ \\
\hline Mop/s total & 40.32 & $-(V I)$ \\
\hline Mop/s/process & 40.32 & $-(V I I)$ \\
\hline Operation type & floating point & $-(V I I I)$ \\
\hline Verification & SUCCESSFUL & \\
\hline Version & 2.3 & $-(I X)$ \\
\hline Compile date & 07 Mar 1999 & $-(X)$ \\
\hline Compile options: & & \\
\hline MPIF77 & $=\operatorname{mpx} l f$ & $-(I)$ \\
\hline FLINK & $=\operatorname{mpxlf}$ & \\
\hline FMPI_LIB & $=-L /$ usr/lpp/ppe.poe/lib -lmpi & $-(I I)$ \\
\hline FMPI_INC & $=-\mathrm{I} / \mathrm{usr} / \mathrm{lpp} / \mathrm{ppe} \cdot \mathrm{poe} / \mathrm{include}$ & $-(I I)$ \\
\hline FFLAGS & $=-03$ & $-($ III) \\
\hline FLINKFLAGS & $=$ (none) & \\
\hline RAND & $=$ (none) & $-($ IV) \\
\hline
\end{tabular}

Figura 22 -sp.S.1.res

NAS Parallel Benchmarks 2.3 -- BT Benchmark

No input file inputbt.data. Using compiled defaults Size: $12 \times 12 \times 12$

Iterations: 60

dt: $\quad .010000$

- (a)

Number of active processes:

1

$-(\mathrm{I})$

Time step 1

$-(b)$

Time step 20

Time step 40

Time step 60

Verification being performed for class $S$

accuracy setting for epsilon $=.1000000000000 \mathrm{E}-07 \quad$ - (c)

Comparison of RMS-norms of residual

$1.1703428370954 \mathrm{E}+00 \quad .1703428370954 \mathrm{E}+00 \quad .7788507794337 \mathrm{E}-13$

$2.1297525207003 \mathrm{E}-01 \quad .1297525207003 \mathrm{E}-01 \quad .2175214076906 \mathrm{E}-12$

$3.3252792698949 \mathrm{E}-01 \quad .3252792698949 \mathrm{E}-01 \quad .1666037968144 \mathrm{E}-12$

$4.2643642127515 \mathrm{E}-01 \quad .2643642127517 \mathrm{E}-01 \quad .4891217557528 \mathrm{E}-12$

$5.1921178413175 \mathrm{E}+00 \quad .1921178413174 \mathrm{E}+00 \quad .6587905836301 \mathrm{E}-13$

Comparison of RMS-norms of solution error

$\begin{array}{lllll}1 & .4997691334580 \mathrm{E}-03 & .4997691334581 \mathrm{E}-03 & .2145542565161 \mathrm{E}-12 \\ 2 & .4519566678297 \mathrm{E}-04 & .4519566678296 \mathrm{E}-04 & .2817216819540 \mathrm{E}-12 \\ 3 & .7397376517295 \mathrm{E}-04 & .7397376517292 \mathrm{E}-04 & .3816206191492 \mathrm{E}-12 \\ 4 & .7382123863238 \mathrm{E}-04 & .7382123863244 \mathrm{E}-04 & .8419242306024 \mathrm{E}-12 \\ 5 & .8926963098749 \mathrm{E}-03 & .8926963098749 \mathrm{E}-03 & .2647664956014 \mathrm{E}-13\end{array}$

verification Successful

BT Benchmark Completed.

$\begin{array}{llrr}\text { Class } & = & \mathrm{S} & - \text { (II) } \\ \text { Size } & = & 12 \times 12 \times 12 & - \text { (III) } \\ \text { Iterations } & = & 60 & - \text { (IV) } \\ \text { Time in seconds } & = & 4.10 & \\ \text { Total processes } & & 1 & - \text { (V) } \\ \text { Compiled procs } & = & 1 & - \text { (VI) } \\ \text { Mop/s total } & = & 55.71 & - \text { (VII) } \\ \text { Mop/s/process } & = & 55.71 & \end{array}$




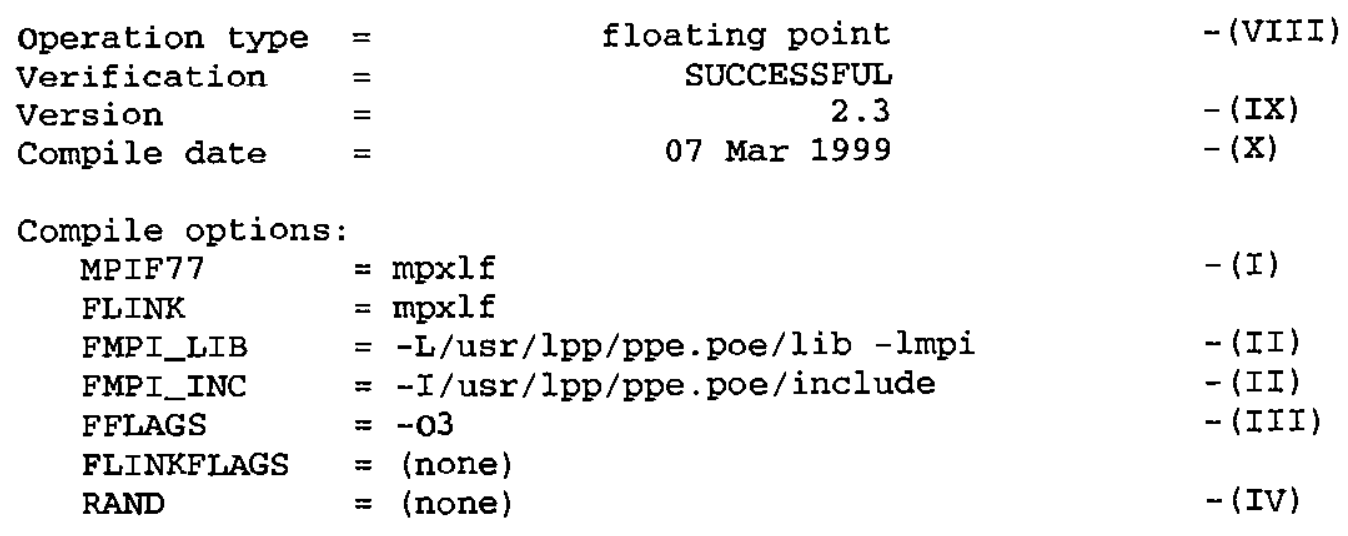

Figura 23 - bt.S.1.res

Dentre os benchmarks do NPB não há nenhum que analise somente comunicação, a comunicação existente esta implícita nos kernels e aplicações. Os dados obtidos servem basicamente para analisar computação.

\subsubsection{Considerações sobre o NPB}

A versão do NPB executada foi a 2.3 de 1997 , que é a última versão do NPB. Também neste caso, a análise dos resultados gerados é feita pelo usuário. O NPB analisa principalmente capacidade computacional do sistema ( $M o p / s)$.

As classes A, B e C necessitam de muitos nós para executar, o que se torna um problema para o SP2 do CISC, que possui apenas 3 nós. O NPB serve basicamente para comparar sistemas em relação aos algoritmos implementados, que testam computação intensa. É útil para previsão de desempenho de máquinas.

O NPB é de fácil configuração e execução, sendo que nenhum problema foi constatado quanto ao seu código fonte e nem quanto a sua instalação. Os problemas constatados quanto a sua execução no ambiente LINUX estão relacionados ao ambiente e não ao NPB. 


\subsection{ParkBench}

O ParkBench foi escolhido por sem bem conhecido e por não tratar apenas de um conjunto de benchmarks, mas de um comitê que pretende estabelecer um padrão entre todos os benchmarks existentes, evitando duplicações.

O ParkBench distributed memory benchmarks é um conjunto de benchmarks organizados em múltiplas camadas que mede desde características básicas do computador como sub-rotinas típicas até problemas completos. As linguagens utilizadas são Fortran e C e o ambiente de passagem de mensagem pode ser PVM ou MPI.

A versão implementada é a 2.1 de 1996 e é portável para as seguintes plataformas: IBM SP2, Alpha, CM5, RS6000, SGI5, SUN4, CSPP, HPPA e Paragon.

Na versão executada os benchmarks de baixo nível, que são sintéticos, são os mesmos do Genesis (seção 5.4), os kernels incluem alguns do NPB (seção 5.2), alguns do Genesis e alguns outros, as aplicações incluem as do NPB e o PSTSWM (seção 5.5).

Quanto aos kernels tem-se:

- NPB: FT, e MG;

- Genesis: TRANS e SOLVER;

- Outros: MATMUL, QR e TRD. Esses dois últimos são do ScaLAPACK.

O ParkBench utiliza as métricas de desempenho citadas na seção 4.2 , que são desempenho temporal, desempenho de simulação, desempenho de benchmark e desempenho de hardware.

\subsubsection{Execução}

O código fonte pode ser encontrado na rede pelo seguinte endereço, http://www.netlib.org/parkbench/index.html. O primeiro passo para se executar o ParkBench é configura-lo para a execução na máquina específica. Para realizar essa configuração, basta ler o arquivo README. Este arquivo contém todos os passos necessários para a instalação $\mathrm{e}$ execução do ParkBench.

Inicialmente tentou-se executar o ParkBench utilizando o PVM3, mas como os problemas encontrados foram muitos, tendo o ambiente que ser totalmente reconfigurado, $o$ 
PVMe passou a ser utilizado. Os executáveis gerados foram os de baixo nível e alguns kernels. Passando para a utilização do MPI apenas os benchmarks de baixo nível foram executados.

A execução do Parkbench no SP2 apresentou vários problemas, alterações foram realizadas no script para configurar o ambiente de execução, vários erros de compilação foram encontrados, conseguiu-se detectar e resolver alguns, sendo que outros não puderam ser resolvidos. A dificuldade em se detectar e resolver os erros deve-se ao fato de que o ParkBench é composto de vários benchmarks e possui dentro dele várias bibliotecas que também devem ser compiladas com os benchmarks. A compilação das bibliotecas apresentou problemas. Não há nenhuma documentação que especifique ou pelo menos de uma noção dos problemas que podem ser encontrados na configuração do ParkBench, o que facilitaria na resolução dos mesmos.

Como os erros de compilação não foram todos resolvidos não foi possível gerar os executáveis de todos os benchmarks que fazem parte do Parkbench. Apenas os benchmarks de baixo nível e alguns kernels foram executados.

No LINUX também houve problemas. O script para essa plataforma não está disponível. Desta forma, um script seguindo o padrão utilizado pelo ParkBench foi desenvolvido. Os erros de compilação continuaram também para esta plataforma, sendo que alguns, inclusive os relacionados às bibliotecas, eram os mesmos encontrados no SP2.

\subsubsection{Considerações sobre o ParkBench}

A versão considerada foi a 2.1 de 1996, que é a última versão do ParkBench. O ParkBench analisa vários aspectos computacionais, que incluem desde características básicas do computador como resolução do clock, gargalo do cache e gargalo da memória, como também comunicação e computação.

O ParkBench é um benchmark de difícil configuração e execução, mesmo seguindo todos os passos indicados para configuração do ambiente e para sua execução não se conseguiu chegar a um resultado satisfatório. Problemas foram constatados quanto a sua instalação, inclusive alguns relacionados ao próprio ParkBench, e não apenas a configuração do ambiente.

Deve-se ressaltar que o Parkbench não se trata apenas de um conjunto de benchmarks, mas de um comitê que pretende estabelecer um padrão entre todos os benchmarks existentes, 
assim como evitar duplicações. Esperava-se que o ParkBench fosse bem estruturado e organizado, ou seja, de fácil utilização e compreensão, visto que pretende ser um padrão para todos os benchmarks existentes. Mas o que foi constatado é que o grupo de benchmarks do Parkbench ainda tem muito a evoluir, principalmente quanto às diretivas de compilação e execução.

Se o ParkBench cumprir todas as suas diretivas (estabelecimento de um padrão para a técnica de benchmarking, evitar duplicações, cobrir todas, ou a maioria das áreas da computação), e forem sanados os problemas, este será um dos melhores benchmarks para avaliação de desempenho.

Um problema a ser ressaltado é que pelo fato dele se propor a cobrir as várias áreas existentes na computação, este se torna muito extenso e complexo.

Exemplos do resultado dos benchmarks do ParkBench são listados no Apêndice D. Esses exemplos foram obtidos da internet no seguinte endereço: http://www.netlib.org/cgibin/gbis/papiani-new-gbis-results-list-with-links.query. 


\subsection{Genesis}

O Genesis Distributed-Memory Benchmarks é um dos benchmarks que fazem parte do ParkBench. Ele foi escolhido por ser voltado para computadores que utilizam memória distribuída. O Genesis foi introduzido pelo fato de que sua total execução não estava sendo possivel através do ParkBench, devido aos fatos apresentados na seção anterior. A intenção foi a de conseguir sua execução individualmente, fora do ParkBench.

O Genesis é um conjunto de programas seqüenciais e paralelos escritos em Fortran. Testam computadores de memória distribuída que utilizam o paradigma de comunicação de passagem de mensagem. O Genesis avalia o desempenho e os pontos fortes e fracos de sistemas MIMD de memória distribuída em uma variedade de problemas científicos e de engenharia.

Esse é um conjunto de benchmarks organizado em múltiplas camadas com 3 níveis: no primeiro nível têm-se os fragmentos de código sintéticos, que foram projetados para medir propriedades básicas da máquina relacionadas à vetorização, comunicação e sincronização; no segundo nível têm-se os kernels de aplicações, ou códigos de computação intensa que frequientemente são partes de uma aplicação mais complexa; no terceiro nível têm-se os códigos de aplicações completas, usados principalmente para verificar se os kernels de aplicações fornecem prognósticos de desempenho confí́veis [HEY91].

Os benchmarks que constituem o Genesis são [GLE94]:

- Baixo nível:

- TICK1: mede a resolução do sistema de clock.

- TICK2: mede a precisão do sistema de tempo do clock.

- RINF1: mede parâmetros de vetorização.

- COMMSI: pingpong benchmark.

- COMMS2: avalia a troca de mensagens.

- COMMS3: saturation bandwidth.

- SYNCHI: custo de sincronização do barrier.

- POLY1: avalia o gargalo de memória cache.

- POLY2: avalia o gargalo de memória. 
- POLY3: avalia o gargalo de comunicação.

- Kernels:

- TRANS1: transposição de matrizes usando o algoritmo naive.

- IO1: mede a taxa de transferência paralela e E/S.

- FFT1: FFT uni dimensional.

- SOLVER: conjugate gradient kernel.

- PDE1: poisson solver tri-dimensional usando red-black relaxation.

- PDE2: multi-grid poisson solver bi-dimensional.

- Aplicações compactas:

- QCDI: simulação do quantum chromodynamics usando o método Monte Carlo.

- GR1: aplicação de relatividade geral.

- LPM1: simulação de dispositivo eletrônico.

- MDI: código de dinâmica molecular.

Sua última versão é a 3.0 de 1994. Como já dito antes, os códigos do Genesis foram acrescentados ao ParkBench sendo que este se encarrega de desenvolve-lo e distribuí-lo. $O$ ambiente de passagem de mensagem utilizado pode ser Parmacs ou PVM (somente para alguns códigos). É portável para as seguintes plataformas: ISIS, Cray-XMP, ETA-10, Alliant FX-8, nCUBE-1, Supernode, Meiko, iPSC/2 e Amtek/Symult 2010.

\subsubsection{Execução}

Seu código fonte pode ser obtido através do ParkBench no seguinte endereço: http://www.hpcc.ecs.soton.ac.uk. Os procedimentos para instalação e configuração estão no diretório ReadMe.

Como mostrado anteriormente, essa versão do Genesis não possui um script pronto para SP2 e nem para LINUX. Estes scripts foram feitos seguindo o padrão do Genesis. Quanto a instalação, mesmo sendo uma versão que poderia ser executado em PVM em vez de PARMACS, o Genesis gerava um erro que pedia a instalação de PARMACS. Como PARMACS não estava disponível nas máquinas não foi possível sua execução. 


\subsubsection{Considerações sobre o Genesis}

A versão utilizada foi a 3.0 de 1994. O Genesis analisa vários aspectos computacionais, que incluem desde características básicas do computador como resolução do clock, gargalo do cache e gargalo da memória, como também comunicação e computação.

Sua execução ficou prejudicada pela necessidade da instalação de PARMACS. 


\subsection{PSTSWM}

O Parallel Spectral Transform Shallow Water Model é uma aplicação compacta que faz parte do Parkbench. É um benchmark de troca de mensagem que resolve equações shallow water não lineares em uma esfera rotacional usando o método de transformação spectral. Foi desenvolvido para avaliar algoritimos paralelos para o método de transformação spectral usado em modelos de circulação atmosférica global [WOR96].

O PSTSWM é escrito em Fortran 77 com extensões VMS e um pequeno número de diretivas C. A troca de mensagens é implementado utilizando MPI, PICL, PVM e bibliotecas de troca de mensagem nativas, sendo a escolha feita em tempo de compilação.

Como o PSTSWM faz parte do Parkbench esperava-se pelo sua execução através deste, mas devido aos problemas surgidos na execução do Parkbench não chegou-se a sua execução.

\subsection{SPEChpc96}

Este é um benchmark suite que mede o desempenho de sistemas de computação highend executando aplicações de estilo industrial. Essa linha de benchmarks é adaptado para avaliar o desempenho de arquiteturas de computadores paralelos e distribuídos.

Este benchmark se distingue dos outros pelo fato de incluir aplicações utilizadas na indústria e por pesquisadores para representar o mundo real, e por abranger todas as arquiteturas de computadores de alto desempenho. As aplicações implementadas no benchmark são utilizadas em uma grande variedade de sistemas, incluindo workstations, clusters, SMPs, vector systems e MPPS. Os modelos de programação utilizados podem ser executados em todos os sistemas de alto desempenho utilizados atualmente [HPG99].

SPEChpc96 foi desenvolvido pelo Standard Performance Evaluation Corp's HighPerformance Group e inclui três áreas: processamento sísmico (SPECseis96), química computacional (SPECchem96), e modelamento climático (SPECclimate):

- SPECseis96: contem uma aplicação industrial -Seismic- que simula o tempo gasto e as migrações realizadas para localizar depósitos de gás e óleo.

- SPECchem96: contem programas -GAMMES- utilizados na química.

- SPECclimate: contem um modelo projetado -MM5- para simular ou predizer circulação atmosférica. 
A execução deste benchmark não foi realizada pelo fato de seu código não ser disponível gratuitamente. 


\subsection{Comparação dos Benchmarks}

Esta seção apresenta uma comparação entre os benchmarks analisados nas seções anteriores. Diversos aspectos são abordados nessa comparação, tais como biblioteca de troca de mensagem utilizada, facilidade de execução, documentação disponível, métricas utilizadas, versão e ano, tipo, linguagem de desenvolvimento, plataformas disponíveis para execução, componentes analisados, entre outros.

\subsubsection{MPBench X NAS}

São benchmarks diferentes quanto a camada que analisam. Enquanto o MPBench se preocupa somente com comunicação, ou seja o ambiente de passagem de mensagem, o NAS se preocupa um pouco com comunicação e principalmente com computação. Outra diferença que se nota é quanto a forma em que apresentam seus resultados. O MPBench adota métricas que se adequam melhor a cada função analisada. Já o NAS adota $M o p / s$ como uma métrica genérica para todos os benchmarks que executa.

Quanto à facilidade de compreensão e execução do benchmark os dois se comportam de uma maneira semelhante, sendo que ambos são de fácil compreensão e execução. $O$ MPBench agrupa todas as funções em um único código, isso facilita o entendimento e a depuração do código, visto que estes são simples e curtos. O NAS cria um diretório para cada um dos benchmarks que o compõem. Nesse diretório estão contidos todos os códigos e bibliotecas necessários para sua execução. Aqui os códigos são mais complexos e longos o que dificulta a depuração do código quando algum erro precisa ser encontrado.

Os dois benchmarks analisados foram de compreensão e execução relativamente fácil. Alguns pequenos erros foram encontrados e sanados.

\subsubsection{MPBench X ParkBench}

São benchmarks diferentes quanto a camada que analisam. Enquanto o MPBench se preocupa somente com comunicação, ou seja o ambiente de passagem de mensagem, 0 ParkBench se preocupa tanto com comunicação como com computação. Outra diferença que se nota é quanto a forma em que apresentam seus resultados. O MPBench adota métricas que se adequam melhor a cada função analisada. Já o ParkBench adota métricas de desempenho (temporal, de simulação, de benchmark e de hardware) para análise dos resultados obtidos. Essa diferença na forma de apresentação dos resultados é justificável pelo fato de serem 
benchmarks que analisam aspectos diferentes do sistema. Como o MPBench é de baixo nível e analisa comunicação seus resultados podem ser expressos de uma forma mais simples e serem bem compreendidos. Já o ParkBench analisa o sistema como um todo e por isso deve expressar seus resultados de uma forma mais abrangente, englobando em seu resultado todos os dados que foram analisados.

Quanto à facilidade de compreensão e execução dos benchmarks os dois se comportam de maneira bem diferente. Um dos motivos é que um é de baixo nível e outro de alto nível, o que já adiciona uma certa complexidade ao benchmark de alto nível. No entanto, o ParkBench apresentou bem mais problemas que o esperado. O MPBench agrupa todas as funções em um único código, isso facilita o entendimento e a depuração do código, visto que estes são simples e curtos. O ParkBench cria um diretório para cada um dos níveis de benchmarks que o compõem (baixo nível, kernels e aplicações compactas). Se sua execução funcionasse de acordo com o indicado não haveria problema, mas como isso não aconteceu se tornou necessário que o benchmarker tivesse total conhecimento da forma como os códigos estão organizados para que os problemas fossem resolvidos. A documentação disponível não auxilia neste "total conhecimento" necessário.

\subsubsection{MPBench X Genesis}

São benchmarks diferentes quanto a camada que analisam. Enquanto o MPBench se preocupa somente com comunicação, ou seja o ambiente de passagem de mensagem, o Genesis se preocupa tanto com comunicação como com computação. Outra diferença que se nota é quanto a forma em que apresentam seus resultados. O MPBench adota métricas que se adequam melhor a cada função analisada. Já o Genesis adota as métricas de desempenho temporal, desempenho de benchmark e desempenho de simulação.

Como no caso do MPBench x ParkBench, essa diferença na forma de apresentação dos resultados é justificável pelo fato de serem benchmarks que analisam aspectos diferentes do sistema. O MPBench é de baixo nível e analisa comunicação, portanto seus resultados podem ser expressados de uma forma mais simples. Já o Genesis analisa o sistema como um todo e por isso deve expressar seus resultados de uma forma mais abrangente.

Quanto à facilidade de compreensão e execução os dois se comportam de maneira diferente, visto que são de níveis diferentes. O MPBench é de fácil compreensão e execução, o Genesis não pode ser analisado. 


\subsubsection{NAS X ParkBench}

Estes dois benchmarks são de alto nível e analisam tanto comunicação como computação. Os dois benchmarks são organizados em camadas que abrangem baixo nível, kernels e aplicações. A diferença está na área de abrangência proposta pelos benchmarks. $\mathrm{O}$ NAS foi desenvolvido com o propósito de avaliar o desempenho de aplicações CFD (Computational Fluid Dynamics), já o ParkBench foi desenvolvido para ser utilizado como padrão para confecção e execução de benchmarks.

O NAS também é distribuído como parte do ParkBench, porém a última versão do ParkBench, que é de 1996 engloba a versão 2.1 do NAS. Existe uma versão mais atual que é a 2.3 de 1997 distribuída pela NASA. Logo, apesar de fazer parte do ParkBench, seu desenvolvimento continua a cargo da NASA e não do ParkBench, como é o caso do Genesis.

A forma de apresentar os resultados é diferente para os dois benchmarks. O NAS adota a métrica de $M o p / s$ (Milhões de operações por segundo) como uma métrica genérica para todos os benchmarks que executa, enquanto o ParkBench utiliza as métricas de desempenho temporal, desempenho de hardware, desempenho de simulação e desempenho de benchmark para expressar seus resultados.

Quanto à facilidade de compreensão e execução dos benchmarks, apesar dos dois serem de alto nível, o NAS se apresentou bem mais eficiente do que o ParkBench, não apresentando problemas quanto a sua execução, o que já não aconteceu com o ParkBench.

\subsubsection{NAS X Genesis}

Os dois benchmarks são organizados em camadas que abrangem baixo nível, kernels e aplicações. A diferença está na área de abrangência dos benchmarks. O Genesis foi desenvolvido para avaliar o desempenho e os pontos fracos e fortes de problemas de engenharia, já o NPB foi desenvolvido para lidar com aplicações CFD (Computational Fluid Dynamics).

As métricas utilizadas para analisar o desempenho são diferentes, sendo que o NAS utiliza Mop/s e o Genesis as métricas de desempenho temporal, de benchmark e de simulação.

Quanto à facilidade de compreensão e execução dos benchmarks, pode-se dizer que o NAS é de fácil compreensão e execução, não apresentando problemas. O Genesis não foi 
executado, pela necessidade da instalação de Parmacs, o que é um ponto negativo que se pode considerar quanto a sua execução.

\subsubsection{ParkBench $X$ Genesis}

Os dois benchmarks são organizados em camadas que abrangem baixo nível, kernels e aplicações. A diferença está na área de abrangência proposta pelos benchmarks. O Genesis foi desenvolvido com o propósito de avaliar o desempenho e os pontos fracos e fortes de problemas de engenharia, já o ParkBench foi desenvolvido para ser utilizado como padrão para confecção e execução de benchmarks.

O ParkBench englobou os códigos do Genesis e se tornou responsável pela sua manutenção, distribuição e desenvolvimento. A versão do Genesis distribuída pelo ParkBench já permite comunicação através de MPI, o que não acontecia na última versão do Genesis distribuída antes de sua incorporação ao ParkBench.

As métricas utilizadas para analisar o desempenho são as mesmas para os dois benchmarks.

Quanto à facilidade de compreensão e execução dos benchmarks, como já dito antes, o ParkBench apresentou vários problemas de difícil compreensão e depuração. Também não foi possível a execução do Genesis pela necessidade da utilização de macros Parmacs. 


\subsection{Benchmarks de Baixo Nível $x$ Benchmarks de Alto Nível}

O benchmark de baixo nível analisado foi o MPBench, o ParkBench também possui em seu código alguns benchmarks de baixo nível. Em geral benchmarks de baixo nível medem o desempenho de partes específicas do sistema, como comunicação, cache, E/S, memória, sincronização, etc. Já os benchmarks de alto nível fazem uma análise mais geral, envolvendo comunicação e computação. Estes são utilizados para verificar o comportamento da máquina quanto a problemas de áreas específicas, os códigos do NPB, por exemplo, tratam de problemas relacionados a aplicações CFD (Computational Fluid Dynamic), que normalmente exigem muita computação.

Por serem mais simples e analisarem partes específicas do sistema os benchmarks de baixo nível são mais fáceis de serem compreendidos que os de alto nível, visto que os de alto nível tratam de problemas de áreas específicas que às vezes não fazem parte da área de conhecimento do benchmarker.

Os benchmarks de alto nível exigem uma melhor organização/estruturação para que possam funcionar adequadamente, ou seja, serem de fácil utilização. Um benchmark que se propõe a cobrir uma grande área, como o ParkBench, não pode conter erros de estruturação, como os que foram observados durante sua execução. Um exemplo desses erros foi a compilação de várias bibliotecas com uma determinada formatação (nome) e a chamada das mesmas, nos códigos dos benchmarks, serem realizadas com outro formato. Como o ParkBench contém vários códigos e bibliotecas não foi possível a localização de todos para que fosse alterado o formato das bibliotecas. 


\subsection{Principais características dos Benchmarks}

A Tabela 10 resume as características principais de seis benchmarks. Dentre os benchmarks considerados nessa tabela, tem-se os quatro benchmarks analisados neste capítulo e adicionalmente os benchmarks SPEChpc96 e PSTSWM, cujos dados na tabela baseiam-se apenas na literatura consultada.

O SPEChpc96 não foi considerado nesse capítulo por não ser "freewere" e não estar disponível nos ambientes considerados. Pretendia-se a execução do PSTSWM como parte do ParkBench, mas pelos diversos motivos já citados não foi possível sua execução. Seus dados foram analisados separadamente ao ParkBench, mas sua execução não foi realizada.

As características avaliadas na Tabela 10 incluem tanto pontos levantados na literatura consultada quanto aspectos observados na utilização dos benchmarks (para o caso do MPBench, ParkBench, NASPB e Genesis). As seguintes características são consideradas:

- Benchmark: nome do benchmark analisado.

- Descrição: breve descrição do objetivo do benchmark.

- Métricas: métricas utilizadas pelo benchmark para expressar seus resultados.

- Versão/Ano: versão e ano do benchmark em questão.

- Tipo: informa se o benchmark é sintético, kernel, aplicação compacta, suite ou suite em múltiplas camadas.

- Comunicação: ambiente de comunicação utilizado pelo bençhmark.

- Linguagem: linguagem em que foram desenvolvidos os códigos do benchmark.

- Plataforma: plataformas em que o benchmark pode ser executado.

- Componentes: componentes que o benchmark analisa.

- Endereço: endereço na internet onde pode ser encontrado o benchmark.

- Orgão responsável: pessoa ou órgão responsável pelo benchmark. Essa pessoa/órgão é o encarregado de tirar as dúvidas que possam surgir, assim como receber sugestões e críticas sobre o benchmark. 
- Preço: indica se o benchmark pode ser obtido sem nenhum custo ou se é necessário algum tipo de gasto para ter acesso ao código.

- OBS: qualquer observação importante sobre o benchmark.

- Nível: indica se o benchmark e de baixo nível ou alto nível.

- Documentação: informa a qualidade da documentação existente sobre o benchmark.

- Facilidade de Instalação e Execução: classifica a facilidade de instalação e execução do benchmark. 


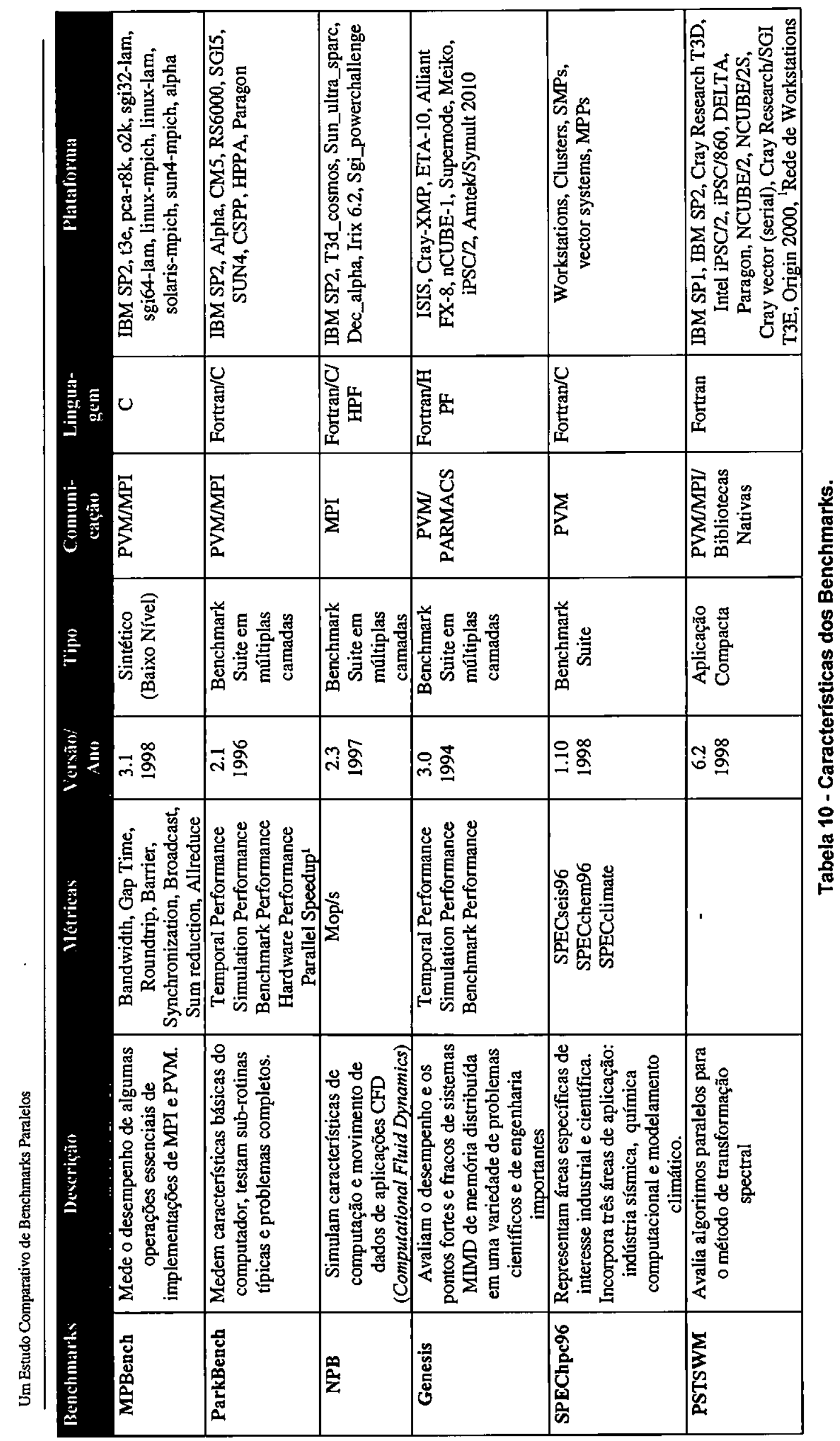

| 


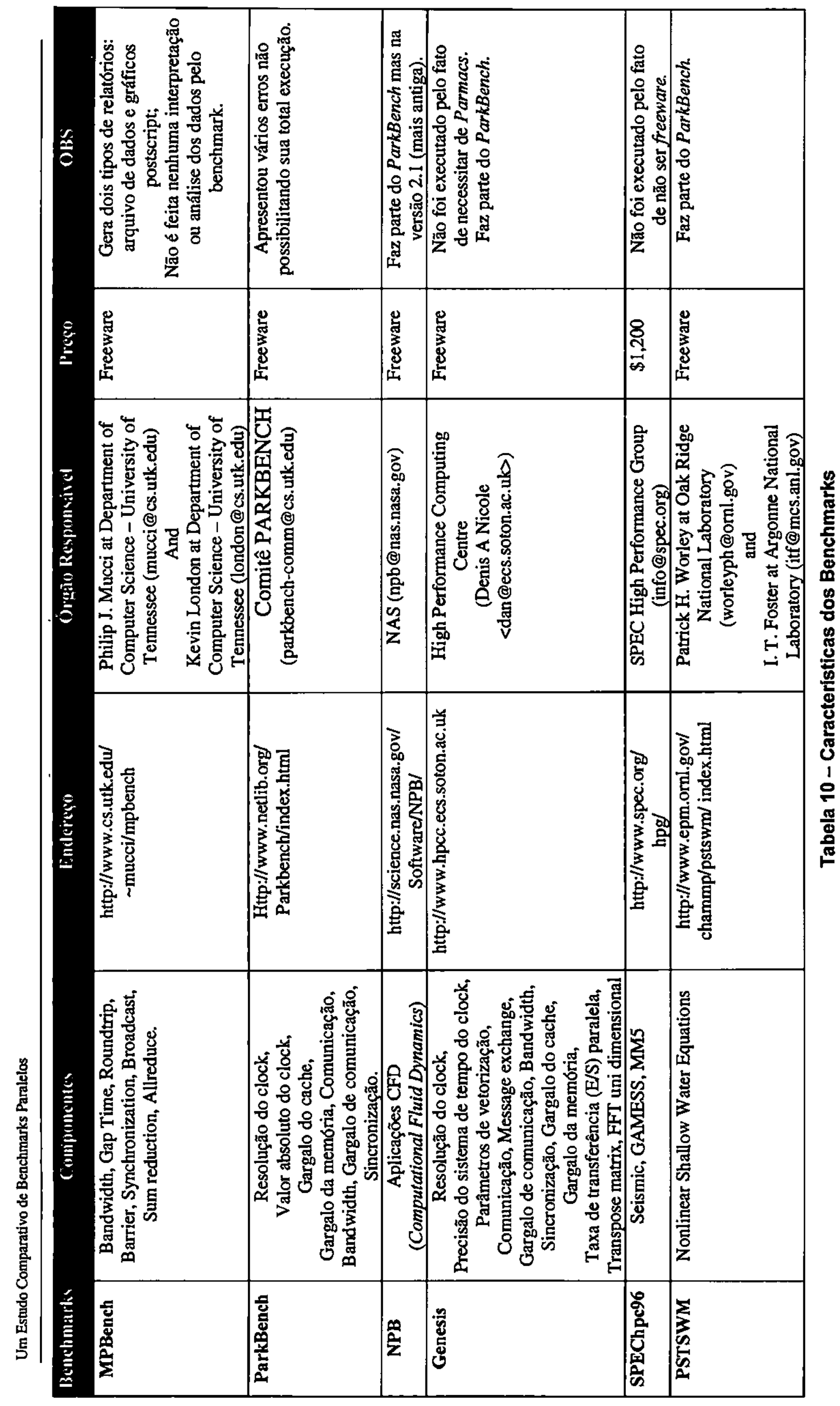

窝 


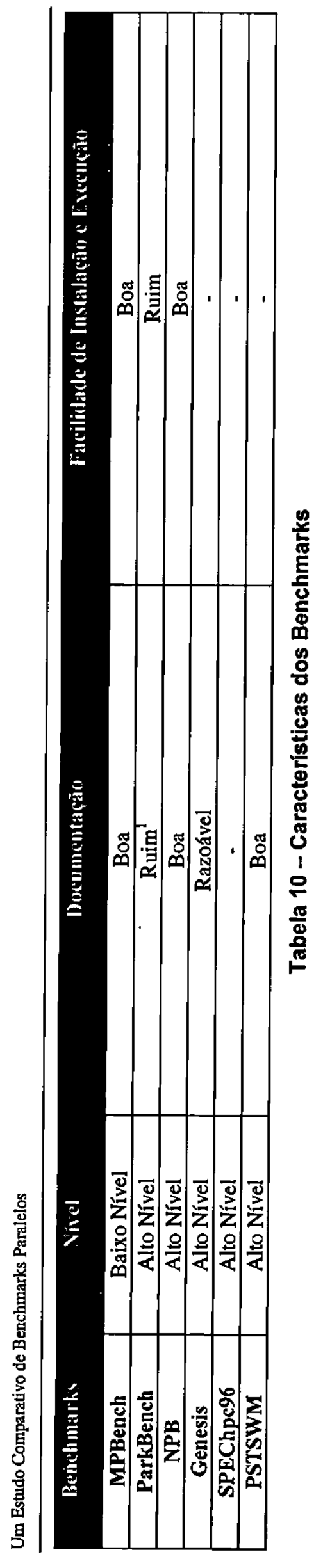

空

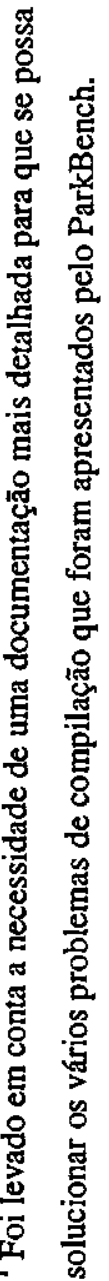

ล 


\subsection{Conclusão}

Os benchmarks de baixo nível possuem uma estrutura mais simples que os de alto nível, pois um tem como objetivo a análise de componentes do sistema e o outro a análise do sistema como um todo. No MPBench os poucos problemas encontrados, que geralmente estavam relacionados a descuidos de programação, foram de fácil solução, sendo localizados e corrigidos rapidamente. O ParkBench apresentou vários problemas de compilação relacionados a organização de sua estrutura e também a descuidos de programação. Ao contrário dos benchmarks de baixo nível não foi possível a solução de todos os problemas encontrados, visto que o ParkBench é composto de vários benchmarks.e bibliotecas, o que dificulta a localização do problema. Outro motivo para a não solução dos erros encontrados é a falta de uma documentação mais detalhada para que através dela o benchmarker possa localizar o problema com maior facilidade.

O NPB é um benchmark de alto nível que não apresentou maiores problemas, sua instalação e execução transcorreram tranqüilamente, não houve problemas com a compilação e não foi necessário nenhum tipo de alteração além das necessárias para a configuração do benchmark ao sistema analisado. O NPB apresenta seus resultados em Mop/s (milhões de operações por segundo), sendo que o tipo de operação (ponto flutuante, inteiro, números randômicos gerados e chaves geradas) dependente do benchmark executado. Também é informado o tempo de utilização de CPU e o tempo total de execução de cada benchmark que compõe o NPB. Nenhuma interpretação dos resultados é realizada pelo benchmark, ficando a cargo do benchmarker interpretar os resultados gerados.

O versão 3.0 do código do Genesis foi obtido de um site pessoal na internet e foi constatado que não se encontra mais disponível. Nota-se que a versão 2.1 do ParkBench inclui, nos benchmarks de baixo nível todos os benchmarks do Genesis, nos kernels benchmarks alguns do NPB, alguns do Genesis e alguns outros, e nas aplicações compactas os do NPB e o PSTSWM. A documentação oferecida no site do ParkBench é de 1994 e esta desatualizada. A documentação informa que os kernels do ParkBench são, além dos encontrados na versão 2.1, todos os do NPB e todos os do Genesis. É necessário uma atualização do documento para que este represente o código atual, visto que este é de 1994 estando desatualizado. 
Seria interessante que nessa atualização fosse realizado uma revisão total do ParkBench, visto que foram constatados diversos problemas, tais como: realização de mudanças em alguns códigos e não atualização dos mesmos nos níveis superiores do benchmark; mensagens de erro de compilação muito alto nível, dificultando a localização do erro; etc.

A intensão do ParkBench de estabelecer um padrão para a metodologia de benchmarking e evitar duplicações é muito boa, mas pelo que foi observado é necessário uma melhor organização dos vários benchmarks que compõem o ParkBench, pois não adianta reunir os vários benchmarks existentes se sua execução se torna muito complicada.

Como pode-se constatar cada um dos benchmarks apresentados possuem características particulares que não dependem de seu tipo e outras que dependem. $\mathrm{O}$ benchmark pode ser de alto nível e de fácil execução e instalação, como pode ser de baixo nível e de difícil execução e instalação, tudo depende de sua organização e estrutura. 


\section{Colcitisa}

Este capítulo apresenta uma análise da revisão bibliográfica, as conclusões desta dissertação de mestrado, suas contribuições e as propostas para trabalhos futuros.

\subsection{Análise da Revisão Bibliográfica}

Houve um progresso significante em muitas áreas relacionadas à computação de alto desempenho em geral e computação paralela em particular. Atualmente, existe um número substancial de pessoas que usam computadores paralelos para executar aplicações reais. Consequentemente, novos algoritmos, novos sistemas operacionais, novas linguagens, e novos paradigmas de programação, bem como ferramentas de software, para sistemas de computação massivamente paralelos e outros sistemas de alto desempenho tem surgido.

Vários fatores explicam a necessidade do processamento paralelo. O principal deles trata da busca por maior desempenho. As diversas áreas na qual a computação se aplica, sejam científicas, industriais ou militares, requerem cada vez mais potência computacional, em virtude de algoritmos complexos que são utilizados e do tamanho do conjunto de dados a ser processado. Outros fatores que motivam o desenvolvimento da computação paralela são o desenvolvimento tecnológico, as restrições físicas (velocidade da luz), a tolerância a falhas, entre outras.

O principal objetivo da computação paralela é o aumento de desempenho na solução de problemas. Portanto, desempenho é um fator fundamental no projeto de computadores paralelos. Desempenho não é um atributo isolado de sistemas de computadores ou algoritmos, mas depende da interação entre ambos. Consequientemente, avaliação de desempenho é necessária para identificar a eficácia e os pontos fracos de sistemas de computadores e aplicações em particular. Essencialmente, avaliação de desempenho consiste do estudo da interação entre um computador e um programa [GON96].

Benchmarks envolvem a execução de programas em plataformas reais e é talvez a metodologia para avaliação de desempenho mais frequientemente utilizada. A principal vantagem de se utilizar benchmarks sobre outros métodos de avaliação de desempenho é que eles permitem avaliar o sistema de computador como um todo. A execução de um programa real avalia todos os aspectos necessários, incluindo aqueles relacionados à arquitetura do sistema, eficiência do compilador, sobrecarga do sistema operacional, etc. Caracterização de desempenho de 
componentes individuais é útil, mas insuficiente para descrever o desempenho de um sistema como um todo. É extremamente difícil predizer as conseqüências da interação entre os componentes de um sistema de computador. Portanto, a execução de programas reais normalmente é considerada a palavra final em termos de medidas de desempenho.

Um benchmark consiste em um conjunto de programas, selecionados de maneira a criar uma composição representativa da carga de trabalho, executado num sistema que se deseja avaliar [MAC79]. Um benchmark permite determinar se um sistema particular pode processar adequadamente uma carga real, se a relação custo/desempenho do sistema proposto é adequada e quais as melhores op̧ões de configuração (tanto de hardware quanto de parâmetros do sistema operacional), constituindo-se, pois, em uma técnica fundamental para a área de seleção de sistemas. Também é uma técnica útil para avaliação de sistemas já existentes, quando se deseja verificar se uma alteração no sistema produzirá os efeitos esperados sobre seu desempenho no processamento da carga corrente.

Benchmarks podem ser usados para medir desempenho de vários elementos do sistema, tais como velocidade de processamento, bandwidth de memória, implementações de linguagens, memória cache em geral, o sistema operacional e o subsistema de E/S. Qualquer aspecto de desempenho de um sistema computacional que importe aos usuários pode ser objeto de medição através de benchmarks. Todavia, deve-se tomar certos cuidados com relação à utilização dos benchmarks, como por exemplo, analisar se a própria execução do benchmark não afeta os resultados obtidos e verificar se todos os aspectos relacionados ao elemento, que esta sendo analisado, foram devidamente cobertos pelo benchmark.

Quando arquiteturas paralelas são consideradas, os requisitos para um bom benchmark são ainda maiores. Um benchmark para computação paralela deve ser capaz de avaliar, além dos elementos já citados, o subsistema de comunicação, o protocolo e as bibliotecas de comunicação, os compiladores de paralelização, etc.

Certos tipos de benchmarks não são adequados para a medição de desempenho de máquinas paralelas, como por exemplo, os populares kernel benchmarks [HOC91], que são porções do programa de intensa computação. Os requisitos de computação e de memória desses programas não fazem justiça ao vasto aumento de capacidade de novas máquinas paralelas. Já um outro tipo de benchmark, que é usado para medição de desempenho de máquinas paralelas, 
são as aplicações compactas, que são completas (representam o programa por inteiro), mas possuem códigos simplificados da aplicação que contêm todas as características necessárias do problema, mas são suficientemente simples de executar e analisar.

Para cada tipo de sistema (paralelo, distribuído ou seqüencial) e para cada componente do sistema (rede de comunicação, processador, unidade de ponto flutuante, dispositivos de E/S, memória, etc.) que se deseja analisar, tem-se que utilizar um tipo de benchmark diferente, ou seja, aquele que seja mais apropriado.

Além disso, a grande quantidade e grande variedade de benchmarks existentes dificulta a escolha do mais adequado quando deseja-se avaliar o desempenho de um determinado elemento. Por essa razão, muitas vezes essa etapa de avaliação de desempenho é ignorada.

\subsection{Conclusões}

Após analise dos benchmarks conclui-se que a técnica de benchmarking é boa para realizar análise de desempenho tanto de componentes como de todo o sistema. No entanto, alguns benchmarks exigem tempo e experiência do benchmarker para que seja possível aplica-lo com eficiência. Para isso o usuário precisa conhecer o benchmark, saber como esta organizado, como obter e como interpretar os dados.

A utilização do benchmark adequado é essencial na obtenção de resultados que realmente representem o dispositivo do sistema que se deseja avaliar. A Tabela 10 facilita esta escolha apresentando as principais características dos benchmarks analisados, assim como cita o nível de facilidade de execução e instalação dos mesmos e comentários sobre a documentação existente. A situação ideal seria que todos os benchmarks existentes estivessem nessa tabela. Uma organização como o ParkBench, que visa reunir todos os benchmarks para evitar duplicações e esforços de desenvolvimento desnecessários, poderia organizar uma tabela desse tipo. Assim, a medida que novos benchmarks fossem aparecendo seus desenvolvedores cuidariam de acrescentar suas características na tabela, cabendo à organização responsável pela tabela analisar dados como facilidade de execução e instalação e qualidade da documentação, podendo até sugerir aos desenvolvedores alterações no benchmark e na documentação que facilitem a utilização destes pelos usuários, ou seja, o benchmarker. 
Os benchmarks deveriam ser confeccionados de forma a facilitar ao máximo sua compreensão e utilização, visto que a aplicação da técnica já requer do usuário conhecimento específico, tanto do benchmark, como do ambiente em que será aplicado, e das formas de se analisar os resultados obtidos.

Baseando-se nos resultados desta dissertação, a próxima seção apresenta uma análise dos benchmarks sobre duas abordagens: comunicação e computação.

\subsection{Proposta de utilização dos Benchmarks}

Quando o aspecto analisado é a computação a escolha do benchmark deve levar em consideração também o tipo de aplicação que é executada. Por exemplo, o NPB engloba aplicaçōes CFD (Computatinal Fluid Dynamics), o PSTSWM engloba equações shallow water não lineares, e o ParkBench engloba os dois anteriores mais alguns.

Abaixo tem-se as conclusões tomadas com relação a utilização dos benchmarks analisados.

\section{MPBench}

Deve ser utilizado quando deseja-se analisar apenas o ambiente de comunicação de uma máquina paralela ou de um sistema distribuído. Não pode ser utilizado para análise da máquina/ambiente como um todo, pois não realiza nenhum tipo de computação.

\section{NPB}

Deve ser utilizado quando deseja-se analisar computação. Apesar dos benchmarks do NPB realizarem alguma comunicação, este não pode ser utilizado para analisar o ambiente de comunicação, visto que estas comunicações são relacionadas a solução dos problemas e dados específicos da comunicação não são fornecidos.

\section{ParkBench}

Deve ser utilizado quando deseja-se analisar o computador como um todo, visto que é composto de benchmarks de baixo nível, kernels benchmarks e aplicações compactas. Com os benchmarks de baixo nível, que são os mesmos do Genesis, pode-se avaliar clock, memória, cache, comunicação, sincronizaçăo e bandwidth. Os kernels, que são alguns do NPB, alguns do Genesis, e outros, avaliam computação. E por fim as aplicações compactas avaliam o 
comportamento do sistema na solução de problemas reais, ou seja, inclui computação e comunicação.

A diferença entre os kernels e as aplicações compactas é que as aplicações compactas não pegam apenas uma parte do problema, como os kernels, elas abrangem o problema como um todo de uma forma resumida, podendo assim fazer uma melhor análise do comportamento do sistema em relação ao problema no mundo real.

Desta forma, como a proposta do ParkBench é reunir os diferentes tipos de benchmarks em um único pacote, tem-se nesta opção benchmarks para vários tipos de avaliação. $O$ grande problema do ParkBench é a dificuldade em utiliza-lo e a falta de organização e documentação apresentados.

\section{Genesis}

Deve ser utilizado quando deseja-se analisar o computador como um todo, visto que 6 composto de benchmarks sintéticos, kernels benchmarks e aplicações compactas. Todas as considerações feitas ao ParkBench valem também para o Genesis, visto que eles possuem a mesma estrutura de organização.

\subsection{Contribuições do Trabalho}

Abaixo são apresentadas as contribuições que esse trabalho oferece.

- Apresentação das principais características dos benchmarks analisados;

- Classificação dos benchmarks analisados quanto a facilidade de execução e instalação;

- Análise da documentação dos benchmarks analisados;

- Análise dos benchmarks quanto aos componentes do sistema que podem avaliar com eficácia;

- Apresentação de uma tabela que visa facilitar a escolha do benchmark mais adequado a ser utilizado na avaliação de um sistema que se adequaria mais as necessidades de avaliação requeridas pelo benchmarker. 


\subsection{Trabalhos Futuros}

Os trabalhos que podem ser desenvolvidos futuramente são:

- Análise de outros benchmarks com a posterior comparação com os já analisados;

- Expansão da tabela de comparação considerando tanto outros benchmarks quanto outras características que possam ser úteis;

- Análise de benchmarks visando novas utilizações, mais específicas, como por exemplo, benchmark para ser utilizado para implementar escalonamento de processos. 


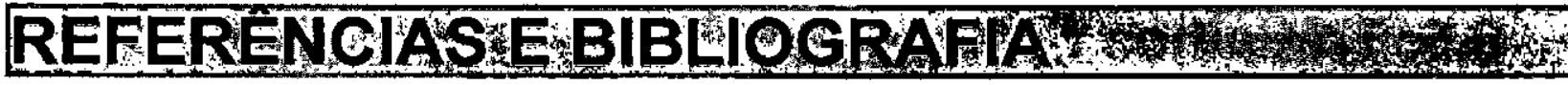

[ADA79] Adam, N. R. and Dogramaci, A.; Current Issues in Computer Simulation; 1979; Academic Press.

[ALM94] Almasi, G. S. and Gottlieb, A.; Highly Parallel Computing; 1994; 2 edição; The Benjamin Cummings Publishing Company; Inc.

[AME96] Ames, Research Center; Measurement and Prediction of Parallel Program Performance: AIMS - An Automated Instrumentation and Monitoring System; 07/08/96; Internet - http://www.uni-paderborn.de/pc2/projects/warp/prediction/Projects/main.htm.

[AXF89] Axford, Tom; Concurrent Programming Fundamental Techniques for Real-Time and Parallel Software Design; 1989; Wiley series in parallel computing; University of Birmingham, UK.

[BAI94] Bailey, D. et al; The NAS Parallel Benchmarks; March 1994; RNR Technical Report RNR-94-007; Internet - http://www.nas.nasa.gov/NAS.

[BAI95] Bailey, D. et al; The NAS Parallel Benchmarks 2.0; December 1995; Report NAS95-020; Internet - http://www.nas.nasa.gov/NAS.

[BEG94] Beguelin, A.; PVM: Parallel Virtual Machine. A User's Guide and Tutorial for Networked Parallel Computing; 1994; The MIT Press.

[BEN93] Ben-Dyke, A. D.; Architectural taxonomy, A brief review; 1993; University of Birmingham.

[BER92] Bertsekas, D. and Gallager, R.; Data Networks; 1992; Second Edition, Prentice Hall, Inc.

[BOA84] Boar, B.; Application Prototyping; 1984; Wiley-Interscience.

[CISC96] CISC, Centro de Informática de São Carlos; Guia do Usuário do SP2; 13/12/1996; Internet - http:// www.cisc.sc.usp.br/tutorias/sp2/sp2.html.

[COU96] Coulouris, G. et al; Distributed Systems - Concepts and Design; 1995; Second Edition; Addison-Wesley Publishing Company.

[DIX91] Dixit, K.; The SPEC Benchmarks; 1991; Parallel Computing, vol. 17, pp. 11951209.

[DON87] Dongarra, J. J. et al; Computer benchmarking: paths and pitfalls; July 1987; IEEE Spectrum, pp. 38-43.

[DON91] Dongarra, J. J. et al; Parallel Loops - A test suite for paralleling compilers: Description and example results; 1991; Parallel Computing, vol. 17, pp. 1247-1255. 
[DON93] Dongarra, J. J. and Gentzsch, Wolfgang; Computer Benchmark (Advances in Parallel Computing); 1993; vol. 8.

[DON95] Dongarra, J. J. and Hey, T.; The PARKBENCH Benchmark Collection; 1995; Supercomputer, vol. $11, \mathrm{n}^{\circ} 2-3$, pp. 94-114.

[DRU96] Drum, Philip and Schumann, Matthias; Measurement and Prediction of Parallel Program Performance: APNM - Abstract Parallel Numerical Machine; 07/08/96; Internet - http://www.uni-paderborn.de/pc2/projects/warp/prediction/Projects/main.htm.

[DUN90] Duncan, R.; A Survey of Parallel Computer Architectures; Fevereiro1990; IEEE Computer, pp. 5-16.

[ENS78] Enslow Jr, Philip H.; What is a "distributed" data processing system?; Jan. 1978; Computer, Long Beach, 11 (1) : 13-21.

[FER92] Fernandes, M. M.; Modelagem Analítica de Desempenho de Sistemas Multiprocessadores: Aplicação ao Multiprocessador CPER; Dezembro de 1992; Dissertação de mestrado, Universidade Federal de São Carlos.

[FLY72] Flynn, M. J.; Some Computer Organizations and Their Effectiveness; 1972; IEEE Transactions on Computers, v. C-21, pp. 948-960.

[FOX94] Fox, Geoffrey C. et al; Parallel Computing Works; 1994; Morgan Kaufmann Publishers.

[FOX95] Fox, Geoffrey C.; Basic Issues and Status of Parallel Computing; 1995; Internet http://www.npac.syr.edu

[FRA97] Frances, Carlos Renato Lisboa; Modelagem como Técnica de Avaliação de Desempenho em Sistemas Computacionais Distributdos; Abril 1997; Minidissertacao ICMC-USP.

[GAN94] Ganapati, N. et al; CoMet: A Synthetic Benchmark for Message-Passing Architectures; 1994; Tech. Rep. 94-019, Oregon Graduate Institute of Science and Technology, USA.

[GEH88] Gehani, Narain and Mcgettrick, Andrew D.; Concurrent Programming; 1988; International Computer Science Series; Addison-Wesley Publishing Company.

[GEI94] Geist, Al et al; PVM: Parallel Virtual Machine - A Users' Guide and Tutorial for Networked Parallel Computing; 1994; Internet - http://www.netlib.org/pvm3/book/pvmbook.html.

[GLE94] Glendinning, Ian; The GENESIS Distributed-Memory Benchmark Suite; 1994; Release 3.0; High Performance Computing Centre; University of Southampton.

[GON96] González, Emílio Hernandez; $A$ Methodology for the Design of Parallel Benchmarks; December 26, 1996; Thesis submitted for the degree of Doctor of Philosophy. 
[HEY91] Hey, A.; The Genesis distributed memory benchmarks; 1991; Parallel Computing, vol. 17, pp. 1275-1283.

[HOC91] Hockney, Roger and Berry, Michael; Public International Benchmarks for Parallel Computers; February 7, 1991; Parkbench Committee: Report-1.

[HOC93] Hockney, Roger et al; The genesis distributed-memory benchmarks; 1993; in Computer Benchmarks (J. Dongarra and W Gentzsch, eds.), pp. 257-271, North-Holland.

[HOC96] Hockney, Roger W.; The Science of Computer Benchmarking; 1996; SIAM, Philadelphia, ISBN 0-89871-363-3.

[HPG99] High Performance Group; Answers to Frequently Asked Questions About the SPEChpc96 Benchmark Suite; 1999; Standard Performance Evaluation (SPEC).

[HWA84] Hwang, K. and Briggs, F. A.; Computer Architecture and Parallel Processing; 1984; McGraw-Hill International Editions.

[IBM95] IBM; Scalable POWER Parallel System; 1995; Internet http://ibm.tc.cornell.edu/ibm/pps/sp2/sp2.html.

[JAQ97] Jaquie, K. R. L.; Modelagem Orientada a Objetos para Extensão da Ferramenta de Apoio à Programação Paralela (FAPP) para Ambientes Paralelos Virtuais; em andamento; Instituto de Ciências Matemáticas de São Carlos, Universidade de São Paulo.

[KIM72] Kimbleton, Stephen R.; The role of computer system models in performance evaluation; July 1972; Communications of the ACM, New York, 15 (7) : 586-90.

[KIR91] Kirner, C.; Arquiteturas de sistemas avançados de computação; 1991; Anais da Jornada EPUSP/IEEE em Sistemas de Computação de Alto Desempenho, pp. 307-353.

[KOB78] Kobayashi, H.; Modeling and Analysis - An Introduction to System Performance Evaluation Methodology; 1978; Addison-Wesley Publishing Company.

[LAZ84] Lazowska, E. et al; Quantitative System Performance - Computer System Analysis Using Queuing Network Models; 1984; Prentice-Hall, Inc, N.J.

[LUC71] Lucas, J. R.; Performance Evaluation and Monitoring; September 1971; Computing Surveys, Vol. 3(3",).

[MAC75] Macdougall, M. H.; System Level Simulation - Digital System Design Automation: Languages, Simulation \& Data Base; 1975; Computer Science Press, Inc, Chapter 1: 1115.

[MAC79] Macedo, L. T. de; Análise de Desempenho de Computadores: Avaliação, Controle o Otimização; 1979; Série $1^{\circ}$. Concurso Nacional de Textos sobre Processamento de Dados.

[MAC87] Macdougall, M. H.; Simulating Computing Systems Techniques and Tools; 1987; MIT. 
[MAR80] Maryansky, Fred J.; Digital Computer Simulation; 1980; Haydem Book Company Inc.

[MIC94] Michel, D. T. and Hobart, W. C.; Toward a Unified Model of Program Behavior; 1994; Performance Evaluation, vol. 20, n. 1-3, pp. 27-44.

[MIL96] Miller, Bart et al; Measurement and Prediction of Parallel Program Performance: Paradyn Parallel Performance Tools; 07/08/96; Internet - http://www.unipaderborn.de/pc2/projects/warp/prediction/Projects/main.htm.

[MOU86] Moura, J. A. B. et al; Redes Locais de Computadores-Protocolos de Alto Ntvel e Avaliação de Desempenho; 1986; McGraw-Hill.

[MUC98] Mucci, Philip J.and London, Kevin; The MPBench Report; 1998; Internethttp://www.cs.utk.edu/ mucci/mpbench.

[ORL95] Orlandi, R. C. G. S.; Ferramentas para Análise de Desempenho de Sistemas Computacionais Distribuidos; Março, 1995; Dissertação de Mestrado, Instituto de Ciências Matemáticas de São Carlos (ICMC), Universidade de São Paulo (USP).

[OVE95] Overeinder, B. J. et all; $A$ dynamic load balancing system for parallel cluster computing; November 24, 1995; Parallel Scientific Computing and Simulation Group, Department of Computer Science, University of Amsterdam.

[PER87] Perrott, R. H.; Parallel Programming; 1987; International Computer Science Series; Addison-Wesley Publishing Company.

[PRI89] Price, W.; A Benchmark Tutorial; Oct. 1989; IEEE Micro, 28-43.

[SAN90] Santana, R. H. C.; Performance Evaluation of LAN-Based File Servers; January 1990; PHD Thesis, University of Southamptom.

[SAN96] Santana, M. J. et al; Automatic Generation of Discret-System Simulation Programs; Jul. 1996; In The Proceedings of the 1996 Summer Computer Simulation Conference, Portland, Oregon, USA, 133-138.

[SAN97] Santana, R. H. C. et al; Computação Paralela; Agosto de 1997; Publicação Interna ICMC-USP.

[SIL96] Silva, F. A. B.; Balanceamento de Carga em Ambientes Paralelos Virtuais com Aplicações no PVM-W95; Junho de 1996; Instituto de Ciências Matemáticas de Sāo Carlos, Universidade de São Paulo.

[SIM96] Simon, Jens; Measurement and Prediction of Parallel Program Performance: WARP - Workload Analyzer \& Runtime Predictor; 07/08/96; Internet - http://www.unipaderborn.de/pc2/projects/warp/prediction/Projects/main.htm.

[SOA92] Soares, L. F. G.; Modelagem e Simulação Discreta de Sistemas; 1992; Editora Campus Ltda. 
[SOU96] Souza, P. S. L. e Santana, M. J.; Máquina Paralela Virtual em Ambiente Windows; São Carlos 1996; Dissertação (Mestrado) - Instituto de Ciências Matemáticas de São Carlos, Universidade de São Paulo.

[STE95] Steen, A. Van Der; Status and Direction of the Euroben Benchmark; 1995; Supercomputer, vol. 11, $n^{\circ}$.4, pp. 4-18;

[STR84] Strack, Jair; Sistemas de Processamento Distributdo; 1984; Livros Técnicos e Científicos, Editora S. A.

[STU87] Stus, J. M.; Consideraçöes sobre o Desenvolvimento por Protótipo; 1987; XX Congresso Nacional de Informática.

[SUN95] Sun Microsystems Computer Company; Evaluating Performance Through Benchmarks - The Nature of Benchmarking; November 1995; White Paper; Internet http://bbs-koi.uniinc.msk.ru/product/sun/ultra/bm_natu.html.

[TAN95] Tanenbaum, A. S.; Distributed Operating Systems; 1995; Prentice Hall International Inc.

[WEI84] Weicker, R.; Dhrystone: a Synthetic Systems Programming Benchmark; 1984; Communications of the ACM, vol. 27, $\mathrm{n}^{\circ} 10$, pp. 1013-1030.

[WEI90] Weicker, R.; An Overview of Common Benchmarks; Dec. 1990; IEEE Computer, 65-75.

[WES75] Westphall, C. B. et al; Medidas Para Avaliar Desempenho Em Redes Base; 1975; XX Congresso Nacional de Informática, vol. 2, pp. 722-726.

[WOR96] Worley, Patrick H.; PSTSWM; 1996; Internet - http:// http://www.epm.ornl.gov/ chammp/pstswm/ index.html.

[ZAL91] Zaluska, E. J.; Research lines in distributed computing systems and concurrent computation; 1991; Anais do Workshop em Programação Concorrente, Sistema Distribuídos e Engenharia de Software; pp. 132-155. 
a

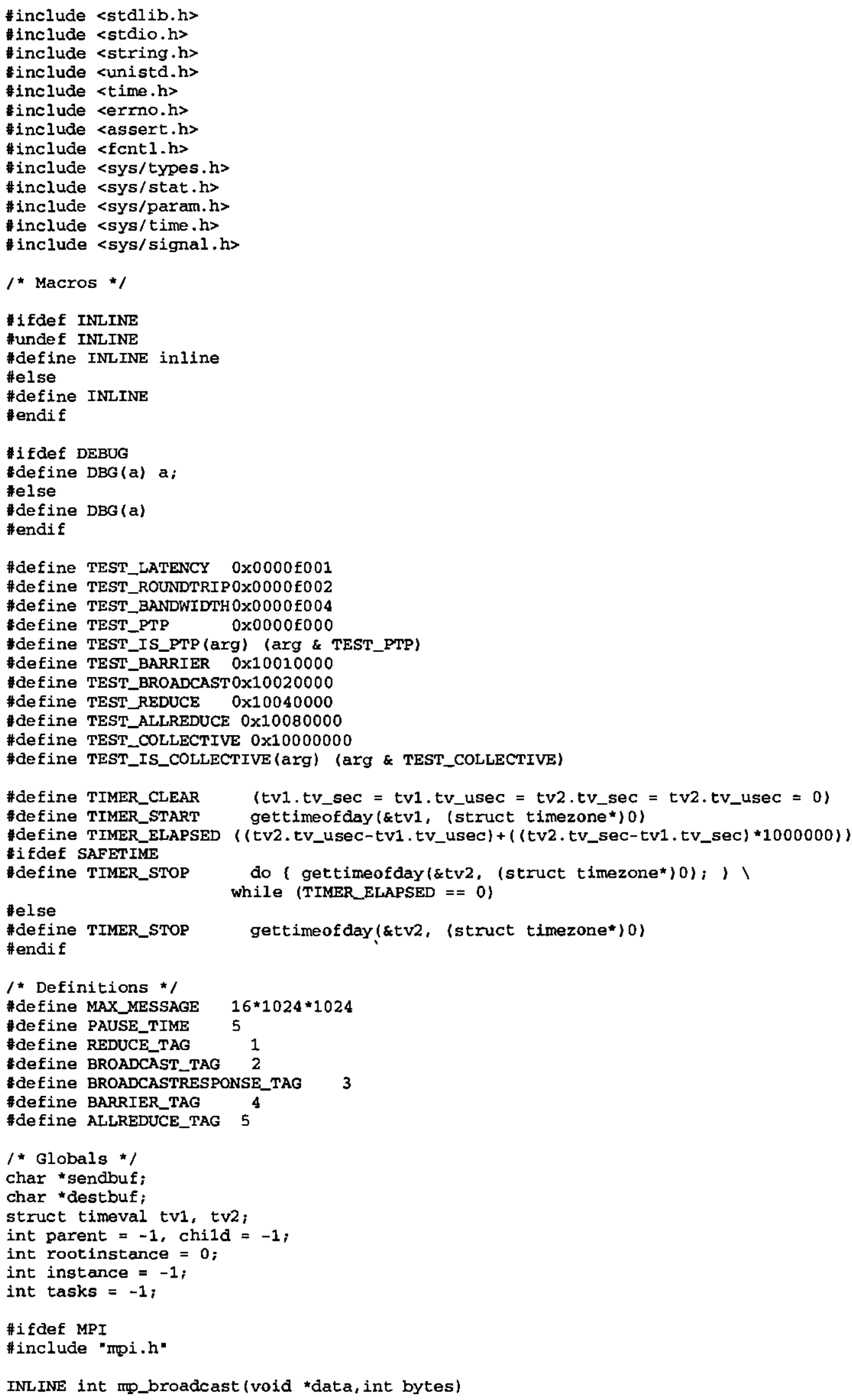




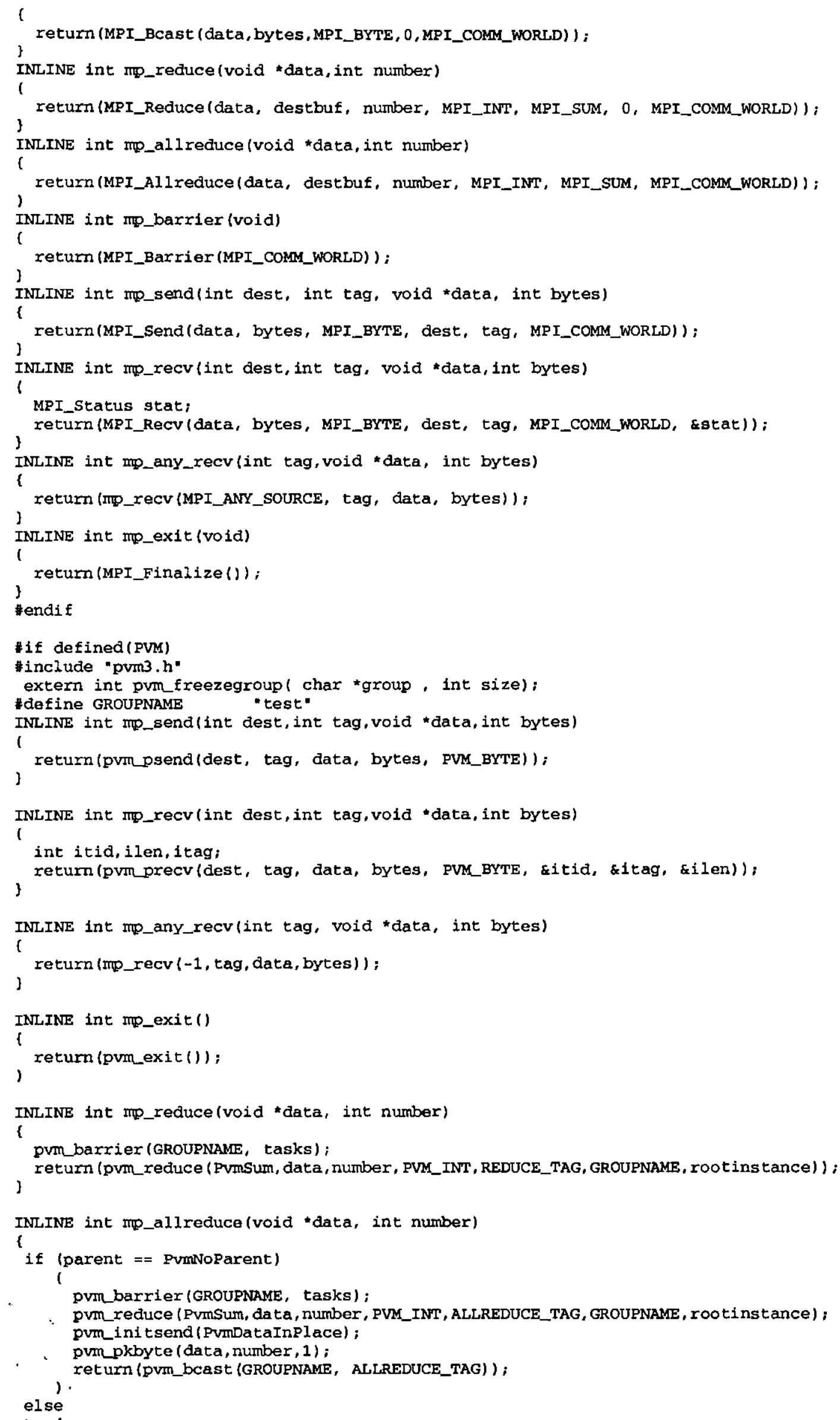




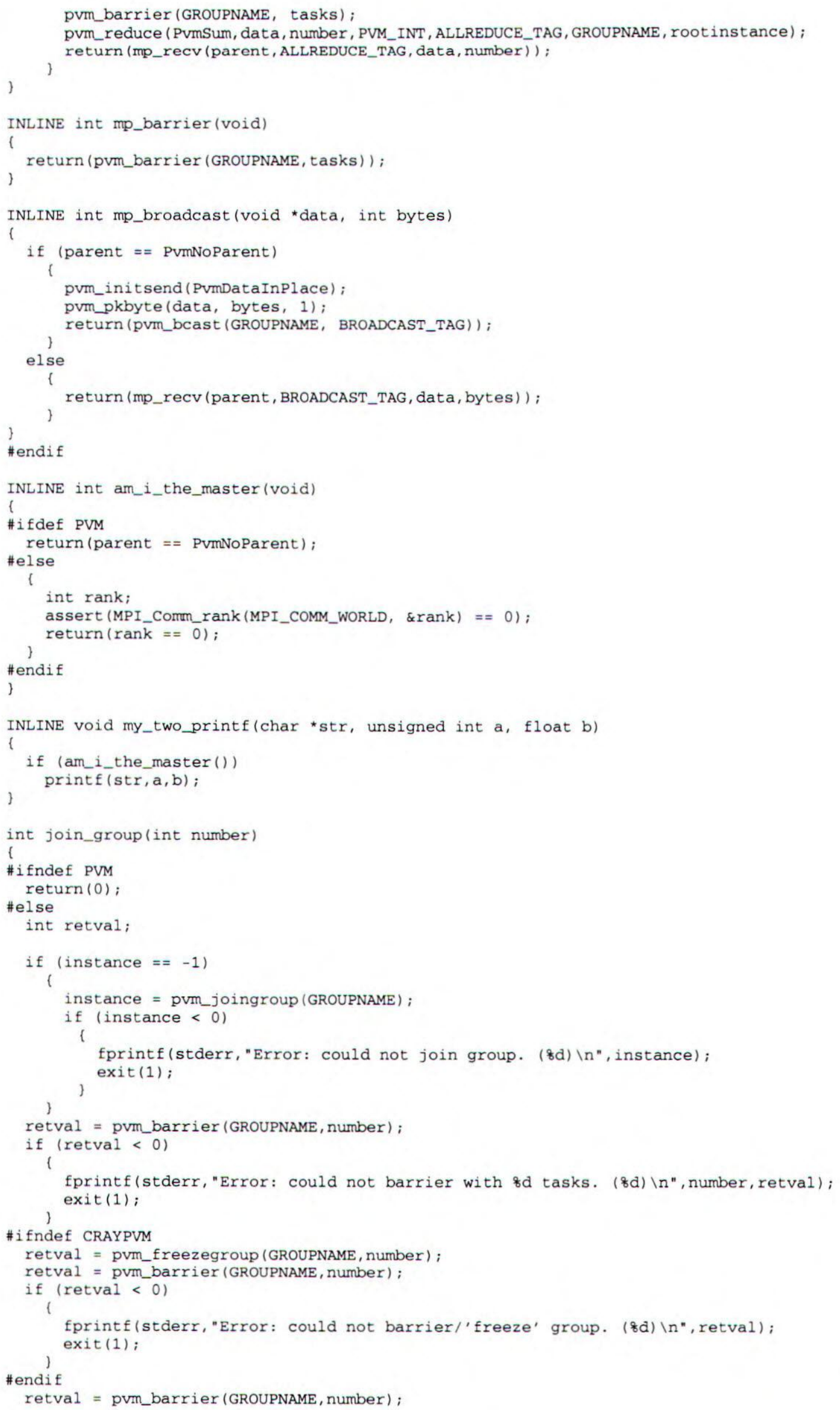




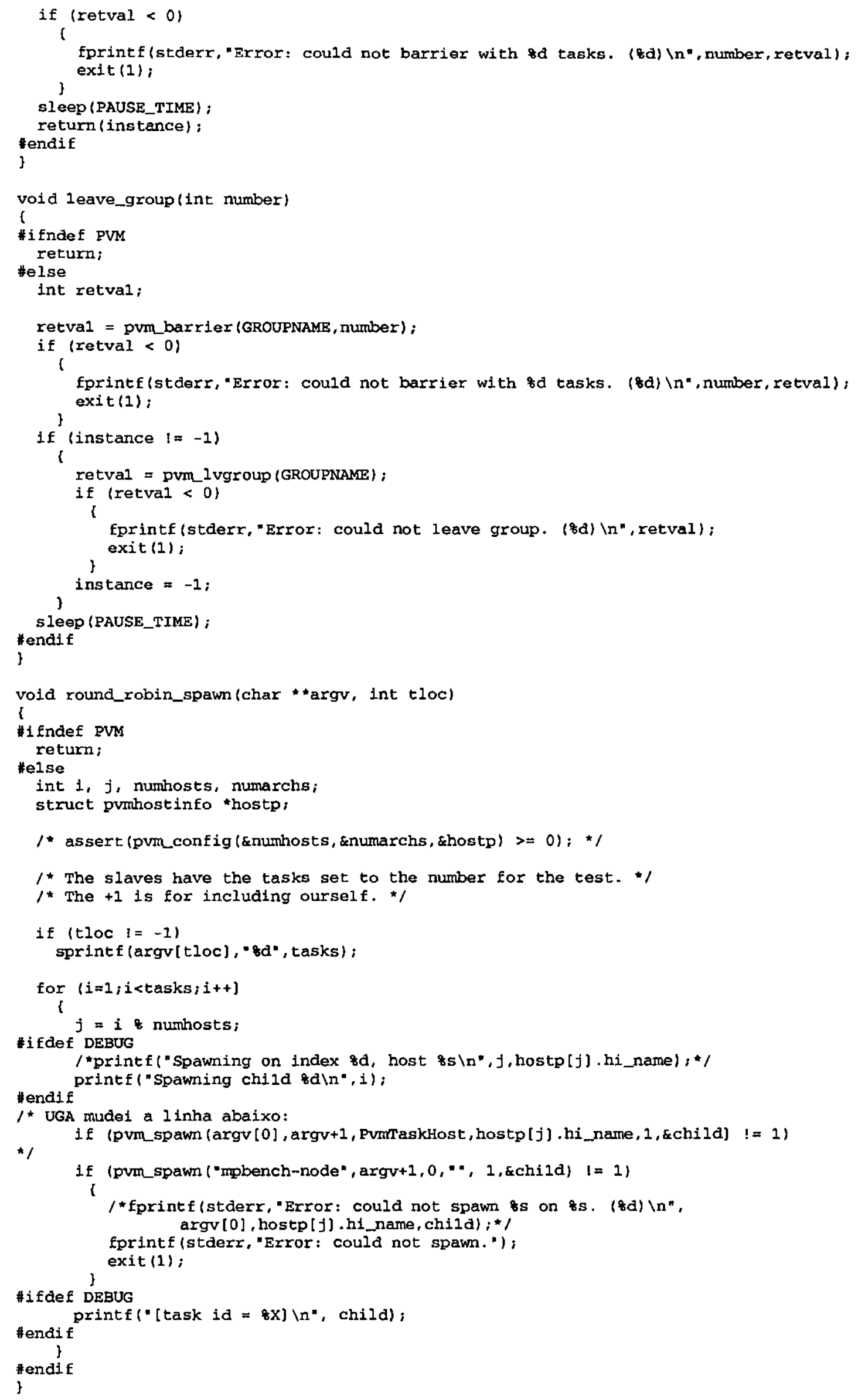




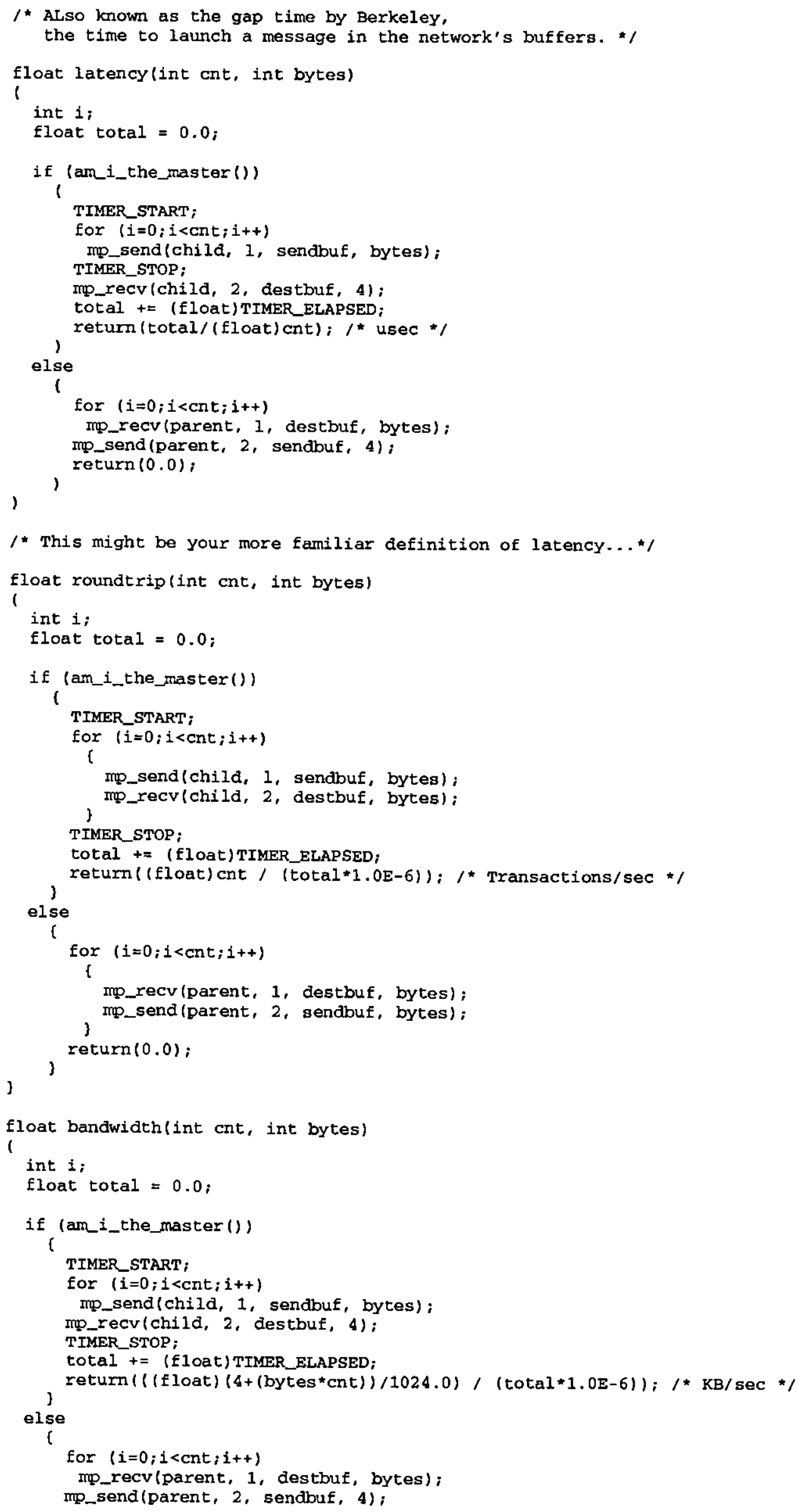




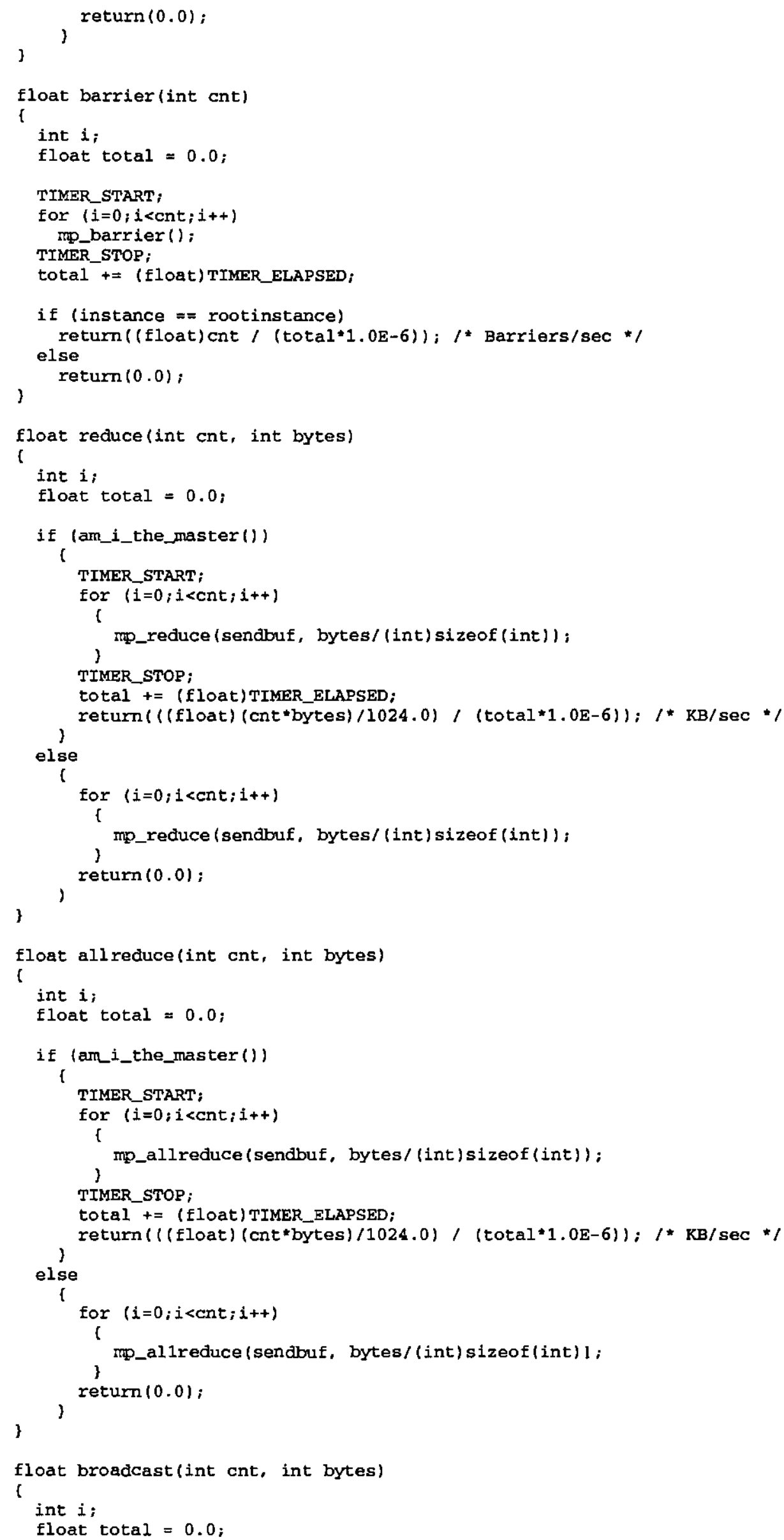




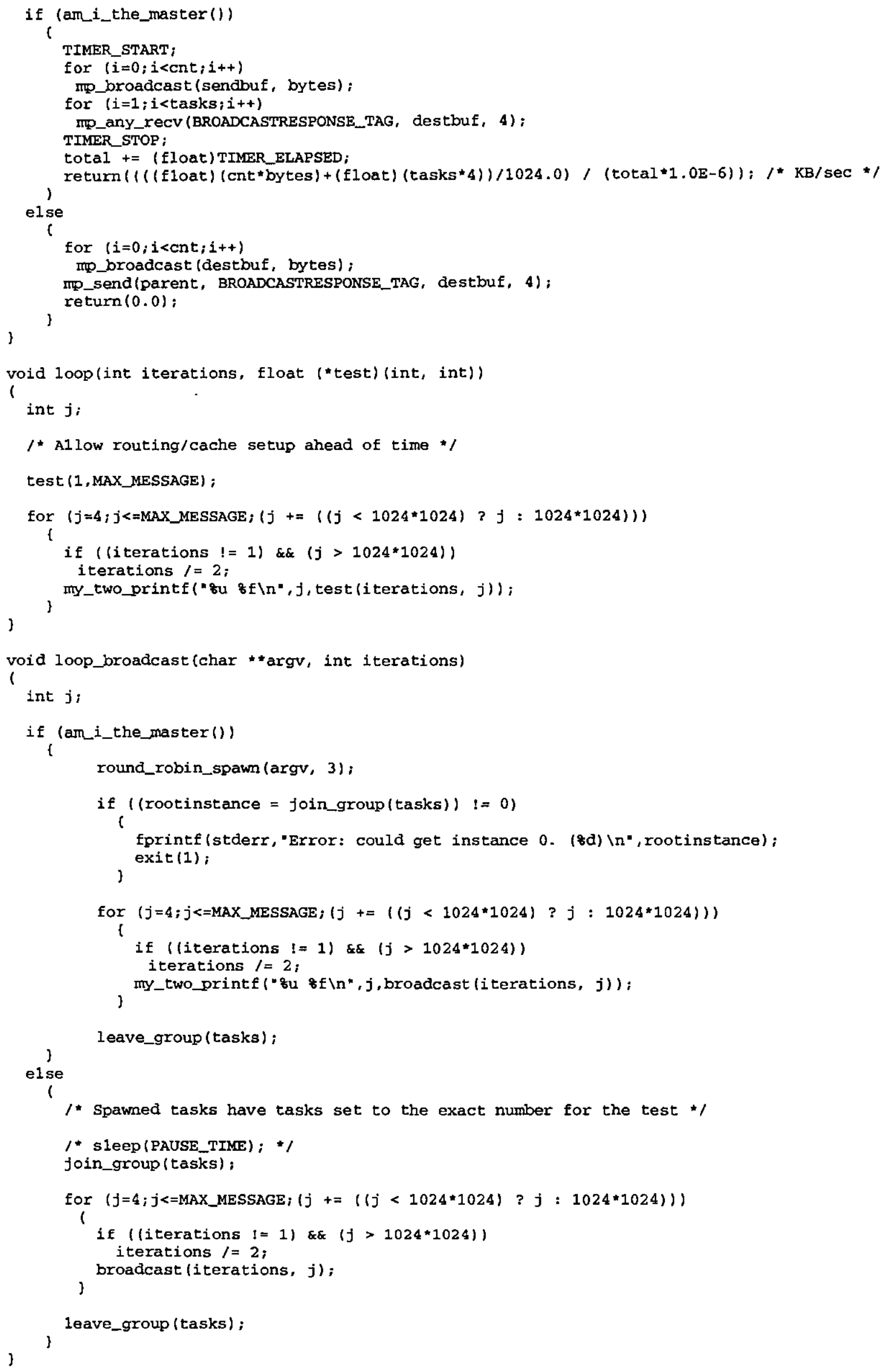




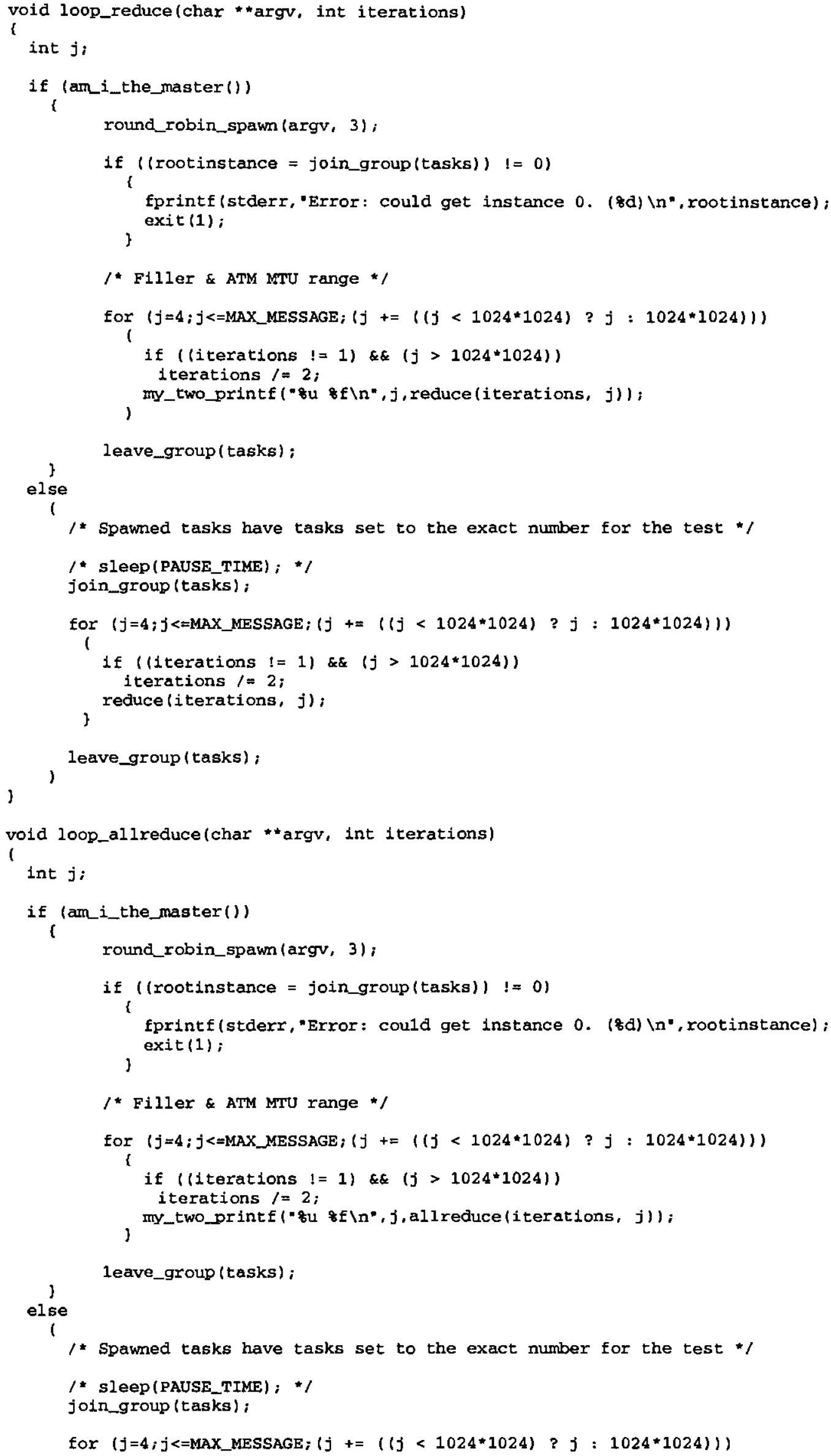




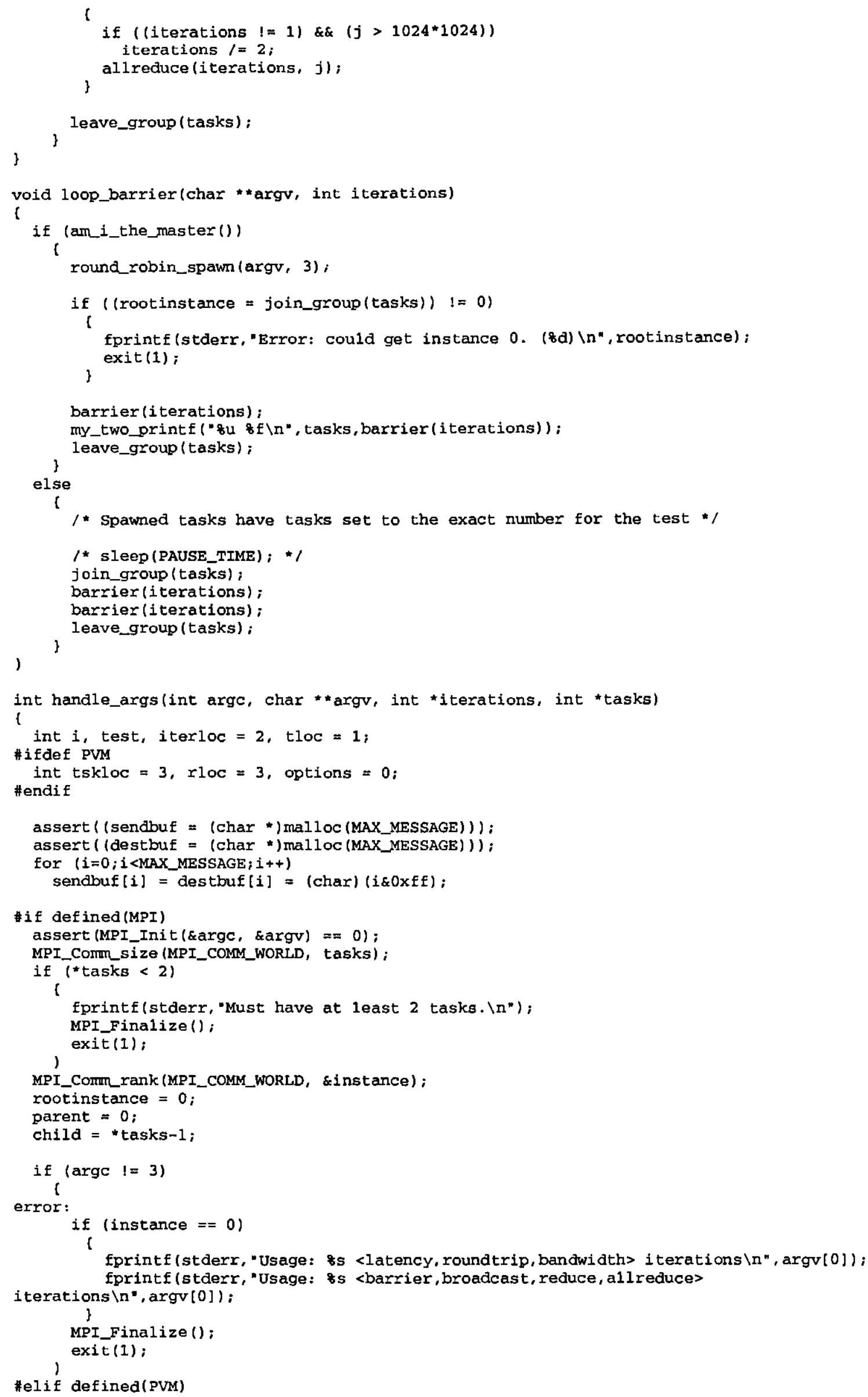




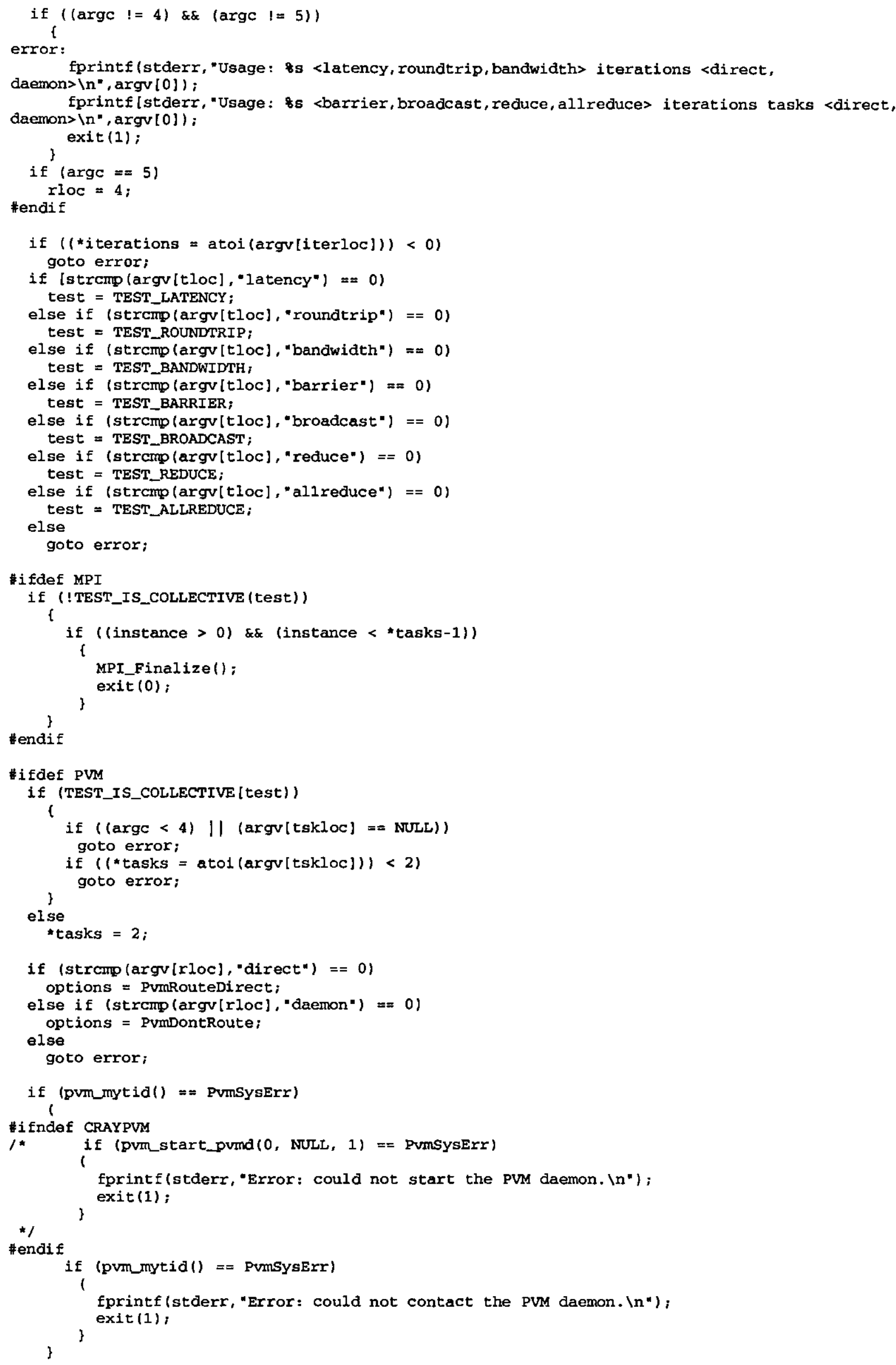




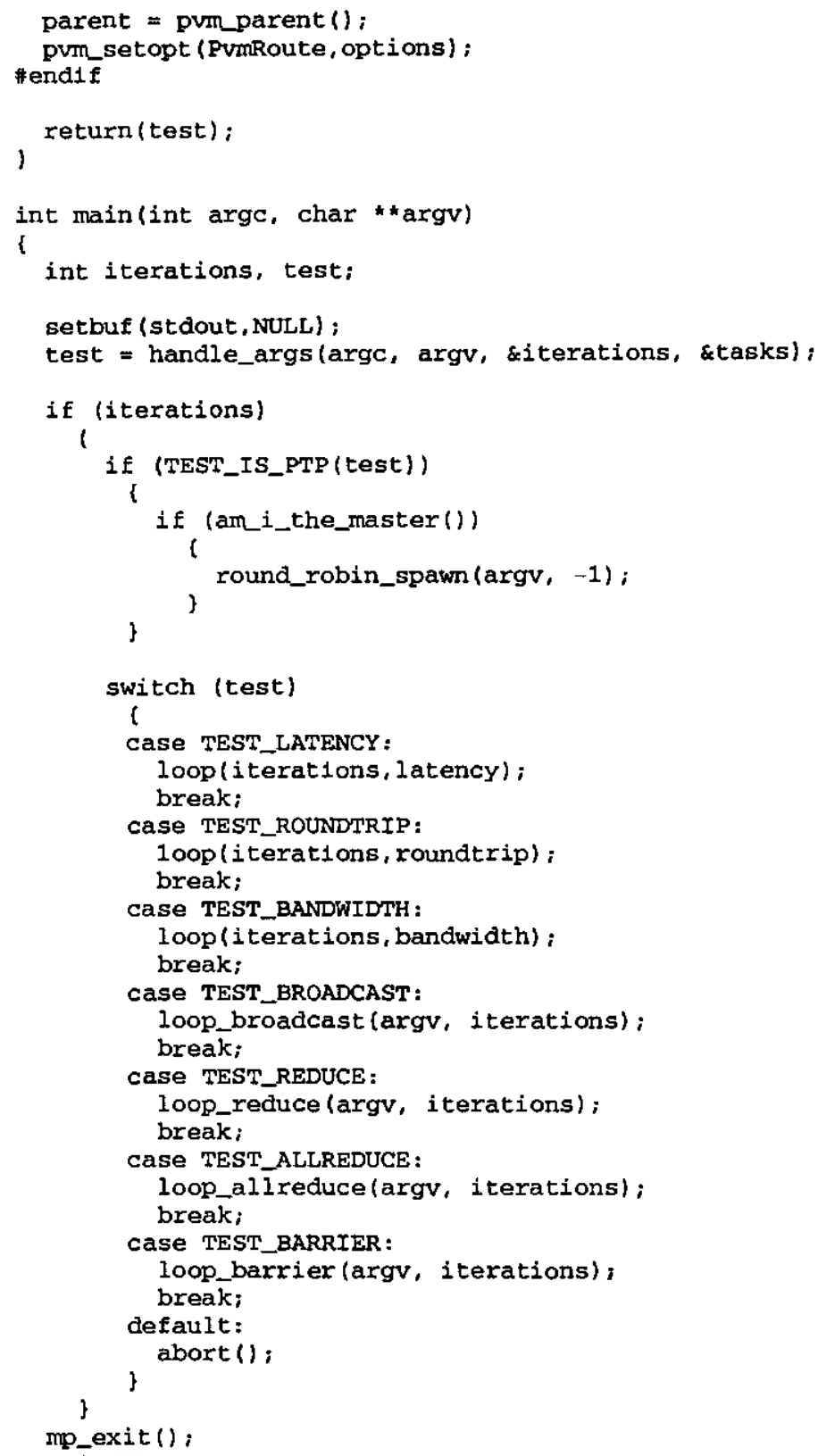




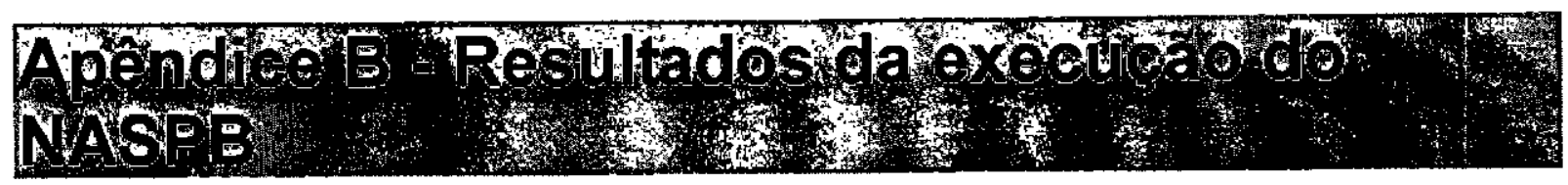

EP - SP2

Classe A com 2 processadores: ep.A.2.res

NAS Parallel Benchmarks 2.3 - EP Benchmark

Number of random numbers generated: 536870912 Number of active processes:

EP Benchmark Results:

CPU Time $=401.8481$

$N=2^{\wedge} 28$

No. Gaussian Pairs $=210832767$.

Sums $=\quad-4.295875165638583 \mathrm{D}+03 \quad-1.580732573678574 \mathrm{D}+04$

Counts :

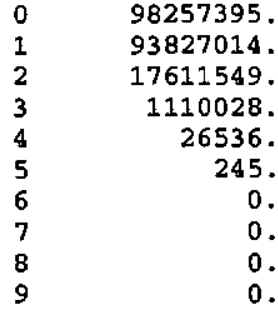

EP Benchmark Completed.

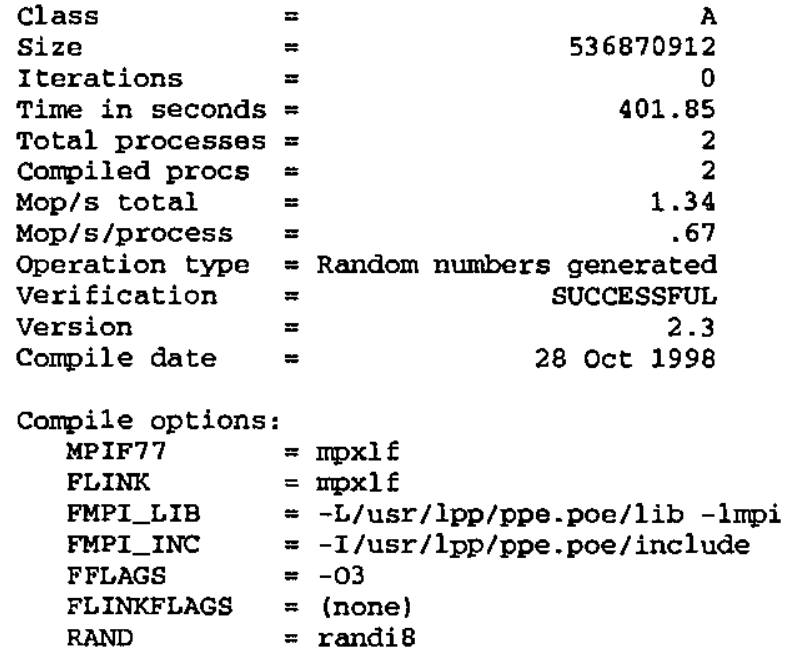

Please send the results of this run to:

NPB Development Team

Internet: npbenas.nasa.gov

If email is not available, send this to:

MS T27A-1

NASA Ames Research Center

Moffett Field, CA 94035-1000

Fax : 415-604-3957

Classe B com 2 processadorea: Qp.B.2.res

NAs Parallel Benchmarks 2.3 -- EP Benchmark

Number of random numbers generated: 2147483648

Number of active processes:

EP Benchmark Results:

CPU Time $=1609.3098$

$\mathrm{N}=2^{\wedge} \quad 30$ 


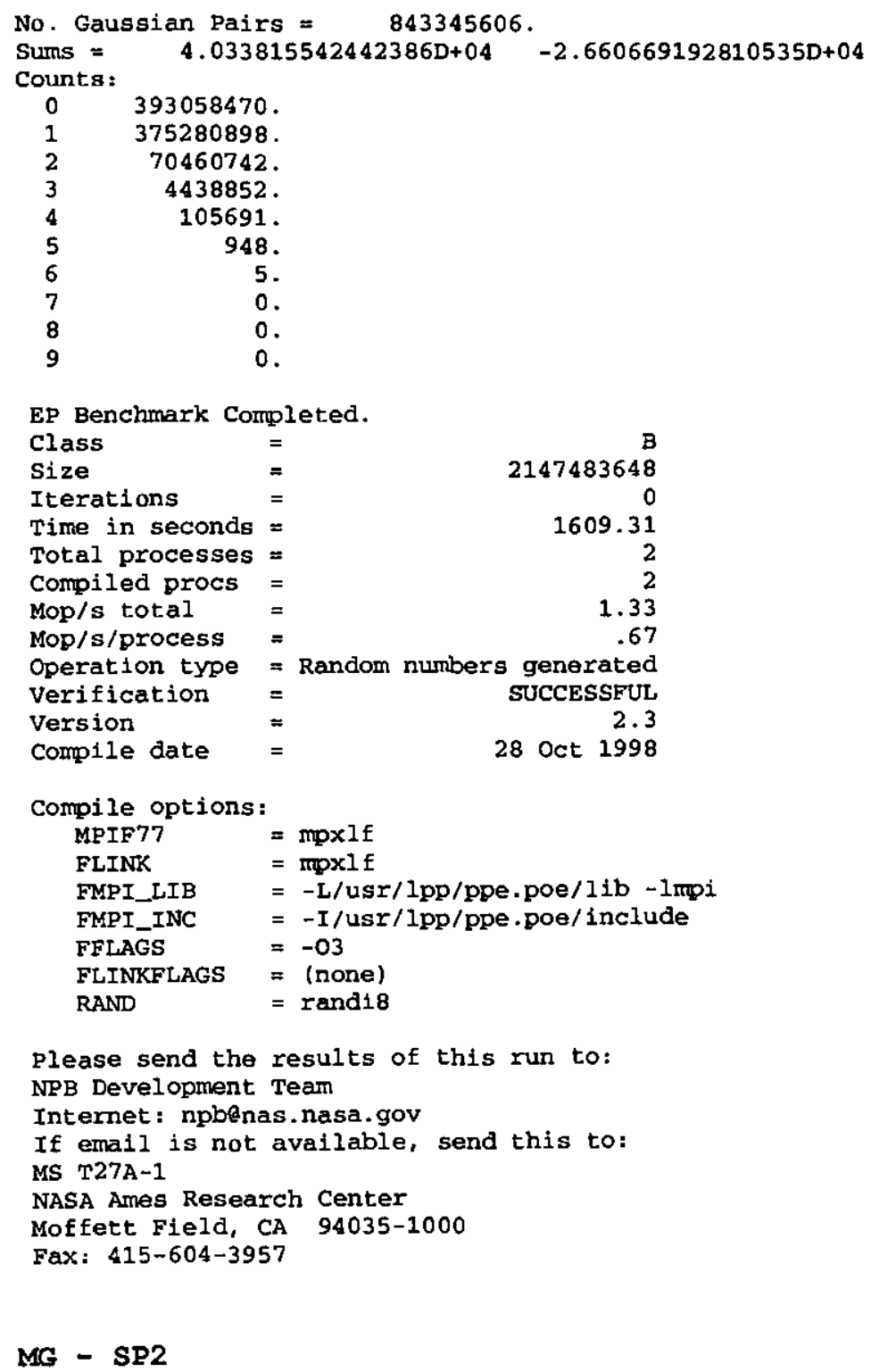

Please send the results of this run to: NPB Development Team

Internet: npbenas.nasa.gov

If email is not available, send this to:

MS T27A-1

NASA Ames Research Center

Moffett Field, CA 94035-1000

Fax: 415-604-3957

$M G$ - SP2

Classe $\mathrm{W}$ com 2 proceseadores: ing.W.2.xes

NAS Parallel Benchmarks 2.3 -- MG Benchmark

No input file. Using compiled defaults

Size: $64 \times 64 \times 64$ (class W)

Iterations: 40

Number of processes: 2

Initialization time: $\quad .652$ seconds

Benchmark completed

VERIFICATION SUCCESSFUL

L2 Norm is .234141719879E-17

Error is $\quad-.162496772513 E-18$

MG Benchmark Completed.

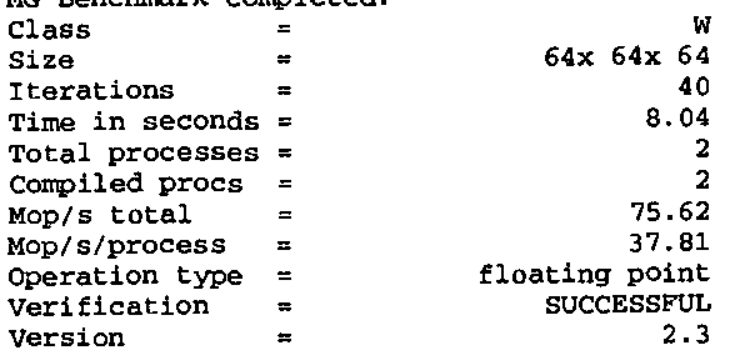




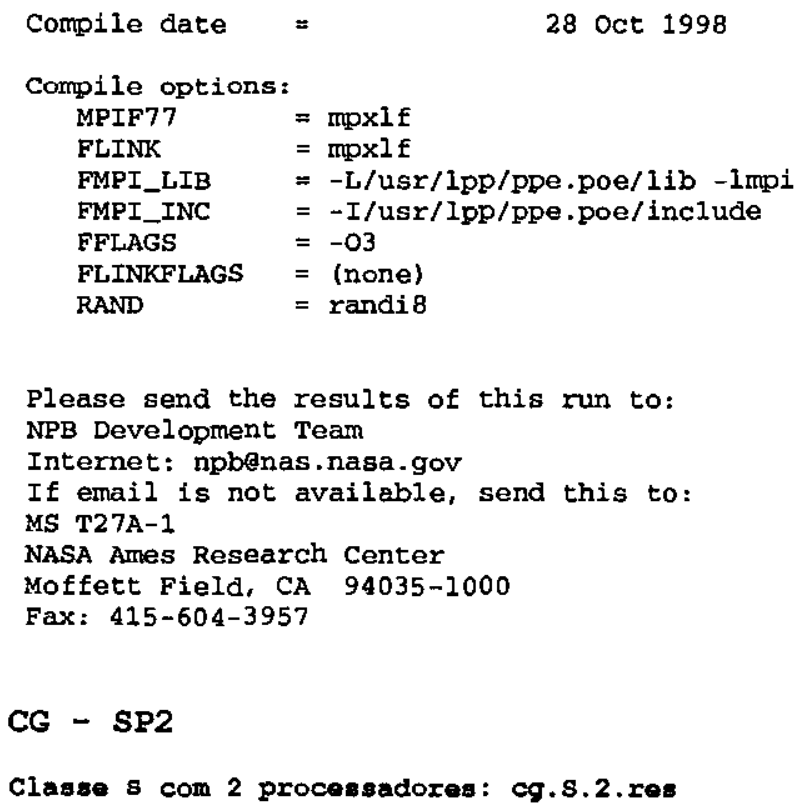

NAS Parallel Benchmarks 2.3 -- CG Benchmark

\begin{tabular}{|c|c|c|}
\hline \multicolumn{3}{|c|}{$\begin{array}{l}\text { Size: } \quad 1400 \\
\text { Iterations: } \quad 15 \\
\text { Number of active processes: }\end{array}$} \\
\hline $\begin{array}{c}\text { iteration } \\
1\end{array}$ & $\begin{array}{c}|| r|| \\
.13981247976171 \mathrm{E}-12\end{array}$ & $\begin{array}{c}\text { zeta } \\
9.998644157914 \mathrm{C}\end{array}$ \\
\hline 2 & $.22154746686549 \mathrm{E}-14$ & 8.5733279203222 \\
\hline 3 & $.21278427318763 \mathrm{E}-14$ & 8.5954510374058 \\
\hline 4 & $.21926572809500 \mathrm{E}-14$ & 8.5969972340737 \\
\hline 5 & $.22269282400252 \mathrm{E}-14$ & 8.5971549151767 \\
\hline 6 & $.21779845942197 \mathrm{E}-14$ & 8.5971744311608 \\
\hline 7 & $.20829800856823 \mathrm{E}-14$ & 8.5971770704913 \\
\hline 8 & $.22134073704918 \mathrm{E}-14$ & 8.5971774440630 \\
\hline 9 & $.21788057584891 \mathrm{E}-14$ & 8.5971774983942 \\
\hline 10 & $.21477138168328 \mathrm{E}-14$ & 8.5971775064409 \\
\hline 11 & $.21068135155352 E-14$ & 8.597177507648 \\
\hline 12 & $.19911008787811 E-14$ & 8.5971775078318 \\
\hline 13 & $.20591198772405 E-14$ & 8.5971775078598 \\
\hline 14 & $.20884490438356 \mathrm{E}-14$ & 8.5971775078641 \\
\hline 15 & $.20185513428001 E-14$ & 8.5971775078648 \\
\hline
\end{tabular}

Benchmark completed

VERIFICATION SUCCESSFUL

Zeta is $\quad .859717750786 \mathrm{E}+01$

Error is $\quad .888178419700 \mathrm{E}-14$

CG Benchmark Completed.

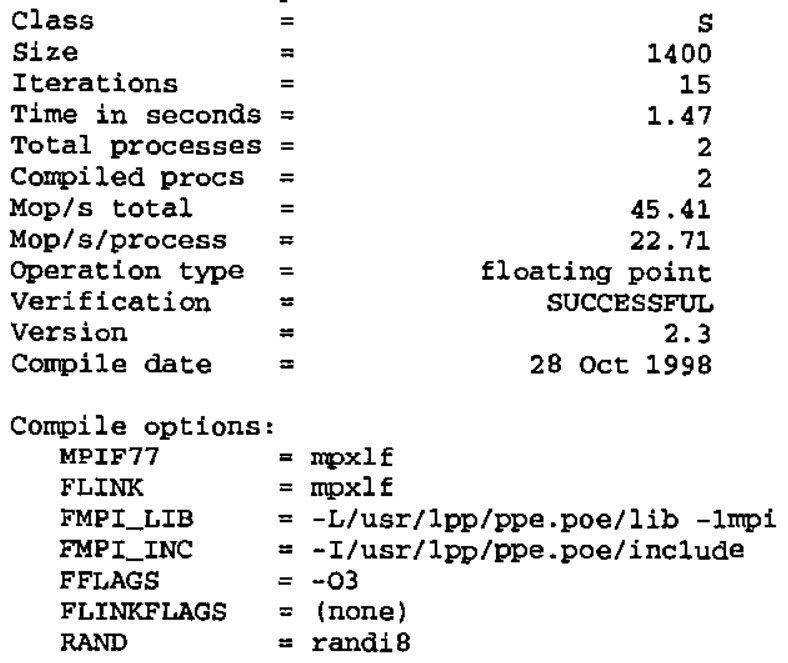


Please send the results of this run to: NPB Development Team

Intexnet: npbanas.nasa.gov

If email is not available, send this to:

MS T27A-1

NASA Ames Research Center

Moffett Field, CA 94035-1000

Fax: 415-604-3957

Classe W com 2 processadores: cg.w.2.res

NAS Parallel Benchmarks 2.3 -- CG Benchmark

Size: 7000

Iterations : $\quad 15$

Number of active processes: 2

$\begin{array}{cc}\text { iteration } & || \mathrm{r}|| \\ 1 & .18309893580046 \mathrm{E}-12 \\ 2 & .25556791532055 \mathrm{E}-14 \\ 3 & .24926716390329 \mathrm{E}-14 \\ 4 & .25372087489823 \mathrm{E}-14 \\ 5 & .25497579404507 \mathrm{E}-14 \\ 6 & .24811843266737 \mathrm{E}-14 \\ 7 & .24520120756529 \mathrm{E}-14 \\ 8 & .24517762283222 \mathrm{E}-14 \\ 9 & .24122548490998 \mathrm{E}-14 \\ 10 & .24326230414547 \mathrm{E}-14 \\ 11 & .24050771064707 \mathrm{E}-14 \\ 12 & .24581380083339 \mathrm{E}-14 \\ 13 & .24139134299931 \mathrm{E}-14 \\ 14 & .23387380507917 \mathrm{E}-14 \\ 15 & .23388641746210 \mathrm{E}-14\end{array}$

zeta

11.9997003727381

10.3457275664058

10.3617880137963

10.3625416284965

10.3625905854467

10.3625946467087

10.3625950398342

10.3625950817269

10.3625950864815

10.3625950870452

10.3625950871141

10.3625950871227

10.3625950871238

10.3625950871240

10.3625950871240

Benchmark completed

VERIFICATION SUCCESSFUL

zeta is $\quad .103625950871 \mathrm{E}+02$

Error is $\quad .000000000000 \mathrm{E}+00$

CG Benchmark Completed.

$\begin{array}{lrr}\text { Class } & & \mathrm{W} \\ \text { Size } & = & 7000 \\ \text { Iterations } & & 15 \\ \text { Time in seconds } & = & 7.61 \\ \text { Total processes } & = & 2 \\ \text { Compiled procs } & = & 2 \\ \text { Mop/s total } & = & 55.30 \\ \text { Mop/s/process } & = & 27.65 \\ \text { Operation type } & = & \text { SUCCESSFU } \\ \text { Verification } & = & 2.3 \\ \text { Version } & \text { floating point } \\ \text { Compile date } & = & 28 \text { oct } 1998\end{array}$

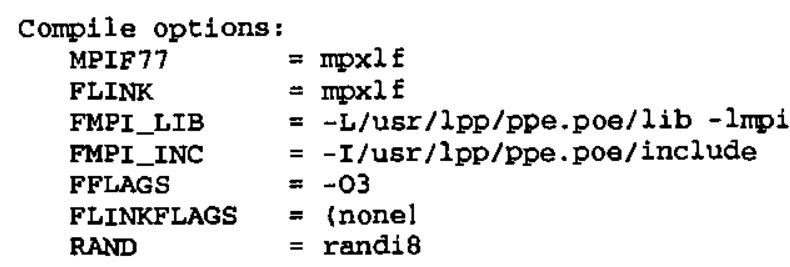

Please send the results of this run to:

NPB Development Team

Internet: npbenas.nasa.gov

If email is not available, send this to:

MS T27A-1

NASA Ames Research Center

Moffett Field, CA 94035-1000

Fax: 415-604-3957 
FT - SP2

Classe $w$ con 2 processadores: tt.w.2.res

NAS Parallel Benchmarks 2.3 -- FT Benchmark

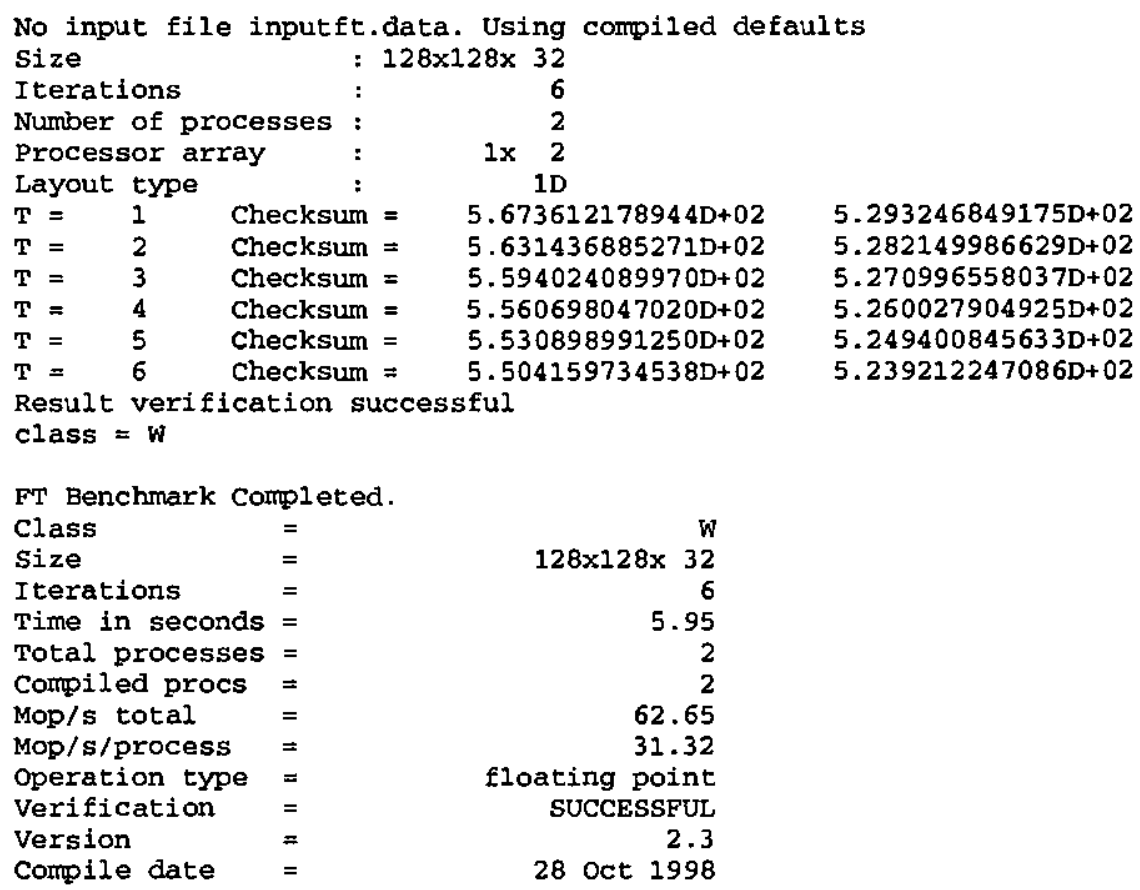

Compile options:

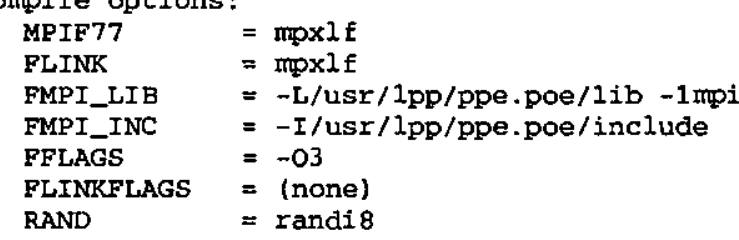

please send the results of this run to:

NPB Development Team

Internet: npbenas.nasa.gov

If email is not available, send this to

MS T27A-1

NASA Ames Research Center

Moffett Field, CA 94035-1000

Fax: 415-604-3957

IS - SP2

Classe $\mathrm{W}$ com 2 processadores: is.w.2.res

NAS Parallel Benchmarks 2.3 -- IS Benchmark Size: 1048576 (class $W$ )

Iterations: 10

Number of processes: iteration

$$
\begin{aligned}
& 1 \\
& 2 \\
& 3 \\
& 4 \\
& 5 \\
& 6 \\
& 7 \\
& 8 \\
& 9 \\
& 10
\end{aligned}
$$

Is Benchmark Completed

Class 


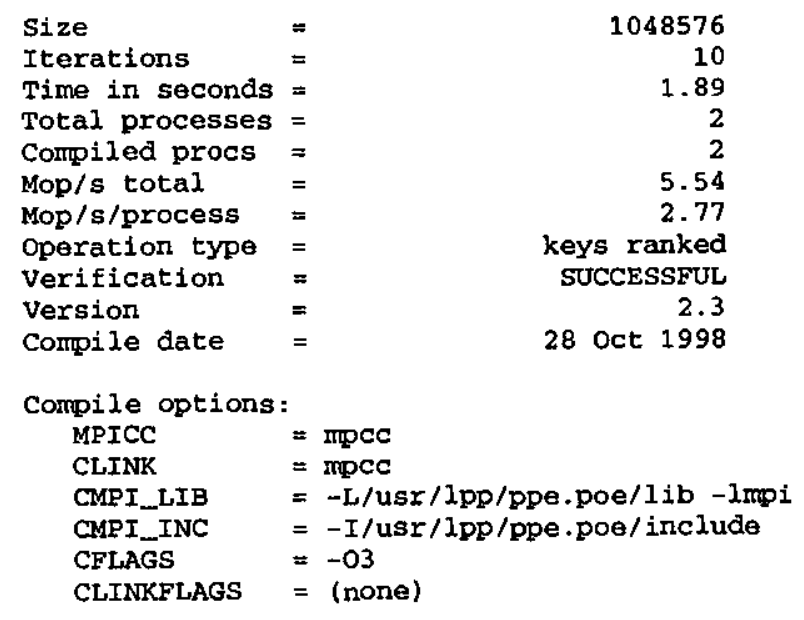

Please send the results of this run to: NPB Development Team

Internet: npbßnas.nasa.gov

If email is not available, send this to: MS T27A-1

NASA Ames Research Center

Moffett Field, CA 94035-1000

Fax: 415-604-3957

Classe A con 2 processadores: is.A.2.res

NAS Parallel Benchmarks 2.3 -- IS Benchmark Size: 8388608 (class A)

Iterations: 10

Number of processes: 2

iteration

1
2
3
4
5
6
7
8
9
10

IS Benchmark Completed

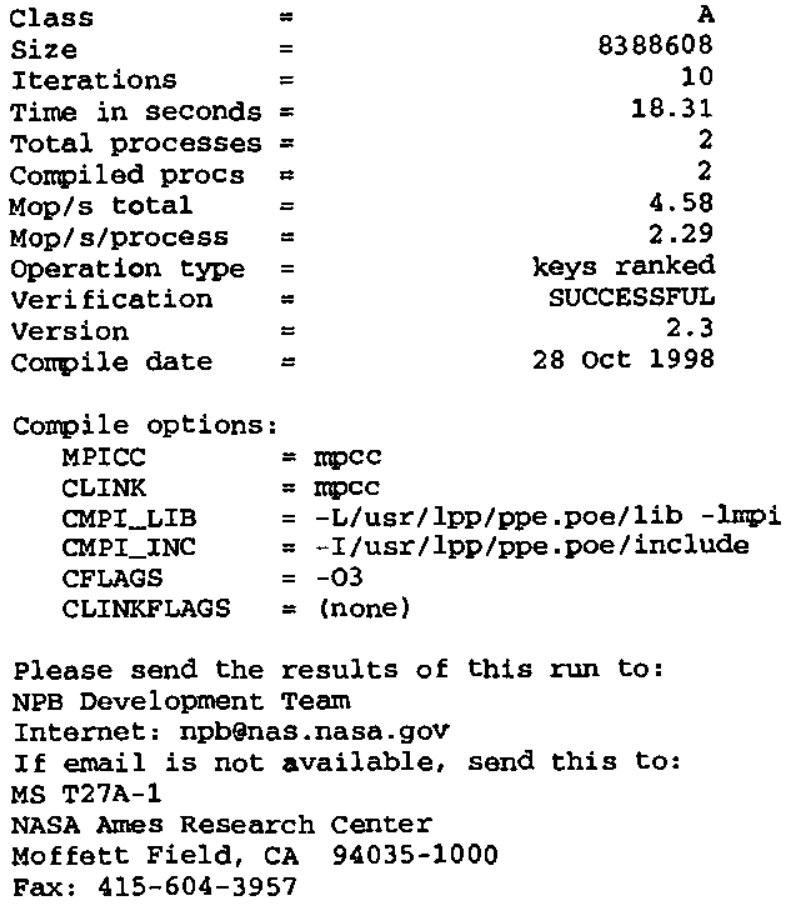

Please send the results of this run to: NPB Development Team

Internet: npbenas.nasa.gov

If email is not available, send this to:

MS T27A-1

NASA Ames Research Center

Moffett Field, CA 94035-1000

Fax: 415-604-3957 
LU - SP2

classe $s$ com 2 processadores: Iu.S.2.rea

NAS Parallel Benchmarks 2.2 -- LU Benchmark Size: $12 \times 12 \times 12$

Iterations: 50

Number of processes: 2

$\begin{array}{lr}\text { Time step } & 1 \\ \text { Time step } & 20 \\ \text { Time step } & 40 \\ \text { Time step } & 50\end{array}$

Verification being performed for class $S$

Accuracy setting for epsilon $=.1000000000000 \mathrm{E}-07$ Comparison of RMS-norms of residual

$\begin{array}{llll}1 & .1619634321098 \mathrm{E}-01 & .1619634321098 \mathrm{E}-01 & .8568469824972 \mathrm{E}-13 \\ 2 & .2197674516484 \mathrm{E}-02 & .2197674516482 \mathrm{E}-02 & .6362121010874 \mathrm{E}-12 \\ 3 & .1517992765339 \mathrm{E}-02 & .1517992765340 \mathrm{E}-02 & .4298260718362 \mathrm{E}-12 \\ 4 & .1502958443600 \mathrm{E}-02 & .1502958443599 \mathrm{E}-02 & .1866928014106 \mathrm{E}-12 \\ 5 & .3426407315590 \mathrm{E}-01 & .3426407315590 \mathrm{E}-01 & .3078185913844 \mathrm{E}-13\end{array}$

Comparison of RMS-norms of solution error

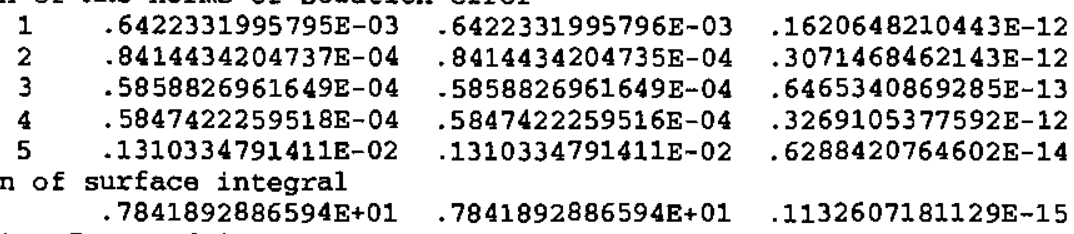

Comparison of surface integral

Verification Successful

LU Benchmark Completed.

$\begin{array}{lrr}\text { Class } & = & \mathrm{S} \\ \text { Size } & = & 12 \times 12 \times 12 \\ \text { Iterations } & =50 \\ \text { Time in seconds } & = & 1.00 \\ \text { Total processes } & & 2 \\ \text { Compiled procs } & = & 2 \\ \text { Mop/s total } & = & 102.47 \\ \text { Mop/s/process } & = & 51.24 \\ \text { Operation type } & = & \text { floating point } \\ \text { Verification } & = & \text { SUCCESSFU } \\ \text { Version } & 28 \text { Oct } 1998 \\ \text { Compile date } & = & 2.3\end{array}$

Compile options:

$\begin{array}{ll}\text { MPIF77 } & =\operatorname{mpxlf} \\ \text { FLINK } & =\operatorname{mpxlf} \\ \text { FMPI_LIB } & =-\mathrm{L} / \mathrm{us} / 1 \mathrm{pp} / \mathrm{ppe} \cdot \mathrm{poe} / 1 \mathrm{ib}-1 \mathrm{mpi} \\ \text { FMPI_INC } & =- \text { I/Usr/1pp/ppe.poe/include } \\ \text { FFLAGS } & =-03 \\ \text { FLINKFLAGS } & =\text { (none) } \\ \text { RAND } & =\text { (none) }\end{array}$

Please send the results of this run to: NPB Development Team

Internet: npbonas.nasa.gov

If email is not available, send this to:

MS T27A-1

NASA Ames Research Center

Moffett Field, CA 94035-1000

Fax: 415-604-3957

classe W com 2 procesandoreล: lu.พ.2.รes

NAS Parallel Benchmarks 2.2 -- LU Benchmark

Size: $33 \times 33 \times 33$

Iterations: 300

Number of processes: 2

Time step 1

Time step 20

Time step 40

Time step 60 


$\begin{array}{lr}\text { Time step } & 80 \\ \text { Time step } & 100 \\ \text { Time step } & 120 \\ \text { Time step } & 140 \\ \text { Time step } & 160 \\ \text { Time step } & 180 \\ \text { Time step } & 200 \\ \text { Time step } & 220 \\ \text { Time step } & 240 \\ \text { Time step } & 260 \\ \text { Time step } & 280 \\ \text { Time step } & 300\end{array}$

Verification being performed for class $W$ Accuracy setting for epsilon $=.1000000000000 \mathrm{E}-07$ Comparison of RMS-norms of residual

\begin{tabular}{lllll}
\multicolumn{5}{c}{ of RMS-norms of residual } \\
1 & $.1236511638192 \mathrm{E}+02$ & $.1236511638192 \mathrm{E}+02$ & $.1472501919228 \mathrm{E}-12$ \\
2 & $.1317228477799 \mathrm{E}+01$ & $.1317228477799 \mathrm{E}+01$ & $.3762472240357 \mathrm{E}-12$ \\
3 & $.2550120713095 \mathrm{E}+01$ & $.2550120713095 \mathrm{E}+01$ & $.9125165909460 \mathrm{E}-13$ \\
4 & $.2326187750252 \mathrm{E}+01$ & $.2326187750252 \mathrm{E}+01$ & $.1870904124596 \mathrm{E}-12$ \\
5 & $.2826799444189 \mathrm{E}+02$ & $.2826799444189 \mathrm{E}+02$ & $.1510670256674 \mathrm{E}-12$
\end{tabular}

Comparison of RMS-norms of solution error

.1510670256674E-12

$\begin{array}{rllll}1 & .4867877144216 \mathrm{E}+00 & .4867877144216 \mathrm{E}+00 & .5017568401613 \mathrm{E}-13 \\ 2 & .5064652880982 \mathrm{E}-01 & .5064652880982 \mathrm{E}-01 & .9193123238525 \mathrm{E}-13 \\ 3 & .9281818101960 \mathrm{E}-01 & .9281818101960 \mathrm{E}-01 & .1554964680581 \mathrm{E}-13 \\ 4 & .8570126542733 \mathrm{E}-01 & .8570126542733 \mathrm{E}-01 & .5991488530873 \mathrm{E}-14 \\ 5 & .1084277417792 \mathrm{E}+01 & .1084277417792 \mathrm{E}+01 & .2570061633750 \mathrm{E}-12 \\ \text { Comparison of } & \text { surface integral } \\ \text {.1161399311023E+02 } & .1161399311023 \mathrm{E}+02 & .3089584074600 \mathrm{E}-13 \\ \text { Verification successful } & & & \end{array}$

LU Benchmark Completed.

$\begin{array}{llr}\text { Class } & = & \mathrm{W} \\ \text { Size } & = & 33 \times \\ \text { Iterations } & = & 33 \times 33 \\ \text { Time in seconds } & & 300 \\ \text { Total processes } & = & 173.39 \\ \text { Compiled procs } & = & 2 \\ \text { Mop/s total } & = & 2 \\ \text { Mop/s/process } & = & 104.16 \\ \text { Operation type } & = & 52.08 \\ \text { Verification } & = & \text { Eloating point } \\ \text { Version } & = & \text { successfuL } \\ \text { Compile date } & = & 28 \text { oct } 1998\end{array}$

Compile options:

$\begin{array}{ll}\text { MPIF77 } & =\operatorname{mpxlf} \\ \text { FLINK } & =\operatorname{mpxlf} \\ \text { FMPI_LIB } & =-\mathrm{L} / \mathrm{usr} / 1 \mathrm{pp} / \mathrm{ppe} \cdot \mathrm{poe} / 1 \mathrm{ib}-1 \mathrm{~m} \text { i } \\ \text { FMPI_INC } & =-I / \text { usr } / 1 \mathrm{pp} / \text { ppe } . \text { poe/include } \\ \text { FFLAGS } & =-03 \\ \text { FLINKFLAGS } & =\text { (none) } \\ \text { RAND } & =\text { (none) }\end{array}$

Please send the results of this run to: NPB Development Team

Internet: npbenas.nasa.gov

If email is not available, send this to:

MS T27A-1

NASA Ames Research Center

Moffett Field, CA 94035-1000

Fax: 415-604-3957

Clasee B com 2 proceseadores: lu.B.2.rea

NAS Parallel Benchmarks 2.2 -- LU Benchmark

Size: $102 \times 102 \times 102$

Iterations: 250

Number of processes:

2

$\begin{array}{lr}\text { Time step } & 1 \\ \text { Time step } & 20 \\ \text { Time step } & 40 \\ \text { Time step } & 60 \\ \text { Time step } & 80 \\ \text { Time step } & 100\end{array}$ 


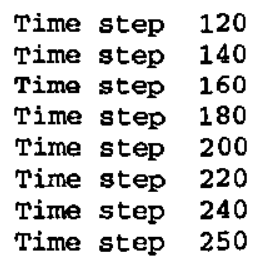

Verification being performed for class $B$

Accuracy setting for epsilon $=.1000000000000 \mathrm{E}-07$ Comparison of RMS-norms of residual

$\begin{array}{ccccc}1 & .3553267296998 \mathrm{E}+04 & .3553267296998 \mathrm{E}+04 & .1663740739831 \mathrm{E}-14 \\ 2 & .2621475079531 \mathrm{E}+03 & .2621475079531 \mathrm{E}+03 & .4119913123677 \mathrm{E}-14 \\ 3 & .8833372185095 \mathrm{E}+03 & .8833372185095 \mathrm{E}+03 & .3346239373622 \mathrm{E}-14 \\ 4 & .7781277473942 \mathrm{E}+03 & .7781277473943 \mathrm{E}+03 & .7159049483859 \mathrm{E}-14 \\ 5 & .7308796959255 \mathrm{E}+04 & .7308796959255 \mathrm{E}+04 & .3359835700016 \mathrm{E}-14 \\ \text { Comparison of } & \text { RMS-norms of solution } & \text { error } & \\ 1 & .1140117638021 \mathrm{E}+03 & .1140117638021 \mathrm{E}+03 & .6481475424527 \mathrm{E}-14 \\ 2 & .8109896365542 \mathrm{E}+01 & .8109896365542 \mathrm{E}+01 & .2190357014854 \mathrm{E}-15 \\ 3 & .2848059731770 \mathrm{E}+02 & .2848059731770 \mathrm{E}+02 & .4864920209631 \mathrm{E}-14 \\ 4 & .2590539456783 \mathrm{E}+02 & .2590539456783 \mathrm{E}+02 & .1919985869081 \mathrm{E}-14 \\ 5 & .2605490750486 \mathrm{E}+03 & .2605490750486 \mathrm{E}+03 & .1221739687854 \mathrm{E}-13 \\ \text { Comparison of surface integral } & & & \\ & .4788716270331 \mathrm{E}+02 & .4788716270331 \mathrm{E}+02 & .8902712488886 \mathrm{E}-15\end{array}$

Verification Successful

Comparison of RMS-norms of solution exror

LU Benchmark Completed.

$\begin{array}{lrr}\text { Class } & = & \mathrm{B} \\ \text { Size } & = & 102 \times 102 \times 102 \\ \text { Iterations } & 250 \\ \text { Time in seconds } & = & 4682.94 \\ \text { Total processes } & = & 2 \\ \text { Compiled procs } & = & 2 \\ \text { Mop/s total } & = & 106.52 \\ \text { Mop/s/process } & = & 53.26 \\ \text { Operation type } & = & \text { floating point } \\ \text { Verification } & = & \text { SUCCESFUL } \\ \text { Version } & = & 2.3 \\ \text { Compile date } & = & 28 \text { oct } 1998\end{array}$

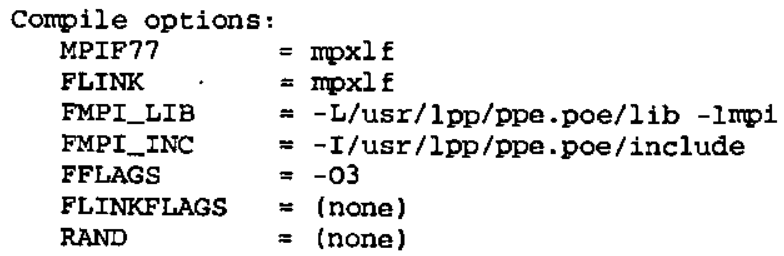

Please send the results of this run to: NPB Development Team

Internet: npbenas.nasa.gov

If email is not available, send this to: MS T27A-1

NASA Ames Research Center

Moffett Field, CA 94035-1000

Fax: $415-604-3957$

SP

- SP2

Classe พ com 1 processador: sp.พ.I.xes

NAS Parallel Benchmarks 2.3 -- SP Benchmark

No input file inputsp.data. Using complled defaults size: $36 \times 36 \times 36$

Iterations: $400 \mathrm{dt}: \quad .001500$

Number of active processes: 1

Time step 1

Time step 20

Time step 40

Time step 60 


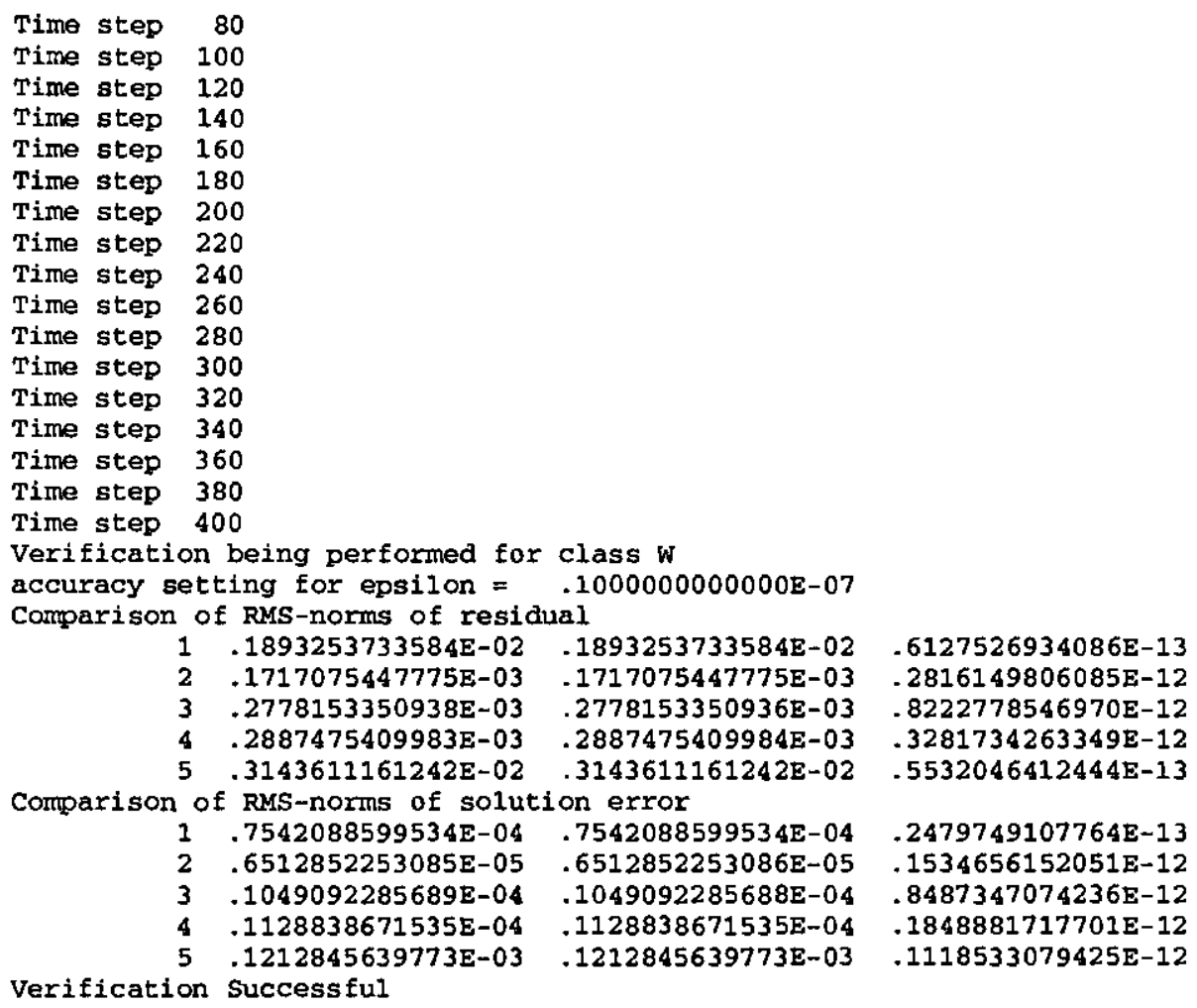

SP Benchmark Completed.

$\begin{array}{lrr}\text { Class } & = & \mathrm{W} \\ \text { Size } & = & 36 \times 36 \times 36 \\ \text { Iterations } & 400 \\ \text { Time in seconds } & = & 333.01 \\ \text { Total processes } & = & 1 \\ \text { Compiled procs } & = & 1 \\ \text { Mop/s total } & = & 42.56 \\ \text { Mop/s/process } & = & 42.56 \\ \text { Operation type } & = & \text { floating point } \\ \text { Verification } & = & \text { SUCCESSFUL } \\ \text { Version } & & 2.3 \\ \text { Compile date } & = & 07 \text { Mar } 1999\end{array}$

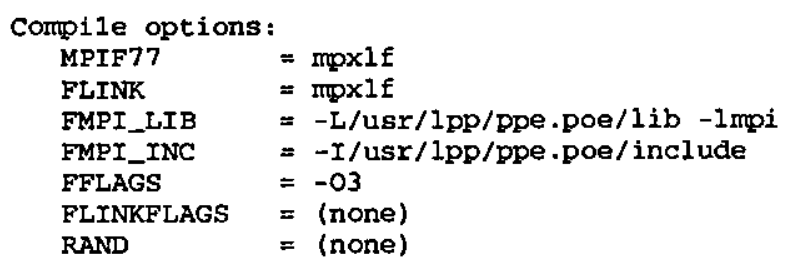

Please send the results of this run to: NPB Development Team

Internet: npbenas.nasa.gov

If email is not available, send this to:

MS T27A-1

NASA Ames Research Center

Moffett Field, CA 94035-1000

Fax: 415-604-3957

Classe $\mathbf{x} \operatorname{con} 1$ proceseador: p.M.1.rea

NAS Parallel Benchmarks 2.3 -- SP Benchmark

No input file inputsp.data. Using compiled defaults Size: $64 \times 64 \times 64$

Iterations: 400 dt: .001500

Number of active processes: 1

$\begin{array}{lr}\text { Time step } & 1 \\ \text { Time step } & 20 \\ \text { Time step } & 40\end{array}$ 


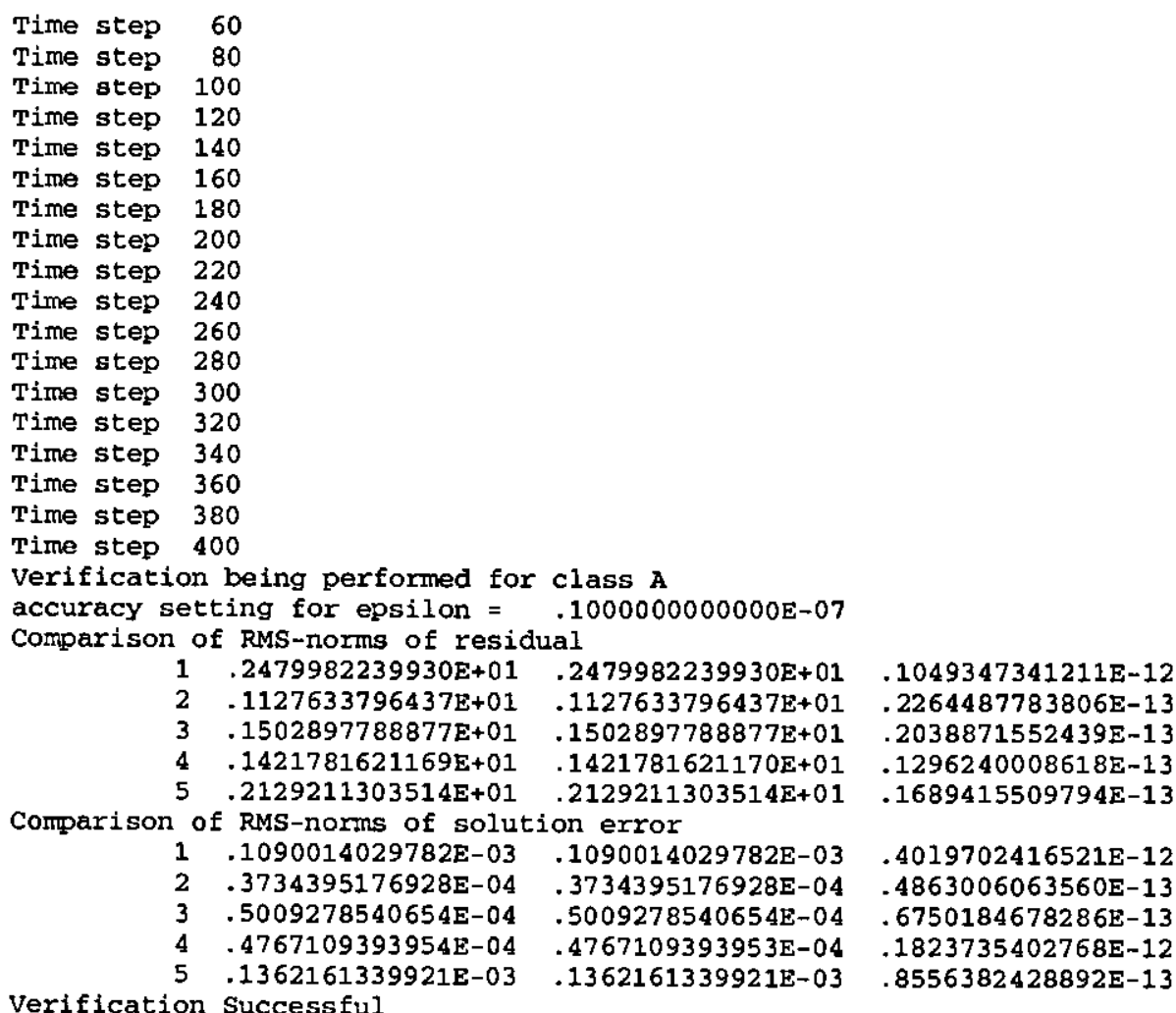

\begin{tabular}{|c|c|c|}
\hline $\begin{array}{l}\text { SP Benchmark Cor } \\
\text { Class }\end{array}$ & $\begin{array}{l}\text { mleted. } \\
=\end{array}$ & \\
\hline Size & $=$ & $64 \times 64 \times 64$ \\
\hline Iterations & $=$ & 400 \\
\hline Time in seconds & $=$ & 2330.04 \\
\hline Total processes & $=$ & \\
\hline Compiled procs & $=$ & 1 \\
\hline Mop/s total & $=$ & 36.48 \\
\hline Mop/s/process & $=$ & 36.48 \\
\hline Operation type & $=$ & floating point \\
\hline Verification & $=$ & SUCCESSFUL \\
\hline Version & $=$ & 2.3 \\
\hline Conqile date & $=$ & 07 Mar 1999 \\
\hline
\end{tabular}

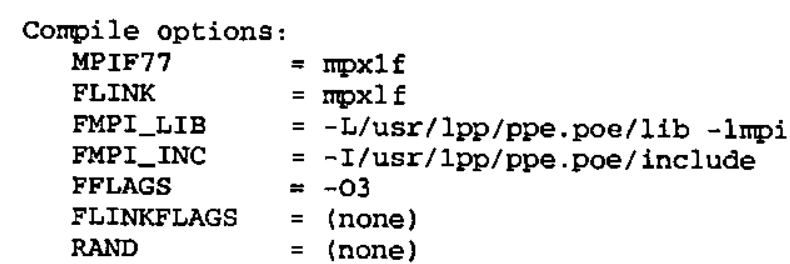

Please send the results of this run to: NPB Development Team

Internet: npb\&nas.nasa.gov

If email is not available, send this to: MS T27A-1

NASA Ames Research Center

Moffett Field, CA 94035-1000

Fax: 415-604-3957

BT - SP2

Classe $\mathrm{W}$ com 1 processador: bt.W.1.Ies

NAS Parallel Benchmarks 2.3 -- BT Benchmark

No input file inputbt.data. Using compiled defaults Size: $24 \times 24 \times 24$

Iterations: $200 \mathrm{dt}: \quad .000800$

Number of active processes: 1 


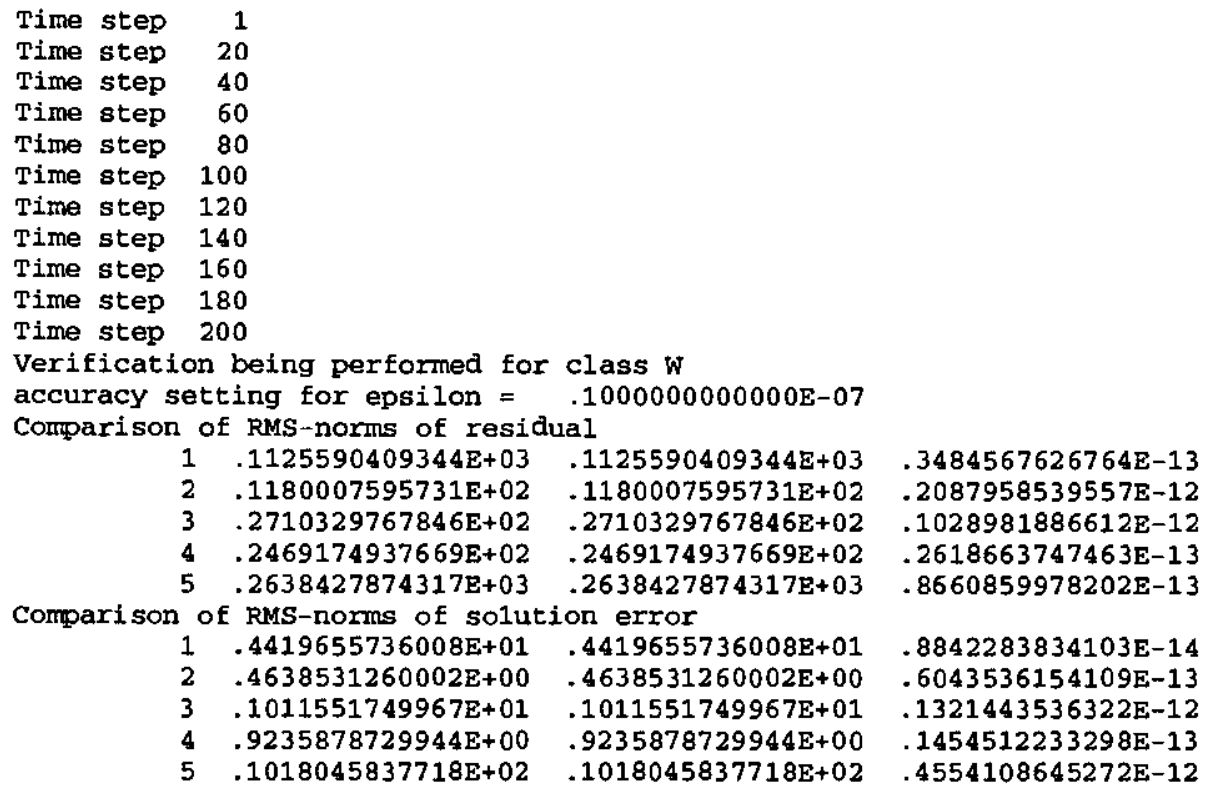

Verification Success ful

BT Benchmark Completed.

$\begin{array}{llr}\text { Class } & = & \mathrm{W} \\ \text { Size } & = & 24 \times 24 \times 24 \\ \text { Iterations } & 200 \\ \text { Time in seconds } & = & 140.11 \\ \text { Total processes } & = & 1 \\ \text { Compiled procs } & = & 1 \\ \text { Mop } / \text { total } & = & 55.09 \\ \text { Mop } / \text { s } / \text { process } & = & 55.09 \\ \text { Operation type } & = & \text { floating point } \\ \text { Verification } & = & \text { SUCCESSFUL } \\ \text { Version } & & 2.3 \\ \text { Compile date } & = & 08 \text { Mar } 1999\end{array}$

Compile options:

$\begin{array}{ll}\text { MPIF77 } & =\operatorname{mpxlf} \\ \text { FLINK } & =m p x 1 \mathrm{f} \\ \text { FMPI_LIB } & =-\mathrm{L} / \mathrm{us} / 1 \mathrm{pp} / \mathrm{ppe} . \mathrm{poe} / 1 \mathrm{ib}-1 \mathrm{mpi} \\ \text { FMPI_INC } & =-\mathrm{I} / \mathrm{us} / \mathrm{pp} / \mathrm{ppe} . \mathrm{poe} / \mathrm{include} \\ \text { FFLAGS } & =-03 \\ \text { FLINKFLAGS } & =\text { (none) } \\ \text { RAND } & =\text { (none) }\end{array}$

Please send the results of this run to:

NPB Development Team

Internet: npbenas.nasa.gov

If email is not available, send this to:

MS T27A-1

NASA Ames Research Center

Moffett Field, CA 94035-1000

Fax: 415-604-3957 


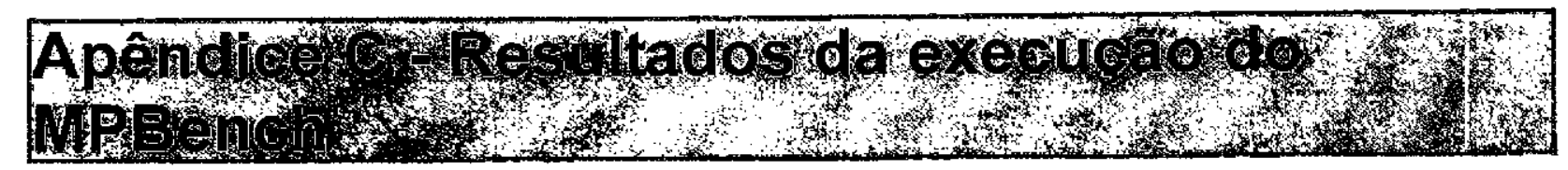

SP2 - 1 iteração - 2 processadores - MPI
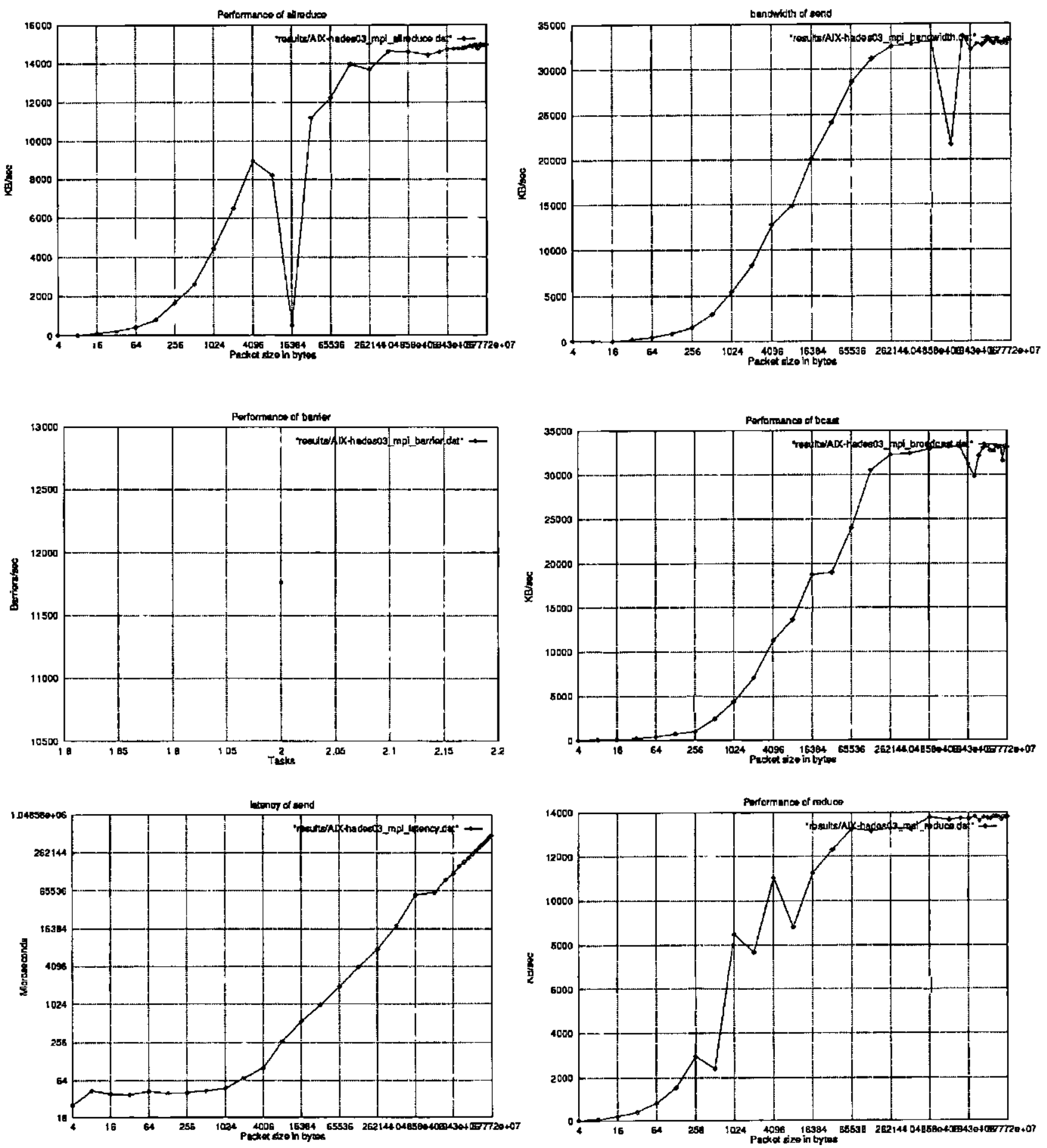


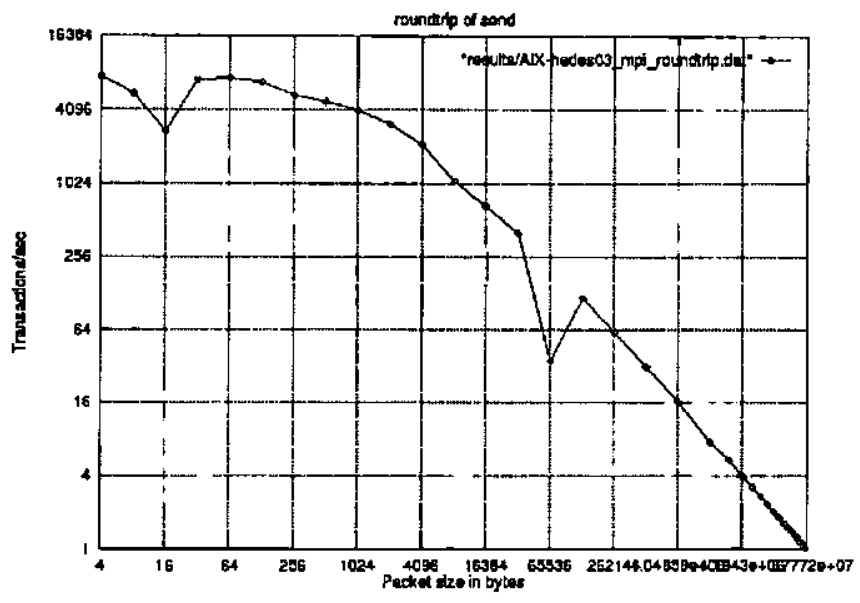

SP2 - 1 iteração - 2 processadores - PVM
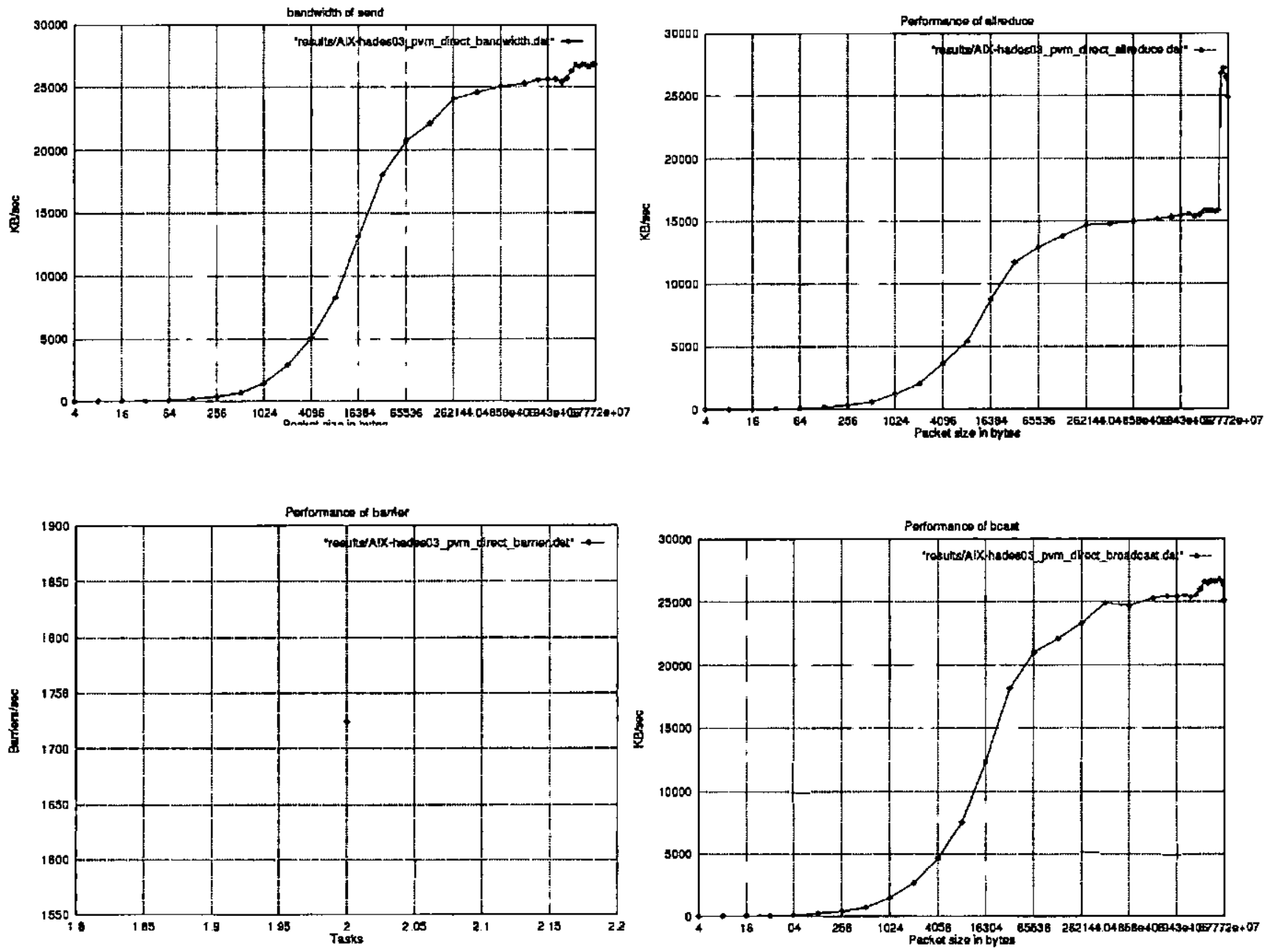

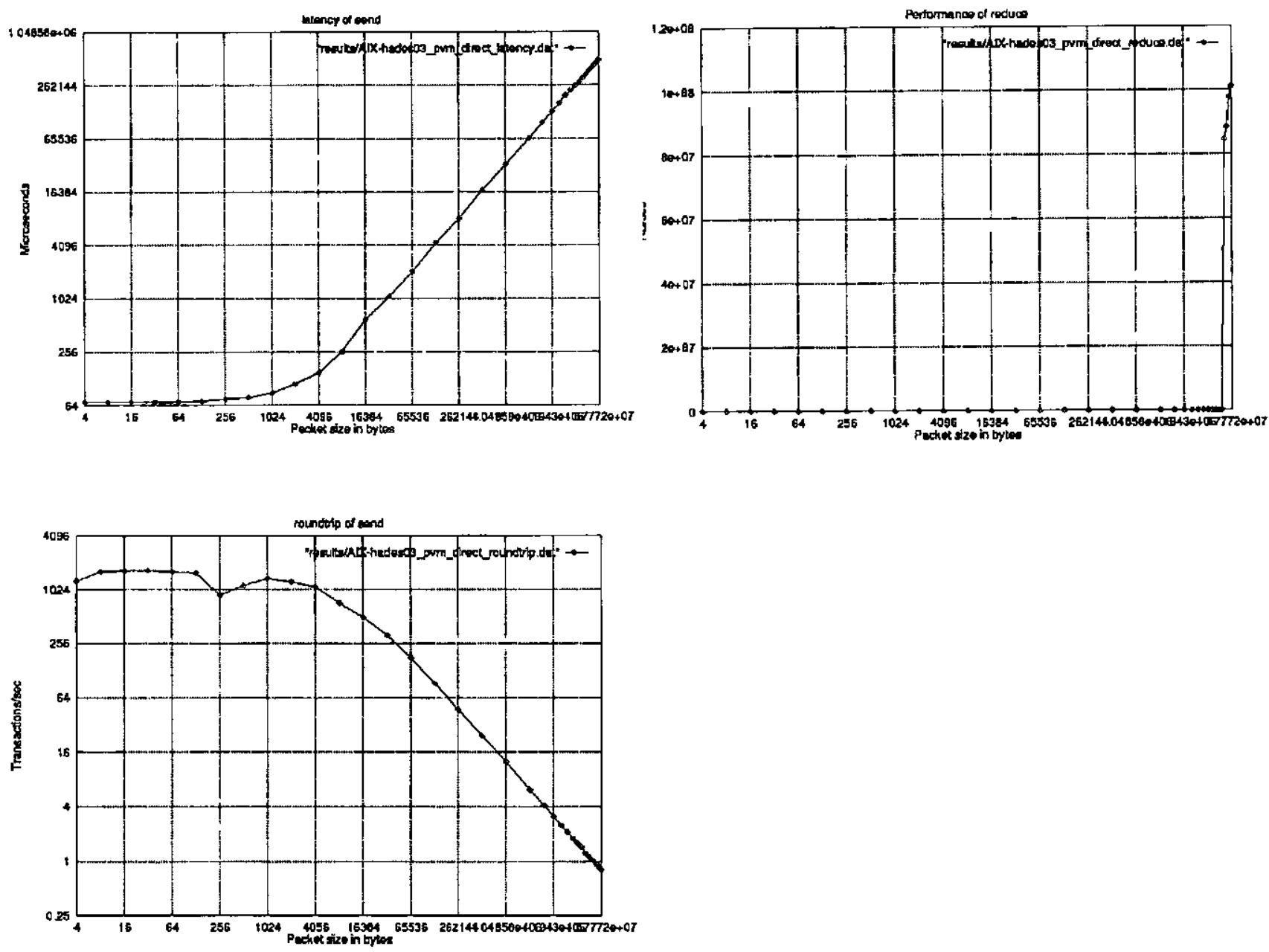

SP2 - 1 iteração - 3 processadores - MPI
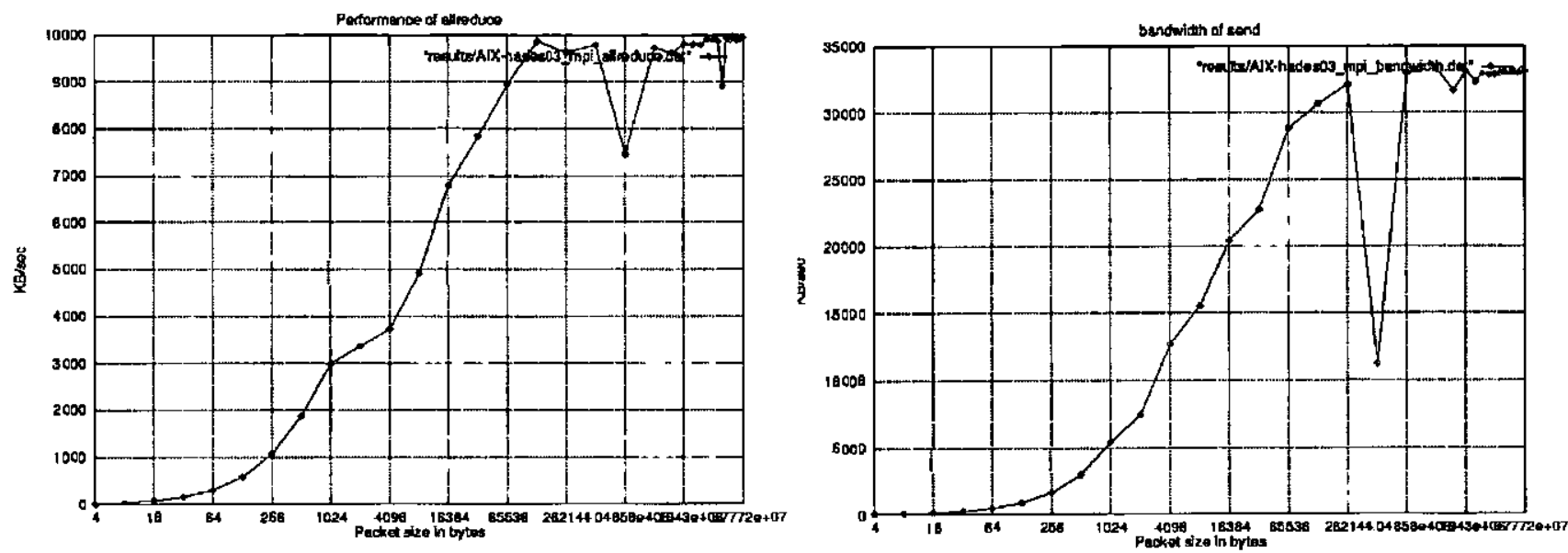

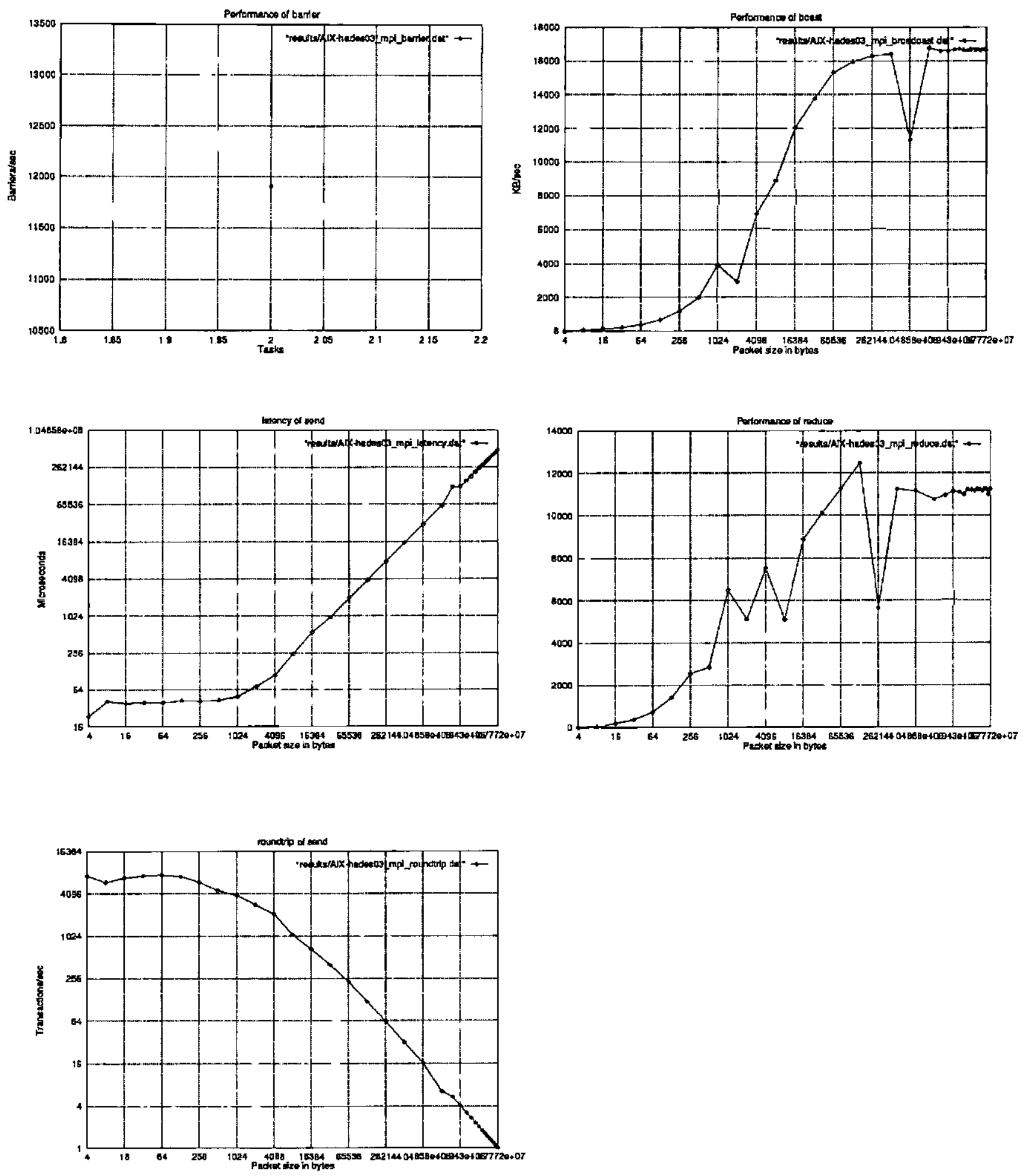
SP2 - 1 iteração - 3 processadores - PVM
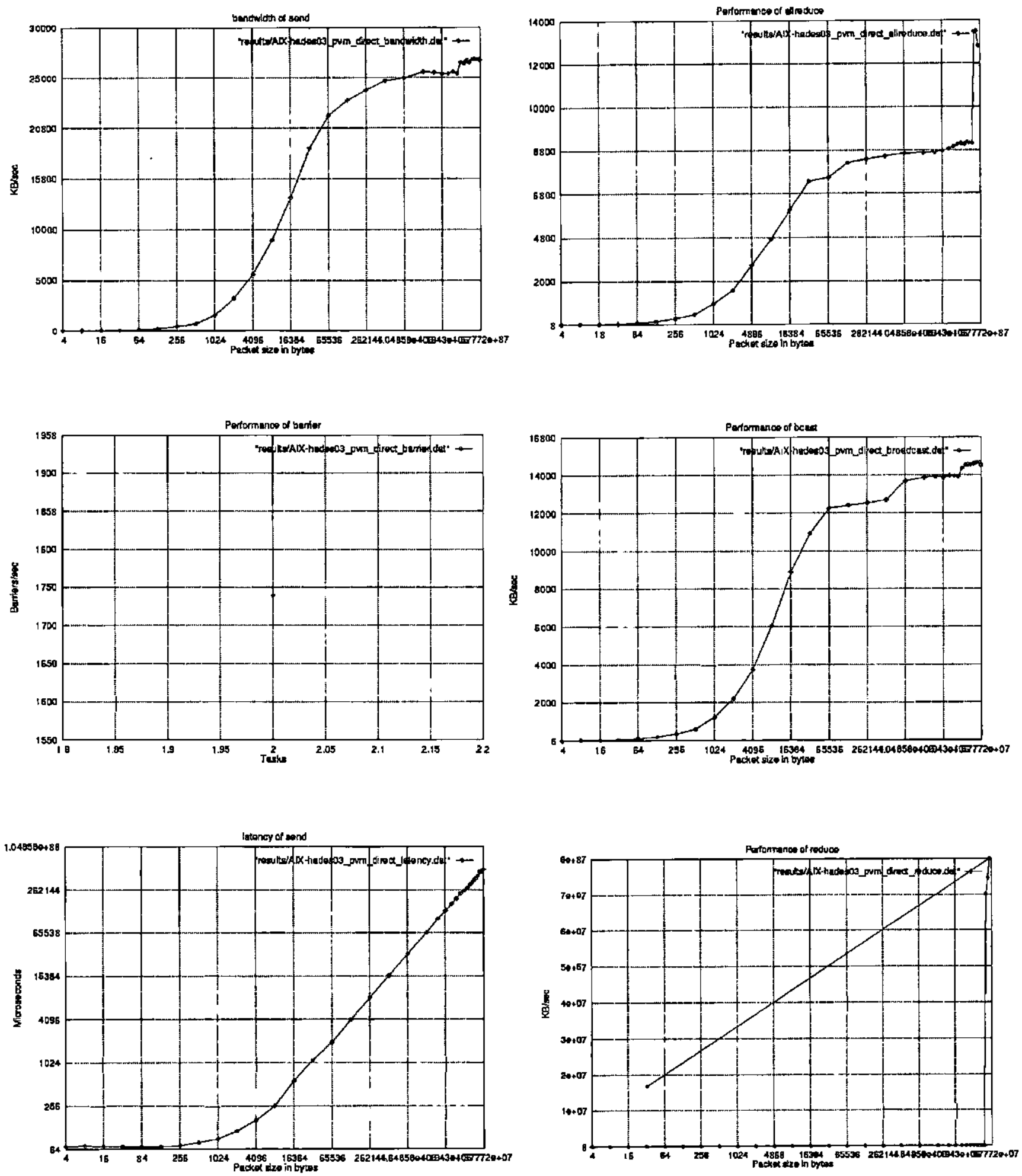


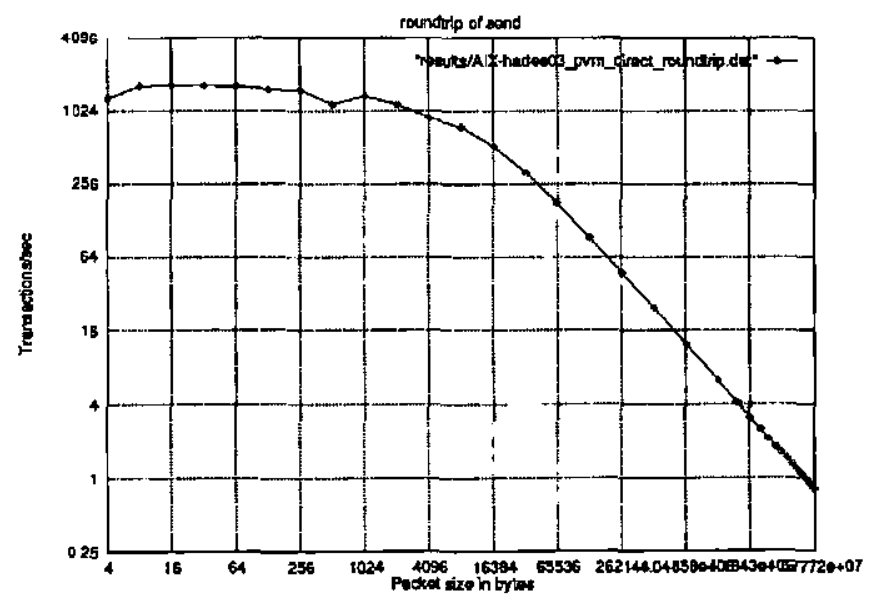

SP2 - 10 iterações - 2 processadores - MPI
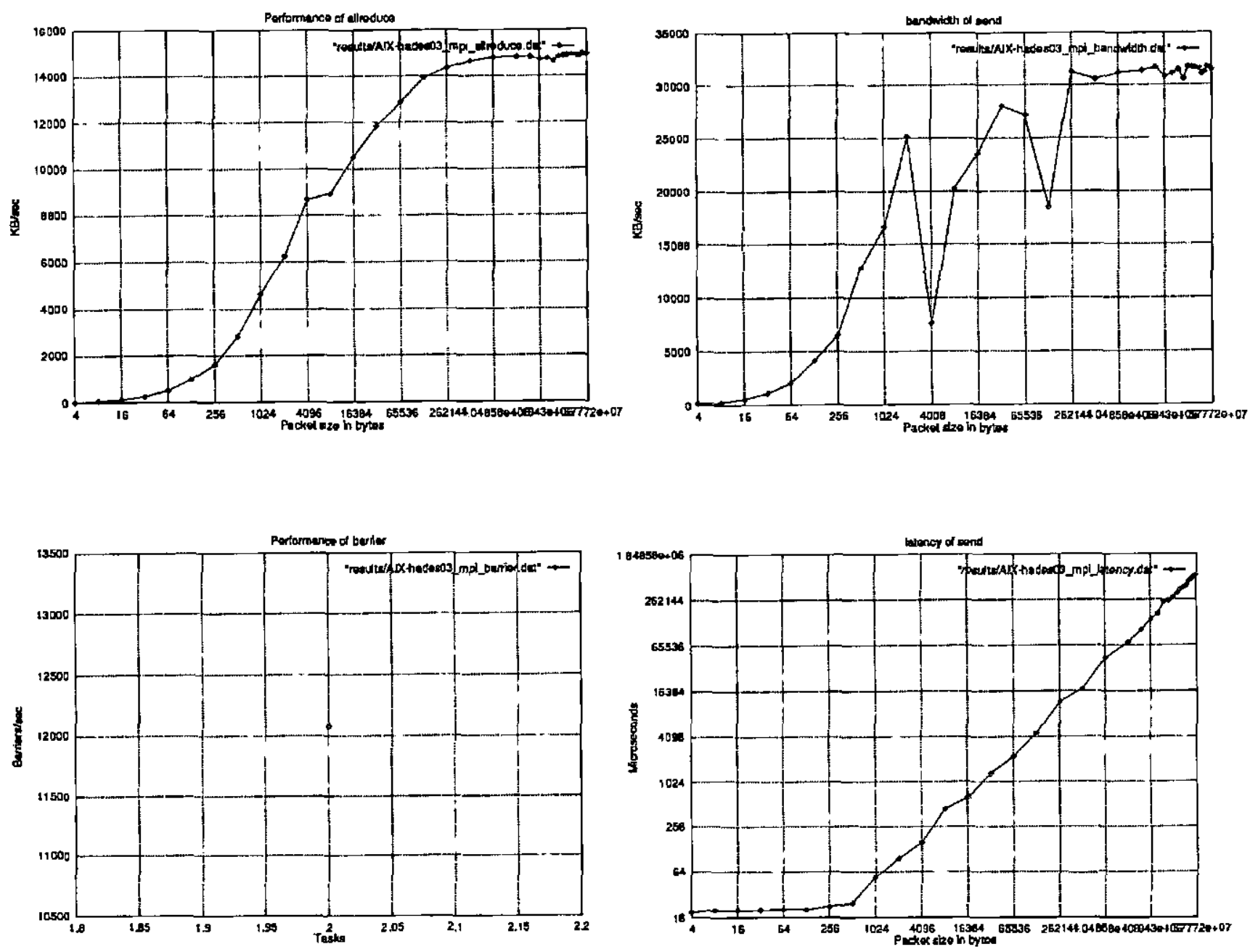

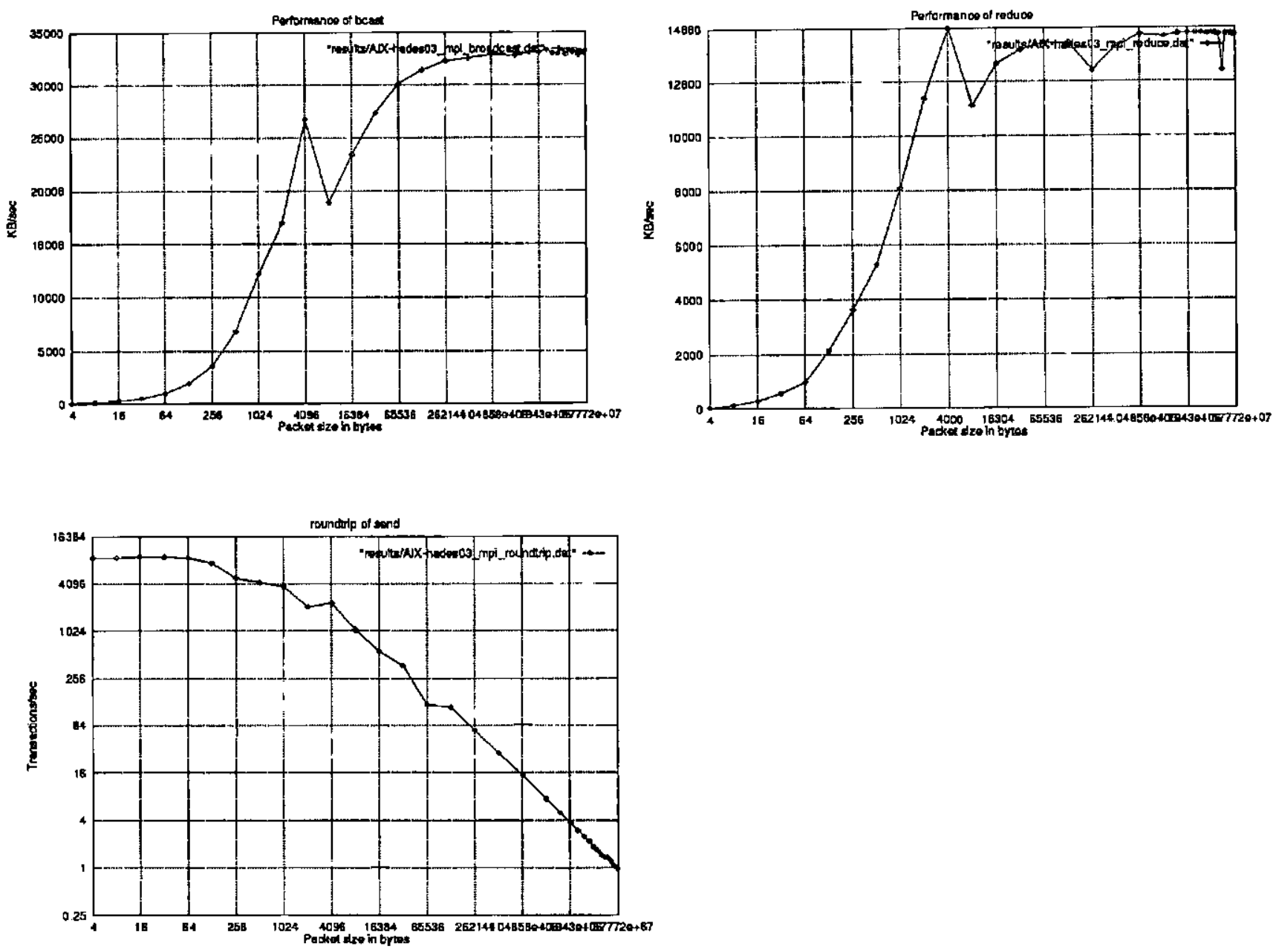

SP2 - 10 iteraçöes - 2 processadores - PVM
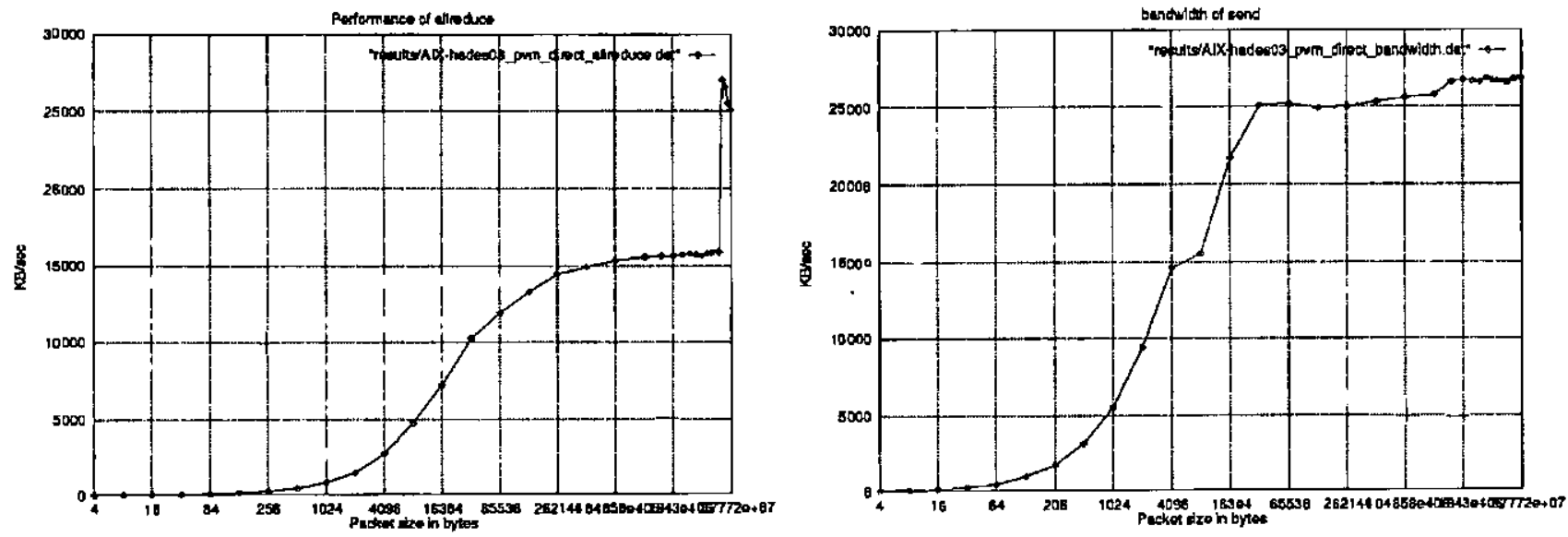

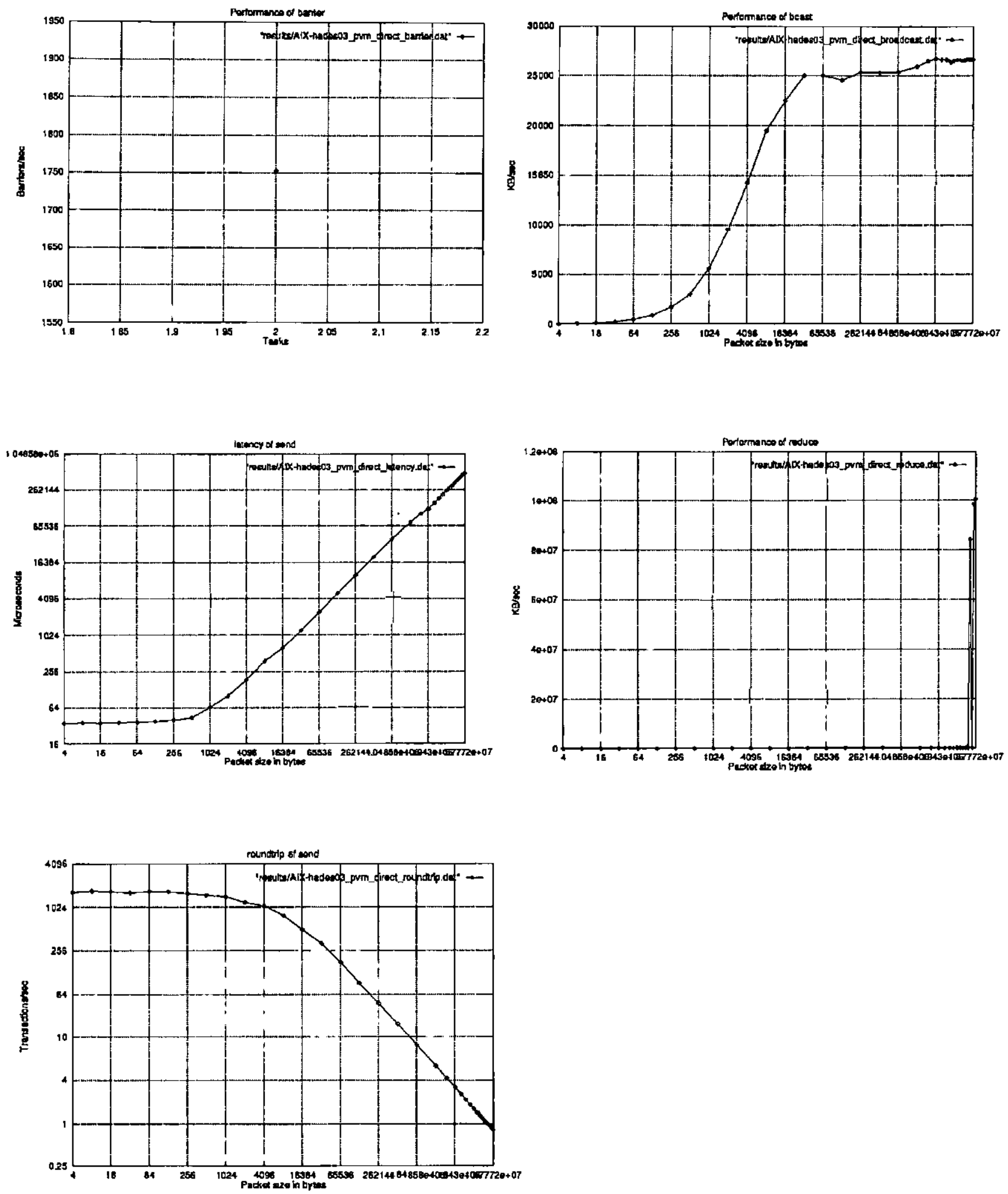
SP2 - 10 iteraçōes - 3 processadores - MPI
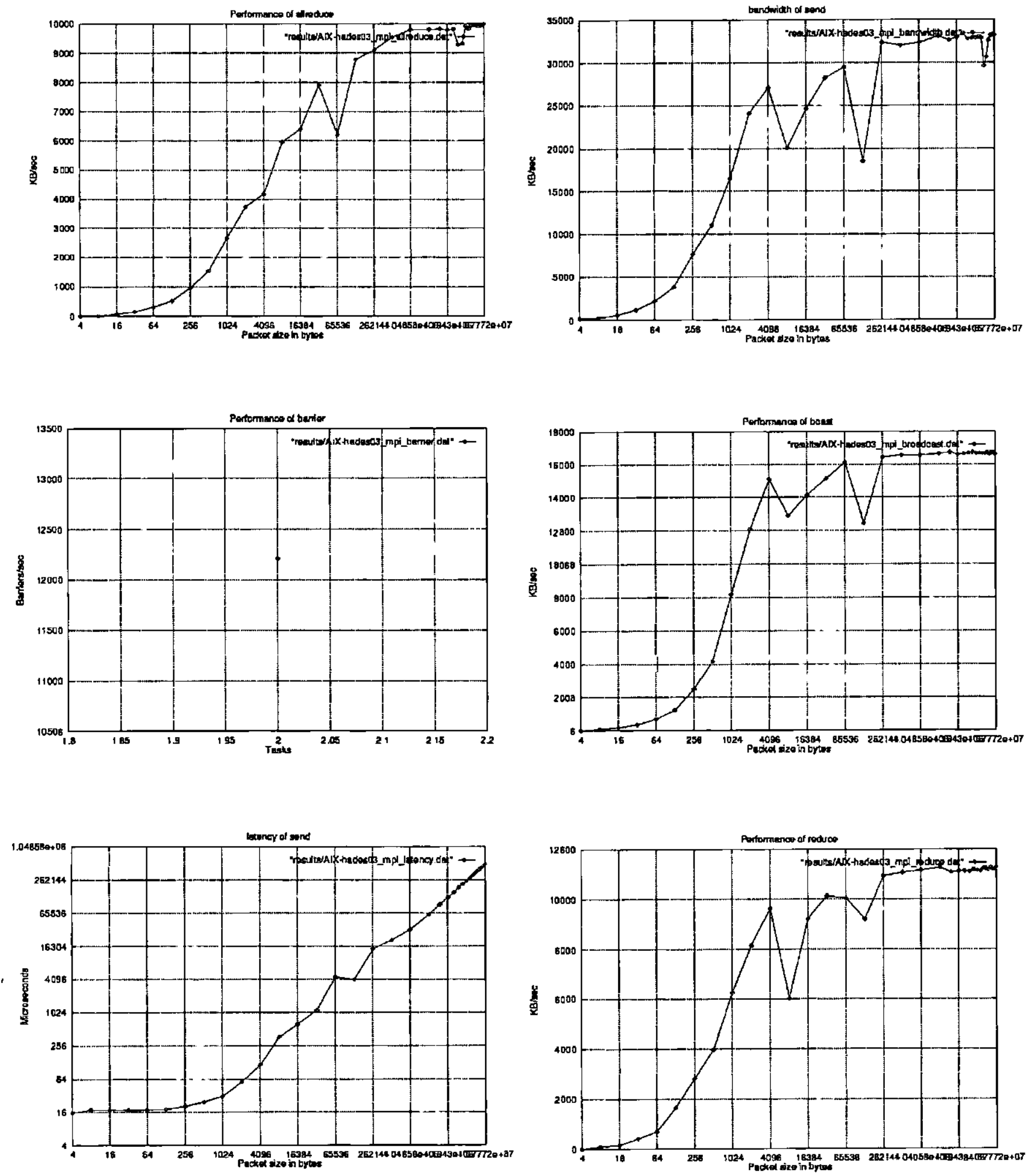


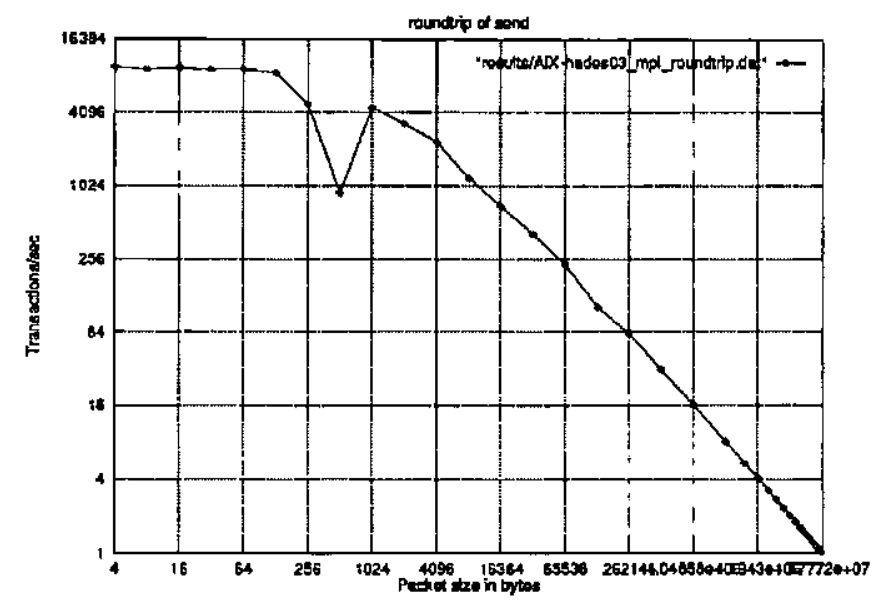

SP2 - 10 iterações - 3 processadores - PVM
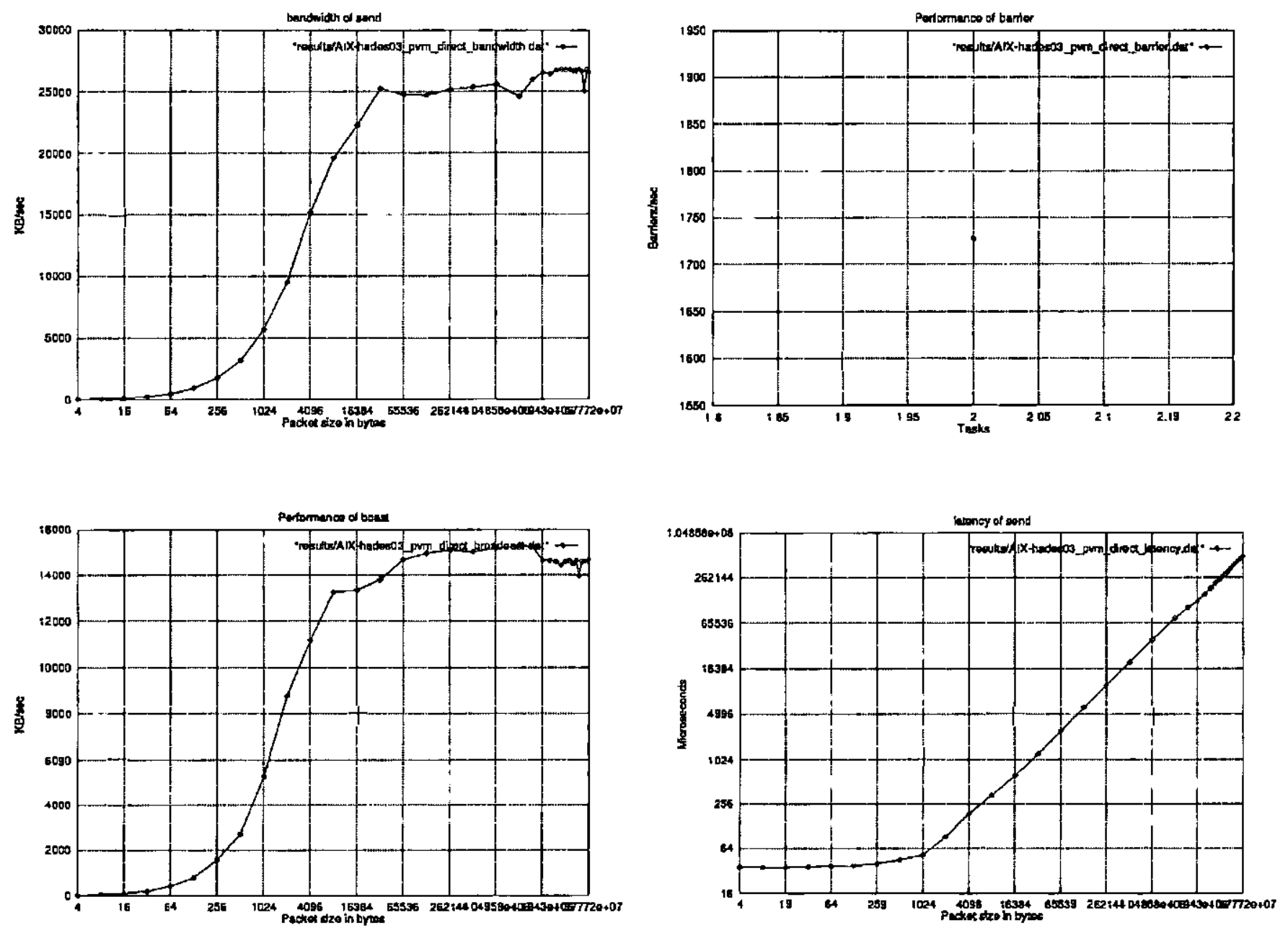

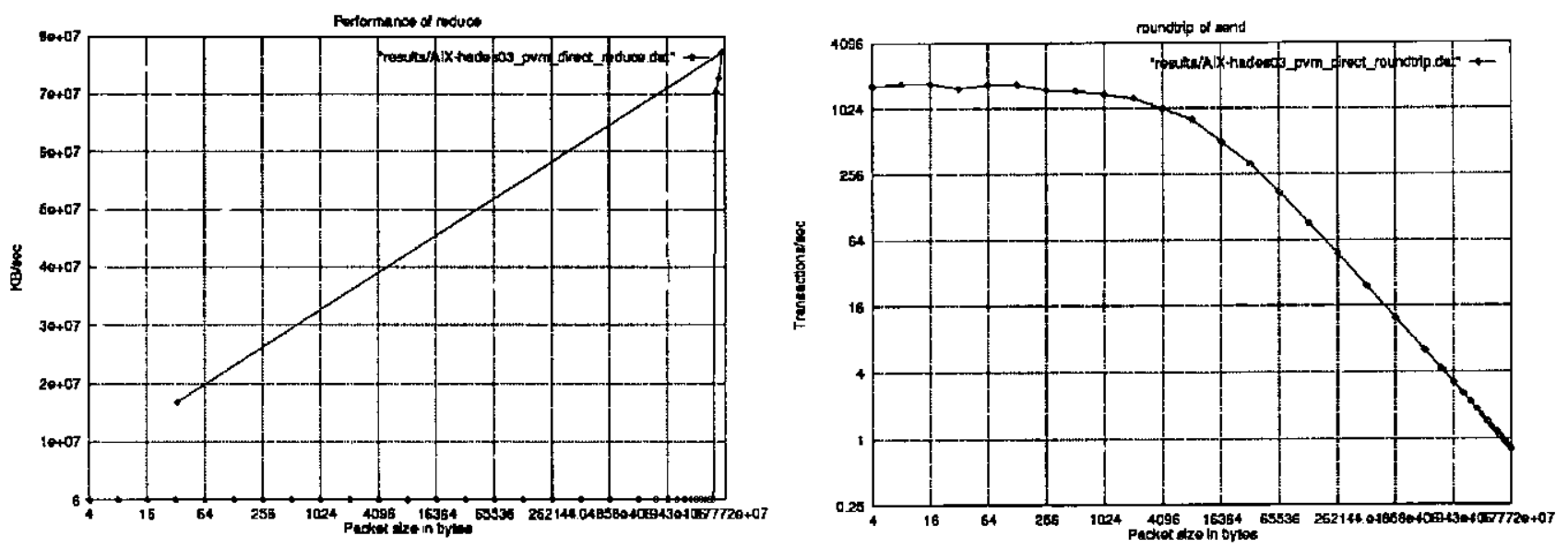

SP2 - 100 iteraçöes - 2 processadores - MPI
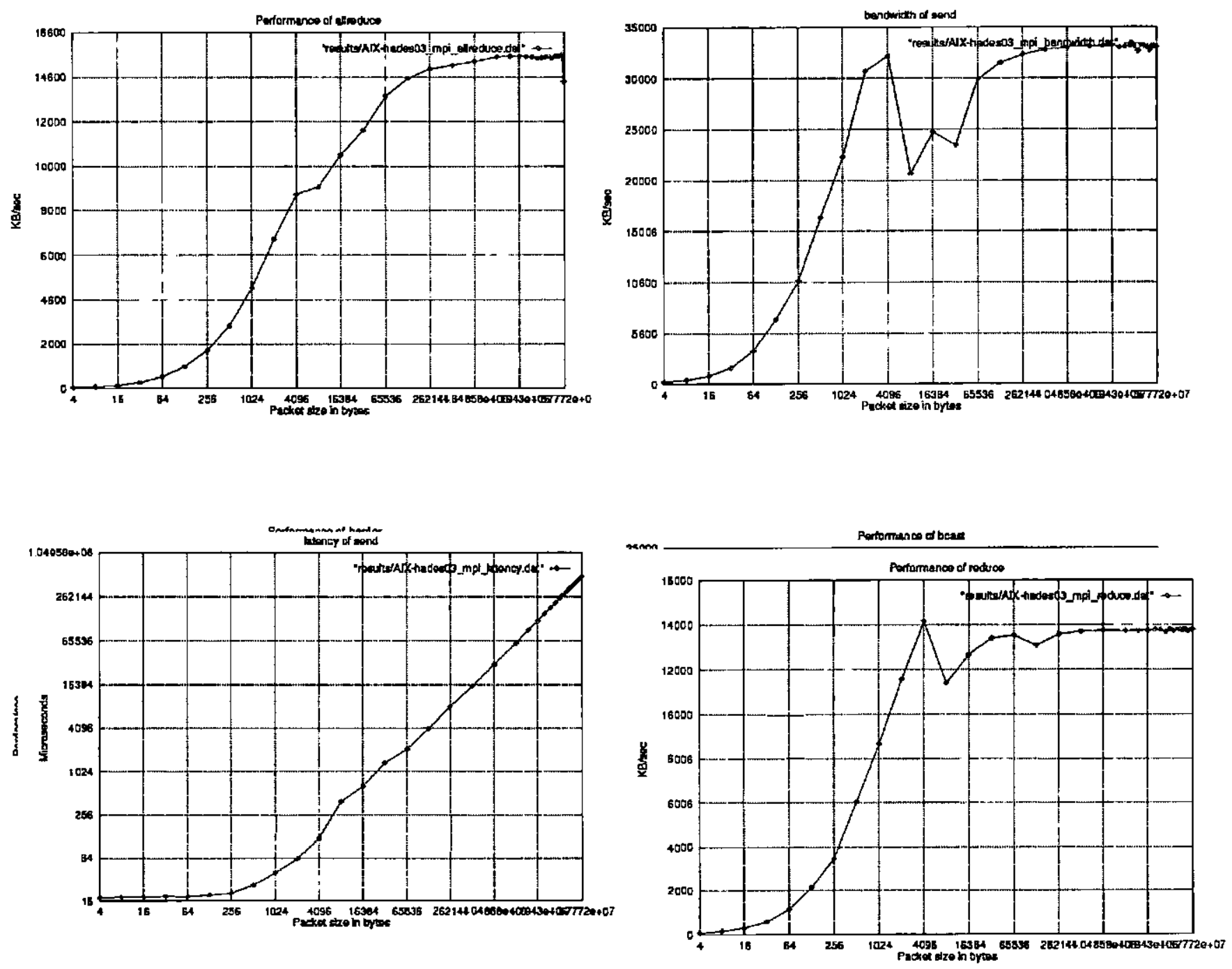


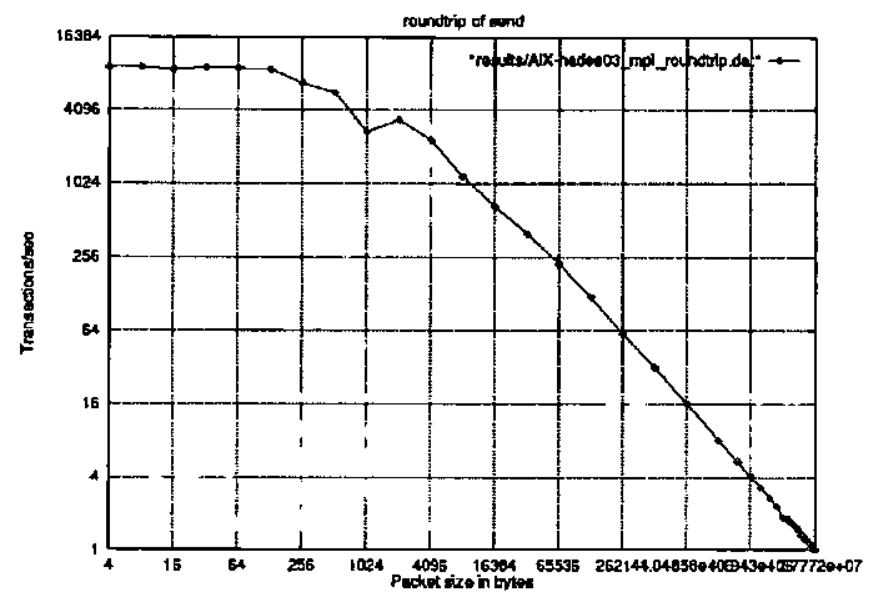

SP2

- 100 iteraçōes - 2 processadores - PVM
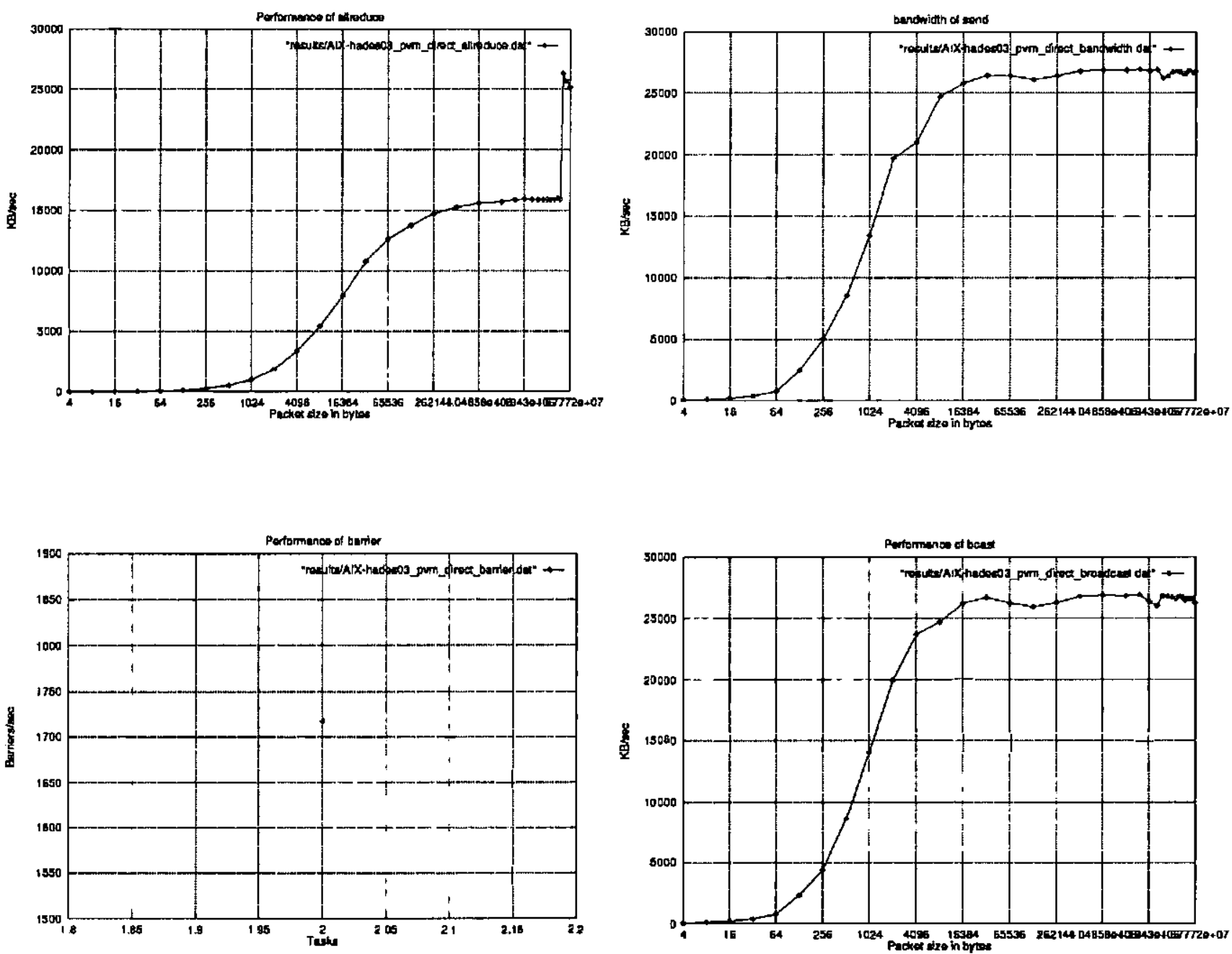

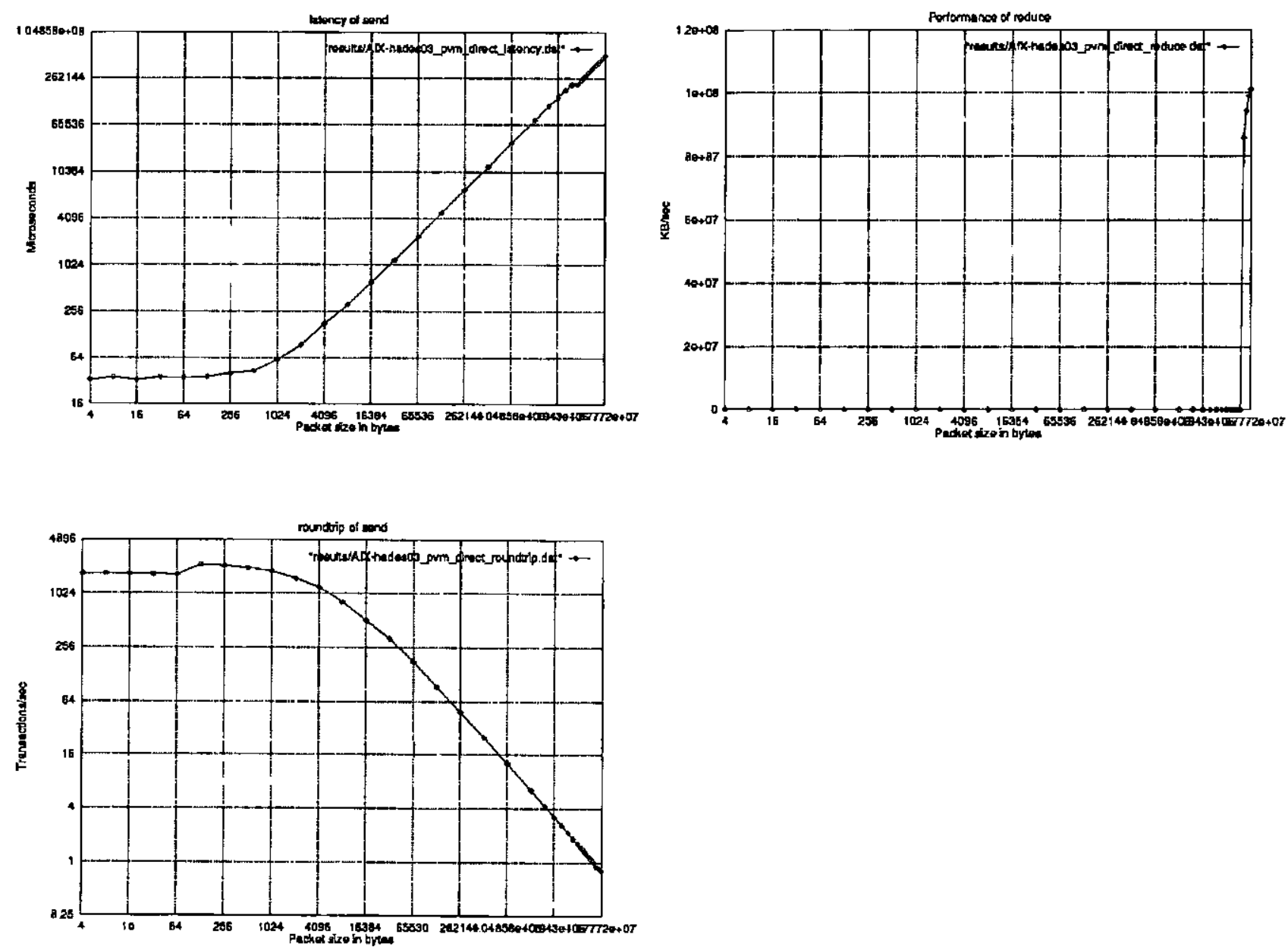

SP2 - 100 iteraçōes - 3 processadores - MPI
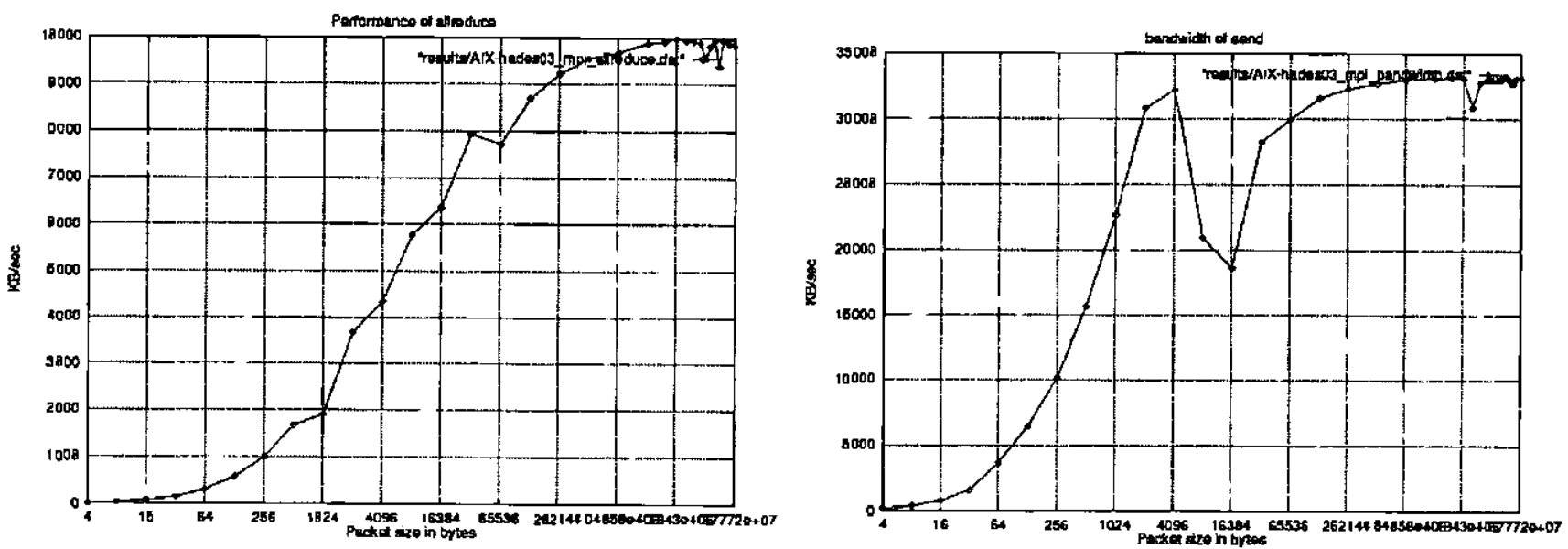

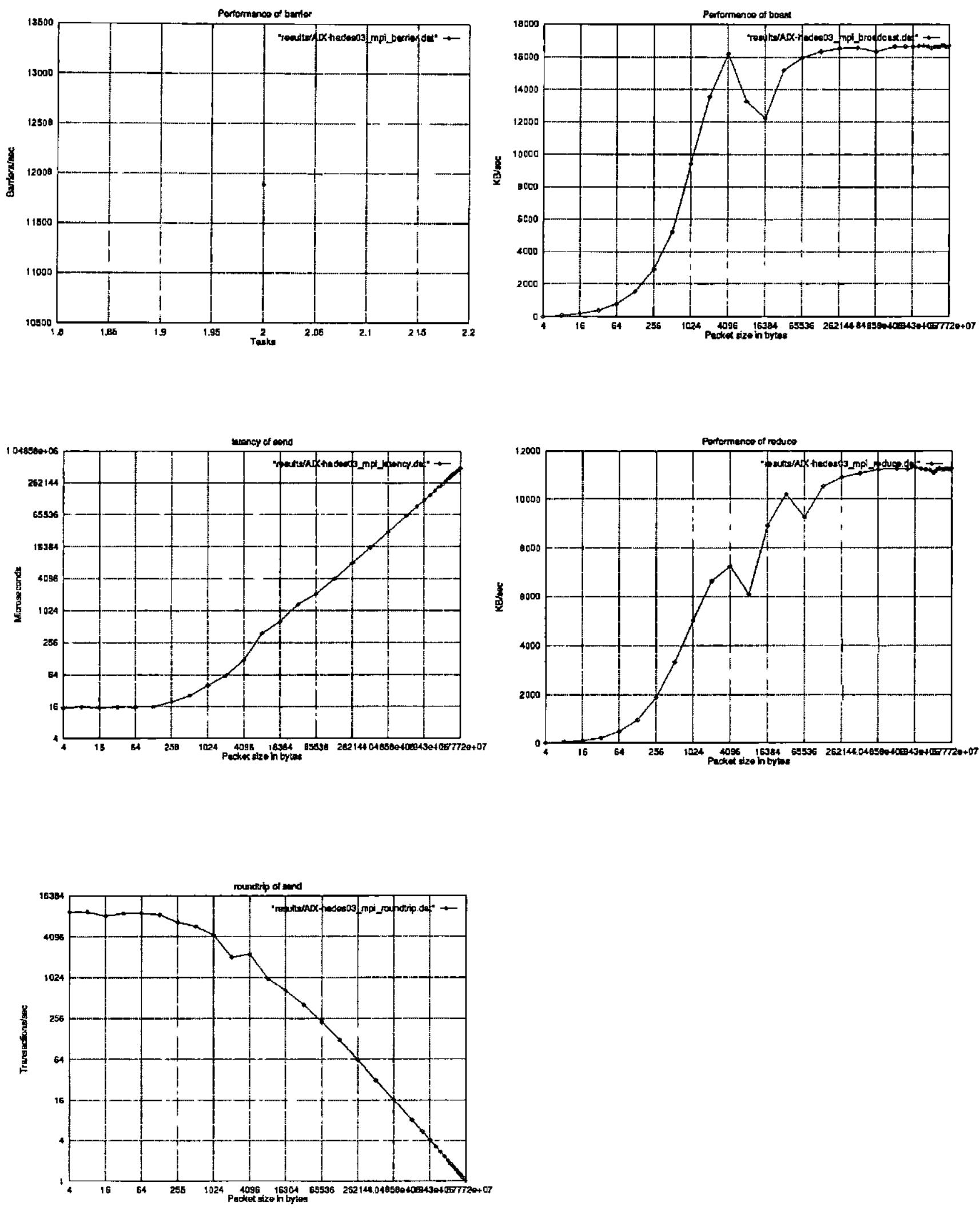
SP2

- 500 iterações - 2 processadores

- MPI
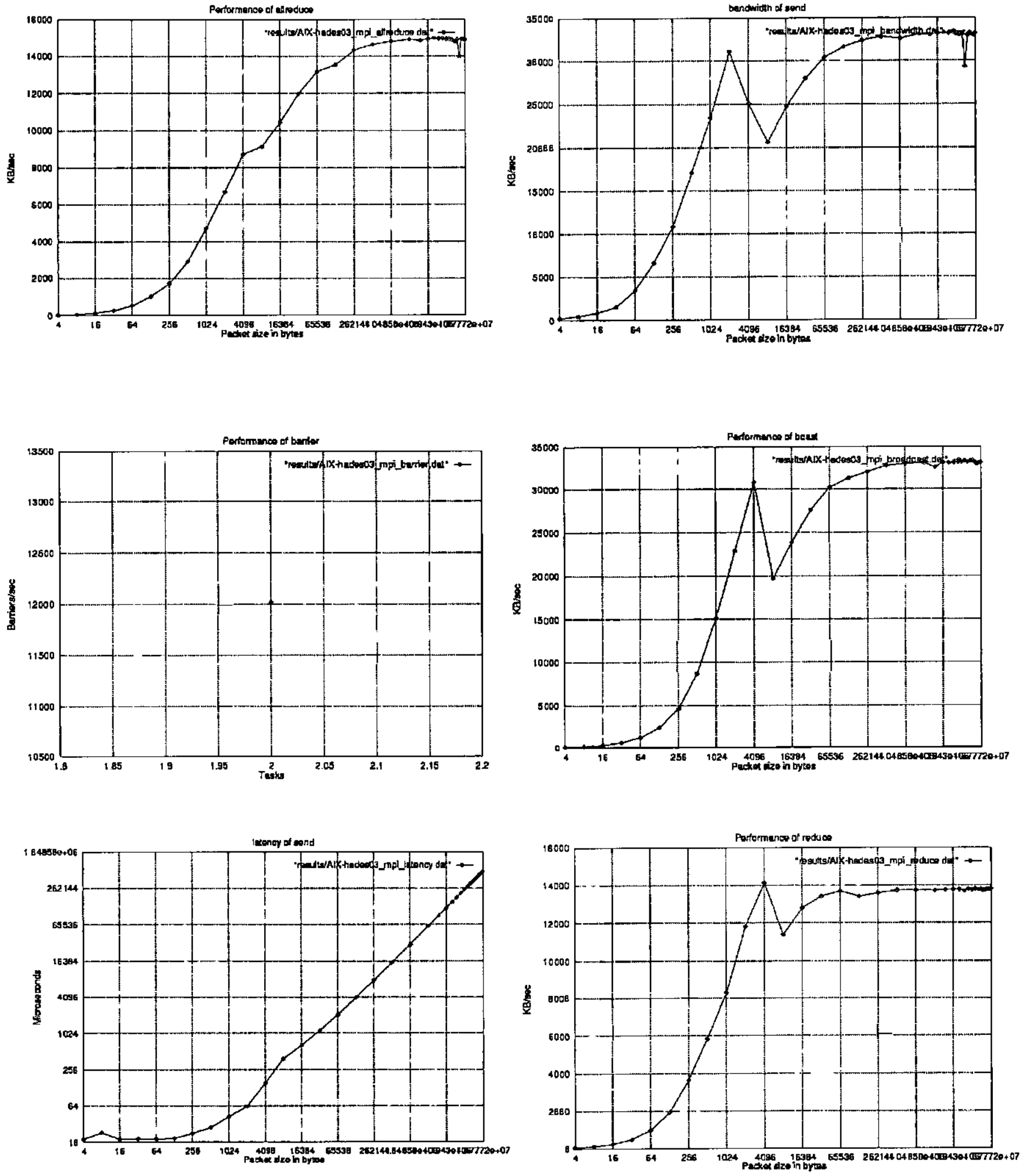


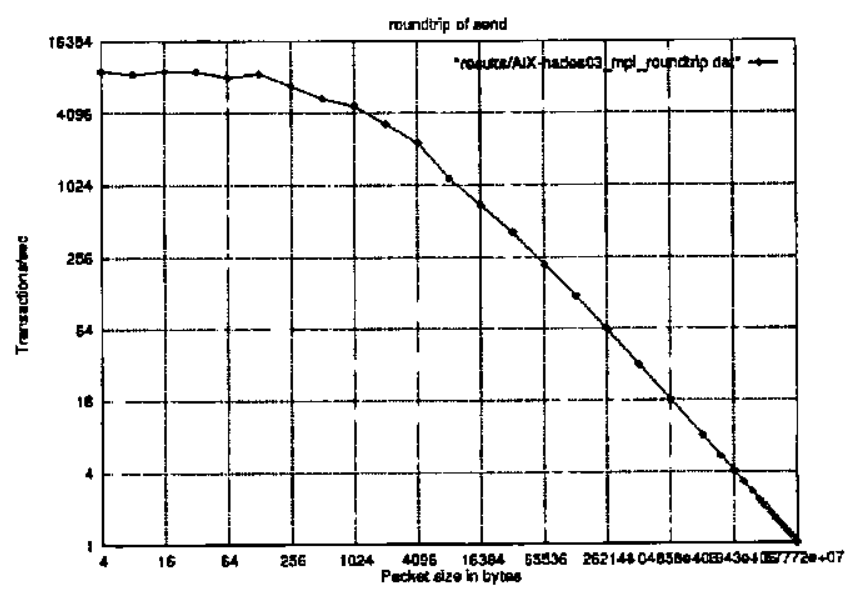

SP2 - 500 iteraçōes - 2 processadores - PVM
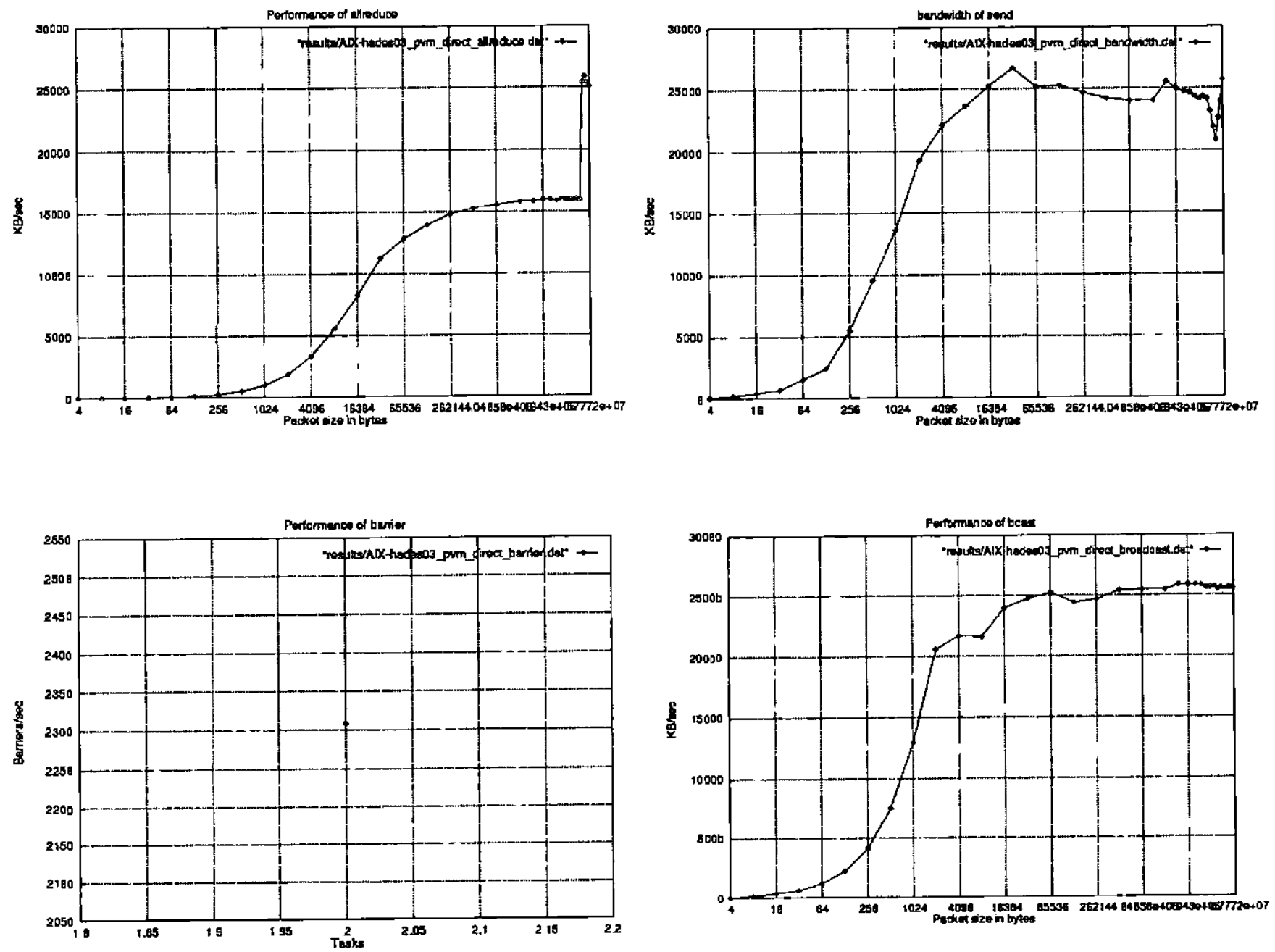

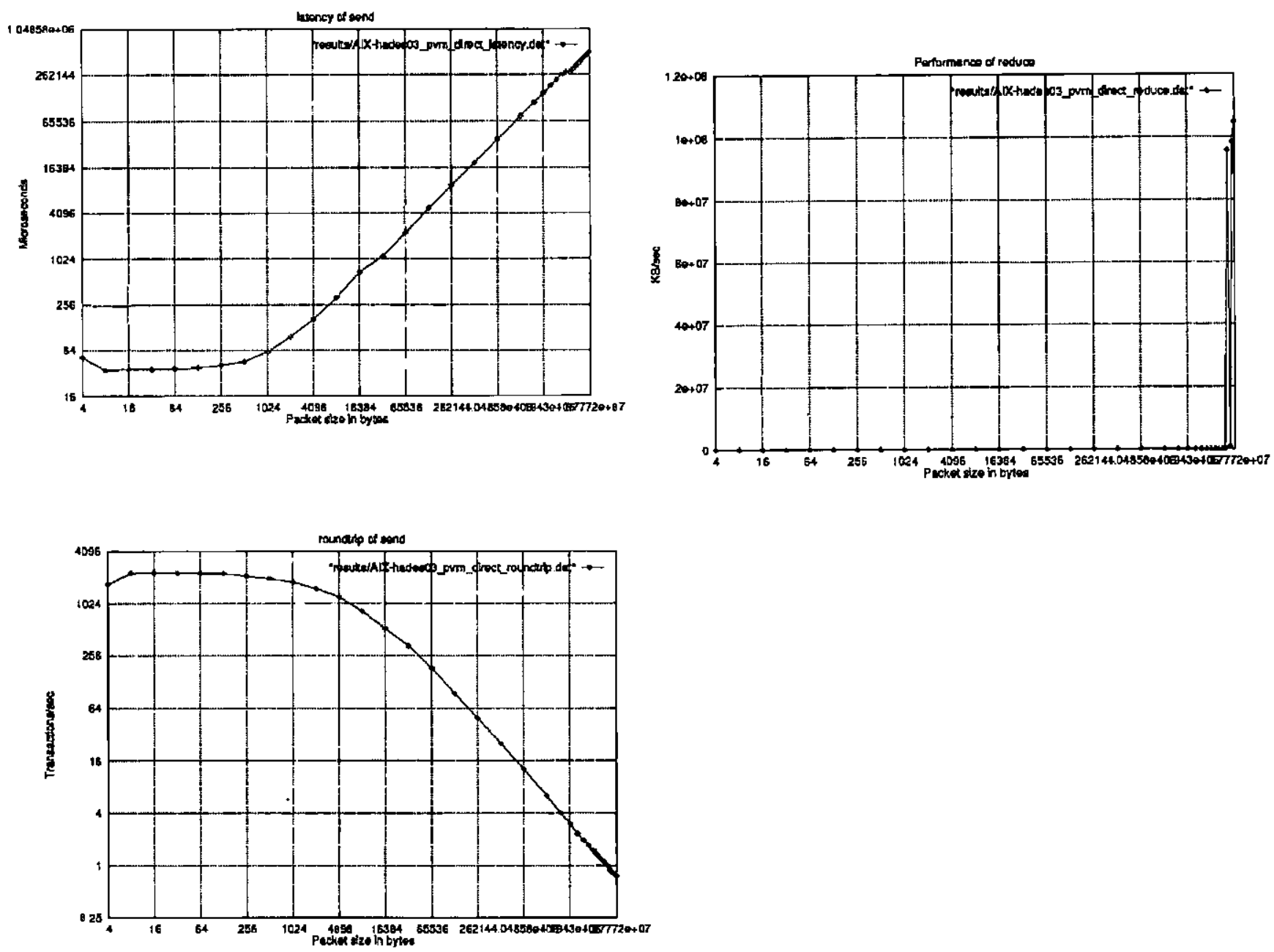

SP2 - 1000 iterações - 2 processadores - MPI
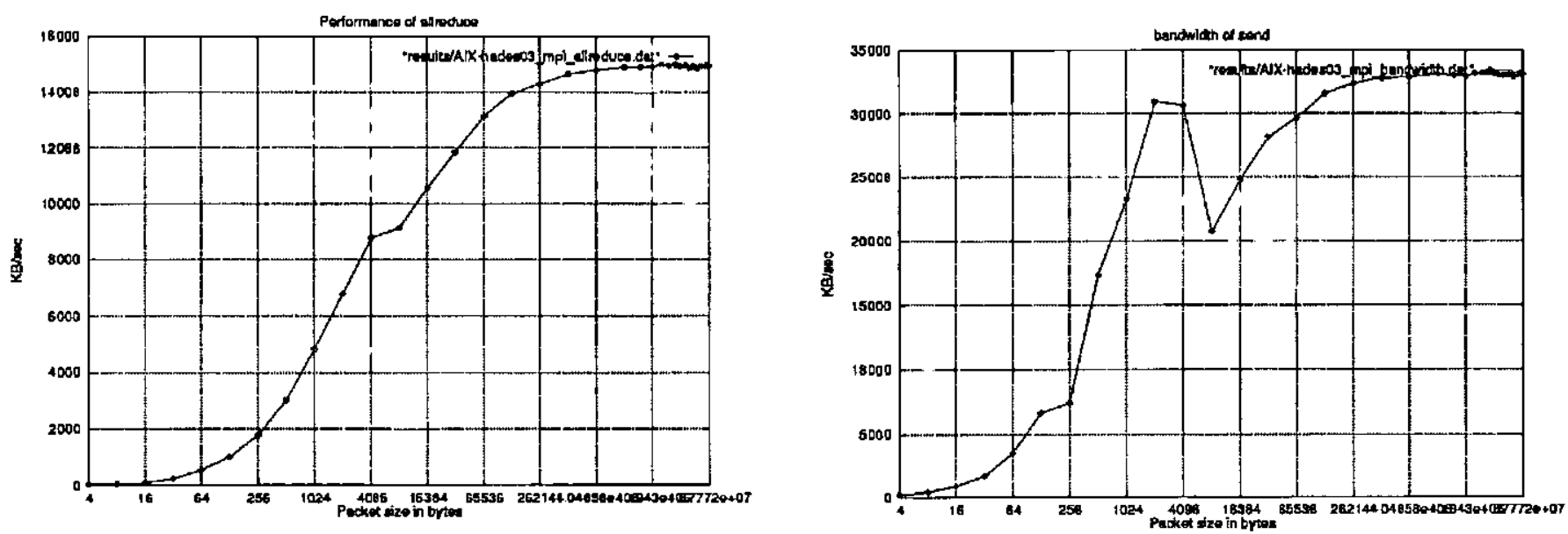

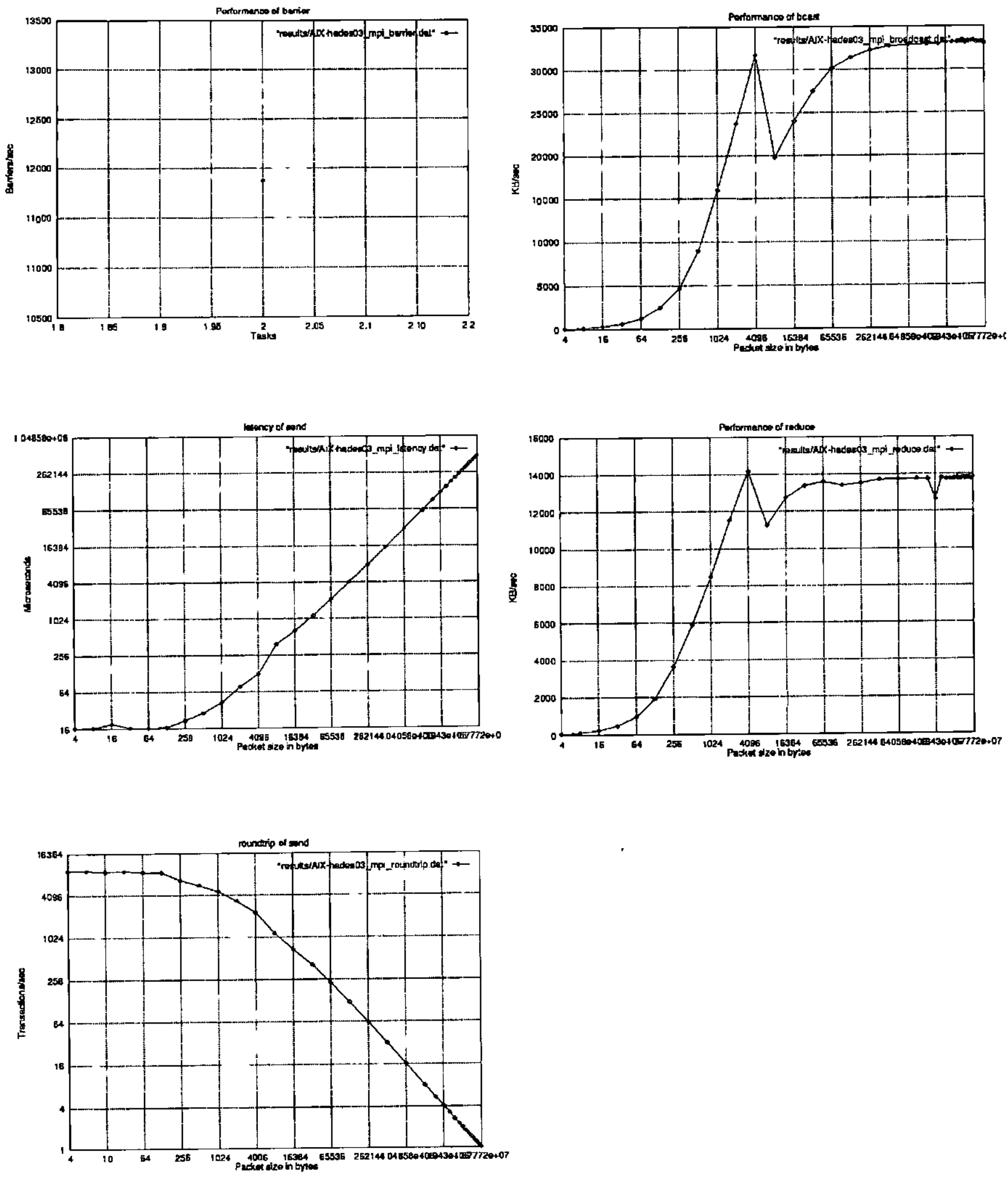
SP2 - 1000 iterações - 3 processadores - MPI
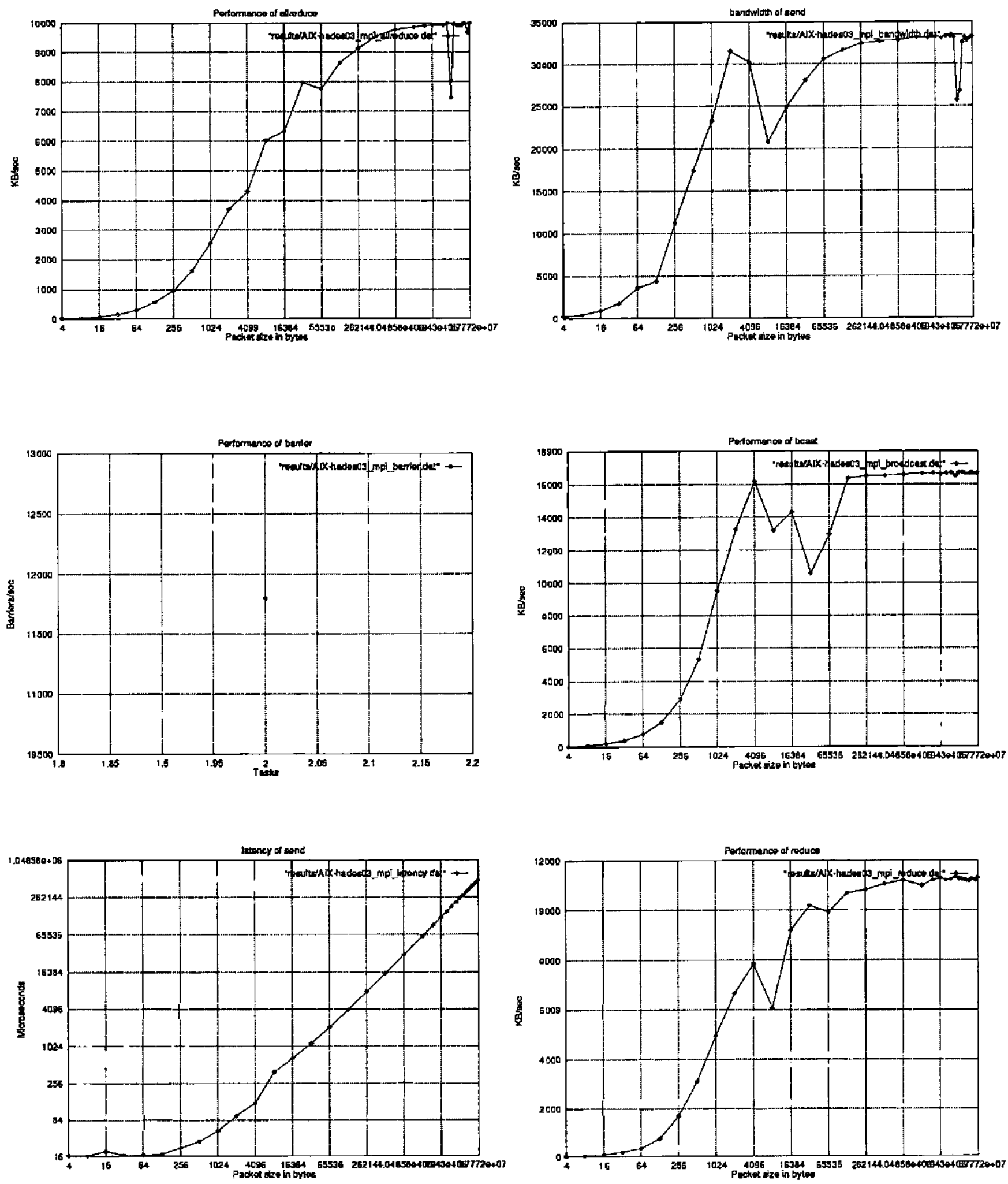


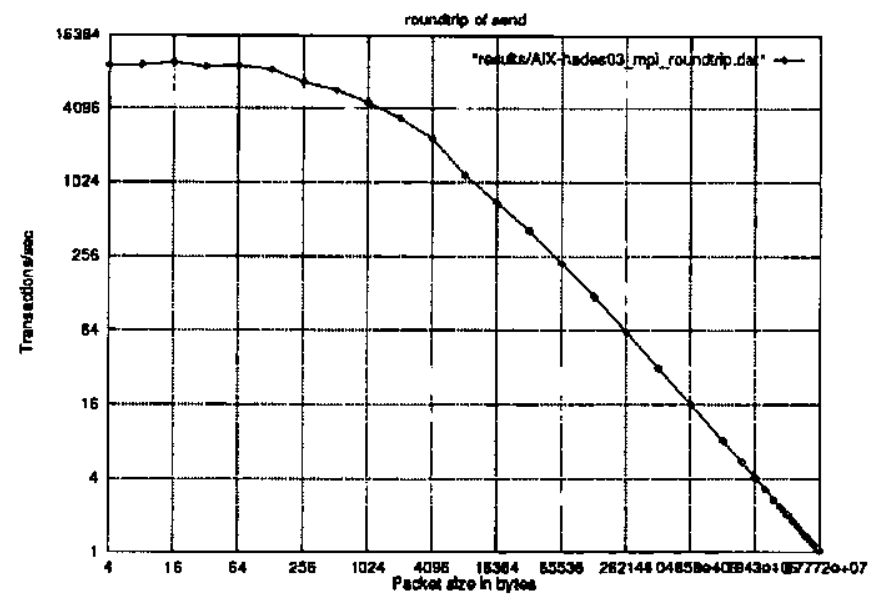

Linux - 1 iteração - 2 processadores - PVM
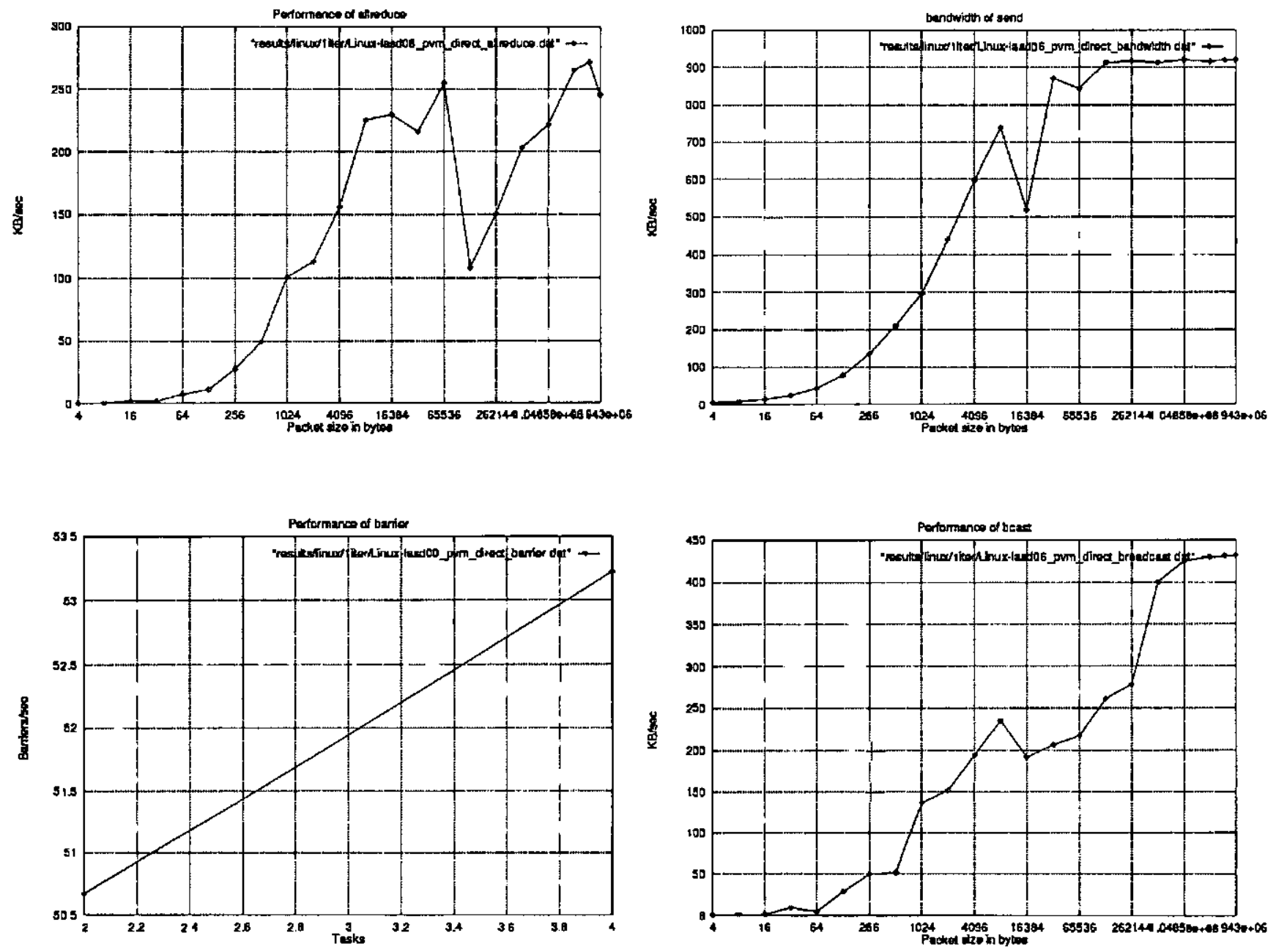

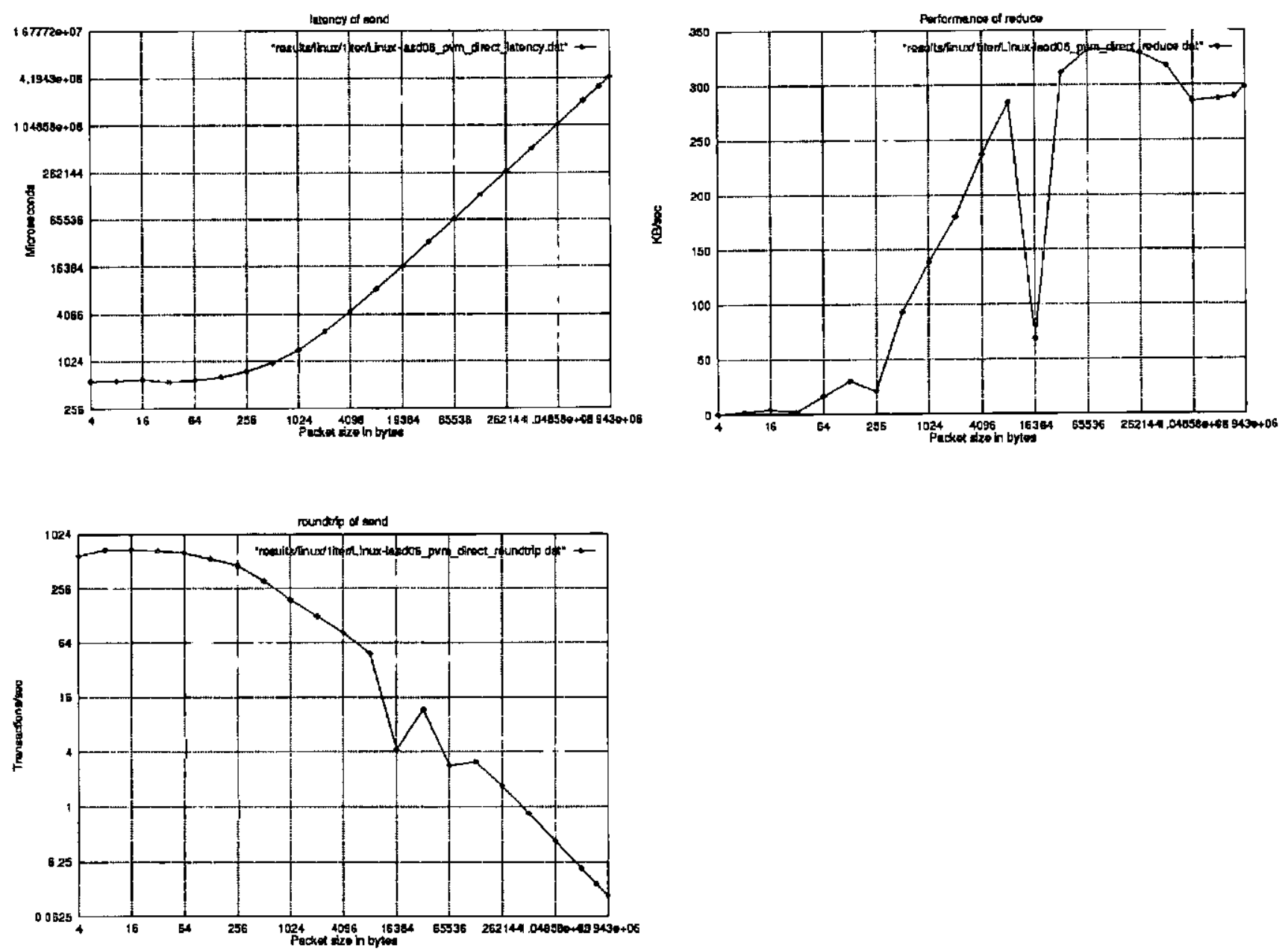

Iinux - 1 iteração - 3 processadores - PVM
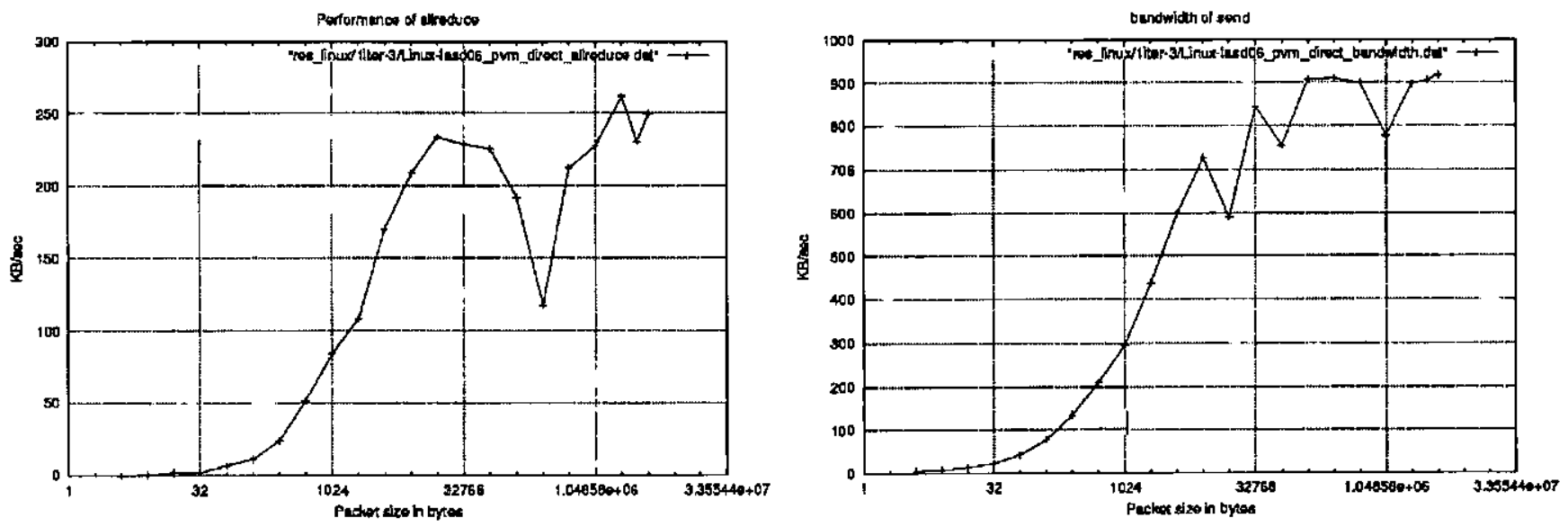

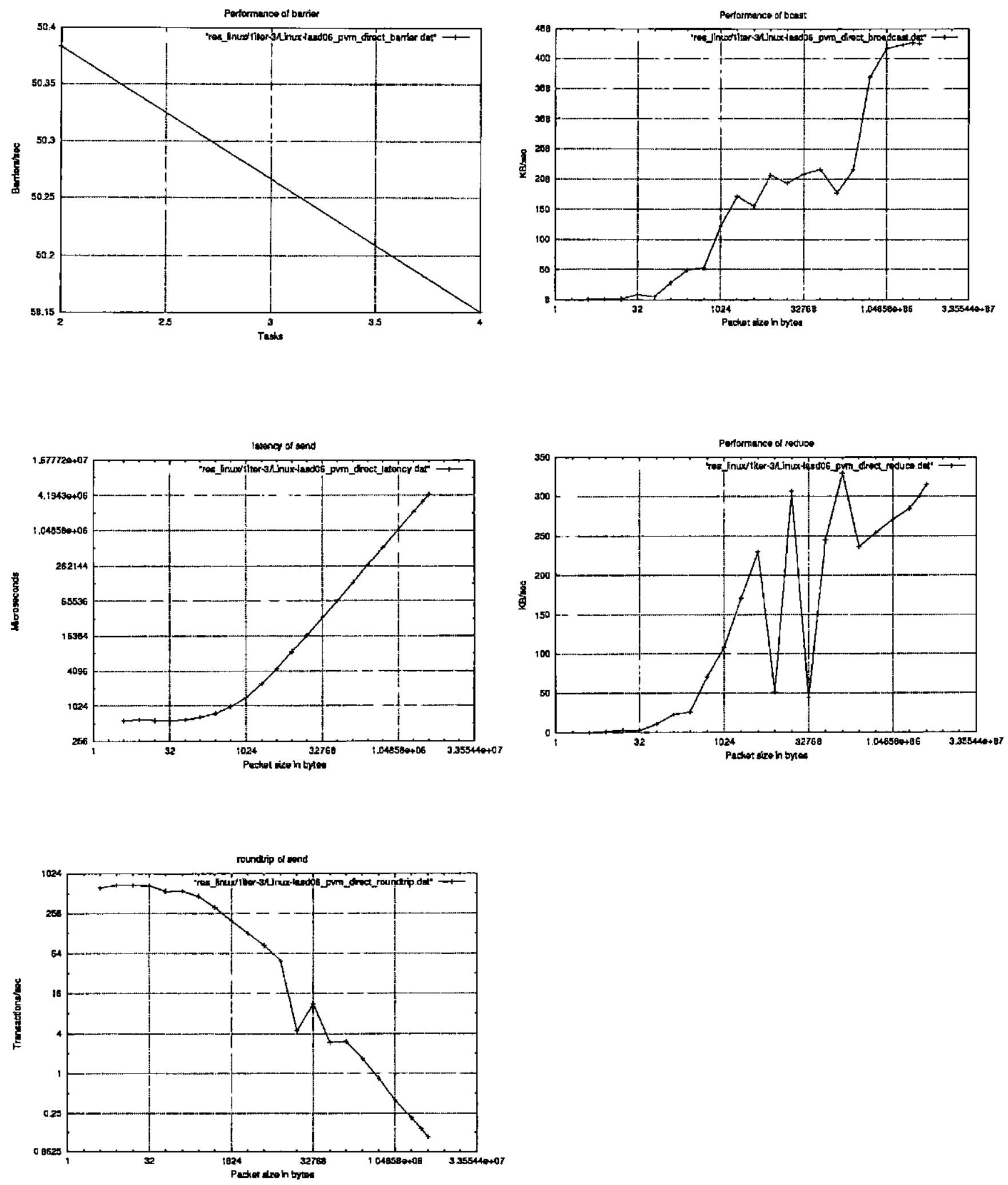


\section{Isinux - 10 iterações - 2 processadores - PVM}
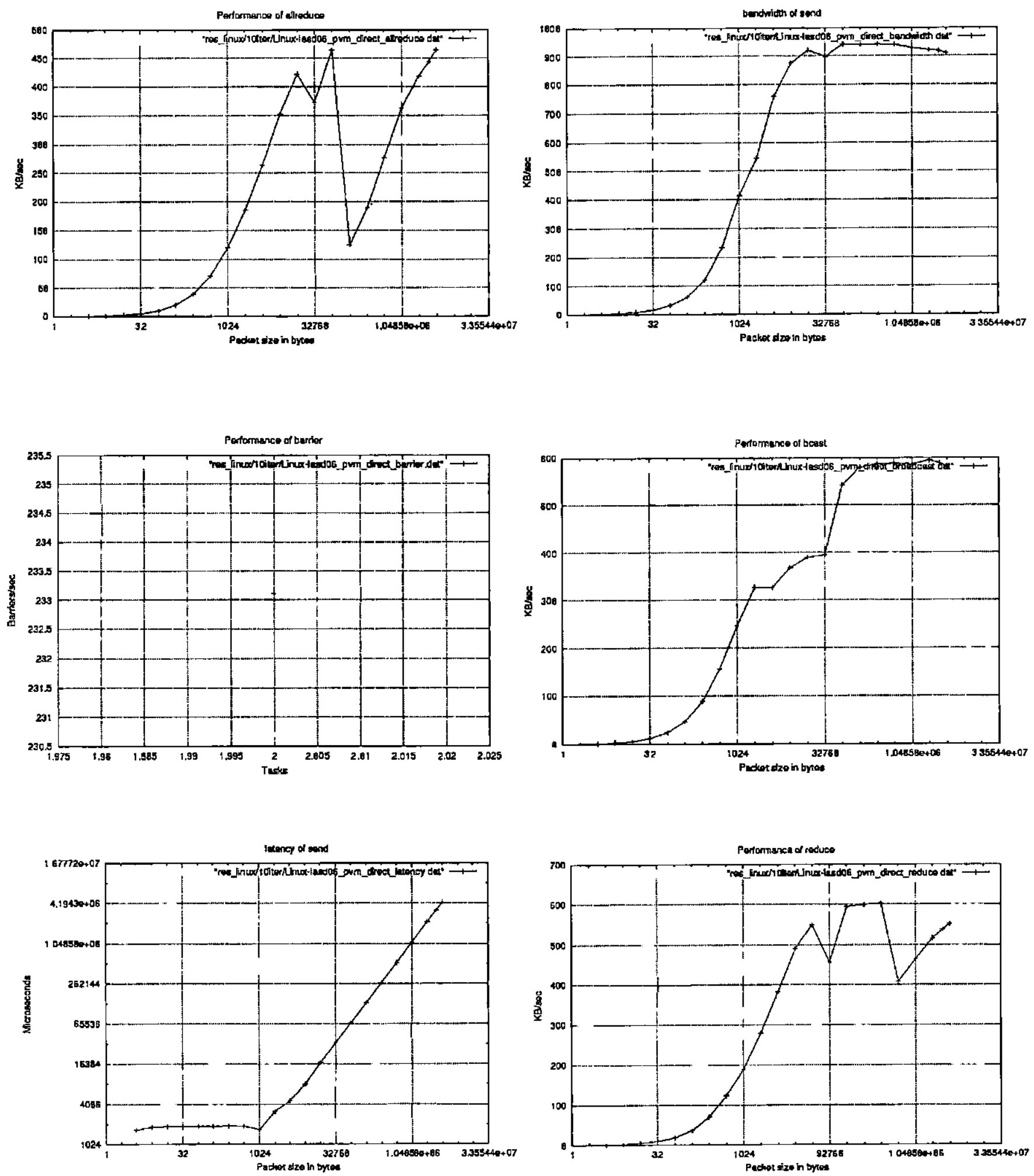


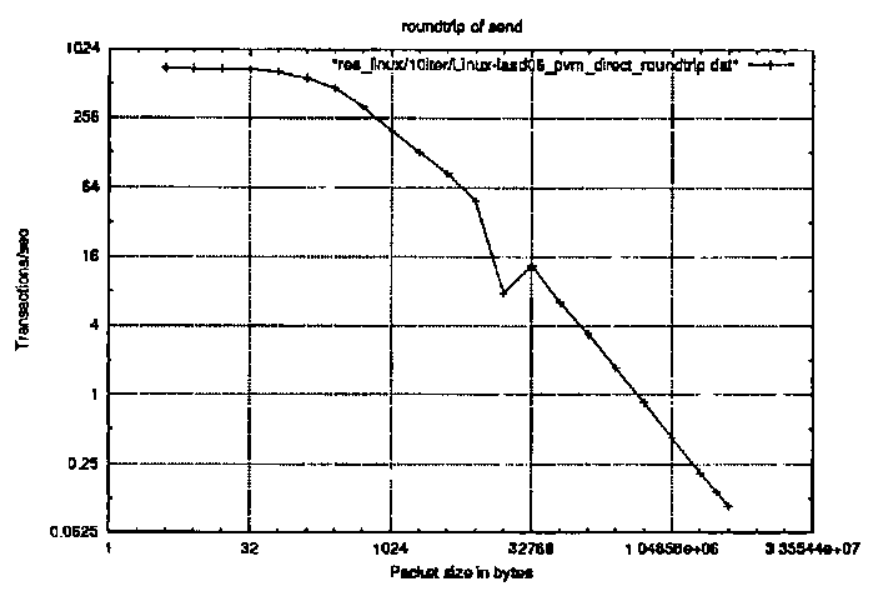

Linux - 10 iterações - 3 processadores - PVM
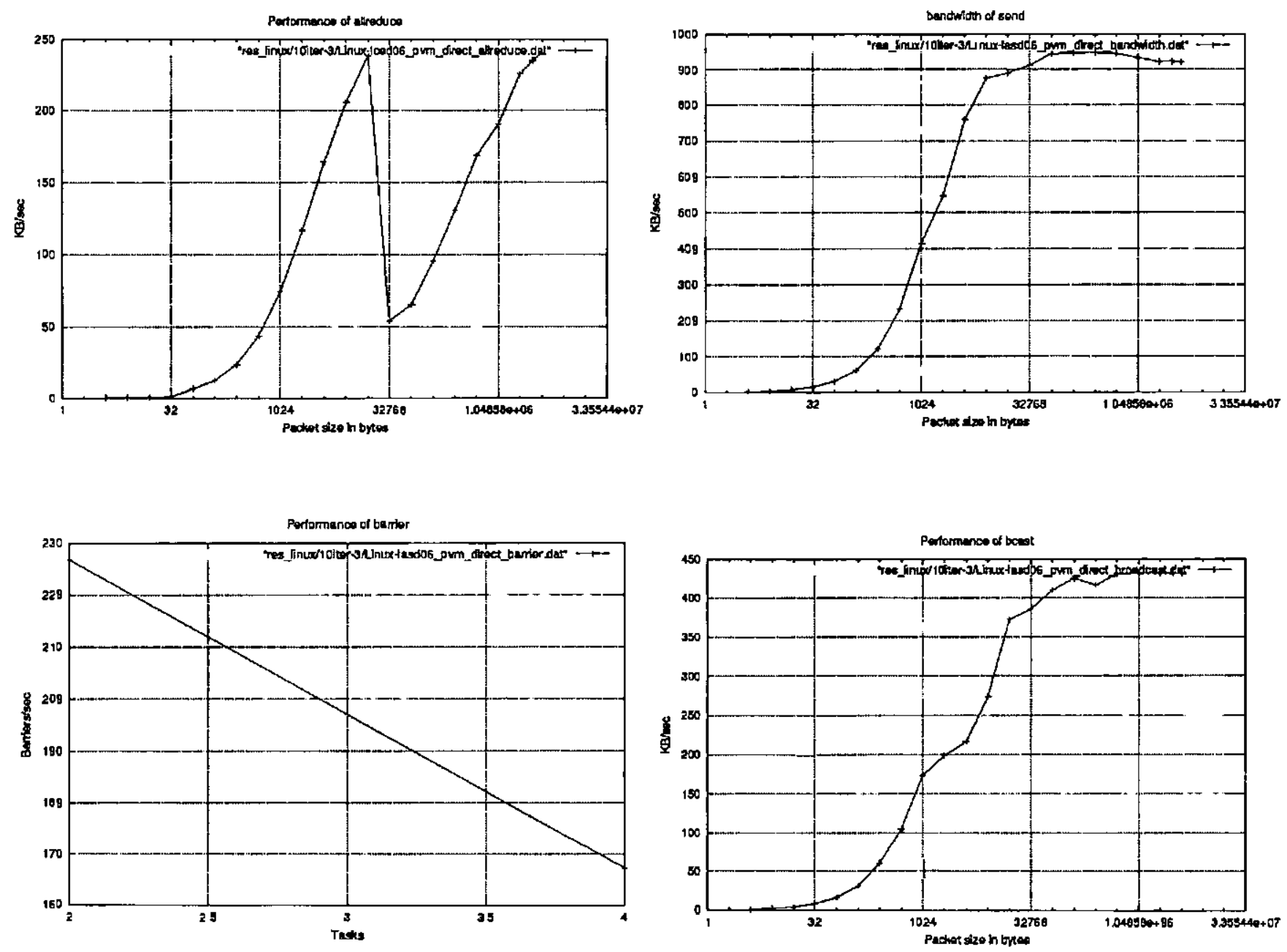

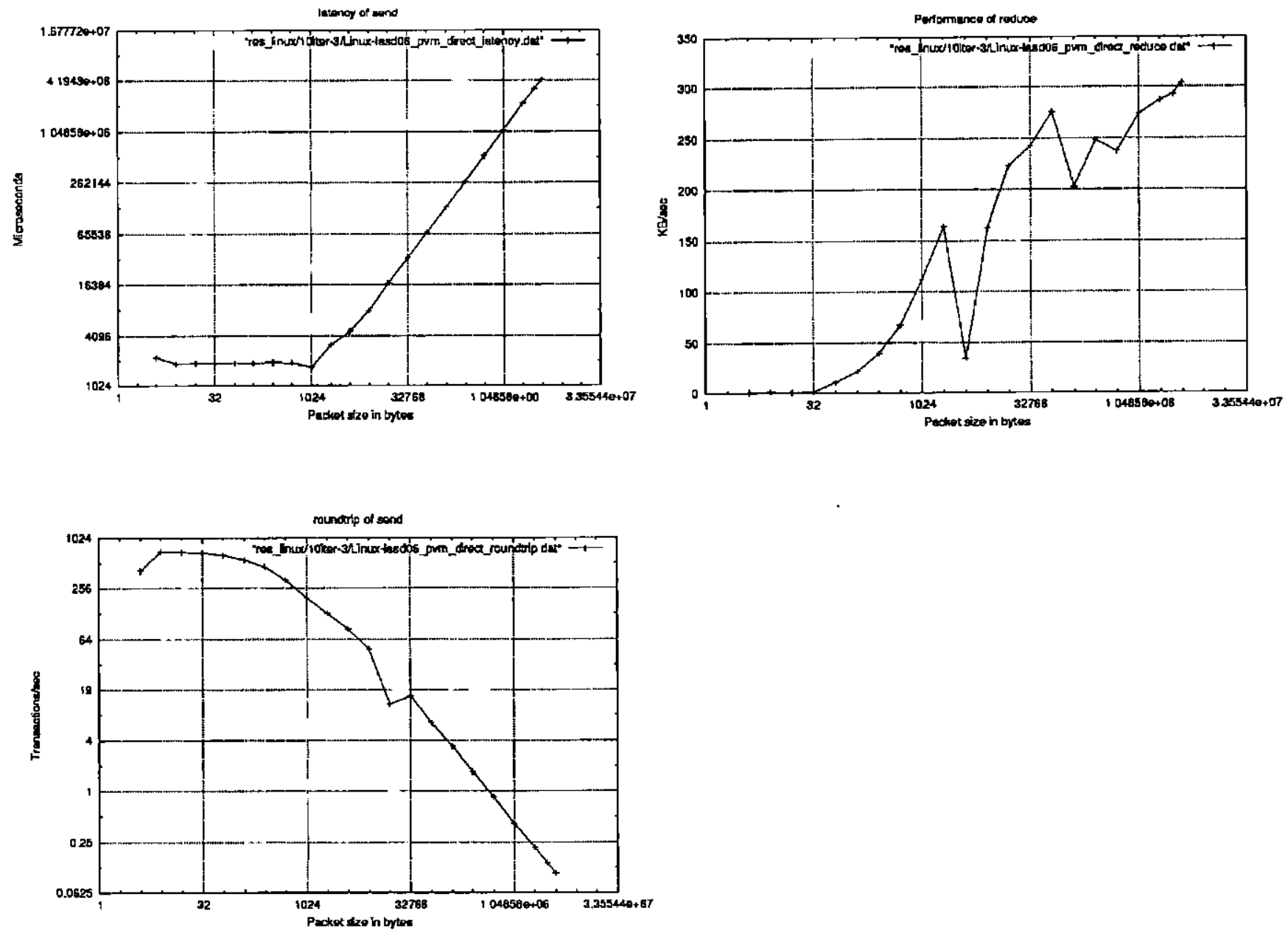

Linux - 100 iteraçöes - 2 processadores - PVM
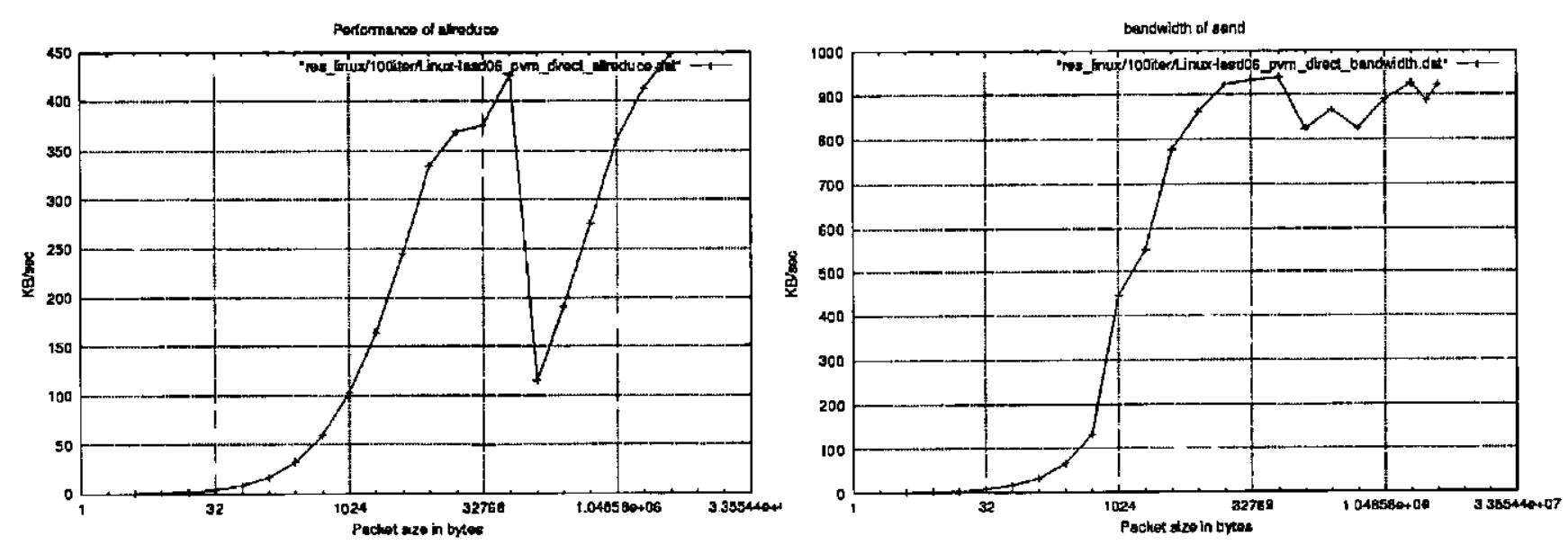

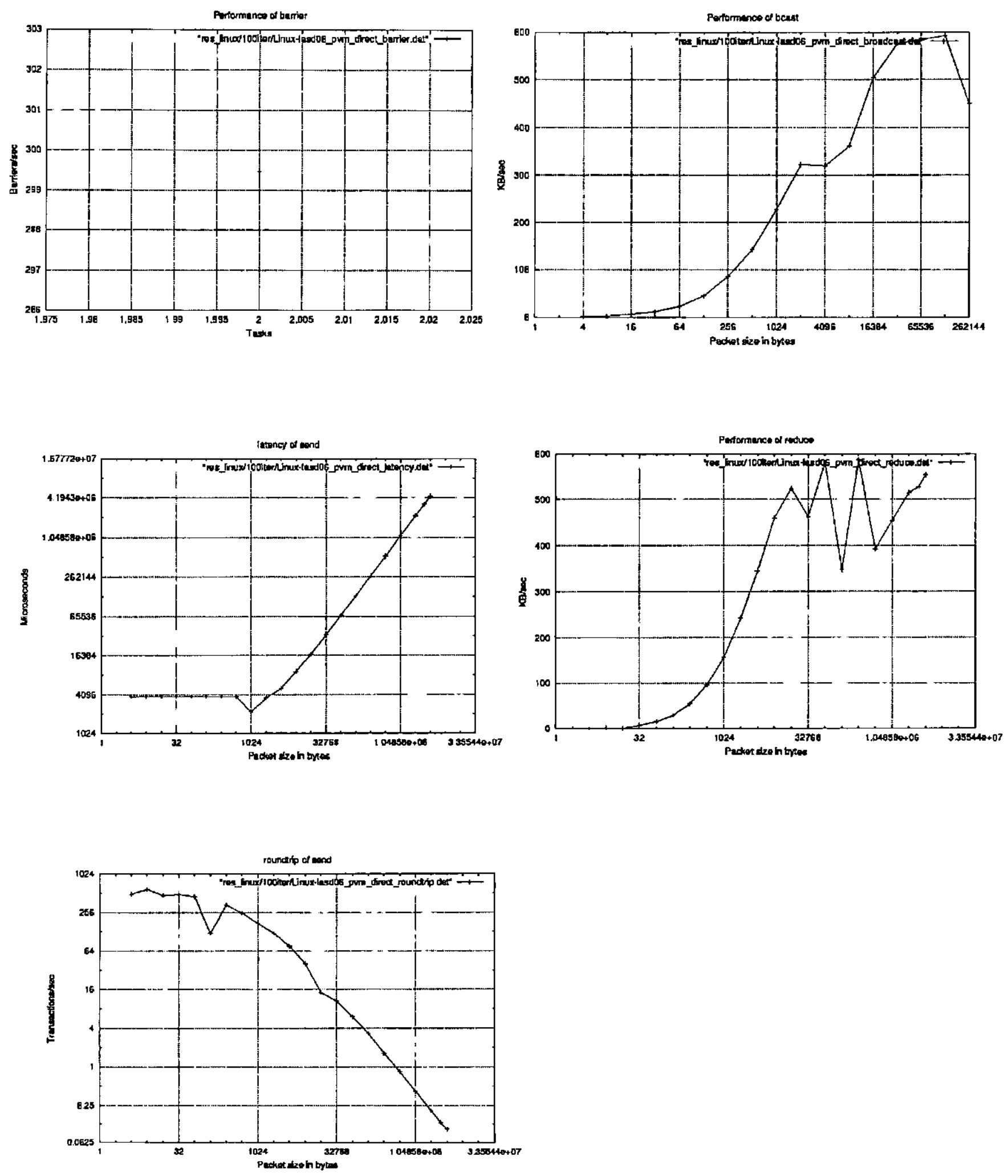
Linux - 100 iteraçöes - 3 processadores - PVM

Partormases of atrodiseo

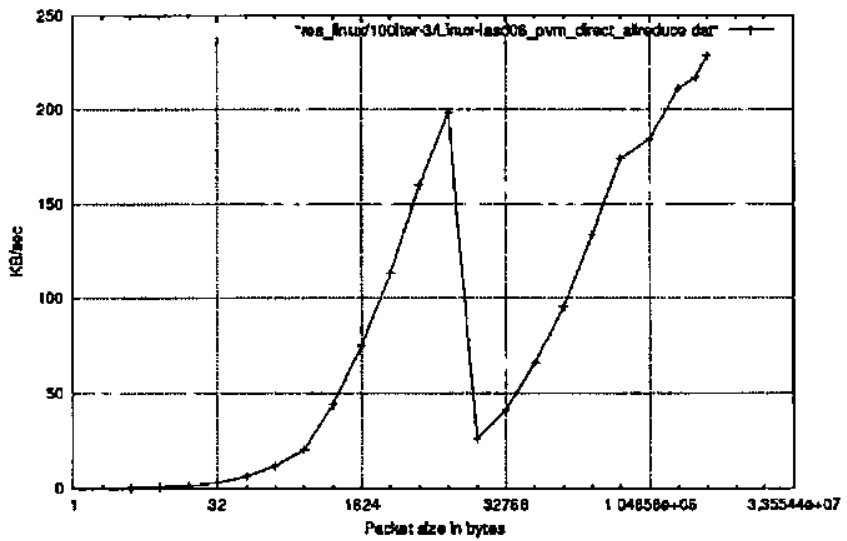

Pextormances of batrier

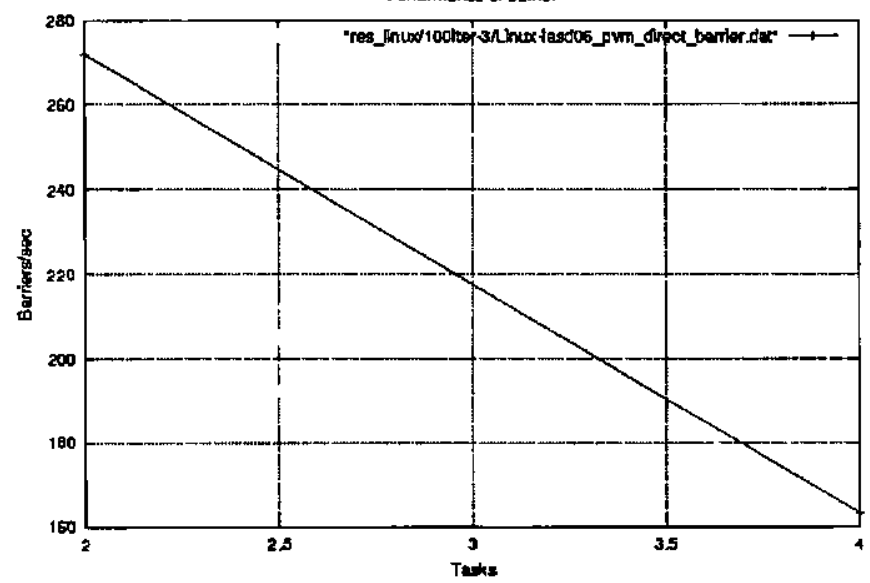

atoncy at and

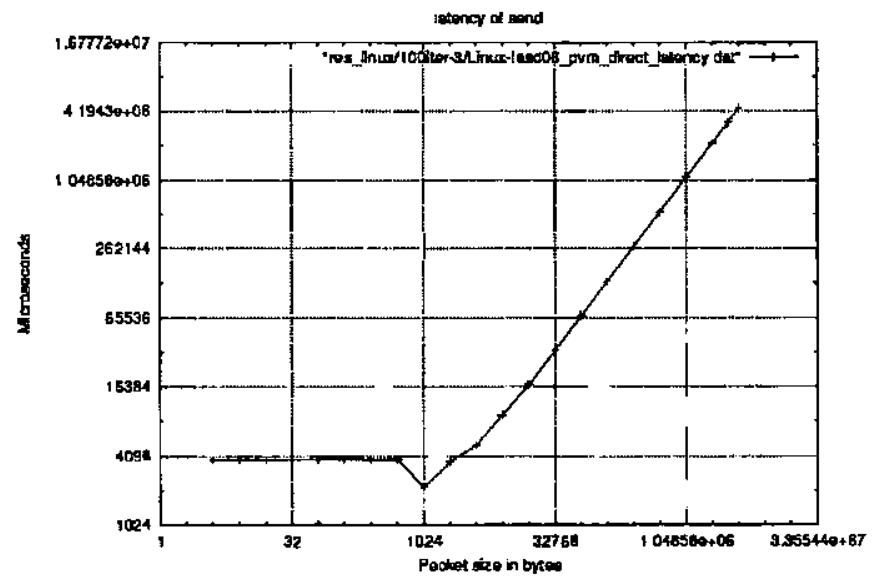

bandwitth of send

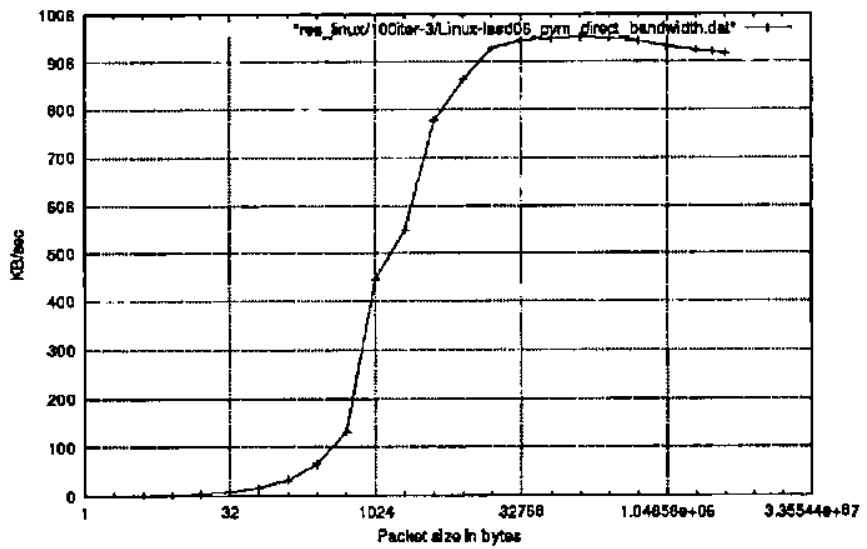

Pofommence of boast

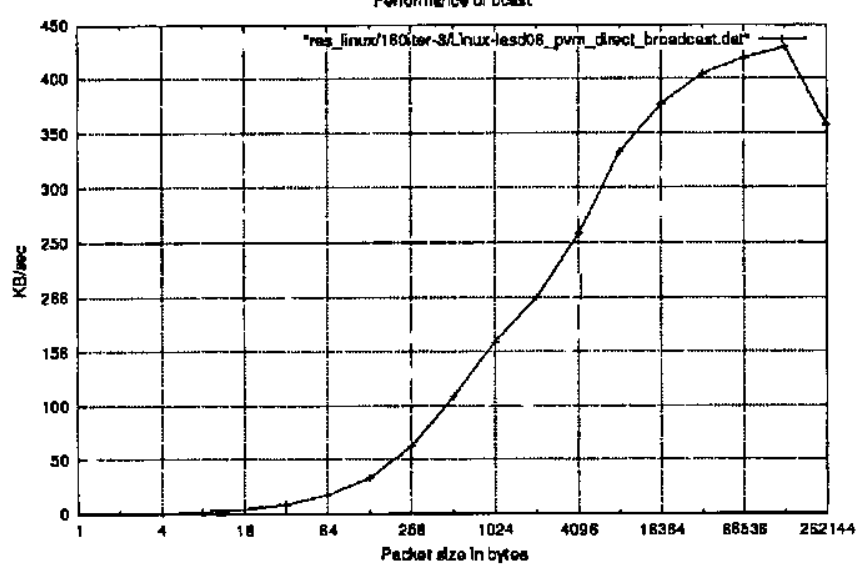

Pertormance of roduce

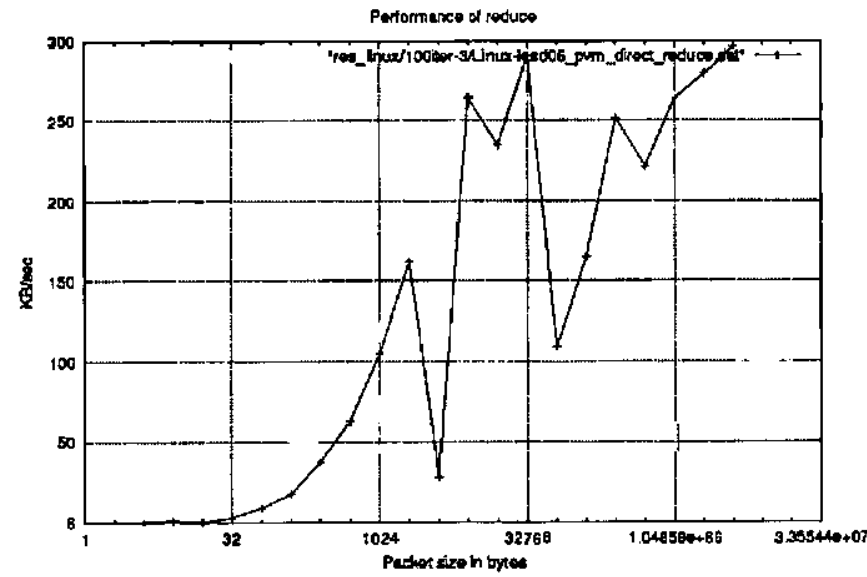




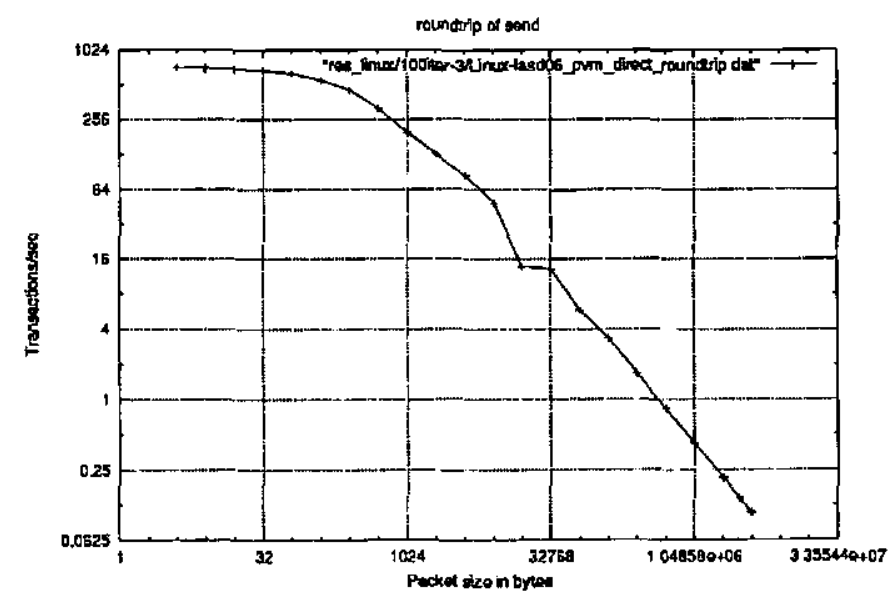




\title{
Apêndice D - Exemplos de resultados do ParkBench
}

\author{
Benchmarks de Baixo Nível \\ TICX1 \\ $\#$ include $\langle$ stalib.h> \\ \#! SP2 \\ \#\#16 Thin node system at University of Southampton, UK, June 1995 \\ \#\#IBM 390 Power2 nodes, 62.5MHz, 128MByte Memory, 2*2GByte SCSI Disk \\ \#\#Compiler version : xlc 1.3.0.19 \\ \#\#Operating system : AIX 3.2.5 \\ \#Benchmarker was Dr Simeon Warner

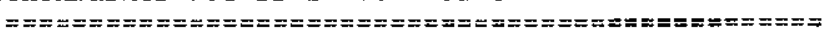 \\ $== \pm \quad==$ \\ $===$ GENESIS / PARKBENCH Parallel Benchmarks $== \pm$ \\ $=\equiv \quad \quad==$ \\ $= \pm=$ TICK1 $= \pm=$ \\ $== \pm \quad===$ \\ $\begin{array}{lll}== \pm \text { Program: Measure clock tick interval } & == \pm \\ = \pm= & \text { Version: Standara Fortran } 77 & ===\end{array}$ \\ $=$ Author: Roger Hockney $= \pm=$ \\ $==$ Modified: Ian Glendinning $===$ \\ $==$ Updates: Apr 1994 - Release: $2.3 \quad$ = $=$ \\ $= \pm \quad$ Apr 1992 - Release: $2.2 \quad===$

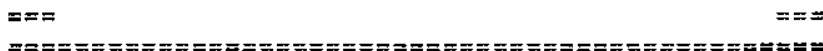

TIME CHANGES BETWEEN SUCCESSIVE SAMPLES OF TIME BY SUBROUTINE TIMER

TIME CHANGE $=1.108646 \mathrm{E}-05 \quad 6.914139 \mathrm{E}-06 \quad 7.033348 \mathrm{E}-06 \quad 5.960464 \mathrm{E}-06$

7.033348E-06

TIME CHANGE $=1.192093 \mathrm{E}-0$

$5.960464 \mathrm{E}-06$

TIME CHANGE $=1.001358 \mathrm{E}-05$

7.033348E-06

TIME CHANGE $=1.001358 \mathrm{E}-$

$6.914139 \mathrm{E}-06$

TIME CHANGE $=1.001358 \mathrm{E}-0$

$7.033348 \mathrm{E}-06$

TIME CHANGE $=1.001358 \mathrm{E}-0$

7.033348E-06

TIME CHANGE $=1.001358 \mathrm{E}-05$

7. $033348 \mathrm{E}-06$

TIME CHANGE $=1.001358 \mathrm{E}-05$

6. $914139 \mathrm{E}-06$

TIME CHANGE $=1.096725 \mathrm{E}-05$

$7.033348 \mathrm{E}-06$

TIME CHANGE $=1.001358 \mathrm{E}-05$

$6.914139 \mathrm{E}-06$

TIME CHANGE $=1.001358 \mathrm{E}-05$

7.033348E-06

TIME CHANGE $=1.001358 \mathrm{E}-05$

$5.960464 \mathrm{E}-06$

TIME CHANGE $=1.001358 \mathrm{E}-0$

$7.033348 \mathrm{E}-06$

TIME CHANGE $=9.894371 \mathrm{E}-0$

$7.033348 E-06$

$5.960464 E-06$

$7.033348 \mathrm{E}-06$

$7.033348 \mathrm{E}-06$

$7.033348 \mathrm{E}-06$

$5.960464 E-06$

$7.033348 \mathrm{E}-06$

$7.033348 \mathrm{E}-06$

$6.914139 \mathrm{E}-06$

$6.079674 E-06$

$6.914139 \mathrm{E}-06$

$5.960464 \mathrm{E}-06$

$7.033348 \mathrm{E}-06$

5.960464E-06

$7.033348 \mathrm{E}-06$

$7.033348 \mathrm{E}-06$

$7.033348 \mathrm{E}-06$

$7.033348 \mathrm{E}-06$

$5.960464 \mathrm{E}-06$

$5.960464 \mathrm{E}-06$

$7.033348 \mathrm{E}-06$

$5.960464 \mathrm{E}-06$

$7.033348 \mathrm{E}-06$

$5.960464 E-06 \quad 7.033348 \mathrm{E}-06$

$7.033348 \mathrm{E}-06$

$5.960464 \mathrm{E}-06$

$7.033348 \mathrm{E}-06$

$7.033348 E-06$

$5.960464 E-06$

$7.033348 E-06$

$7.033348 \mathrm{E}-06$

$5.960464 \mathrm{E}-06$

$7.033348 \mathrm{E}-06$

$5.960464 \mathrm{E}-06$

$5.960464 \mathrm{E}-06$

$7.033348 E-06$

$6.914139 \mathrm{E}-06$

$6.079674 \mathrm{E}-06$

6.079674E-06

6. 914139E-06

$7.033348 \mathrm{E}-06$

$5.960464 \mathrm{E}-06$

$6.914139 E-06$

$6.079674 \mathrm{E}-06$

$6.914139 \mathrm{E}-06$

$7.033348 \mathrm{E}-06$

$7.033348 E-06$

$5.960464 \mathrm{E}-06$

$7.033348 \mathrm{E}-06$

$5.960464 \mathrm{E}-06$

$5.960464 E-06$

TIME CHANGE $=1.096725 E-05$

$7.033348 \mathrm{E}-06$

$7.033348 E-06$

$5.960464 \mathrm{E}-06$

$7.033348 \mathrm{E}-06$

7. $033348 \mathrm{E}-06$ TIME CHANGE $=1.001358 \mathrm{E}-05$

5. $960464 \mathrm{E}-06$

$7.033348 E-06$

$5.960464 \mathrm{E}-06$

$7.033348 \mathrm{E}-06$

$7.033348 \mathrm{E}-06$

$5.960464 \mathrm{E}-06$

$7.033348 E-06$

5.960464 E-06

7. $033348 \mathrm{E}-06$

TIME CHANGE $=9.894371 \mathrm{E}-06$

7. $033348 \mathrm{E}-06$

TIME CHANGE $=8.940697 \mathrm{E}-06$

$7.033348 E-06$

$7.033348 \mathrm{E}-06$

5. $960464 E-06$

$7.033348 \mathrm{E}-06$

6. $914139 \mathrm{E}-06$ TIME CHANGE $=1.096725 \mathrm{E}-05$

$7.033348 \mathrm{E}-06$

$6.914139 \mathrm{E}-06$

$6.079674 \mathrm{E}-06$

$7.033348 \mathrm{E}-06$

$7.033348 \mathrm{E}-06$

TIME CHANGE $=1.001358 \mathrm{E}-05$

$7.033348 \mathrm{E}-06$

TIME CHANGE $=1.001358 \mathrm{E}-05$

$7.033348 \mathrm{E}-06$

$6.914139 E-06$

$6.079674 E-06$

$6.914139 \mathrm{E}-06$

7.033348E-06

$6.914139 E-06$

6.079674E-06

6.914139E-06

$6.914139 E-06$

$6.079674 \mathrm{E}-06$

6.914139E-06

$7.033348 \mathrm{E}-06$ 

$7.033348 E-06$

TIME CHANGE $=1.001358 \mathrm{E}-05$

$7.033348 \mathrm{E}-06$

TIME CHANGE $=1.001358 \mathrm{E}-05$

$5.960464 E-06$

TIME CHANGE $=1.001358 \mathrm{E}-$

$5.960464 \mathrm{E}-06$

TIME CHANGE $=1.001358 \mathrm{E}-05$

$5.960464 \mathrm{E}-06$

TIME CHANGE $=1.001358 \mathrm{E}-$

$6.079674 \mathrm{E}-06$

TIME CHANGE $=1.001358 \mathrm{E}-0$

$7.033348 E-06$

TIME CHANGE $=1.001358 \mathrm{E}-05$

$7.033348 \mathrm{E}-06$

TIME CHANGE $=1.096725 \mathrm{E}-05$

7.033348E-06

TIME CHANGE $=1.001358 \mathrm{E}-0$

$7.033348 \mathrm{E}-06$

TIME CHANGE $=1.001358 \mathrm{E}-05$

$6.079674 \mathrm{E}-06$

TIME CHANGE $=9.894371 \mathrm{E}-06$

$6.914139 \mathrm{E}-06$

TIME CHANGE $=1.001358 \mathrm{E}-05$

$7.033348 \mathrm{E}-06$

TIME CHANGE $=1.204014 \mathrm{E}-05$

$7.033348 \mathrm{E}-06$

TIME CHANGE $\approx 9.894371 \mathrm{E}-06$

5.960464E-06

TIME CHANGE $=1.001358 \mathrm{E}-05$

$7.033348 \mathrm{E}-06$

TIME CHANGE $=1.001358 \mathrm{E}-05$

$7.033348 \mathrm{E}-06$

TIME CHANGE $=1.001358 \mathrm{E}-05$

$7.033348 \mathrm{E}-06$

TIME CHANGE $=1.001358 \mathrm{E}-05$

5.960464E-06

TIME CHANGE $=1.001358 \mathrm{E}-0$

$6.079674 \mathrm{E}-06$

$6.914139 \mathrm{E}-06$

$6.079674 \mathrm{E}-06$

$6.914139 \mathrm{E}-06$

$7.033348 \mathrm{E}-06$

$5.960464 E-06$

$7.033348 \mathrm{E}-06$

$5.960464 \mathrm{E}-06$

7.033348E-06 5.960464E-06

$7.033348 \mathrm{E}-06$

$7.033348 \mathrm{E}-06$

$7.033348 \mathrm{E}-06$

$5.960464 E-06$

$7.033348 \mathrm{E}-06$

$7.033348 \mathrm{E}-06$

$7.033348 \mathrm{E}-06$

$7.033348 \mathrm{E}-06$

$5.960464 E-06$

$7.033348 \mathrm{E}-06$

$7.033348 \mathrm{E}-06$

5.960464E-06

7. $033348 \mathrm{E}-06$

$6.914139 \mathrm{E}-06$

$5.960464 E-06$

$7.033348 \mathrm{E}-06$

$7.033348 \mathrm{E}-06$

$5.960464 \mathrm{E}-06$

$6.079674 \mathrm{E}-06$

$6.914139 E-06$

$6.079674 E-06$

$6.914139 E-06$

$5.960464 \mathrm{E}-06$

$7.033348 E-06$

$7.033348 \mathrm{E}-06$

$5.960464 \mathrm{E}-06$

$7.033348 \mathrm{E}-06$

6. $914139 \mathrm{E}-06$

$6.079674 \mathrm{E}-06$

$6.914139 \mathrm{E}-06$

$6.914139 \mathrm{E}-06$

$6.079674 \mathrm{E}-06$

$6.914139 \mathrm{E}-06$

$7.033348 \mathrm{E}-06$

$6.079674 \mathrm{E}-06$

$6.914139 \mathrm{E}-06$

$7.033348 \mathrm{E}-06$

$6.079674 \mathrm{E}-06$

5.960464E-06

$7.033348 \mathrm{E}-06$

$7.033348 \mathrm{E}-06$

$5.960464 \mathrm{E}-06$

$5.960464 \mathrm{E}-06$

$7.033348 \mathrm{E}-06$

$7.033348 \mathrm{E}-06$

5.960464 E-06

$7.033348 \mathrm{E}-06$

$5.960464 \mathrm{E}-06$

$7.033348 \mathrm{E}-06$

$7.033348 \mathrm{E}-06$

$6.079674 \mathrm{E}-06$

$6.914139 \mathrm{E}-06$

$7.033348 \mathrm{E}-06$

$5.960464 \mathrm{E}-06$

$5.960464 \mathrm{E}-06$

$7.033348 \mathrm{E}-06$

$7.033348 \mathrm{E}-06$

$5.960464 \mathrm{E}-06$

$7.033348 \mathrm{E}-06$

$6.914139 \mathrm{E}-06$

$6.079674 \mathrm{E}-06$

$6.914139 \mathrm{E}-06$

$7.033348 \mathrm{E}-06$

$5.960464 \mathrm{E}-06$

$7.033348 \mathrm{E}-06$

$7.033348 \mathrm{E}-06$

$7.033348 \mathrm{E}-06$

TIME CHANGE $=1.096725 \mathrm{E}-05$

$7.033348 \mathrm{E}-06$

$6.914139 \mathrm{E}-06$

$6.079674 \mathrm{E}-06$

$6.914139 \mathrm{E}-06$

$7.033348 \mathrm{E}-06$

TIME CHANGE $=1.001358 \mathrm{E}-05$

$6.079674 \mathrm{E}-06$

$6.914139 \mathrm{E}-06$

$6.079674 \mathrm{E}-06$

$6.914139 E-06$

$5.960464 E-06$

$7.033348 \mathrm{E}-06$

$7.033348 \mathrm{E}-06$

$5.960464 \mathrm{E}-06$

TIME CHANGE $\approx 1.001358 \mathrm{E}-05$

$6.914139 \mathrm{E}-06$

TIME CHANGE $\approx 1.001358 \mathrm{E}-05$

$7.033348 \mathrm{E}-06$

$7.033348 \mathrm{E}-06$

$5.960464 E-06$

$7.033348 \mathrm{E}-06$

7.033348E-06

TIME CHANGE $=1.001358 \mathrm{E}-05$

6. $914139 \mathrm{E}-06$

TIME CHANGE $=1.001358 \mathrm{E}-05$

7.033348E-06

TIME CHANGE $=9.894371 \mathrm{E}-06$

$7.033348 \mathrm{E}-06$

$5.960464 \mathrm{E}-06$

$7.033348 \mathrm{E}-06$

$5.960464 \mathrm{E} \cdots 06$

5.960464E-06

$7.033348 \mathrm{E}-06$

$6.914139 E-06$

$6.079674 \mathrm{E}-06$

$6.079674 \mathrm{E}-06$

$6.914139 \mathrm{E}-06$

$7.033348 \mathrm{E}-06$

$5.960464 \mathrm{E}-06$

5.960464E-06

TIME CHANGE $=1.001358 \mathrm{E}-05$

$7.033348 \mathrm{E}-06$

$6.079674 \mathrm{E}-06$

$6.914139 \mathrm{E}-06$

$7.033348 \mathrm{E}-06$

$6.914139 \mathrm{E}-06$

TIME CHANGE $=1.001358 \mathrm{E}-05$

$7.033348 \mathrm{E}-06$

$6.914139 \mathrm{E}-06$

$6.079674 \mathrm{E}-06$

$7.033348 \mathrm{E}-06$

7.033348E-06

$6.914139 \mathrm{E}-06$

$6.079674 \mathrm{E}-06 \quad 7.033348 \mathrm{E}-06$

$5.960464 \mathrm{E}-06$

CLOCK TICK is less than or equal to

$5.960464 \mathrm{E}-06 \mathrm{sec}$

IICK2

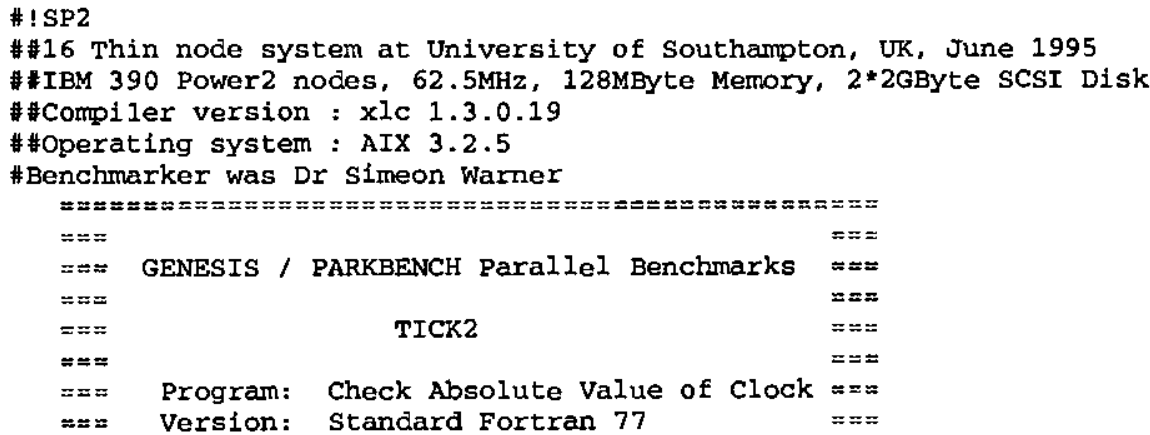




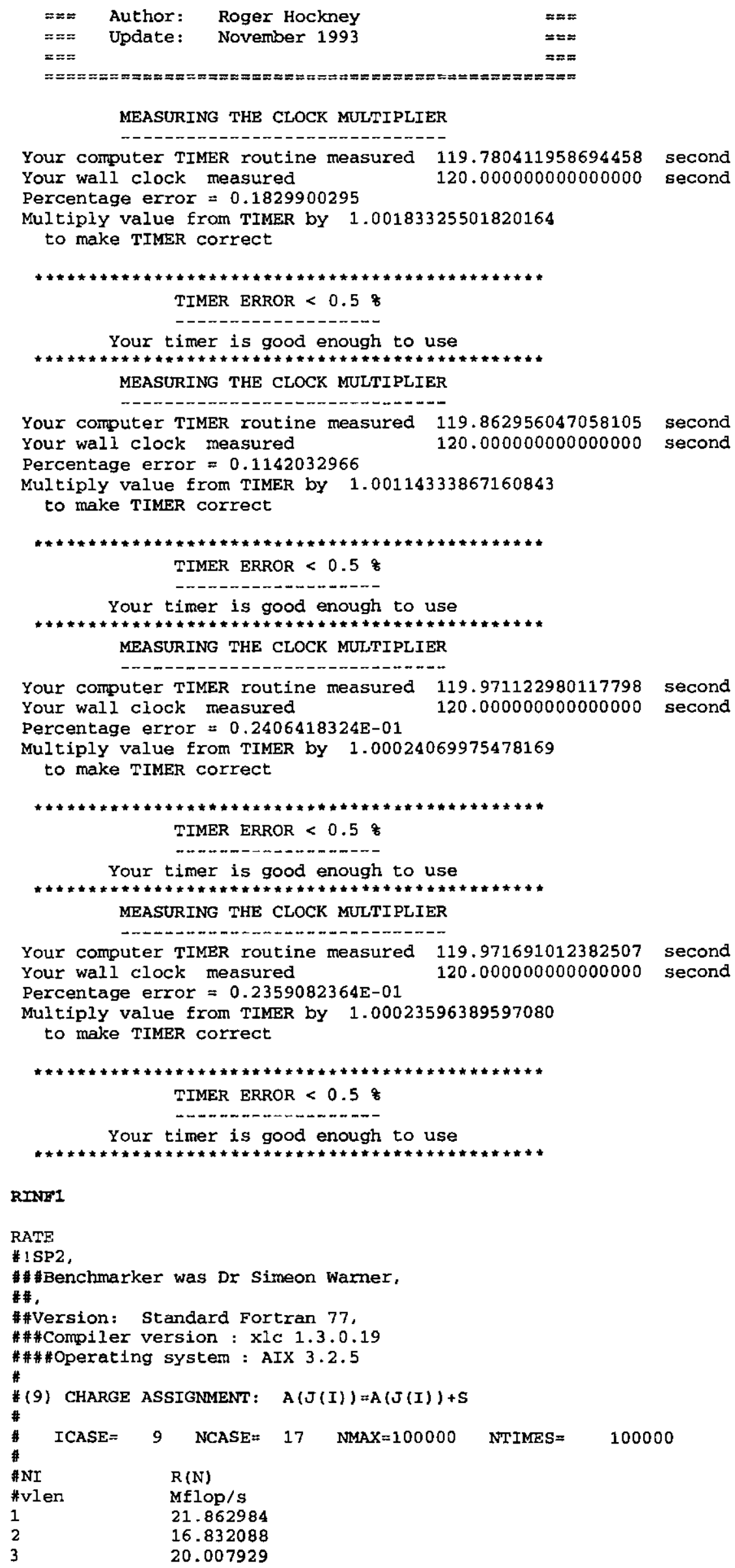




\begin{tabular}{ll}
4 & 14.947626 \\
5 & 12.450254 \\
6 & 13.826975 \\
7 & 12.722099 \\
8 & 13.493667 \\
9 & 12.781150 \\
10 & 11.904644 \\
20 & 11.730186 \\
30 & 11.660692 \\
40 & 11.625173 \\
50 & 11.607638 \\
60 & 11.593691 \\
70 & 11.533413 \\
80 & 11.628073 \\
90 & 11.571731 \\
100 & 11.569856 \\
200 & 10.011945 \\
600 & 10.892449 \\
700 & 9.355185 \\
800 & 11.467993 \\
900 & 11.282996 \\
1000 & 11.471758 \\
2000 & 10.527474 \\
3000 & 10.880308 \\
4000 & 5.783332 \\
5000 & 11.033867 \\
6000 & 11.107368 \\
7000 & 10.822870 \\
8000 & 11.506679 \\
9000 & 11.073849 \\
10000 & 11.087683 \\
20000 & 10.593015 \\
30000 & 9.677550 \\
40000 & 10.448049 \\
50000 & 10.146119 \\
60000 & 10.425595 \\
70000 & 10.539020 \\
80000 & 7.770737 \\
90000 & 10.452950 \\
100000 & 9.802982 \\
& \\
\hline &
\end{tabular}

\section{TIME}

"sp2.

\#\#\#Benchmarker was Dr Simeon warner,

\#\#,

* Version: Standard Fortran 77,

\#\#Compiler version : xlc 1.3.0.19

\#\#\#0perating system : AIX 3.2 .5

\#

\#(9) CHARGE ASSIGNMENT: A $(J(I))=\mathrm{A}(\mathrm{J}(\mathrm{I}))+\mathrm{S}$

\#

ICASE $=9 \quad$ NCASE $=17 \quad$ NMAX $=100000 \quad$ NTIMES $=100000$

\#NI TI

\#v1en sec

$14.573941 \mathrm{E}-08$

$1.188207 \mathrm{E}-07$

$1.499406 \mathrm{E}-07$

$2.676010 \mathrm{E}-07$

4.015982E-07

4. $339344 \mathrm{E}-07$

$5.502237 \mathrm{E}-07$

$5.928707 \mathrm{E}-07$

$7.041620 \mathrm{E}-07$

8.400083E-07

$1.705003 \mathrm{E}-06$

$2.572746 \mathrm{E}-06$

$3.440809 \mathrm{E}-06$

4.307508E-06

$5.175229 \mathrm{E}-06$

$6.069322 \mathrm{E}-06$

$6.879902 \mathrm{E}-06$

$7.777575 \mathrm{E}-06$

$8.643150 \mathrm{E}-06$

$1.997614 \mathrm{E}-05$

$5.508403 \mathrm{E}-05$

$7.482482 \mathrm{E}-05$ 


$\begin{array}{ll}800 & 6.975937 \mathrm{E}-05 \\ 900 & 7.976605 \mathrm{E}-05 \\ 1000 & 8.717060 \mathrm{E}-05 \\ 2000 & 1.899791 \mathrm{E}-04 \\ 3000 & 2.757275 \mathrm{E}-04 \\ 4000 & 6.916428 \mathrm{E}-04 \\ 5000 & 4.531503 \mathrm{E}-04 \\ 6000 & 5.401820 \mathrm{E}-04 \\ 7000 & 6.467785 \mathrm{E}-04 \\ 8000 & 6.952484 \mathrm{E}-04 \\ 9000 & 8.127256 \mathrm{E}-04 \\ 10000 & 9.019017 \mathrm{E}-04 \\ 20000 & 1.888037 \mathrm{E}-03 \\ 30000 & 3.099958 \mathrm{E}-03 \\ 40000 & 3.828466 \mathrm{E}-03 \\ 50000 & 4.927993 \mathrm{E}-03 \\ 60000 & 5.755067 \mathrm{E}-03 \\ 70000 & 6.641984 \mathrm{E}-03 \\ 80000 & 1.029503 \mathrm{E}-02 \\ 90000 & 8.610010 \mathrm{E}-03 \\ 100000 & 1.020098 \mathrm{E}-02\end{array}$

coms 1

RATE

\#! SP2

\#16 Thin node system at University of Southampton, UK, June 1995

\#\#IBM 390 Power2 nodes, $62.5 \mathrm{MHz}$, 128MByte Memory, 2*2GByte SCSI Disk

\#\#Compiler version : x1c 1.3.0.19

\# \#Operating system : AIX 3.2 .5

\#Benchmarker was Dr Simeon Warner

$\#$

\#Message Length /Byte Transfer Rate /(Byte/s)

0

14568.296

9033.4240000000008877

17145.306

27002.700

36281.179

44984.255999999993946

88066.930999999996857

119047.619

174748.79899999999907

213128.72999999998137

251783.466

292275.574

317712.470

326323.42300000000978

366568.91499999997905

407558.35499999998137

437317.784

459851.43299999996088

479780.67199999996228

495867.76899999997113

530152.41899999999441

551768.906

584415.584

614687.803

665557.404

691244.23999999999069

778210.11700000008568

806734.479

842696.629

868658.79100000008475

882552.6140000000596

928792.57000000006519

971210.54500000004191

989761.092

1027045.532

1281229.9809999999125

1873243.8340000000317

2568218.2990000001155

3254149.040

5527915.9759999997914

10002000.400

12150668.287000000477

14285714.286000000313 


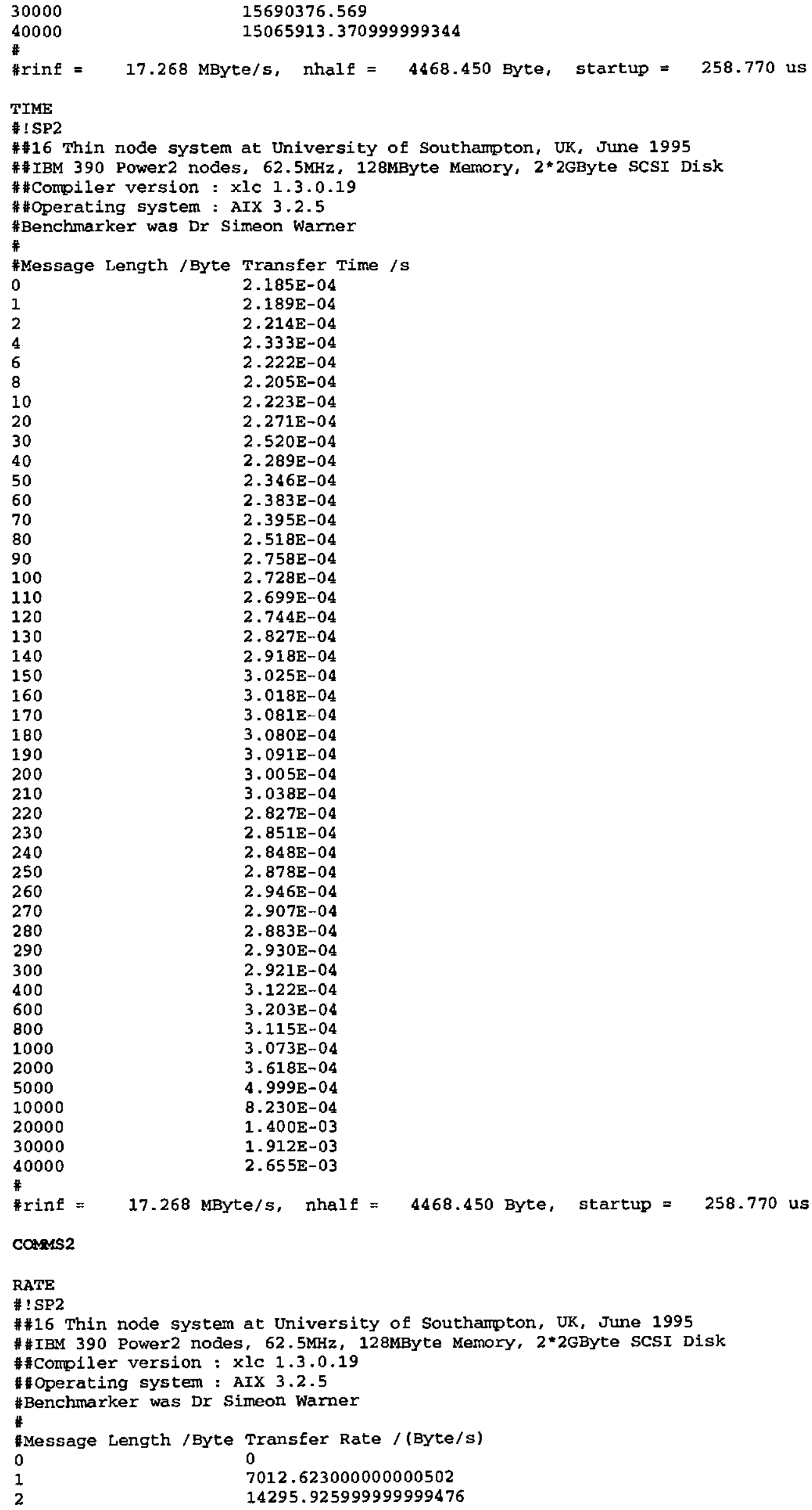




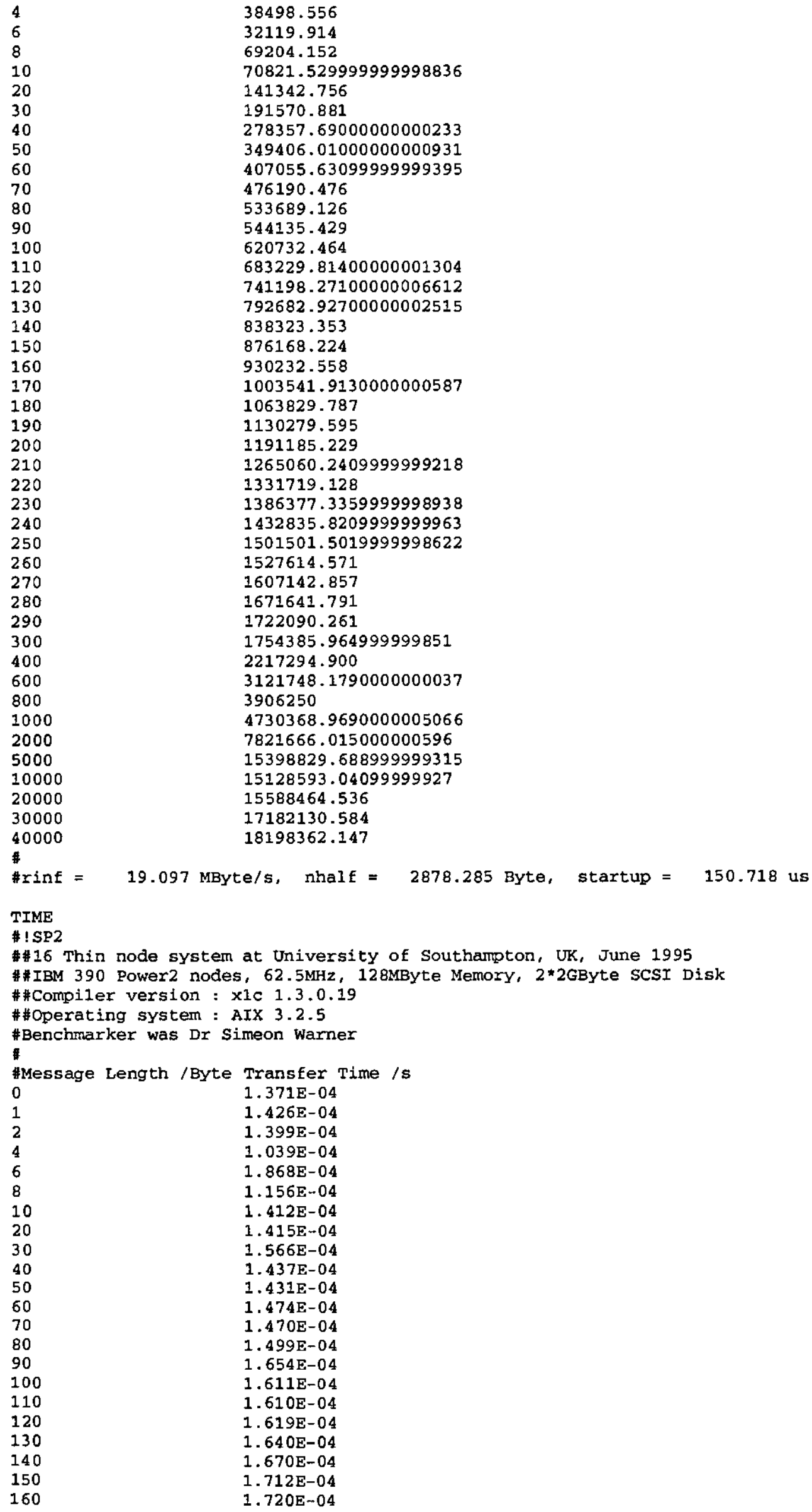




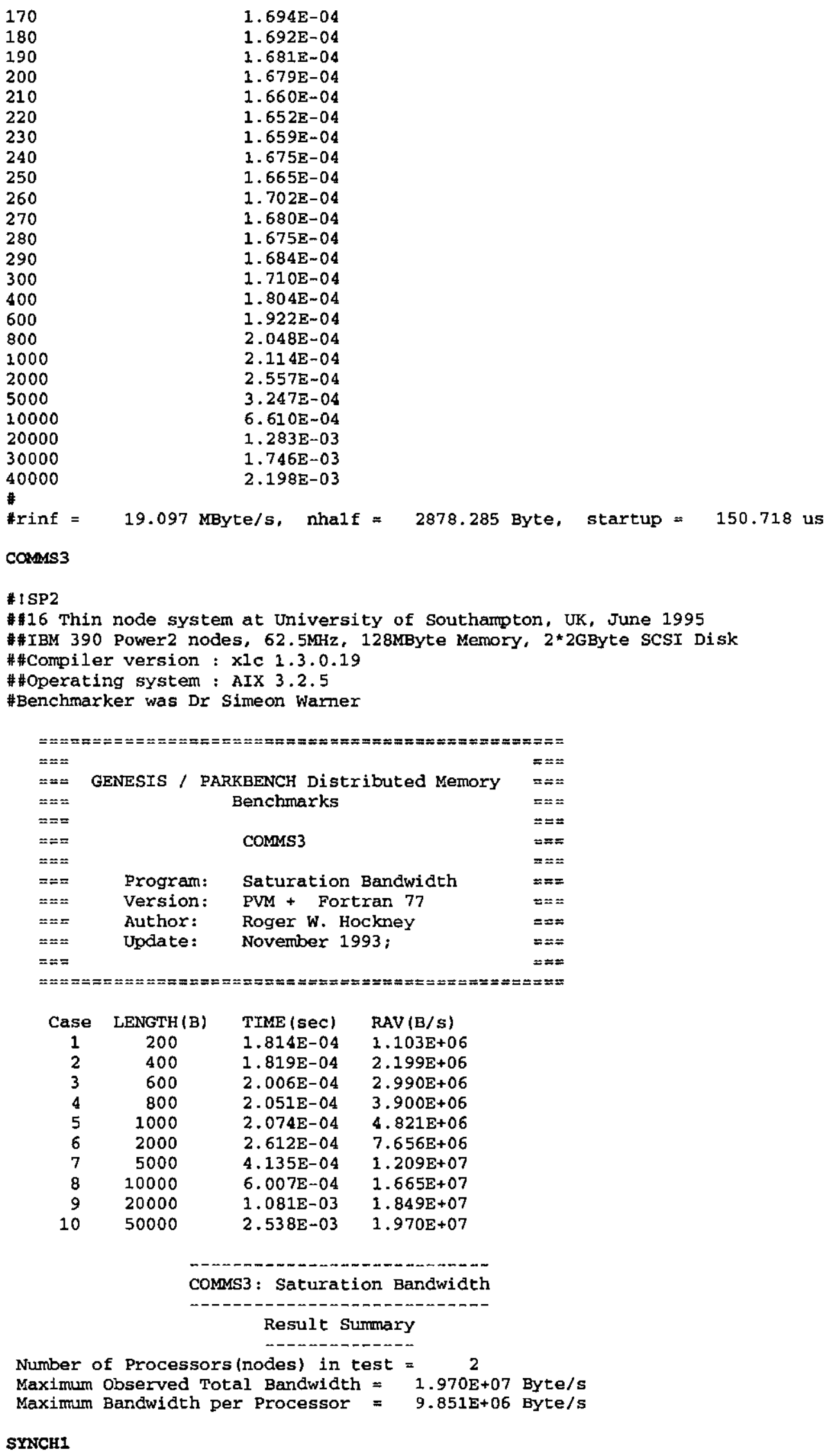

$\begin{array}{cccl}\text { Case } & \text { LENGTH (B) } & \text { TIME (sec) } & \text { RAV (B/s) } \\ 1 & 200 & 1.814 \mathrm{E}-04 & 1.103 \mathrm{E}+06 \\ 2 & 400 & 1.819 \mathrm{E}-04 & 2.199 \mathrm{E}+06 \\ 3 & 600 & 2.006 \mathrm{E}-04 & 2.990 \mathrm{E}+06 \\ 4 & 800 & 2.051 \mathrm{E}-04 & 3.900 \mathrm{E}+06 \\ 5 & 1000 & 2.074 \mathrm{E}-04 & 4.821 \mathrm{E}+06 \\ 6 & 2000 & 2.612 \mathrm{E}-04 & 7.656 \mathrm{E}+06 \\ 7 & 5000 & 4.135 \mathrm{E}-04 & 1.209 \mathrm{E}+07 \\ 8 & 10000 & 6.007 \mathrm{E}-04 & 1.665 \mathrm{E}+07 \\ 9 & 20000 & 1.081 \mathrm{E}-03 & 1.849 \mathrm{E}+07 \\ 10 & 50000 & 2.538 \mathrm{E}-03 & 1.970 \mathrm{E}+07\end{array}$

COMMS3: Saturation Bandwidth

Result Summary

Number of Processors (nodes) in test $=2$

Maximum Observed Total Bandwidth $=1.970 \mathrm{E}+07$ Byte/s

Maximum Bandwidth per Processor $=9.851 \mathrm{E}+06 \mathrm{Byte} / \mathrm{s}$

SYNCH1

\#! SP2

\#\#16 Thin node system at University of Southampton, UK, June 1995

\# IBM 390 Power2 nodes, 62.5MHz, 128MByte Memory, 2*2GByte SCSI Disk

\# \#Compiler version : xlc 1.3.0.19 
\#\#perating system : AIX 3.2 .5

* Benchmarker was Dr Simeon Warner

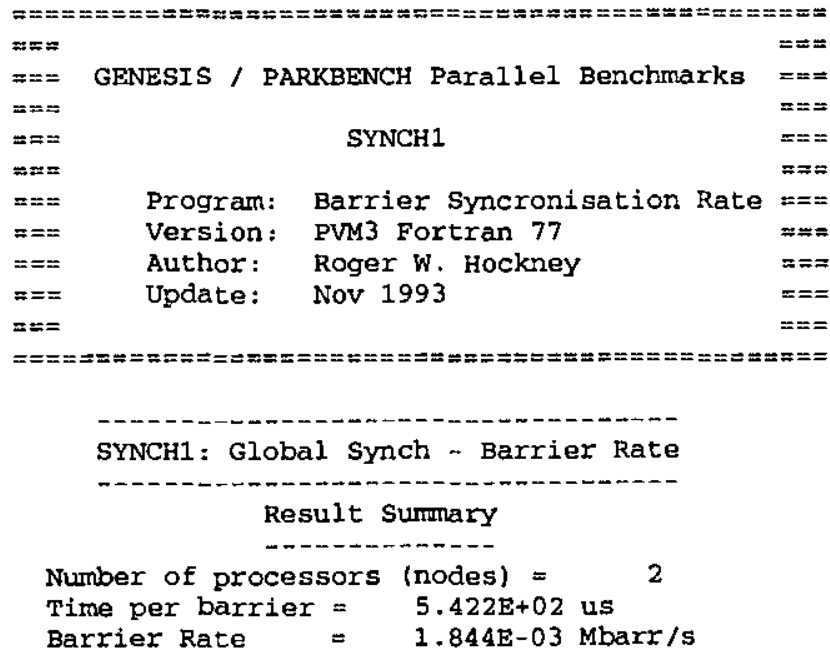

$\operatorname{POLY} 1$

\#! SP2

\# \#16 Thin node system at University of Southampton, UK, June 1995.

\#\#IBM 390 Power2 nodes, 62.5MHz, 128MByte Memory, 2*2GByte scsr Disk,

\# Compiler version : xlc 1.3.0.19,

\#\#Operating system : AIX 3.2.5,

\# Benchmarker was Dr simeon Warner

\#Computational Intensity (flop/mref) RINF (Mflop/s)

1. 0

33.382320

66.909935

80.317177

75.570404

66.843147

66.902435

66.688667

71.226341

70.866821

66.772591

10.0

\#LAST VALUES : $\quad$ RHAT $=71.620033 \mathrm{Mflop} / \mathrm{s}$ FHALF $=\quad .2916$ flop/mref

POLY2

\section{\# 1 SP2}

\#16 Thin node system at University of Southarpton, UK, June 1995,

\#\#IBM 390 Power 2 nodes, $62.5 \mathrm{MHz}, 128 \mathrm{MBy}$ te Memory, 2*2GByte SCSI Disk,

\#\#Compiler version: xlc 1.3.0.19.

\# \#perating system : ArX 3.2.5.

\# Benchmarker was Dr Simeon warner

\#

"Computational Intensity (flop/mref) RINF (Mflop/s)

1.0

2.0

3.0

5.0

6.0

7.0

8.0

9.0

10.0

20.937386

41.692852

60.764954

72.524796

64.051620

66.207420

65.082939

66.100670

65.089249

66.453400

\#LAST VALUES : $\quad$ RHAT $=79.150215 \mathrm{Mflop} / \mathrm{s}$ FHALF $=1.5149$ flop/mref

POLY3

\# ! SP2

\#16 Thin node system at University of Southanpton, UK, June 1995, 
\#\#IBM 390 Power2 nodes, 62.5MHz, 128MByte Memory, 2*2GByte SCSI Disk,

\#\#Compiler version : xlc 1.3.0.19,

\#\#perating system : AIX 3.2.5,

\#enchmarker was Dr Simeon Warner

$\#$

\#Computational Intensity (flop/mref) RINF (Mflop/s)

1.0

2.0

3.0

4.0

5.0

6.0

7.0

8.0

9.0

10.0

20.0

40.0

60.0

80.0

100.0

1.796461

3.690003

5.514913

7.279613

8.801824

10.219805

11.661831

13.001848

14.213192

15.495632

25.117649

36.436207

42.953144

46.990753

49.694172

56.971310

61.348904

62.277542

63.674088

600.0

64.201447

1000.0

$\#$

"LAST VALUES : $\quad$ RHAT $=66.230499 \mathrm{Mflop} / \mathrm{sFHALF}=33.1004 \mathrm{flop} / \mathrm{mref}$

\section{Kernels Benchmarks}

\section{MATMUL}

xps150> xdMATMUL_MPI

ScaLAPACK driver for full matrix multiply.

'for PARKBENCH LINALG kernel suite'

Running tests for $C:=$ alpha*op $(A){ }^{*}$ op $(B)+$ beta ${ }^{*}$.

The following scaled residual check will be computed:

||$C$-alpha*op (A)*op (B) -beta*C||/(||C||*eps*N)

The matrix $A, B$ and $C$ are randomly generated for each test.

An explanation of the input/output parameters follows:

$M \quad:$ The number of rows in the matrices $A$ and $C$.

$\mathrm{N} \quad$ : The number of colurms in the matrices $\mathrm{B}$ and $\mathrm{C}$.

$K \quad$ : The number of colums in the matrices $A$ and the number of rows in $B$.

MB : The size of the row-blocks of $A$ and $C$.

NB : The size of the col-blocks of $B$ and $C$.

$\mathrm{KB} \quad$ : The size of the col-blocks of $\mathrm{A}$ and row-blocks of $\mathrm{B}$

$P \quad$ : The number of process rows.

$Q \quad$ : The number of process colums.

THRESH : If residual value is less than THRESH, CHECK is flagged as PASSED.

TIME : Time in seconds to perform the matrix multiplication

Mflops : Execution rate of computation.

RESID : value of the scaled residual

The following parameter values will be used:

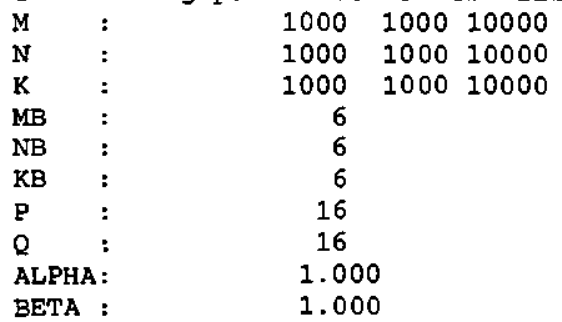

The matrices start in process $(0,0)$.

Relative machine precision (eps) is taken to be $0.111022 \mathrm{E}-15$

Routines pass computational tests if scaled residual is less than -2.000000

TIME TA TB $M \quad N \quad K \quad M \quad N B \quad K B \quad P \quad Q \quad$ TIME Mflops CHECK RESID

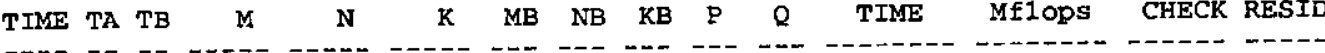




\begin{tabular}{|c|c|c|c|c|c|c|c|c|c|c|c|c|c|c|}
\hline WALL & $\mathbf{N}$ & $\mathrm{N}$ & 1000 & 1000 & 1000 & 6 & 6 & 6 & 16 & 16 & 0.76 & 2629.29 & BYPASS & 0.00 \\
\hline WAL & $\mathbf{N}$ & $\mathrm{N}$ & 1000 & 1000 & 1000 & 6 & 6 & 6 & 3 & 16 & 0.49 & 4112.26 & BYPASS & \\
\hline WALL & $\mathbf{N}$ & $\mathrm{N}$ & 10000 & 10000 & 10000 & 6 & 6 & 6 & 16 & 16 & 188.32 & 10620.10 & BYPASS & 0.00 \\
\hline
\end{tabular}

Finished 3 tests, with the following results:

3 tests completed without checking

0 tests skipped because of illegal input values.

END OF TESTS.

FORTRAN STOP

$\mathrm{QR}$

xps150> XdQR_MPI

SCaLAPACK QR factorizations routines.

' for PARKBENCH LINALG kernel suite'

Tests of the parallel real double precision QR factorizations routines.

The following scaled residual checks will be computed:

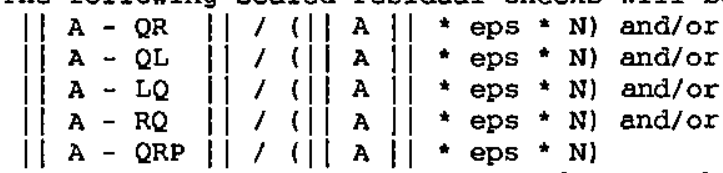

The matrix A is randomly generated for each test.

An explanation of the input/output parameters follows:

TIME : Indicates whether WALL or CPU time was used.

$M \quad:$ The number of rows in the matrix $A$.

$\mathrm{N} \quad$ : The number of columns in the matrix A.

MB : The row blocksize of the blocks the matxix $\mathrm{A}$ is split into.

NB : The column blocksize of the blocks the matrix A is split into.

$P \quad:$ The number of process rows.

$Q \quad$ : The number of process columns.

THRESH : If a residual value is less than THRESH, CHECK is flagged as PASSED

Fact Time: Time in seconds to factor the matrix.

MFLOPS : Execution rate of the factorization.

The following parameter values will be used:

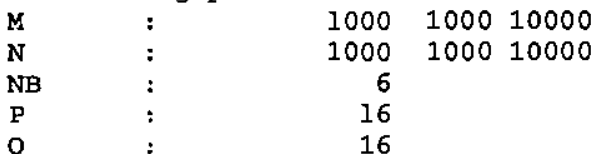

Relative machine precision (eps) is taken to be $0.111022 \mathrm{E}-15$

Routines pass computational tests if scaled residual is less than -3.0000

$\mathrm{QR}$ factorization tests.

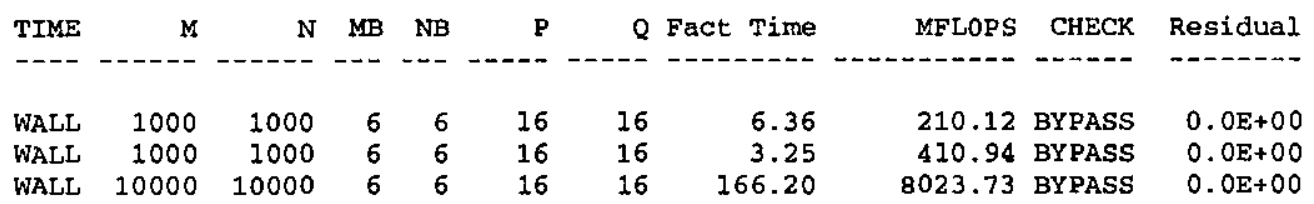

Finished 3 tests, with the following results:

3 tests completed without checking.

0 tests skipped because of illegal input values.

END OF TESTS.

FORTRAN STOP

TRD

XPs150> XdTRD_MPI

ScaLAPACK Reduction Routine to symmetric tridiagonal form.

' for PARKBENCH LINALG kernel suite'

Tests of the parallel real double precision symetric tridiagonal

reduction routines.

The following scaled residual checks will be computed:

||$A-Q T Q \cdot||$ / ( ||A||* eps * N\}

The matrix $A$ is randomly generated for each test.

An explanation of the input/output parameters follows:

UPLO : Whether the 'Upper' or 'Lower' part of A is to be referenced. 


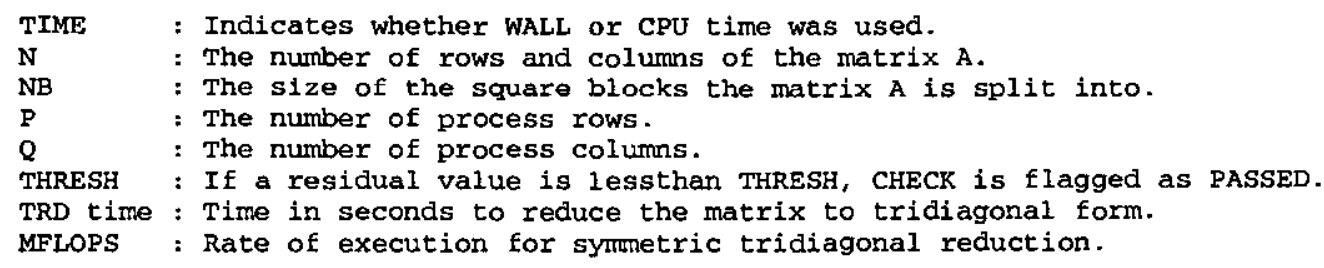

The following parameter values will be used:

\begin{tabular}{llrl} 
UPLO : & \multicolumn{4}{c}{ L } & \\
$\mathrm{N}$ & $:$ & 1000 & 100010000 \\
$\mathrm{NB}$ & $:$ & 8 & \\
$\mathrm{P}$ & $:$ & 16 & \\
$\mathrm{Q}$ & $:$ & 16
\end{tabular}

Relative machine precision (eps) is taken to be $0.111022 \mathrm{E}-15$ Routines pass computational tests if scaled residual is less than -10.000

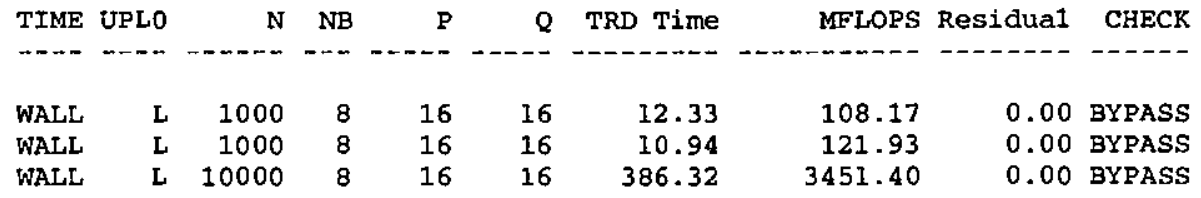

Finished 3 tests, with the following results:

3 tests completed without checking.

0 tests skipped because of illegal input values.

END OF TESTS.

FORTRAN STOP

\section{Aplicaçôes Compactas}

RSTSWA

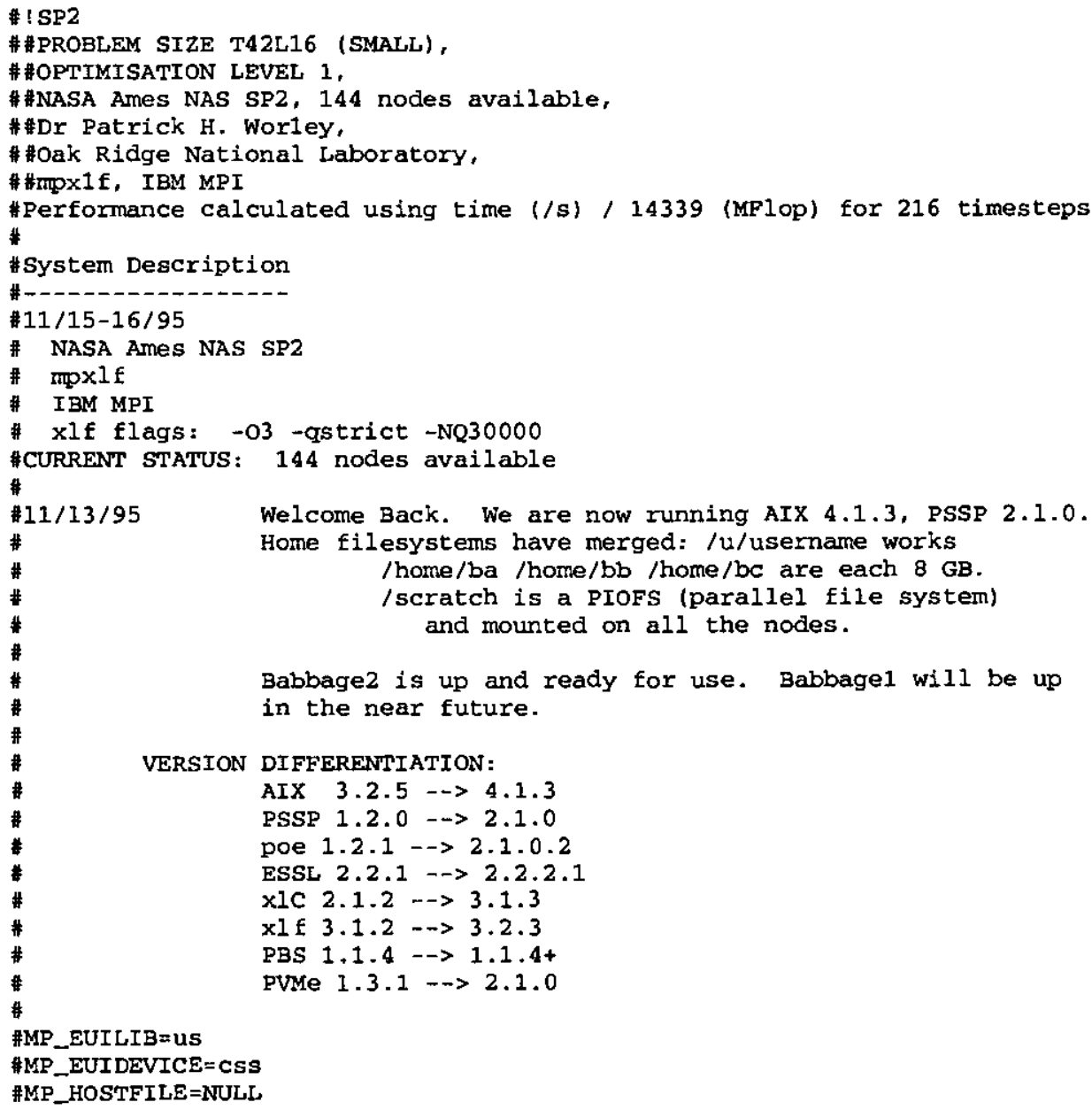




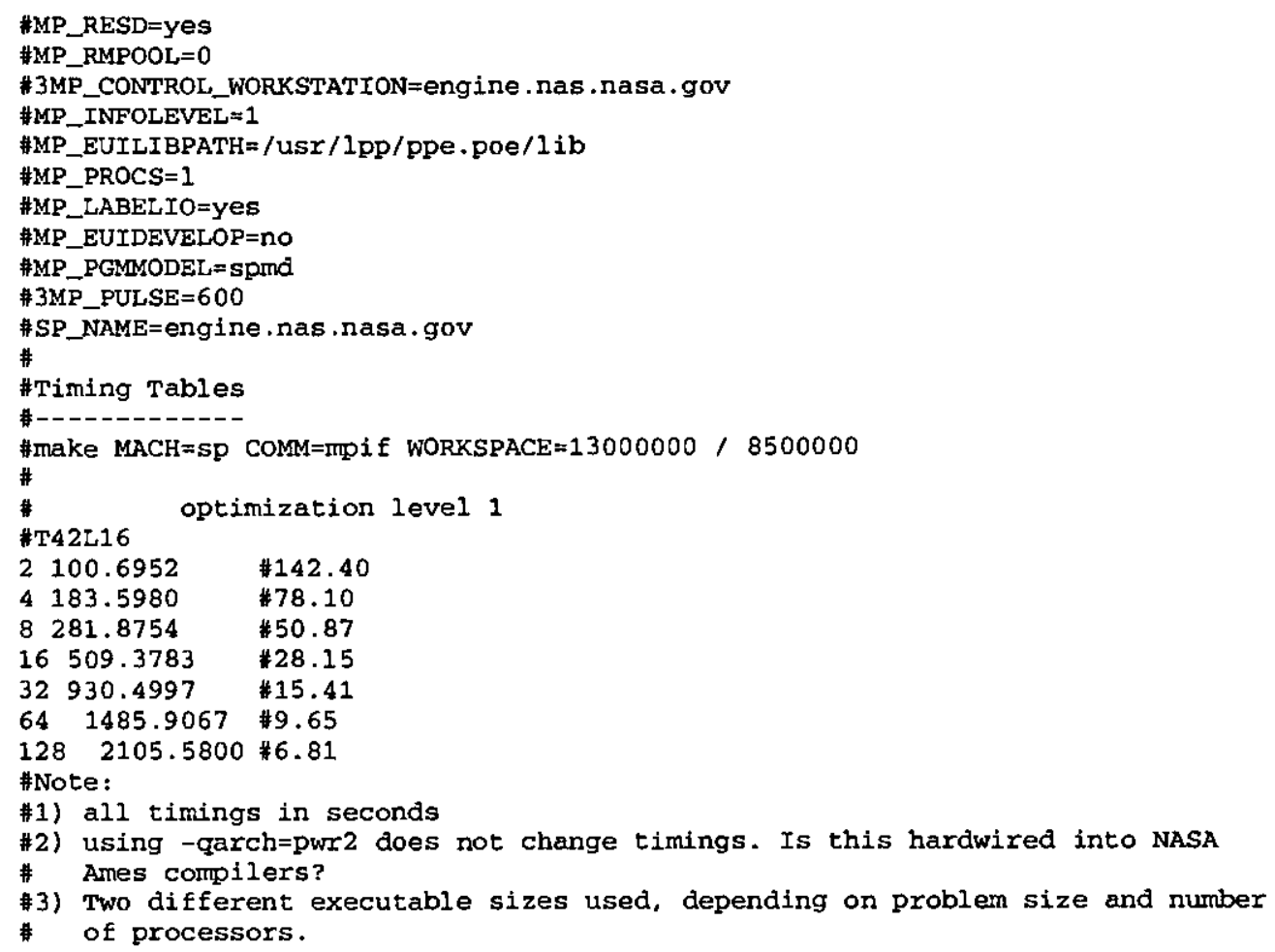

\#3) Two different executable sizes used, depending on problem size and number * of processors. 